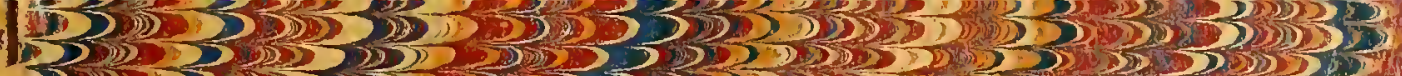

2.53

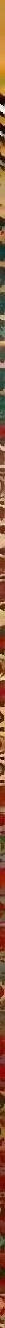

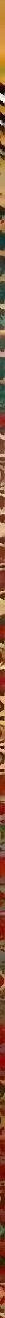

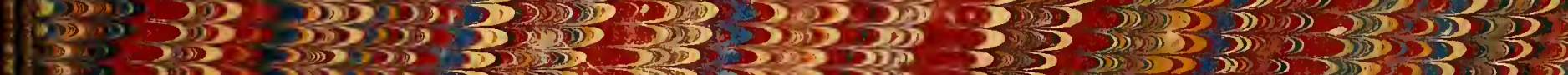

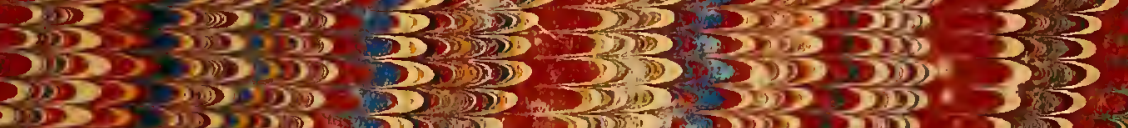

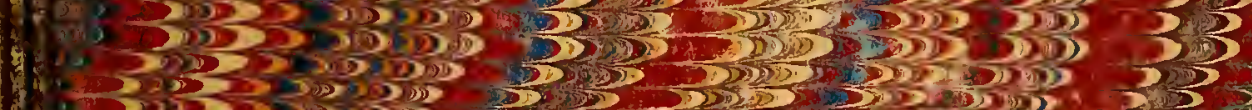

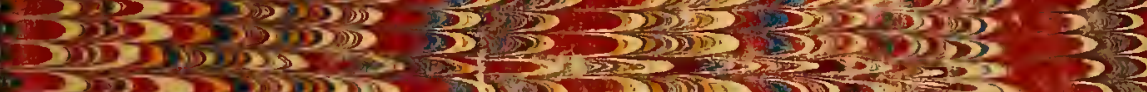

in

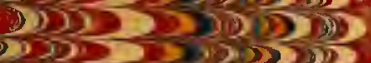

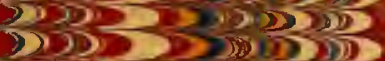

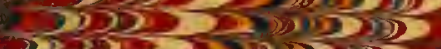

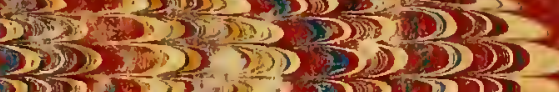

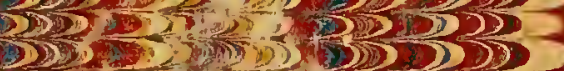
50253525 33.3525 in

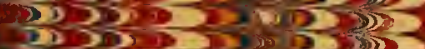

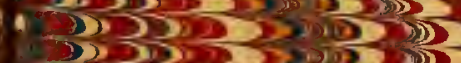

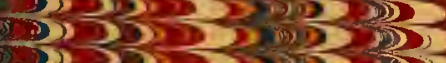
333035050 23250202 33390351535

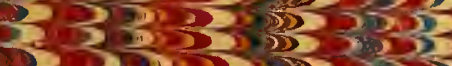

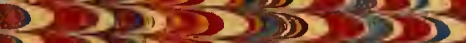
$3 \times 39035.5353$ 3350325353

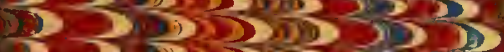

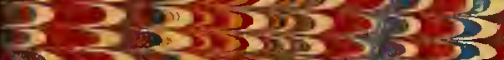

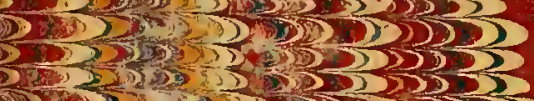

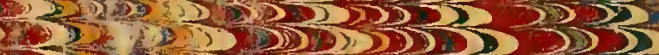

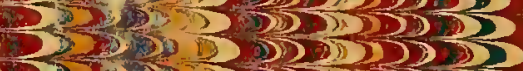

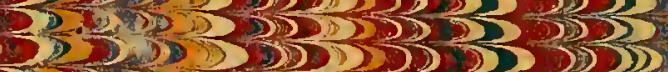

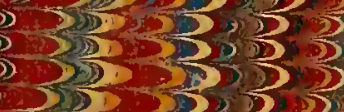
(D) $>5$ 


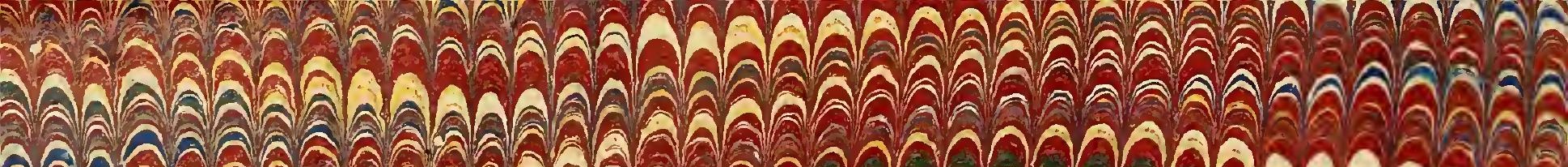

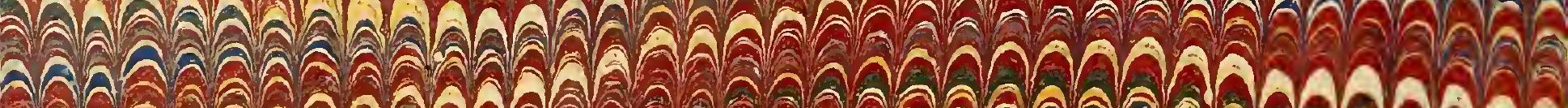
a

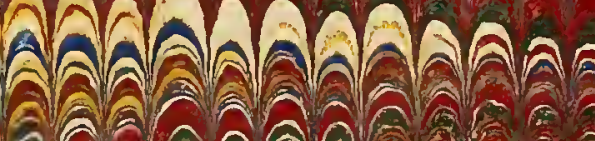

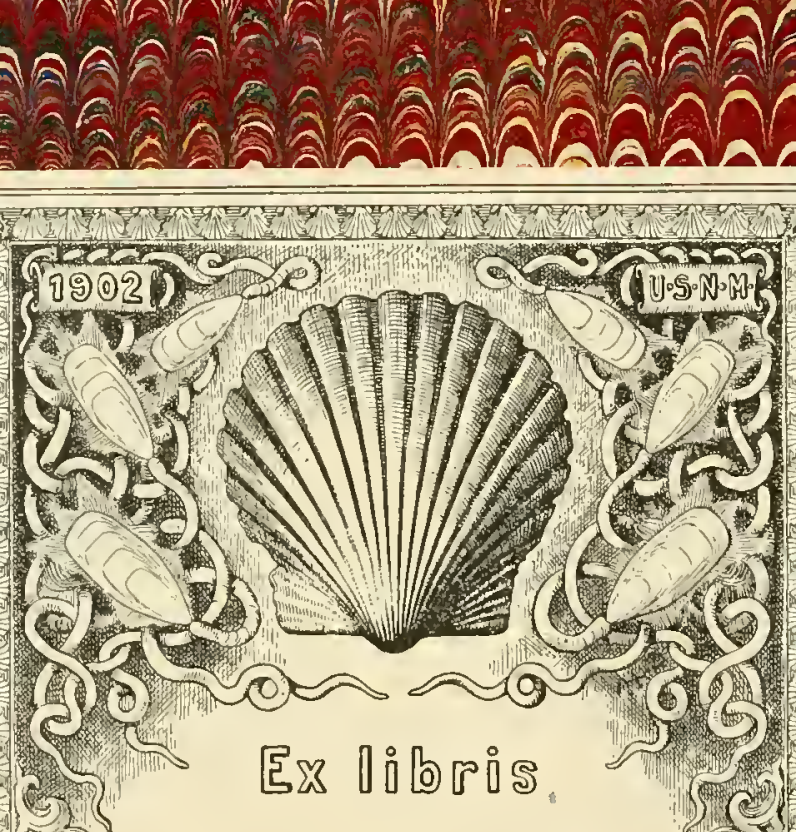

ล) âคคดคล

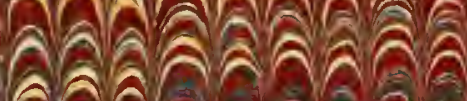

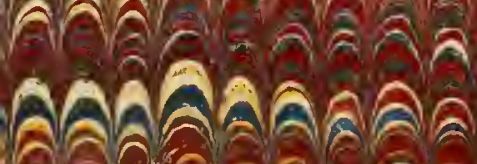

(1) ลค

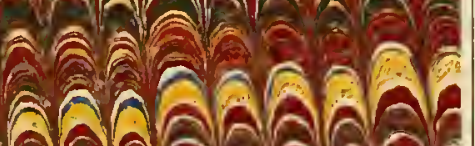
(a)

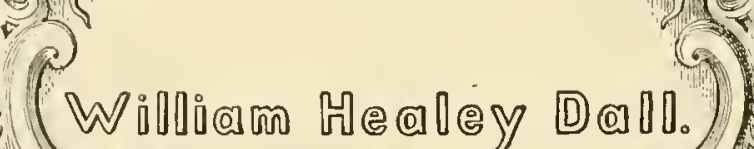
(2)

Whทิคลิ

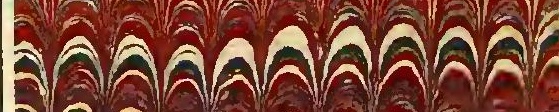
ลลลลลลลลลล กคล

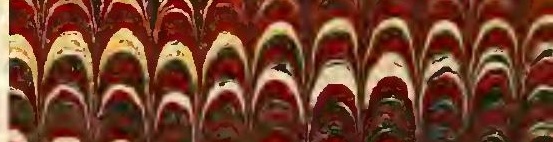
TAกAARAAA

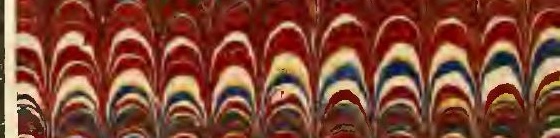
ลลลลดล

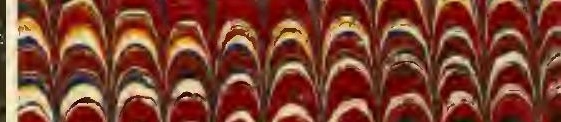

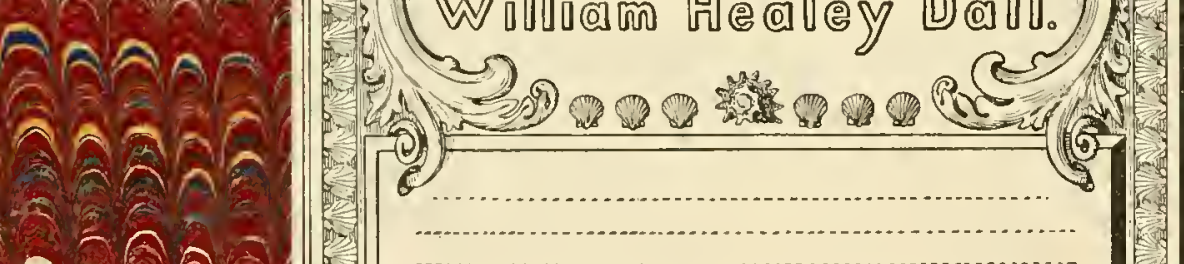

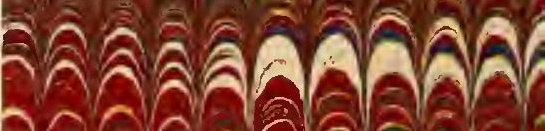

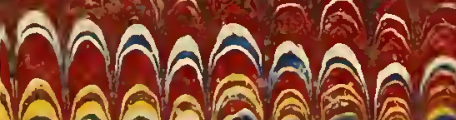

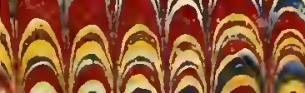

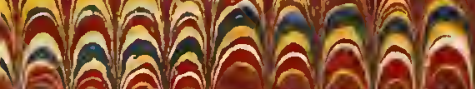

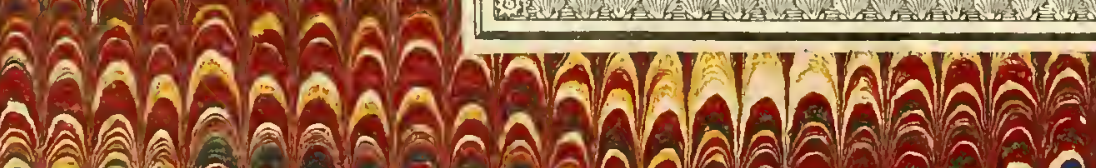

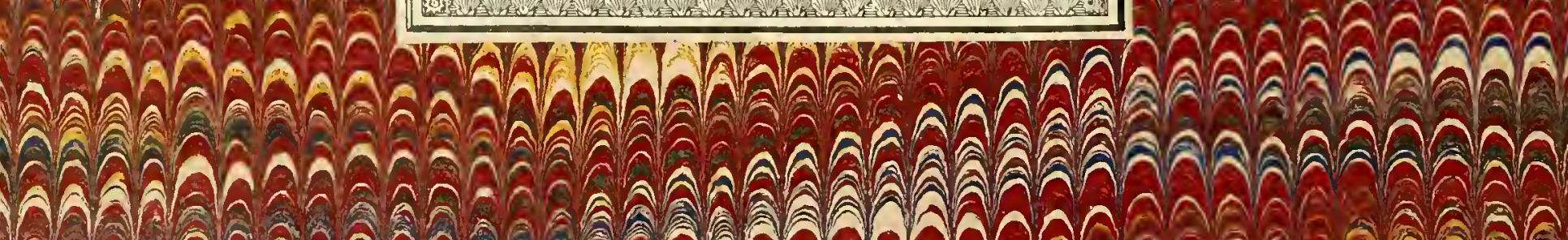

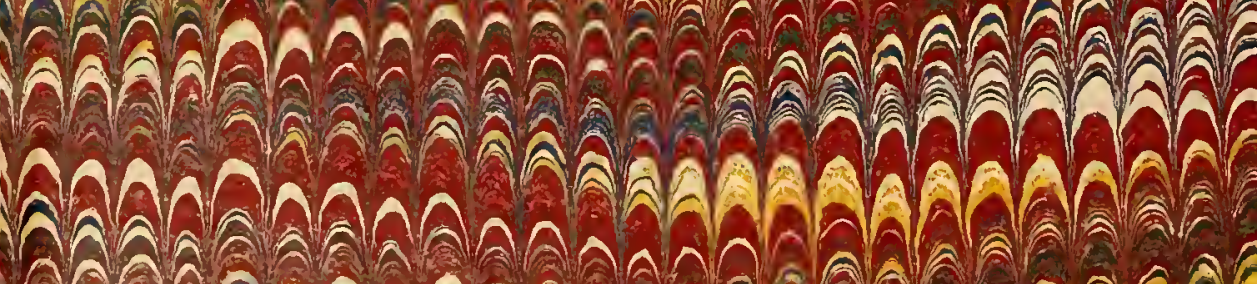

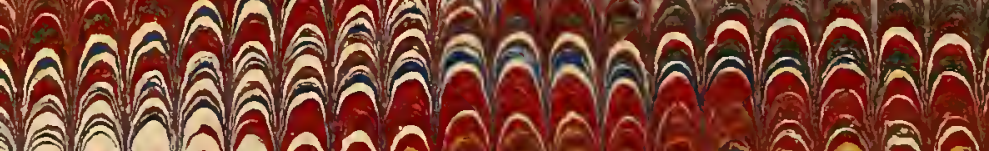

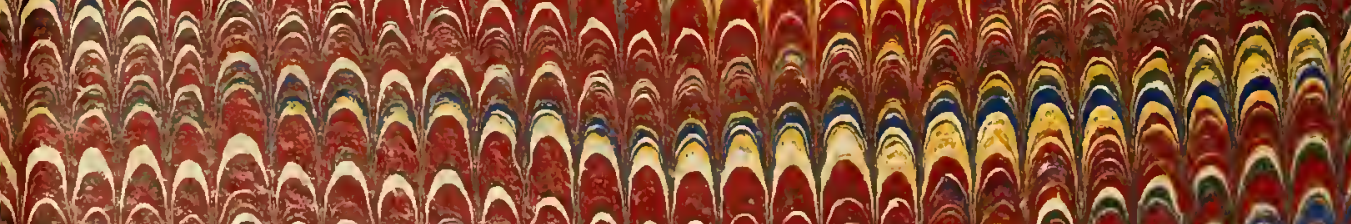

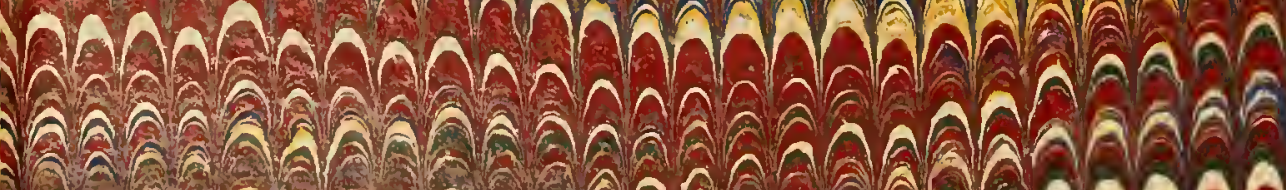

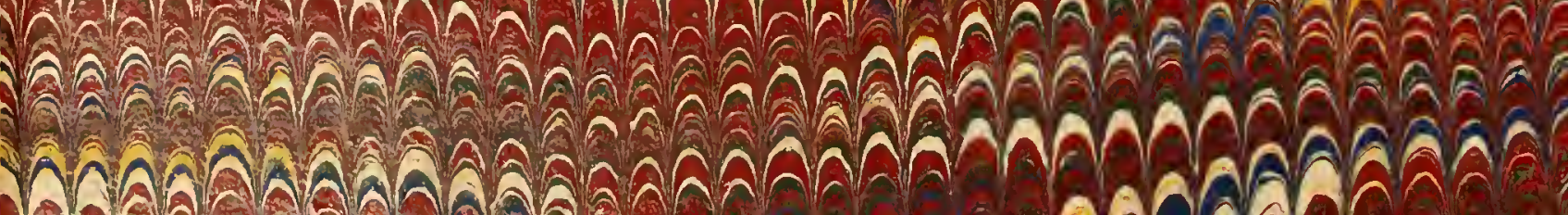




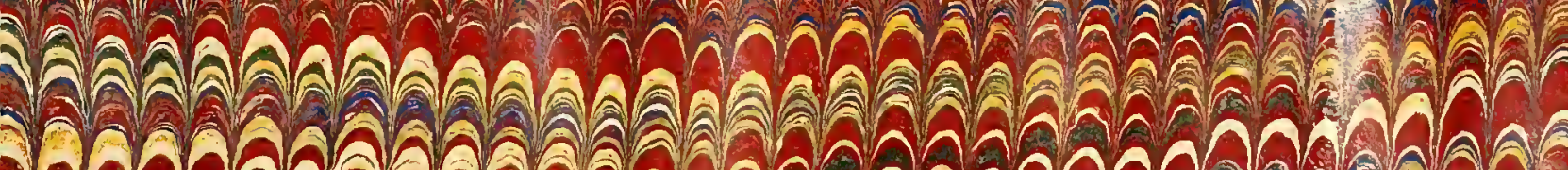

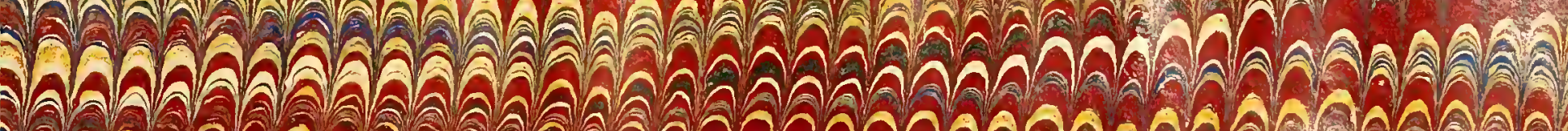

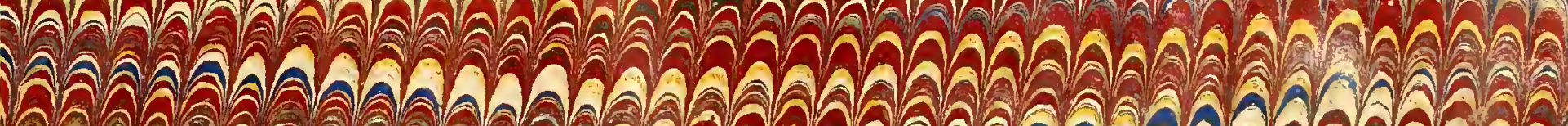

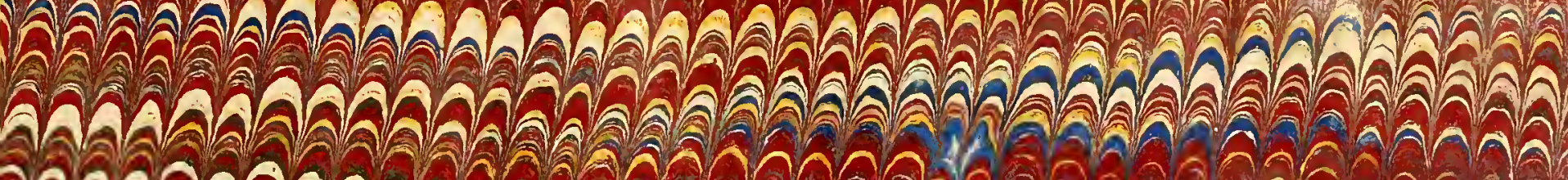

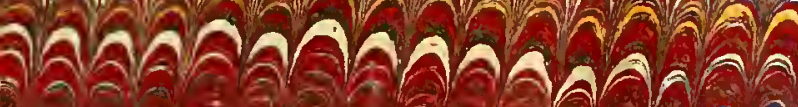

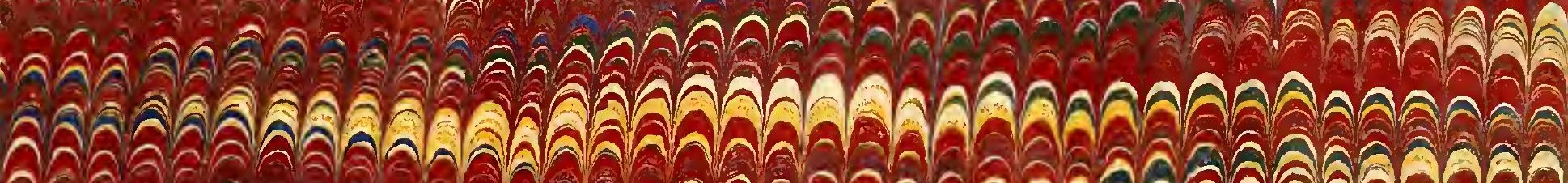

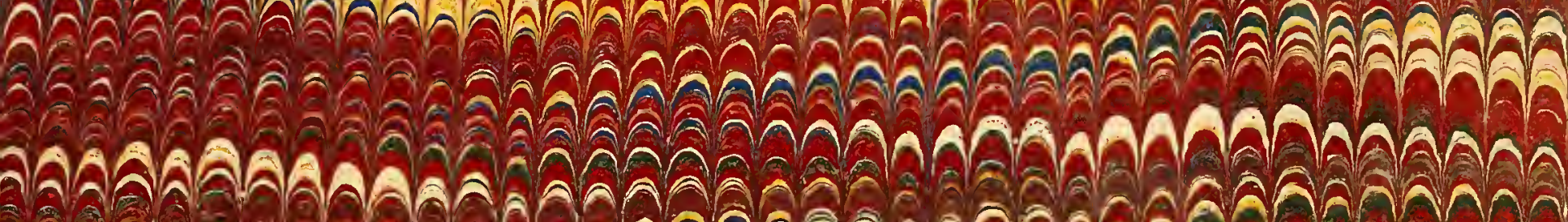

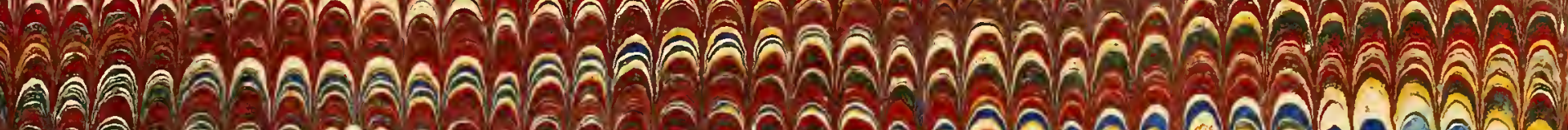
ล A An A 2 A

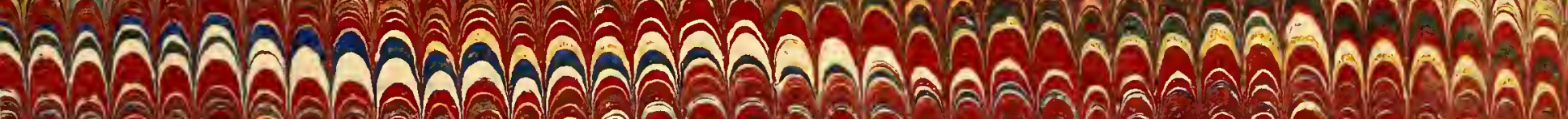

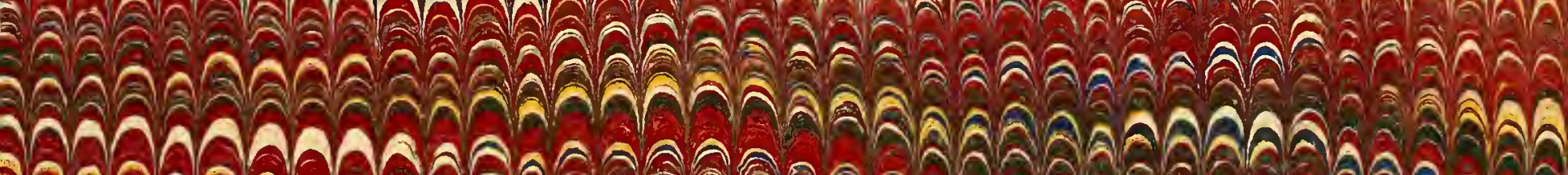

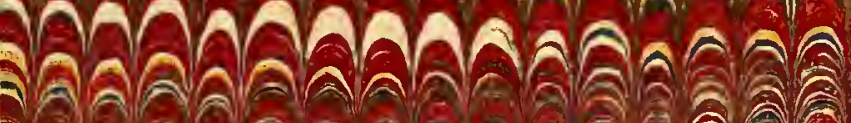

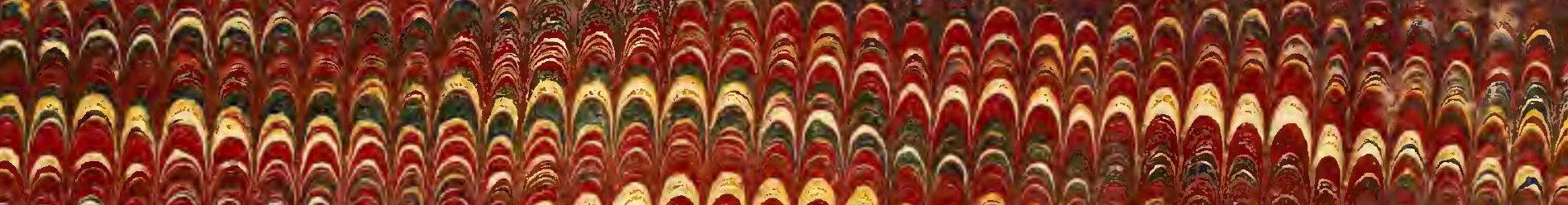

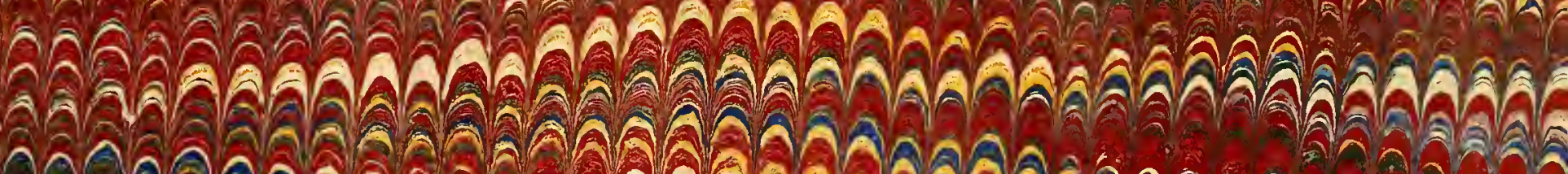

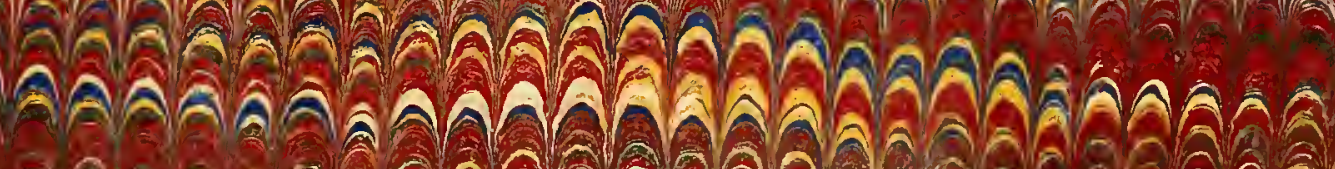

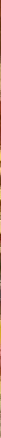

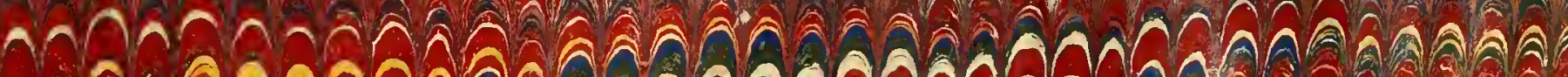




-

, 


\title{
NOVITATES CONCHOLOGICAE.
}

\author{
MOLLUSCA MARINA.
}

\section{Beschreibung und Abbildung}

neuer oder wenig gekannter Meeres-Conchylien.

Herausgegeben

ron

Dr. Will. Dunker.

Mil 45 colorirten Tafeln.

\section{CASSEL.}

Verlag von Theodor Fischer.

$1858-1870$. 



\section{Vorwort.}

Schon vor längerer Zeit beabsiehtigte ich Centurien neuer Mollusken mit Abbildungen berauszugeben, die als Fortsetzung der Abbildungen und Besclureibungen nemer oder wenig gekannter Conchylien von Dr. Philippi angesehen werden möchten, doch traten verschiedene Umstände ein un das Erscheinen der Hefte bis jetzt zu verzögern. Mittlerweile erschienen die Novitates conchologicae des Jerrn Dr. L. Pfeilfer. Da in denselben jedoch bis jelzt nur Land- und Süsswasser-Conchylien aufgenommen wurden, su habe ich mich an dem Werke meines verehrten Freundes Pfeifler in der Art be(heiligt, dass ich unter demselben Titel, Novitates conchologicae, zweite Abtheilung" die Herausgabe neuer oder nicht genügend bekannter Heeres-Conchylien übernommen habe, und die für jene Centurien bestimmt gewesenen Süswasser-Mollusken nebst einigen wenigen Landschuecken in der ersten Abtheilung des Werkes Aufnalıme finden werden. Es liegt bereits eine Reilse aul's Sorglältigste ausgeführter Tafelu mit interessanten Gegenständen vor, die bis jetzt nirgend abgebildet worden sind. Ueberhaupt ist ein reichhaltiges Material vorhanden, und haben auch mehre Conchyliologen Beiträge zugesichert. Und so mögen demn diese meine Novitates ebenfalls eine günstige Aufnalme finden.

Marburg, am 15. Juli 1858.

Dr. W. Dunker.
Préface

11 y a long tems que $\mathrm{j}$ invais lintention de publier des Centuries de Mollusigues avec figures, qui pourraient être regardées comme suite des „Abbild. u. Beschreib. never oder wenig gekannter Conchylien du Dr. Philippi, mais diverses cireonstances ont conconru pour retarder l'édition des firrajsons jusquà présent. Pendant ce tems les „Novitates cunchologicae" du Dr. L. Pfeiller ont commencé à paraitre. Comme celles-ci ne contiennent que des mollusques terrestres et d'eau donce, j’aj pris part i lunvage de mon ami Pleifler en $p u-$ bliant sous le nène titre:

Noritates conchylogicae, deuxième série des espèces nonvelles on peu connues de coquilles marines, et en insérant dans la première série les mullusques d'eau douce et le petit nombre de terrestres qui élaient déstinées pour mes Centuries. Un bon nombre de planches soigneusement exécutées, contenant des objets uulle part figurés, est déjà jréparé et en général de riches matériaux ne sont pas seulement it ma disposition, mais plusieurs Conchyliologues ont promis leur concurrence, et de cette maniere jespere, que mes "Novitates"s trouveront le mème accueil bienveillant, comme la première sérıs.

Marburg 15. Juillet 1858.

Ir. W. Dunker. 



\section{NOTITATES CONCHOLOGICAL.}

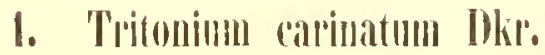

Tab. II. Fig. 3. 4.

T. Iesta onato-conica, crassinscula, anfractibus septonis transtersim sulcatis, in medio costa crassa obtusa unica anyulato-carinatis, sutura profinda sejunctis, anfractu ullimo carinis crassis tribus obtusis instructo; apertura lata: labro albido flerescente incrassato subeffuso pantlame reflexo; canali brevi recurco, emargimato; columella callosa albida: fancibus finscis.

Habitat ad Sitcham Russorum insulam: exstat in coll. clar. E. A. Romberg, Ilamburgensis.

Cochlea insignis $52 \mathrm{~m} . \mathrm{m}$. longa of $54 \mathrm{~m}$. m. lata, albido, subcocruleo el rubro rariegata quasi marmoratu, in anfractu nltimo obuse tricarinata, in ceteris unicarinala sulcisque transcersis subtilibus aerme distantibus ormata est. Sub ritro inter sulcens striate undulatae mimulissimate apparent. Striae incrementi praesertim labrume rersus conspicinutur. Specimen unicmm, quod crstat, hime alque illine erosum et decorticutum est, ita ut color fuseus internus transluceat. Epidermide virescente temi obdncta fuit cachlea, ul ejusdem restigia declarant.

Die ausgezeichnete $82 \mathrm{~m}$. $\mathrm{m}$. lange und $54 \mathrm{~m} . \mathrm{m}$. breite, bläulich weisse, rotbbraun gefleckte, fast marmorirte Sclneeke ist auf der lezten Windung mit 3 stumpfen, doch stark hervortretenden lielen umgeben, wovon der oberste stakste noch auf den oberen Windungen siehtbar bleibt, während die beiden unteren in dem Gewinde sieh verbergen; ausserdem laufen über das ganze Gehäuse feine linienarlige ziemlich gleich weit entfernt stehende Furchen, zwischen welehen, da wo die Schale ganz
Coquille distinguée, longue de 8: et large de jt mill.. de couleur blanche lıleuâtre, presque marbrée de taches roussàtres, munie, à son dernier tour, de trois carènes obtuses mais bien saillantes, dont la supérieure, qui est la plus forte, se eontinue sur les tours supérieurs, tandis que les deux autres se perdent dans l'intérieur. D'ailleurs toute la coquille est marquée de sillons linéaires, placés à distance presque égale, entre lesquels on remarque, à l'aide de la loupe, sur les parties parfaite- 
unverletzt ist, unter der Lupe sehr feine zum Theil wellenförmige Strichelehen sichtbar werden. Die Wachsthumsansätze der Schale treten zumal nach deren Mündung hin deullich hervor. Das vorliegende Exemplar ist hin und wieder corrodirt, so dass die rothbraune Färbung der untern Schalenschicht durehlenchitet. An einigen Stellen in der Năhe der Mijndung bemerkı man Reste einer dünnen blass olivengrünen Epidermis. ment conservées, des linéoles très-fines, en partie onduleuses. Les périodes d'accroissement du test sont bien visibles, surlout vers louverture. L'exemplaire figuré est rongé en divers endroits de manière à laisser remarquer la couleur rousse de la couche intérieure du test. On remarque des restes d’un épiderme mince, de coulcur pâle olivâtre en plusieurs endroits près de louverture.

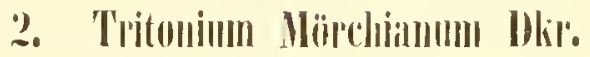

Tab. T. Fig. I. 2.

T. testa solidiuscula ovato-turrita, pallide flava, fasciis badiis haud regularibus cincta, anfraelibus senis rentrosis gradatis transversim tenvilerque suleatis, nodoso-angulatis, per longiudinem plieatis, plicis hand regularibus obliquis ad suturam parmm impressam subnodosis; anfractu ultimo biangulato; columella subplicata; labro albido subeffuso parum reflexo.

Ilabitat cum specie antecedente. Exstat in coll. clar. Romberg.

Cochlea Buccino Groenlandico II ancocl (Reeve Conch. icon. spec. 115 ) affinis, $73 \mathrm{~m}$. m. longa et 42 lata est. Anfractus ullimus, si mensuram a tergo feceris, dimidiam lestae parlem paullo excedit. Spira testae anfractibus earinatis subnodosis gradata vel sealata apparet. Striae transversae regulares smut et aeque distant: sub ritro strigillae undulatae numerosissimae in conspectum renimut ut in specie antecedente. Striae incrementi vix videntur. Fasciae badiae anfractus ultimi in apcrtura translucem.

Diese Sclnecke erinnerl in melirer Beziehung an Buce, Groenlandicum Hane. (Reeve Conch. icon. sp. 118), ist jedach ungleich grosser. Die Länge des vorliegenden Exemplars beträgt $73 \mathrm{~m}$. m. seine grösste Breite $42 \mathrm{~m}$. m. Das Gewinde ist sehr vorgestreckt und erselieint durch die oberlatb der Mitle der Windungen befindliche stumpfe knolige liante treppenformig abgesetzl. Der letate Ungang, welcher noch eine zweite Kante zeigt, die auf den oheren Windungen nicht sichtbar ist, übertrilft uur ein Weniges die halbe Länge der ganzen Schnecke, wenn nämlich die Messung auf dem Rücken der Schale vorgenommen wird. Auch
Celle coquille ressemble, sous plusieurs rapports. au Buccimum Grocnlandicum Hanc. (Reeve Conch. ic. sp. 118), mais elle est beancoup plus grande. Liexemplaire figuré a une longueur de 73 millim. et sa plus grande largeur est de 42 mill. La spire est bien allongée el ses tours sont comme étagés par la carène obluse et tuberculense, qui entoure leur milieu. Le dernier tour, muni d'un second angle, qui niest pas visible sur les tours supérieurs, ne surpasse que très peu la moilié de la longueur tolale, quand la coquille est mésurée du côté du dos. Ainsi que la précédente cette coquille est munie de stries enfoncées, placées à 


\section{$-3-$}

diesc Art ist mit verticften in regehmasiger Entfermung stehenden Linien bedeckt, zwischen welchen unter der lupe zarte wellenförmige Strichelchen sich hemerkbar machen. Wachsthumsansatze sind kaum sichtbar. Die Grundfarbe ist ein blasses Gelb; auf dem letzten Umgang hefinden sich drei breite nicht scharf abgegräuzte braume Binden, die im Innern durchscheinen und wovon nur dic oberste auf den ührigen Windungen sich zeigt. distances régulières, entre lesquelles on remarque, à l'aide de la loupe, des linéoles lines et ondulcuses. Les périodes daccroissement ne sont guère remarquables. La couleur générale est un jaune pâle: le dernier tour est garni de trois bandes larges, de couleur brune el à contours peu marqués. Ces bandes sont aussi visibles dans l’iutéricur, et la supérienre se continue sur les autres tours.

\section{Tritonium rutilum Hiond. I Tab. If. Fig. 5. 6.}

T. testa onato-turvita, albida pallideque rutila, longitudine nodoso-plicata, transiersim sulcala; anfractibns septenis tumidis, sutma hand profunda sejumclis; colmmella alba parum curvata, indistincte uniplicata; labro subefinso incrassato albo; apertura iulus rutila.

Tritoninm rutilum Horch in sched.

llabilat cum antecedentibus. Exstat in call. clar. Romberg.

Haec cochlea quantum scio nusquam descripla ant depicta $69 \mathrm{~m}$. m. longa. $35 \mathrm{~m}$. m. lata, colore pallide rutilo cxcellit. Anfraclus nltimus circa dimidiam testae partem occupans, obsolete plicatus est, anfractus reliqni distinctins plicati in plicarmm medio subnodosi sumt. Superficies totius testae sulcis haud profundis costulisque planis et laevibus sculpta est.

Die Länge des vorliegenden Exemplars beträgt $68 \mathrm{~m} . \mathrm{m}$. , die grosste Breite desselben $38 \mathrm{m.m}$. Der letzte Ungang nimmt etwas mehr als die llälfte der ganzen Schalenlänge ein. Die Windungen sind ziemlich gewölbt and mit etwas schiefen Langsrippen bedeckt, die in ihrer Mitte knotig erscheinen und auf den oberen Umgängen besonders deutlich hervortreten. Feine dicht stehende Furchen und flache glatte Rippchen laufen quer über die ganze Schale himweg. Die Farbe ist ein blasses gelbliches Roth; unterhalb der Sutur und auf der knotigen Erhöhung der Rippen des letzten Uıngangs sowie am Mundsaum spielt die Farbe in das Weisse, auch die verdickte Mundlippe und die Columella sind weisslich, dagegen ist das Innere blassroth.
L'exemplaire figure a une longueur de 68 millim., son plus grand dianetre est de 38 mill. Le dernier tour occupe un peu plus que la moitié de la longueur totale. Les tours sont asscz convexes et couverts de còtes longiludinales un peu obliques, qui apparaissent tuberculenses à leur milieu et sont plus saillantes sur les tours supérieurs. Toute la coquille est entourée de nombreux sillons et de côtes aplaties et lisses. La couleur est d'un rouge pâle jaunâtre, passant au blanc près de la suture et sur les protubérances des còtes du dernier tour. Le péristome, la lèvre épaissie et la columelle sont blanchâtres, landis que l'inlérieur de la bouche est d'un rouge pale. 


\section{Tritonium Rombergi Mlir.}

Tab. İ . Fig, 5. 6.

T. testa ocato-conica, flaon-albida, teni; spira producta; anfractibns sutura land profunda segaratis, superne paullulum aphlanatis, infra carinatis, lomgitudine oblique plicatis transversimane sulcatis, ultimo tricarinato; apertura ovata; labro dilatato paullum reflexo: fancibus lnteis.

Mabitat cum antecedewtibus. Exstat in coll. clar. Romberg, Hamburgensis.

Haec species $46 \mathrm{~m}$. m. Iongu et $27 \mathrm{~m}$. m. Lata. primo intuitu ad Tritoninm ( $P$ nce.) glaciale Limnasi pertinere rilletur, sed dilfert ab eo curiis notis, praesertim stutura minore, tcsta tcmiore et graciliore, colore crtermo flaro-albido pasne cretaceo nec non interno luteo. Practerea carina anfractunm superiorum nodifera in nostra specie valde prominet. Costulae transurerse sub ritro mimutissime striatae et sulgyranosac apparent. Labrum speciminis depicti terme est intusque sulcatum, nec incrassutum, quapropter cochleam non plane adullume esse opinor.

Cum O. F. Mullerus jem anm 1776 (Zool. Dan.) hoc gemus Tritonionm praesertim in Buccinum undatum Liunaei aliesque similes cochleas mejores arcticas fundarerit, pro talibus tuntummodo cochleis, exceptis Fuso (Neplunea), Vassa alisisune, ut adoptctur mecrsse est. Et sane clar. Deshayes in Lamarchii opere laudato Syst. des anim. sans vert. ed. II. momen genericum Mulleri Buccino unduto vindicavit, clar. O. A. L. Märch pari molo adoptarit in Catal. Conch. com. de Foldi pas. 105. - Nomen genericum Tritomis Lam., quod pervaria complectitur armimalia, pro nostra sententia inter mollusca non amplins locum trmere debet. quippe qued jam antea batrachits quibusdam candatis impositum finerat. ")

Die laange dieser Schnecke beträgl $46 \mathrm{~m} . \mathrm{m}$., ihre Breile $27 \mathrm{~m} . \mathrm{m}$. Beim ersten Blick sclucint sie einer der vielen Varietaten des Tritonium (Bucc.) glaciale $L$. anzugehuren; sie unterscheidet sich jedoch besonders durch viel schlinkere Gestalt und die stark lservortretende kante auf den oheren Windungen, arch weicht die Farbe ab. kleinerer Unterschiede nicht zu gedenkeu. Die Querrippehen erscheinen unter der Lupe sehr fein gestrichelt und etwas kornig. Der Mundsaum des vorliegenden
Cetle corpuille a 40 millim. de longueur et $2 \pi$ de diamétre. Au premier coup d'oeil on la prenIruit pour une des nombreuses variétés du-Tritonium (Burc.) glaciale L.; mais elle s'en 'distingue principalement par sil forme heaucoup plus grèle et langle bien saillaut des tours supérieurs. La conlenr encore est un pen différente et l'on trouve plusieurs autres dillérences peu marpuées. Les pelites côtes transversales. vues à la loupe, apparaissent trés-finement linéolées et un peu granu-

*) Tirlon Limuart (Syst. Nat. ed Xll. prag. 1092) Darwinio tcste (Monogr. on the subclass Cirripedia, Londini 1454 pag. 158) nil nisi exuviae sunt Balani cumsdam fortasse B. porcilli. 
Exemplars ist dün und innen gefurchi, nicht verdickt. wohl eine Folge des nicht ganz ausgebildeten Zustandes der Schnecke.

Da 0. F. Il uller im Jahre 1776 des Genus Tritonium vorzugsweise auf die grosseren nordischen Schnecken wie Bucrimum undalum L. grundete, so sollte nach meiner Ansicht dieser Gattungsname unr den diesem Typus angehorigen Formen rerbleiben, also mit Ausschluss der baucligen Fusi (Noptunea), der Nassae und einiger anderer, und der Genusname Triton Lam. unter welchem verschicdene Schnecken begriflen werden, die als Gattungen langst ilre Namen crhalten habeil, nm so melir wegfallen, als dieser Name schon l76s ron La urenti an einen Wassermoleh verueben war II der That hat auch schon Deshayes in der neuen Ausgabe des Lamarck Jas Buccinum. undutum als Tritonium aufgefulirt Anim. sans vert. vol. X. prag. 154), ebeuso O. A. L. Horeh in seinem Cat. Conch. com. de Yoldi pag. 10\%. - Beiläufig sei hier noclt bemerkt, dass Linnés Triton (Syst. Nat. ed. Xll. pag. 109:2) nach l)arwin (Monogr. on the subclass Cirripedia pag. 158 ) niclits anderes ist als die llant einer Balamasart, vielleicht des $b$. porcalus. leuses. Lo péristone de l'exemplaire lig̣uré est mince et sillonne a lintericur, non épaissi, ce qui provient probablement de lage de la copuille.

Puisque 0. F. Mille r a fonde, en 1756 , le genre Tritonium princijalement pour les grandes coquilles boréales du groupe du Buce. mulatmm L. je crois que ce nom génćrique doit ètre reservé anx formes appartenant au mime type, et que les Fuseaux ventreux (Neptureca), les Nasses et plusieurs autres doivent ent être pxclues. Le nom générique ..Tritun Lam.", yui enbrasse plusieurs copnilles distinguées depuis long-tems par des noms generiques, devra itre rejeté entièrement, d’autant plus, parceque le mime nom a ithé employé en $176 s$ par Laurenti pour nu genre de liatrachiens. En ellet Mrs. Weshayes (dans la nouvelle édition de Lamarck $X$. p. 154) et Mörch (Cat. Yold. p. 1050) ont déji range le Bucr. undatum parmi les Tritonium. En jassant je remarquerai que d'après 1) arwin (Mon. on the subclass Cirripetia p. 58) le genre Triton de Linné nest antre chose que ta pean d'une esprece de Balanus.

\section{Nepenea harpa Viopet. \\ I Tab. 11. Fig. 3. 4 .}

N. testa sinistrorsa ocata, sordide caernlenque albida et rufescente, in apice obtusa; anfraclibus quinis sutura profunda dicisis, transeersim sulcatis, ad longitulinem nodoso-costatis, costis magnis haud regularibns subollignis; apertura longa, paene lumbla: colmella subrecta. callosa; faucibus mefescentibus.

Neptune a le arpa Morele in schedulu.

Habital ad Sitcham, Russorum insulam.

Cochlea insignis sinistrorsa crassa et ponderosa, $84 \mathrm{~m}$. m. longa el $50 \mathrm{~m}$. m. lata est; anfrachus cius ullimus paene ${ }_{5}^{4}$ testae occupat (si mensuram a tergo feceris), ita ut apertura per- 
Innga appareal. Anfractus comexi sulcis lalis costisque elevatis transversis instructi sunt; in ullimo costae circa riginti numerantur. Apex obtusus papillae haud dissimilis laevis est el spadicrus, anfractus ceteri ad longitudinem nodoso-plicali sunt. Color testae sordide racrulenque albidus et rufescens, praesertim iis quoque in locis, ubi corium detritum est. Strite incrementi aperturam versus tantmmmodo expressac sumt.

Haec cochea, quantum scio, mulla loco descripta, ad hac usque tempus certe rarissima, in collectione exstat amici E. A. Romberg, Itamburgensis. Valde accedit ad Fusum de formem lieenei (conf. conch. icon. sp. 45), a quo lamen differt non salum statura longiore et testa crassiore, sed eliam costis transversis elevatis distantibus.

Die Lange dieser ausgrzeichneten linksgewundenen, ziemlich dickschaligen Sthnecke beträgt $84 \mathrm{~m} . \mathrm{m}$., die grössle Breite derselben $50 \mathrm{~m} . \mathrm{m}$. lhre fünf Umgänge nehmen nugemein sehnell zu, so dass der letzte fast " $"$, der länge des ganzen Gehäuses einnimmt und daher auch die Mündung sehr lang erscheint. Die Schale ist mit unregelmässigen, etwas schief liegrnden flacls-knotigen oder etwas buckligen Län@sfalten bedeckt, über welche ziemlich stark hervorthetende in ungleicher Entfernung von einander steliende Querrippen hinweglaulen, deren etwa 20 auf der letzlen Windung sich befinden. Der Apex ist glatl und beinahe zitzenförnig, er erinnert an die Emhryonalwindung der Voluten. Die Farbe der Schnecke ist sclimutzig weiss ins Bläuliche spielend sowie hin und wieder rölllich braun, namentlich auch an den Stellen wo die obere Schalenschicht abgerieben isı, oder durch das Thier selbst aufgelöst wurde, wie das an der Mündung des vorliegenden Exemplares der Fall sein mag. Der Wirbel ist ebenfalls braun, das Innere der Mündung röthlichweiss und braun und von porzellanarligem Anselın. Die Wachsthumsansïlze ersclıeinen nur mach dem Müıdungsrande hin deutlich.

Diese Schnecke, die ich nirgends beschrieben oder abgebildet finde, mag wohl zu den sehr seltenen Arten gehören. Sie kommt dem ebenfalls sehr seltenen linksgewundenen Fusus deformis
Coquille sinistrale, assez éflaisse (longueur 84, grand diamètre 50 millim.). à 5 tours accroissant trés-Japidement, de sorte que le dernier oceupe à peu près ${ }^{4}$ de la longueur totale et la bonche parait très-alongée. Le test est couvert de plis longitudinaux irréguliers, un peu obliques, légèrement tuberculenx, qui sont croisés, à distances inégales, par des còtes transversales assez saillantes, dont il $\mathrm{y}$ a environ 20 sur le dernier tour. Le sommet el lisse, presque mammillaire; il rappelle les tours embryonaux des Volutes. la conleur du test est blanc sâle, tirant sur le bleu, çi et là roussâtre, surtout dans les endroits, où la couclıe suprème est rongée ou dissolue par l’animal même, ce qui parait avoir eu lieu à l'ouverture de notre exemplaire. Le sommet est brun, l'intérieur de la bouclıe blanc rougeâtre et brun, ressemblant à de la porcelaine. Les stries daccroissement ne sont bien marquées que près du peristome.

Cette espèce, que je ne trouve décrite ni figurée nulle part, parait être des plus râres. Elle a quelque rapport avec le Fusus deformis Reeve (Conch. ic. sp. 45) qui est aussi sinistral et trèsrâre, mais elle s'en distingue par sou lest plus épais, sa spire alongée el surtout par les côtes transversales saillantes et les plis longitudiuanx forts et décurrens. 
Reeve (Conch. icon. spec. 45) sehr nahe, unterscheidet sich aber durch ein langeres Gewinde und stärkere Schale, sowie zumal durch die erhabenen Querrippen und die starken tief herablaufenden Längsfalten.

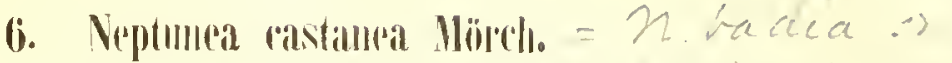 Z' 1 Tab II'. Fig. 1. 2.}

N. testa ovuta, badia, tenni, laebiuscula, spira exserta, apice obtusa; anfractibus semis convexis sutura profunda divisis, plicis incrementi hand regularibus instructis, ultimo peramplo; apertura magna oblonga: columella parum simuata pallume callosa; cauda brevi lata subcurvata; labro simplici; faucibus lacteis, sabroseis.

Neptumea castanea Horch in sehed.

Ex insula Sitcha. Exstat in collectione clar. Romberg Jamburgensis.

Testa unicolor badia $70 \mathrm{~m} . \mathrm{m}$. longa, $36 \mathrm{~m} . \mathrm{m}$. lata lacriuscula, ad longitudinem haud regulariter plicata. Anfractus sex parmm tumidi, ultimus permagmus circa $7 / 10$ longitudinis testae aduequans. Apicis formation in specie antecedente. - A Fuso (stromb.) norvegico Chemn. C. C. vol. X. pag. 318 Tab. 157 fig. 1497 et 1498 spera breciore, cauda minus curvata, colore obscuriore it statura minore paullo aliena differre videtur.

Gemus Molluscorum Neptunea Bolten, anno ligs creatum. ommes pos Fusos rentrosos sensu Lamarchiano complectitur, qui rostro brexi gaudem ut Murex antiquus Linnaei aliique.

Das Gehäuse ist einfarbig nussbraun, ziemlich glatt, nur der Länge nach mit schwachen Längsfalten und Waclsshumsreifen bedeckt. Die 6 nicht stark gewölbten Windungen nehmen auch hier selır schnell an Umfang zu, denn der letzle beträgt ungefälır $7_{10}$ der ganzen Länge der Schnecke. Die Bildung des Wirbels ist der vorigen Art analog; die Mündung und die Beschaffenheit der Columella ebenfalls. Die innere Farbe ist ein blauliches Weiss, welches ins Rosenrolhe übergebt. Die Länge beträgt $70 \mathrm{~m} . \mathrm{m}$., die grösste Breite etwa $36 \mathrm{~m} . \mathrm{II}$.

Diese Art luat mit dem Fusus (Strombus) Norvegicus Chemn. C. C. vol. X. pag. 318 Tab. 157. fig. 1497. 1498 viele Aehnlichkeit, doch scheint sich

Le test est de coulenr uniformément brun-noisette, assez lisse, seulement muni de legers plis longitudinanix et de stries d'accroissement. Les six tours peu convexcs, s'accroissent rapidement, comme dans l'espèce précédente, de sorte que le dernier lorme à peu prés $\bar{T}^{\prime}$ ro de la longueur totale. La formation in sommel est semblable a celle de l'espéce précédente, ainsi que la bonche el les caractères de la columelle. La conleur intérienre esl un blanc bleuatte, prassant all rust. Longueur 70 , grand diamètre 36 millim.

Celle espece ressemble beancoup an Fusus (Strombus) Norregicus Chemn. (C. C. X, p. 318. Pl. 157. f. 1497. 1493), cependant elle parait en dif- 
dieselbe dnrch eine kurzere Spira, minder gelrummten Schnabel, lileinere ziemlich abweichende Form sowie auch durch dunkle Farbung zu mnerscheiden.

Das Genus Neptunea Bolten 1798 umfasst alle bauchigen Fusi (das Genus Fusus im Lamarelischen Sinne aufgefasst), welche durch einen kurzen Schmabel ausgezejchnel sind, wie z. B. Fusus ( $11 u-$ rex) (unliqus $L .{ }^{*}$ ) férer par sa forme el couleur, sa spire plus courte, son bec moins courbé, et sa taille moindre.

Le genre Neplunea Bolt. 1798 embrasse toules les espèces ventriqueuses du genre Fusus (dans le sens Lamarckien), qui sonl distinguées par leur bec raccourci, conme par exemple le Fusus (Murex) antiquus Limn.

\section{i. Sulen Schulzeanus Mir.}

Tab. III. Fig. I.

5. tesla lineari, recta, tenerrime striata. extremitate antica oblique truncala, postica aliquantulum anguslala subrolundata; margine antico aculo extus laeni, non sulcato, intus incrassato, cum margine inferiore seu rentrali anguhum aculum formante; cardine utrinsque valvae unidentato, denticulo calvae dextrae refexo, simistrae subbifido; epidormide tenera pallide virescente.

Solen Schullzeanus Dlir. in Zeilschr. F. Mal. $1850 \% 31$.

Habitat in lilore Lusitaniac (in ostiis Taji prope Lisbonam). Nisit clar. Bellermamn Berolinensis.

Haec species affnis Soleni Guineensi-sub nomine S. Irucali Sou. in Pleilippi Abbild. und Bescher. col. I. pag. 35 Tab. I Fig. 2 descripto et depicto - sed sulco obsoleto in margine antico deficiente, extremilate postica aliquantulum altenuata et subrotumdata aliisque nolis facile distingmenda est.

Speciminum duorum plane comenientium longitudo $01 \mathrm{~m}$. m. clficit, eorumque allitudo $12 \mathrm{~m} . \mathrm{m}$. Clar. Dr. 11. Schultse Halensi hane speciom debemus.

Gehäuse linear, gerade. zarl gereilt, vorn schief abgestutz, hinten elwas verschmälent und gerundet; Vorderrand scharf, aussen glall nieht g efurcht, innen rerdickt mil dem Banchande einen spilzen Winkel bildend. Im Schloss betiudel sich beiderseils ein kleiner Zalu; in der rechlen Schale ist derselbe zurückgebogen, in der linken elwas gespalten. Die Epidermis isl dünn und blassgrüu.
Coquille linéaire, Jroile, finemenl striée, obliquement tronquée en avant, légèrement amincie et arrondie à son extrémité puslérieure. Bord antéricur tranchan, extérienrement lisse el déponrvu de sillons, épaissi à l'iulérieur el formant un angle aigu arec le bord rentral. La charniere contient de chaque côtí une petite dent. qui esı légèrement réféchie dans la valve droite, fendue dans la valve ganche. L'épiderme est mince el d'un vert pâle.

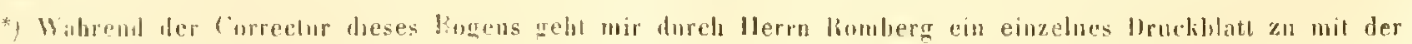

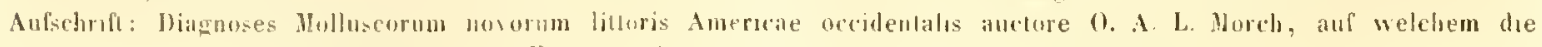

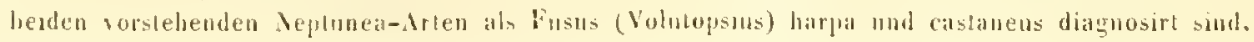


Diese kleine Messerschende, welche sich in der Mündung des Tejo bei Lissabon lindet, ist dem Solen Guinecusis Gray (nicht zu verwechselı mut Solen Gumernsis Chemn., zur Gallung Tugelus gehorend) nieht unälulich; sie unterseheidel sielı jedoch namentlich durch schlankere Gestalt, den Mangel einer schwacheu Furclie am rordern Rande und den acrumeten elwas verschmalerten Hintertleil.

Die beiden vorliegenden vollhommen ubereinslimmenden Exemplare sind 61 แ m. lang und 12 m. m. luoch. Wir rerdanlien diese Art der Güte des llerrn Prof. Dr. M. Scludtze in Ilalle.
Ce pelil Solen, yoi se Iruvve dans les bouclies du Tage près de Lisbonne, est assez semblable au s. Guineensis Gray iquil ne laul pas confondre avec le S. Gumeensis Chemm., qui appartient au grenre Tagelus), mais if en dillere par sa forme plus grèle. par le manque d'un sillon leger au boed autérieur et par sa partie postérieure arrondie el legérement rélecie.

Les deux exemplaires parfaitement miformes, que nous avous sous nos yeux, ont une longrter. de $61 \mathrm{~m}$ in. el une lanteur de $12 \mathrm{~m}$. m. Xous les devous a la libéralite de Mr. le prolesseur, Dr. M. Seloultze a Italle.

\section{Solpu Timmornsis Imis.}

Tab. III. Fig. ?.

S. Lesta lineari, recta, jerlonga, ammotio roseoque picta, extremilate untica oblique truncata, margine simplici ueuto, extus minime suleato, angulo inferiore aculo; extremitate postica opposite truncala: margine cardinali et basali paene parallolis. - Long. baseos 125 $\mathrm{m}$. m., long. marg. cardinatis $110 \mathrm{~m}$. m., altit. conchae antica $\mathrm{s} \mathrm{m}$. m., posticu $20 \mathrm{~m}$. $\mathrm{m}$. Solcn Timorensis Dhr. in Zeitscler. F. Mal. 1552 pay. 56.

Ilabitat ad insulam Timor, teste beato G. Scheepmatier, Amstelodamensi.

Specios rarissima murgine antico et postico diceryentibus valde insignis est Basis cum maryine antico angulum arntum cireiter 7 gradum format, angulus qui respondet postieus pacne s.t gradus efficit. Hargo basalis et cardinalis recti, sed divergentes, cum testa postire paullo altior sit. Cardinis structura et facies interna plerisque speciebus cogmatis respondent.

Selale gerad, sthr lang, orangefarben und rölllich gezeichnel mit helleren den Waehshlumsansatzen paralleleu Streifen; die vordere sehief abgestutzte Eutromitat mit scharfem liamle, ohue äussese Furche bildet mit dem Banchrande einen spitzen Winkel; die hintere Extremitat ist der vorderen entgegengeselzt trunkirt, der vollkommen gerade Schlossrant denı Baucluande nieht ganz parallel. Die Länge des lelzteren beträgt $128 \mathrm{~m}$. m., die Länge des Schılossrandes 116 m. m., die Hölıe der Muschel vorn $18 \mathrm{~m}$. m., hinten $20 \mathrm{~m} . \mathrm{m}$.
Coquille droile, trés-allongée, couleur d'orange et rougeatre, a bandes plus claires, parallèles aux stries d’accroissement. L'extrémité autérieure, à bord tranchant sans sillon extérieur forme un angle aigu avec le bord ventral. L'extrémilé postérienre est tronquée en opposition avec l'antérieure; le bord dorsal, parfaitement reclilintare, n'est pas tout à fait parallele avee le ventral. La longueur du bord ventral est de $128 \mathrm{~m}$. m., eelle du bord dorsal $116 \mathrm{~m} . \mathrm{m}$., la banteur de la coquille en avant $18 \mathrm{~m}$. m., à sa partie postérieure $20 \mathrm{~m}$. $\mathrm{m}$. 
Vaterland: Küste der Insel Timor. (G. Scheepmaker !.

Diese, wie es scheint, sehr seltene Art ist besonders ausgezeichnet durch die entgegengesetzt geneigte Abstumpfung der Extremitaten. Der Basalrand bildet mit dem Vordermal einen spitzen Winkel von etwa it Graden; der entsprechende Winkel am Hinterrande beträgr ungefähr $8+$ Grade; der Schlossrand und die Basis sind nicht vollkommen prallel, da der hintere Theil der Muschel um ein Weniges hoher ist. Die innere Beschaflenheit entspriclıt den meisten verwandien Arten.
Cette espèce à ce qu'i] paraît, très râre, provient des côtes de l'île Timor (selon Mr. Sc ls e epmaker) el son caractere principal consiste dans l'inclinaison divergente de ses extrémités tronquées. Le bord basal forme un angle aigu d'environ $7.4^{\circ}$ avec l'antérieur; langle correspondant du bord postérieur est ì peu pres $84^{\circ}$. Les borils dorsal et basal ne sont pas parfaitemeut parallèles, la partie postérieure de la coquille étant un peu plus haute. Lintérieur de la coquille est comme dans les auires especes voisines.

\section{Cultellus orientilis Dkr.}

Tab. III. Fig. 3.

C. testa magna, crassiuscula, plano-convexa, limeari-ovali, subrecta, concentrice striala, alba, epidermide subolivacea vestita; margine dorsali leviter curvato, margine ventrali recto, in medio perparm simualo; extremilatibus roturdatis; umbonibus obsoletis parum prominemibus; cardine utrinque bidentato, dentibus diceryentibus, altero ntriusque valvae majore; impressione musculari postica obsoletissima; linea palliari nitente basi subparallela. - Long. conchae $107 \mathrm{~m}$. m. Long. allit. crass. ratio haec est 100. 32. 14.

Solen orientalis Dkr. in. Zeitschr. F. Mal. 1850 pag. 31.

Patria: Indiae orientales, Exstat in Muspo Gryphico.

A Solene maximoGmel. Legumimm maxima" Chemn. haee species lesta solidime haud currata et umbonibus magis recedentibus distinguenda est.

Gehäuse gross, ziemlich stark, flach convex, lang oval, fast gerade mit stärkern und schwächern Wachstlımsreifen, unter brännlicher fast olivengrüner Epidermis weiss; Schlossrand sclur schwach gebogen, Bauchrand fast geradlinig, Extremitaten gerundet; Wirbel stumpf, kaum hervortretend. Das Schloss ist in beiden Schalen mil zwei divergirenden ungleich grossen Zähnen verseheu. Der vordere rundliche Muskel ist dentliclı eingedrückt, der hintere dagegen sehr flach und verwischt und nur
Coruille grande, assez épaisse, médiocrement convexe, oblongue ovalaire, presque droile, marquée de stries d'accroissement plus on moins fortes, blanclie, couverte d'un épiderme brunâtre passant à l'olivacé. Bord cardinal trés peu courbé; bord ventral presque rectilinéaire, à extrémités arrondies. Crochets obtus, à peine saillans. La charnière est munie, dans les deux valves, de deux dents inégales, divergentes; l’impression musculaire antérieure arrondie est bien marquée, tandis que la 
am Glanz zu erkennen; die glanzende Mantellinie lauft dem Basalrande last parallel. - Die Linge dieser Muschel beträgt $107 \mathrm{~m}$. m., und das Verhälnniss der Länge, Höle und Dicke isı elwa wie $100,32.14$

Vaterland Ostindien. Das Original befindel sich im Greifswalder academischen Museum.

Von Solen maximus Gmel. unterselıeidel sicl unsere Art darch stäkere nich gebogene Schalen und melı zurisckluetende Wirbel. postérieure est trés peu enfoncée et ne peul cilre distinguce que par sa lueur; la ligne lujsante du manteau va presque parallele avec le bord basil. La longueur de celle coujulle est de $107 \mathrm{ml} . \mathrm{m}$.

L'échantillon typique de eelle espece provenant des Indes urientales, se Lronve dans le Musce académique de Gireil'swall.

Notre esprece se distingue du Solen maximus Gmel. par ses valves plus épaisses et non courbées, el par la direction de ses cruchets.

\section{Cultellus miximus Gimel.}

'Tab. 1]1. Fig. 4.

Leguminum maxima Chemr. vol. ij pay. 51. Tab. 5. Fig. 35. - Solen maximus Gmel. - Solen lacteus Spengl. - Solen nieobaricus bolt. C Cltellus magnus Schum. - Solen planus Lam.

Comparationis causa specimen grande et angustum hains conchae rarissimae ex insula Amboina allatum, ad collectionem mostram pertinens, leic depinximus, ut notae differentes inter hanc et antecedentem speciem magis eluceant. - Utraque speries ad genus Cultello$r u m$ Schumacheri anno $1 \mathrm{~s} 17$ creatum pertinet.

Wil lıaben hier ein grosses und elwas schmales Exemplar dieser sehr seltenen Huschel, welche von Amboina stamm, abgebildet, damil die unterscheidenden Merkmale dieser und der vorkergehenden Art um so deutlicher hervortreten. Beide gehören Schumacher's Gattung Cultellus an, die im Jahre 1817 aufgestellt worden.
Pour faire ressorlir plus clairement les diflérences entre l'espjèce précédente el celle déerite par Chemnilz, nous avons liguré un exemplaire grand de forme un peu rélrécie de la dernière, yui est très-râre et provient de l'ile d'Amboina. Ces deux especes appartiement au genre Cultellus, proposé en 1817 par Sclı umaclıer.

\section{Cytherea cordilor'mis IDkr.}

Tab. 1V. Fig. 1. 2 et 3

C. testa cordato-globosa, crassa, obsolete idlue concentrice striata, striis basin nersus sublamellosis, albida, subflava, punctulis lineisque angulatis nornullis badiis concentrice irregulariterque picta; umbonibus tumidis incurvis antrorsum inclinatis; area magna vix termi- 
nata; labiis tumescentibus; ligamemto profme immerso. - Long. 44 m. m. Long., alt.. crass. mumeris $100,90,7.5$ respondent.

Cytherco rordiformis llkr. in Zeitschr. f Mal. 1848 pag. 18.5.

Ilabitat in litore insulac Zanzbar A/ricae orient. Teste Alberto Rodat.

species peculiaris forma globosa el propriclate nmbomm Glossis sive lsocardies quibusdam fossilibus simillima. Extremitas antica breris. subangulata, area excatuta, cordiformis, latus posticum ot basale circularia: cardo dentibus crassis mmitus, dens anticus valrae sinistrae comicus. Specimina jumiora multo mirms tumescuret.

Gehäuse he rzförmig-kuglig, dickschalig, schwach concentrisch gereift, Reifchen wach dem unteren Rande hin stärker werdend, fast lanellenartig; Farbe weisslich ins Gelbe uluergehend mit bramen unregelmässigen oder concentrisch aneinander gereilieten Pünktchen und einign unlerbrochenen Zickzacklinien geziert; Wirbel antgetrieben, gekrummt und nach vorn geneigl; Area gross, nichl scharf hegrenzt; lippen angescliwollen; Ligament lief eingesenkl. - Länge $4 \mathrm{~m} . \mathrm{m}$. Die Länge, Hohe und Breite verhalten sich etwa wie 100 , 90,75 .

Diese Huschel lelnt an der liuste von Zanzibar. Durch itre kuglige Gestall nnd die gekrümmten Wirhel gleicht sie gewissen fossilen Herzmuscheln. Die vordere Exxtremitat ist kurz und etwas winke$\mathrm{lig}$, die Area ausgehohlt, im Umriss herzförmig, der Hintertheil und die Baurhseite sint kreisrund. Im Schloss beliuden sich starke Zälune; der vordere der linken Valve ist lionisch. Die Beschaflenheit der Muskeln und der Mantellinie ist aus der $\mathrm{Ab}$ bildung fig. 3 ersichllich; dieselben sind an alten Exemplaren slark ausgepritgt. Jüngere Huscheln zeigen eine minder kuglige Gestalı.
Coquille globuleuse subcordiforme. epaisse, munie de stries concentriques légères, qui deviennent. plus fortes el sélèvent presque en lamelles vers le borl inférieur. Coulenr blanchàtre lirant an jaune. marjuée de petits points bruns, irréguliers ou arrangés en lignes concentriques, et de plusicurs lignes ell zigzag interrompues. Crochel. renflis, courbés el inclinés en avant. Aréa grande indistinclement limilé; lèvres renflées; ligament profondément enloncé Longucur $4 \mathrm{~m}$. $\mathrm{m}$.

Cette espèce vit sur la còte de Zanzibar. Par sa forme globulaire el ses crochets courbés elle ressemble à certains Isocardes l'ossiles. L'extrémité anlérieure est courte el légérement anguleuse, laréa enfuncé, à coutour cordiforme: la partie postérieure et ventrale sont circulaires. La charniere est garnie de dents fortes; l’antérieure de la valve gauche est conique. Les caractires des muscles el de la ligne palléale sont recommissables par la figure 3 ; ils sont forlement marqués dins les individus vienx. Les coquilles moins adultes présentent une forme moins glohulaire. 


\section{1:) - \\ 12. Cytherea Ilagenowi Dks.}

Tal. IV. Fig. 13. 14 el 15.

r. testa orata, oblique subcordata, laeri, nitida. concentrice obsolete plicatu, rufa, subradiata, radiis $2-3$ latioribus interrmptis rufo-castancis ornata: umbonibus tmmidis concentrice elcganterque sulcatis: lumula cacatata corlato-lanceolata; area utringue castaneo maculata. - Long. 2 poll. Long. all. et crass. ratio mumeris 100 , 78 at to respondet.

Cytherea II agenowi Dlr. in Zeitsch. F. Mal. 1845 pay. 151.

Ilabitat in mari Erythraco.

Species nostra inter Cytheream pacificam Dilho. et Chionem intermedia, ab har praesertim stainra minore et regione lunulae magis simata, ab illa margine postico rotmulato multo minus attenuato differt.

Gehäuse ciförmig. fast schief herzförmig, glatt, glänzend, concentrisch schwach gefaltet mit röthlichen blassen ungleichen Strahlen, wovon zwei bis drei breitere und unterbrocliene durch dunklere braunrothe Färbung hervortreten; Wirbel anfgetrieben, concentrisch fein gefurcht; die Lunula ansgehöhlt schmal herzförmig, die Area beiderseits castanienbraun gefärbt. - Länge 2 Zoll. Verhailtniss der Lünge, Höhe und Dicke ungefähr wie 1010, 78, 46.

Diese Art, welche im rothen Mecre lebt. steht zwischen Cytherea pacifica Dillw. und Chione $\mathrm{I}_{\text {. }}$. Von der letzleren unterscheidel sie sich durch geringere Grösst und stärker gebuchtele Lunula, von jener durch die gerundete hintere Extremität.
Coquille ovalaire, obliquement subcordiforme, lisse. luisante, munic de plis concentriques peu élevés et de rayons inégaux d'un rouge pale, dont $3--4$, qui sont plus larges el interrompus. se distinguent par leur conlenr rousse plus foncée. Crochets renflés, munis de legers sillons concentriques. Lunule concave, étroitement cordiforme; aréa couleur marron des deux cótés. Longueur 2 pouces.

Cette espece, qui vil dans la Mer hougr. est intermédiaire entre les C. pacifica Dillw. et Chione L. Elle se distingue de la dernièce par sa stature moindre et par sa lunule plus fortement enfoncée, de la première par son estrémité postérieure arrondie.

\section{Venis Rodatzi Mhis.}

Tab. IV. Fig. 4. 5 et 6 .

V. testa oblonga, paene elliptica, sulcis concentricis confertis subirregularibus postice validioribus ex parte dichotomis eleganter sculpta. flarescente, macnlis lineolistue atro-fascis, glaucis et lividis anymlato-flexnosis, undulatis son araneosis rarie picta et saemins intcrmpte inadriraliata: extremitate antica brevi attenuata, postica producta, basi aequaliter parmm- 
que curvata; umbonibus parvulis, aculis; margine ante umbones excavato; lumula angnstata, subcordala, indistincte terminata; area lanceolata labiata; ligamento profundo. Cardo Cylhereae Deshayesii Ilant. similis; color interms sulphureus, dentes plerumqne ciolacei. - Long. I poll. 3 lin. - 1 poll. 8 lin. Long., alt., crass., $=100,65,42$.

Venus Rodatzi Dkr. in Zeitschr. F. Mal. 184S. pag. 155.

Ex itinere Africano allata est a beato Alb. Rodatz.

Species ad gems Mühlfeldtianum Tapetis pertinens, ambitn Veneri Deshayesii respondel, sed multo minor est; praeterea sulcis subtilioribus et pictura graciliore distiuguitur. Tapes quadriradiata Desh. (Proc. Zool. Soc. 1853. pag. 9.) nisi forte eadem species, tamen nostrae simillima est.

Gehäuse länglich, fast elliptisch, vorn kurz und verschmälert, hinten verlängert und un ein Weniges breiter, mit feimen, dichten nicht ganz regelmässigen, nach hinten stärker werdenden, zum Theil gespaltenen und sich wieder vereinigenden concentrisehen Reifchen geziert; Grundfarbe gelblich mit unregrelmässigen schwärzliełı blauen und hräunliehen Flecken und in einander greifenden unterbrochenen Zickzacklinien gezeichnet. An einem der vorliegenden Exemplare bemerkt man auch vier von den Wirbeln herablanlende unterbrocliente breite Strahlen. Die Wirbel snd klein und spitz, die undeutlich begräizte Lunula ist schmil, fast herzförnigg, die Area lanzetfförmig und von schmalen Lippen eingelasst, das ligament liegt ziemlich tief. Das Schloss zeigt viele Analogie mil l'emus Deshuyesii Hanl. Die innere Farbe ist schwefelgell, das Schloss meist violblau. - Lünge 1 Zoll 3 Linien - I Zoll 8 Linien. Länge, IJöhe und Dicke = 1001, (5.), 42 .

Vaterland: Küste von Zanzibar (All). Rodats.)

Diese zu Mühlfeldt's Gallung Tapes gehörende Huschel hat viel Verwandtschaft mit Venus lleshayesii Hanl, doch ist sie viel lileiner und hat auch leinere Furchen und eine zierlichere Zeichnung. Tapes quadriradiata Desh (Proc. Zool. Soc. 18,53 prag. 9) ist, wenn wicht dieselbe Art, doch der unserigen sehr älunlich.
Coquille oblongue, presque elliptique, abrégée et rétrécie en avant, alongée et un peu plus large à son extrémité postérieme, munie de stries élevées concentriques fines, serrées, irrégulières, plus fortes en arrière, femlues ca et lá el se réunissant de nouveau. Couleur jaunâtre, marquée de taches irrégulières de bleu noiràtre et de brun, et de lignes en zigzag interrompues et se croisint. D’ailleurs loun de nos exemplaires présente 4 rayons larges et interrompus, descendant des crochets. Ceux-ci sont petits et pointus; la lunule indistinctement bordée est étroite, presque cordilorme; laréa est lancéolée et entourée de lèves étroites. Le liganent est assez enfoncè. La charnière a une grande ressemblance à celle de la $\mathbf{V}$. Deshayesii Hanl. La couleur de l'intérieur est jaune de soufre, la charniere en géméral violacée. Longueur 1 pouce $3-8$ lignes.

Celte coquille, recueillie à la côte de Zanzibar par Mr. Alb. Rodatz, appartient au genre Tapes de Millufeld: elle a beaucoup de rapports avec la Venus Deshiyesii Hanl., mais elle est beaucoup plus petite, ses sillons sont plus lins et sa coloriation plus élégante. - Tapes quadriradiata Desh. (Proe. Zool. Soc. 1853. p. 9) est très-semblable à notre espèce, si ce n’est pas la même. 


\section{Diplodonta Venezundensis Dhit.}

Tab. IV. Fig. 7. 8 et 9.

1). testa fragili, suborbiculata, subventrosa, albida, concentrice striata, striis confertissimis, temissimis; umbonibus partulis acutis. -- Long. 8 lin. Long., all., erass. $=100,85,54$.

Diplodonta V'enezuelensis Dlor. in Zeitschr. f. Mlal. 1S4S. pag. 184.

Ilabitat in litore prope Porto Cabello Venezuelae. (Dr. G. Tams.)

IIabilu Diplodonlae (Tellinae) rolundalae Homt. pag. 7 I Tab. II. F. 3. (1). rotundatae Phil.) paene respondet, sed magis orbicularis, valvulae antee subangulatae et pro magnitudine subtiliores. Sunt specimina depicto majora.

Selıale diun, zerbrechlieh, fast kreisrund, etwas aufrebliaht, weisslich, zuweilen röthlich schimmernd, zwischen den concentrischen Sclatenansätzen sehr fein und dicht gereift; Wirbel klein und spitz. Länge 8 Linien. Länge, Holse und Dicke wie $100,85,54$.

Iíuste von Venezuela bei Porto Cabello.

In Gestalt der Diplodonla (Tellina) rollundala Mont. pag. 71. Tab. II. fig. 3. nicht unähnlich, doch sind die Schalen dem Kreisrunden melır genähert, vorn etwas winkelig und im Verhältniss zu ilırer Grösse zarter. Uebrigens wird die Musclıcl ziemlich viel grösser als das abgebildete Exemplar.
Coquille mince, fragile, presque circulaire. légèrement renllée, blanchâtre, quelyuelois tirant au rougeâtre, marquée, dans les interstices des accroissemens eoncentriques, de stries très-fines et serrées. Crochets petits et pointus. Longueur 8 lignes.

Cette espèce, provenant de la còte de Venezuela, pris de Puerto Cabello, ressemble, par sa forme, à la Diplodonta (Telliua) rotundata Mont. p. 71. pl. 2. f. 3, mais les values sont plus circulaires, légèrement anguleuses en avant, et plus minces en raison de leur grandemr. Quelapelois la coquille acyniert un volume beaucoup plus considérable, que l'exemplaire liguré.

\subsection{Diplodomta subrumosa Mkip.}

Tab. IV. Fig. I0. 11 et 12.

D. Iesta lactea, orbiculato-subovatu, conrentrice striata ot subrugosu, antice brevi, panllum allemata, postice dilatala; umbonibus paronlis obtusis. Cardo denticulis minimis instructus. - Lomg. 8 lin. Long., alt., crass. = 100, $88,48$.

Jiplodoula subrugosa Dlir. in Keilschr. F. Hal. IS4S pag. I83.

Patria ignola.

Species latere postico circulari striisque concentricis subrugosis insignis est. 
Gehäıse weiss, kreisrund, etwas eiförnig, wenig convex, mit schwachen concentrischen Reifchen und Falten bedeck, vorn kurz und verschmälert, hinten ausgebreitet; Wirbel klein und stumpl; im Schloss sehr kleine Zälnchen, wie bei allen uns bekannten Diplodonten in der rechten Schale der hintere, in der linken der vordere gespalten. - Länge $8 \mathrm{Li}$ nien. Länge, Höhe, Dicke 100, $88,48$.

Vaterland unbekannt.

Diese Art zeichnel sich durch ihren fast kreisrunden Hintertheil, die schwachen concentrisehen Falten und die minder aufgeblasenen Schalen aus.
Coquille blanche, orbiculaire, légèrement oralaire, peu convexe, munie de plis et de stries élevées minces el concentriques, courte et rétrécie en avant, élargie en arrière. Crochets petits et obtus. Dans la charmiere se trouvent de très-petites dents, comme dans toutes les espèces connues de Diplodontes, dans la valve droite la postérienre, dans la valve gauche l'antérieure est fendue. Longueur s lignes.

Cette espèce, de localité inconnue, diflère de toutes les autres par sa partie postérieure presque eirculaire, par ses plis faibles concentriques et ses valves moins renflées.

\section{Hurex Stecriae Reeve.}

Tals. V. Fig. 1. 2.

Jam anno MDCCCXLY. clar. Reeve hane speciem magnificam in Conchologia iconica, opere suo eqregio, sub denominatione Huris Steeriae descripsit el icone illustratit. Cum rero icon illa, ut videtur, junius tantum exemplar nondum adnltum exhibeat, specimen eximium, integerrimum plane adultum heic denuo depinximus, guod amicus L. Gruner Bremensis misit.

Clar. Reeve hanc speciem hisce verbis designat:

Har. testa abbreviato-fusifarmi, crassa, transcersim granoso-lirata, inter varices fortiter tuberculata, trifariams varicosa, caricibus incrassatis frondosis, froudibus crispato-ramosis, subcompressis. breviusculis, fronde parra interveniente; fusca, liris nigricuntibus, frondebus purpuren-roseis: columella et aperturae fauce albis; labro externo incrassato, intus den-. ticulato; camali brevinsculo."

Ilanc speciem intermediam esse inter Muricem palmarosac et Mlar. affinem Reevei. primo obtutn elucet.

Schion in Jahre 1845 wurde diese ausgezeichnete Schnecke unter obiger Bezeichnung von Herrn Recve in seiner Conchologia iconica No. 28 abgebildet und besclurieben. Da jedoch die heeve"sebe Abbildung nur ein kleines und, wie es scheint,
Déjà en 1815 cette belle coquille fut décrite et ligurée par Hr. Reeve dans sa Conch. icon. nr. 28, mais comme celte ligure ne représente qu'un exemplaire petit et qui paraît niètre pas adulte, nous donnons la figure d'un autre exemplaire par- 
nicht ausgewachsenes Exemplar darstellı, so greben wir hier die Abbildung eines vollkommen ausgebildeten und trefflich erhaltenen Exemplares, welches der reichen Sammlung des nun versturbenen Herru Consuls Grumer in Bremen angehört.

Herr Reeve diagnosirt diese Art lolgendermassen:

Gelıäuse kurz spindelförmig, dickschalig, qquer gefurelıt, Furchen und Rippen fein gekönt; zwischen den drei stanken wulstigen Leistem pin dicker línoteı, die Leisten ästig mit krausen Blättern kurz und seitlicl twas zusammengedruckt, kleinere krause blätchen einschliessend. Grundfarbe der Sclunecke braun. Rippen schwarzbraun, die krausen Blatler rosenroth dem Purpurfarbigen genähert: die Columelle und das Innere der Humlung weiss. Die iussere Lippe ist rerdickt und immen gezähnt, der Canal kurz, etwas gebogen.

biese Ant stelıt zwischen Murex palmarosae und affinis heere. fait et fort bien conservé, qui appartient à la collection de feu Mr. le Consul Gruner à Brème.

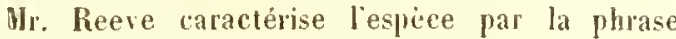
suivante: coquille courtement fusiforure, épaisse, sillonnée transversalement, à sillons el còtes finement granulées. Trois rarices épaisses, garnies de branches assez courtes, comprimées, divisées en rameaux erépus, entre lesquelles se trouve une branchte petite. Interstices des varices fortement tuberculenx. Couleur brume, cites noiritres, branches couleur de rose pourprée. Columelle blanche, ainsi que lintérieur de la bouche. Lère extérieure épaissie, dentelée en dedaus. Canal assez courl, ligèrement courbé.

Il est évident que celte espece est intermédiaire entre les H palmarosae et II. altinis heeve.

\section{Bullous incurvus IDki.}

Tab. V. Fig. 3 et 4

b testu inflata, oblique otata, subpiriformi, temai. albida vel pallide cilrina. costis et striis tenerrimis transversis limeolisque incrementi mululatis sculpta; an/ractibus senis rel septenis rotundatis, ultimo basin versus valde attemato, t, longitndinis totius testae adaequante; spira macromata, canaliculata, exserta. hand depressa: apcrtura obligue orata; camale brevi curvato: labro dextro acuto intus laevi; labro columellari laevigato latissime effuso. - Long. I poll. 6 lin.: lat. 1 poll. 2 lin.

Bulbus incurvas Dhr. in Zcitschr. f. Mal. 1852. pay. 126.

Patria China?

Dno exemplaria quoad formam el sculpturam ommino congrnewtia exstant. umum albidum collectionis Guil. P/effer, allermm pallide citrinum nostrae collectionis, quod est in tabula nostra depictum. Forma singularis ab ammibus cochleis Pyrulinis, quae hucusque immotuerunt, plane diversa, maxime accedit ad Bullam rapam Limaei (Pyrulam papyraceam Lam.), 
sed quamris haee ipsa mirmm in modum variabilis sit, tamen his notis plane differt nostra species: spira exserta, apertura valde obliqua in canalem brexem eurvum desinente, labro colnmellari latissime effuso rimam umbilicarem obtegente, canali curvato resupinato costisque tenerrimis minime crassis neque imbricatis.

Cochlea nostra rarietatem Cassidariae echinaphorae, quae Lamarchio est tyrrhena, in mentem coeat. praesertim quod aftinet ad candam obliquam et labrum columellare latissime effisum. - Pro Bulla rapa Limaei et pro hac specie altera genus llumplereysiamm, „Bulbus ammo 1797 creatum, pra nostra opinione adoptandum est. Conferantur synomyma huins generis Rapa el Rapella in egregio opere Ilerrmamsemi: Gen. Malacos.

Gehäuse aufgeblasen, schief-eiförmig, fast birnenförmig, dünn, weisslich oder blassgelb, zum Theil röthlich, mit ungemein feinen Querreifchen und wellenförmigen Waclısthumsansätzen. Die 6 bis 7 Windungen sind gerundel, die letzte nach der Nase selır verschmälert, etwa $1 / 5$ der Länge des ganzen Gehäuses cinuelımend. Die Spira trill ziemlich stark hervor und endel in eine Spitze; Mundung schief eiförnig; Kanal kurz rückwärts gehogen; der rechte Mundsaum scharf, innen glatl; die Columellarplatte ebenfalls glatl und uber die Nabelritze weit vorgezogen. - Länge I Zoll 6 Linien, Breite 1 Zoll 2 Linien.

Vaterland China?

Von dieser interessanten Schnecke liegen zwei in der Form vollkommen gleiche Exemplare vor, eines weiss, der Sammlung des Herm Wilh. Pfefler in Grebensteiı angehörend, das andere blassgelb, welches unsere Abbildung darstelt, ans unserer Sammlung, das wir llerm Pfeffer verdanken. Wenn auch die Gestalt dieser Schnecke selır eigenthümlich und von allen bislang bekannt gewordenen Birnenschnecken gänzliclı verschieden ist, so lässt sich nicht verkennen, dass dieselbe in der Struktur der Bulla rapa Linnés (Pyrula papyracea Lam.) sehr mahe steht. Obgleich diese ausserordentlich variirt, so unterscheidet sich unsere $A_{r}$ doch von allen Varietăten, wie es scheint, sehr wesentlich durch die ziemlich stark heraustretende Spira, die
Coquille renflée, obliquement ovö̈de, presque piriforme, mince, blanchâtre ou jaune pâle, rongeâtre en partie, munie de stries transversales extrêmement fines et d'innovations onduleuses. Tours de spire an nombre de $6-\tau$, convexes, le dernier formant environ $4 / 5$ de la longueur totale, rétréci vers sa partie inférieure. Spire assez saillante et terminée en pointe. Bouche obliquement ovalaire; canal conrtement recourbé. Bord droit Iranchant, lisse en dedans; lame columellaire lisse et fortement prolongé au dessus de la fente ombilicale. Longuenr 11 pouce, largeur 1 pouce 2 lignes.

Nous avons sous nos yeux deux exemplaires de celle espèce curiense, qui probahlement vient de la Chine. Leur forme est tont à fait égale, mais l'un, qui appartient à la collection de Mr. W. Pfeffer i Grebenstein (llesse) est blanc, l'autre, qui par la bienveillance de Mr. Pfeffer, fait partie de notre collection et qui est representé sur notre planclıe, est d'un jaune pâle. Quoique la forme de celte corpuille est bien différente de tontes les espèces de Pyrulées, l'on ne saurait nier, fue sa struclure est extrêmement semblable à celle de la Bulla rapa Lim. (Pyrula papyracea Lam.), espèce Irèsvariable. Cependant la nôtre semble diflérer essentiellement de tontes les variétés de la Pyr. papyracea par sa spire fortement saillante, par sa bouclie très oblifue prolongée en canal court, par sa lame 
ungemein schiefe in einen kurzen Kanal anslaulende Mundung, durch eine die Nabelritze weit uberdeckende Columellarplatte, die rückwärts gebogene Nase und die sehr feimen Querrippchen. In liucksicht des gebogenen Canals und der Columellarplatte hat unsere Schnecke einige Analogie mit Cassidaria tyrrhena Lam.

Für Linnés Bulla rapa und für diese zweite Species muss wobl das schon 1797 von Humplireys anlgestellte Grund Bulbus angenommen werden Man vergl. uber Bulbus, Rapa und Rapella llerrmannsen Gen. Malacos. columellaire largement recouvrant la fente ombilicale, par son nez recourbé et les còtes transversales très-fines. Par son canal courbé et par la lame columellaire notre coquille montre quelque analugie avec la Cassidaria tyrrhena Lam.

II paraît, que le genre Bubus, proposé en 1797 par Ilumphreys, doit être adopté pour Ia Bulla rapa L. et pour cette secunde espèce. Comparez les articles Bulbus, Rapa et Rapella dans l'ourrage de Hermannsen: Gen. Malacoz.

\section{Pecten Lischkei IMr.}

Tab. Vl. Fig. 1. 2 et 3 particula valvae inlerioris magniludine aucla.

P. testa oblique oxali. temi, plano-conexa, vix aequilatera, raleu sinistra aliquantulum conerexione, costis confertis subtilibus mumerosissimis, inaequalibus eleyantissine imbricutis, partim subgranosis; anriculis partis inacqualibus costatis, costis synamiferis; amiculo vuloue simistrae antico angulum rectum formante; colore raleac derloce albido, ad umbonem rubente, valeae simistrae luteo. - All. 1 poll. $4 \mathrm{lim}$. All., long., crass. $=100.85,24$.

Pecten Lischliei Dlr. in Zeitschr. T. Mal. 1850. pag. 32.

Putria Patagonia. - Exstat in collect. clar. Lisclelic, Berolinensis.

(luond forman haec species Pectini rufiradiato Reevei (Conch. icon. spec. 147.) haml dissimilis, scal testa tomiore, vix arquinaloi costulisque subtilioribus subimbricatis imuequalibus differt.

Geháuse schiel eiförmign, dünn, llach convex, etwas ungleichseitig und ungleichschalig, indem die linke Valve um ein weniges gewölbter ist; Rippchen dicht zusammengedrängt, von ungleicher Grösse, mit feinen Schüppchen besetzt, zum Theil etwas gekörnl; Ohren klein, ungleich mit schuppigen Rippen; das vordere Ohr der linken Valve bildet einen rechten Winkel. Die Färbung Jer recbten Sclate ist an rorliegendem Exemplare gelblich
Coquille obliquement ovalaire, mince, légirement inéquilatérale et inéquivalve (la valve gauche étant un peu plus bombée que la droite). munie de petites còtes bien serlées et inégales, finement sıpumuleuses et en partie granulenses. Oreilleties petites, inégales, munies de còtes écailleuses; loreillette antérieure de la valve gauche forme $\mathrm{m}$ angle de $90^{\circ}$. La couleur de la valve droite est, dans notre exemplatire, blanche jaunâtre, ì sommet 
weiss, am Wirbel roth, der linken urangelarbig -. Die Höhe beträgt I Zoll 4 Linien. Die Hohe, Lange und Dicke entspreclien $100,85,24$.

liucksichtlich der Form ist diese Muschel, welclie aus Patagonien stammt, dem Pecten rufiradiatus Reeve (Conch. icon. spec. 147) der ebenfalls ron Patagonien kommt, nich nnähnlich, sie unterschejdet sich jeduch bei näheres Betrachtung durch die etwas ungleichen Schalen und die feineren ungleichen und schuppigen zum Theil gekörnteı Rippchen. rouge, celle de la valve gauche orangée. Hauteur de la coquille 1 pouce 4 lignes

Cette coruille, qui provient de Patagonie et fait partie de la collection de Mr. Lischke à Berlin, a par sa forme quelque ressemblance avec le l'. l'uliradiatus Reeve (Conch. ic. sp. 147) de la mème contrée, mais elle en dillìre par ses valves inégales et par ses côtes inégales. plus fines, et squamuleuses on en partie granuleuses.

\section{Lulus pulchellus IDki.}

Tab VI. Fig. 4 et 5 .

A. testa ablomgo-omali. paene clliptica, compressa, livila et pallide violacea, radiis tenerrimis strigilatis, ab umbonitus ad marginem basalem decurrentibus. antice et postice lacvissima; cardine valrulae dertrar midentalo, sinistrae bidentato; costa ulbida utriusque valvae a curdina usque ad basin decurrente.

A ulus pulchellus Mkr. in Zeitschr. f. Mal. 1852 pag. 58.

Patria Japonia

Testa 1 poll. 21/3 lin. Ionga, $5 \mathrm{lin}$ alla, tenuis, fragilis, nitidissima, diaphana, ulrinque aequaliter motudata, paene clliptica. Supcrficies testae glaberrima, epidcrmide pallile correa obducta; striae tenerrimae transrersim strigilatae, sub vitro tantum conspicúae ab apicibus radiantes. Cardo valrulae dextrae denticulo bifido subtrigonn. sinistrae dentibus duobus acutis. qui dchticulum illum valoae dextrae recipiant, imstructus. Apices aculi, hand prominentes in specimine, quod cxstal, circiter 4 lin. a marginc antica remoti: intus calrulae costa alba in cxterna pagina transtucente untatae sumt. Impressiones muscularcs ct linea palliaris lenes el obsoletae fere ommino eaedem atque in Solene radiato Limuei (Chemm. VI. fig. 3.).

Hace ccnchula ad genus Aulus (cìns, tubus, scams) reforenda est, quod clarus Otienus amo 1815 a Salenibns disjunxil, Solcnem radialum Limaei pro forma typica respiciens. Nomen Siliyua amo ISH a Mullfeldio ercatum. a clarissimis Gray et Horch usitatum. pro nostra opiniome nan adoptandum est, quoniam Siliqua, teste Jerrmamsen. jam ammo 169.t a 7ournefortio Papilionacearm generi impasilum crat Nomen Leguminaria, quod plures riri locti adoptant, amo 1817 a Sihwmachero crcatme ef nomen Hachaera (urizreece culter lamarius) multo serius (anno IS3I) ab Aug. Gould (Rep. Imert. Mass.) usitatum est. 
Gehäıse verlangert eiformig, fast elliptisch, blatich und blass violett, mit selur feingestrichelten vou den Wirbeln zum Basisrande herablaufenden Strahlen, vorn mo hinten glatt; in der rechten Schale ein Zahn, in der linken zwei, in beiden Schalen eine weissliche fast bis zur hasis herablaufende Leiste.

Japaı.

Die dïnne, zerbrechliche, stark glänzende, durchscheinemle, beiderseits gerundete, fast elliptische Schale ist I Zoll 21, 3 Linien lang und 5 Linien hoch. Sie wird von eimer zarten hell hornfarbigen Epiderm überdecki. Unter der Loupe bemerkt man einige sehr zarte Reihen feiner Quersuichelchen, welche von den Wirbeln herablaufen. In der rechten Schale befindet sich ein fast dreiseitiges gespallenes Zahuchen, welches von zwei spitzen Zilhnchen der linken Schale anfgenommen wird. Die Wirbel sunl sela klein und spitz, laeten aher nicht hervor; sie liegen etwa + Linien rom Vorderande entfernt. Die innere weisse lipple ist hei durchscheinender Schale schun aussen sichtbar. Rücksichllich der Muskeln und der Mantellinie zeigen die Schalen eine grosse Aebulichkeit mit Solen radiatus L.

Diese zierliche Huschel gehört zum Geschlechte Aulus, welches von Oken im Jahre 181.5 aufgestell worden, indem er als typische Form den Solen rudiatus des Limné annahm. In der That herechtigt anch die innere Beschaftenheit der Schale zu einer Abtrennung ron den eigentlichen Messersclueiden. Uebrigeus wurde von Miulsfeld schon 18: f fï. Muschelı von derselben Beschalleulıeil der Name Siliqua gebraucht, der auch von Gray, Hörch und Anderen beibehalten ist, loch dürftc ler Oken'sche Name vorzuziehtun sein, weil schon 1694 Tournefort für ein zu den Papilionaceen geloriges Pflanzengeschlecht den Namen Siliqua einfiilurte. Die Namen Leguminaria und Vachaera sind späteren Ureprungs.
Coquille aroude alongée, presque elliptique, lisse en avant et en arrière. Coulenr blenatre et violet pâle, à rayous très-finement striolés, descendant du sommel jusqua bord basal. La valve droite est munie dune dent, la valve gauche en a deux; tostes les denx sont garmies dune cote blanche descendant presque à la base. Longueur 1 pouce 21/3 lignes, hautemr 5 lignes.

Celle coquille provient du Japon. Elle est mince, fragile, très-luisante, transparente, arrondie des deux côtés, de forme à pen prés elliplique. Elle est converte d'un épiderme mince de conleur cornée claire. Par la loupe on remaryue phosieurs rangées de stries lines transversales, qui descendent des crochets. La valve droite moutre une petite dent fendue presque triangulaire, qui s'enchâsse entre denx lents pointues de la valve gauche. Les crochets sont tres-petits et pointus. mais non saillants: ils sont placés a me distance d"suviron 4 lignes du borl antérienr. La còte interne blanche est remanyuble i travers des valves transparentes. Quant aus muscles et à la ligne palléale les valves présentent la plus grande ressemblance avec le solen radialus $\mathbf{L}$.

Celte jolie coquille appartient au genre Aulus, proposé par Oken en 1815 en prenant pour type le Solen radiatus L. En effet les caractères intérieurs de la coquille autorisent la séparation des Solen proprement dits, Déjì en 1811 Müllfeldt avait dunné le nom de Siliqua à des cocuilles présentant de pareilles cararteres, et ce nom a été retenu par MM. Gray, Morclı etc.; cependant le nom proposé par Oken saurait ètre préferé, parceque en 1694 Tournefort avait introduit le nom de Siligua pour un genre des Papilionacées. -Les noms de Legumunaria el Machaera sont dorigine plus récente. 


\section{Cardium Recreanum Mkr.}

Tah VI. Fig. 6.7 et 8 .

6: testa rrassa. matu, paene obliqur cordala, umbones nersus subaltemala, in margine rarlimali untico ralde curbata. radutim crasse costata, costis mediamis lationibus; interstitiis amgustis; umbomibus tumidis; colore flave marginem rersus amantio. - Allit. 2 poll. Ratio mensurate paene hare est: $100,83,73$.

Cardillm Rerenunm Dhr. in Zeilschr. f. Mal. 1852. pag. 54.

Patria: Nova Hollandia. Exslat in collectione clar. Gramer, Bremensis.

Haec species certe pulcherrimarmm ma ast sui generis. Testa crussa costis 29, in dorso rotundatis, instructa; costae medianae latiores at crassiores, in basi plas mimuse coarctatae, in dorso luteribusque rugulose crenatae: costae latera versus sensim angustiores fiunt, amlicae subimbricalae, posticae imbricalo-serratae apparentes. Sulci profundi el angusti transtrerse rugosi. Color cariabilis: specimen quod exstat, in medio flavm flavo et luteo cariegatum, ad umbones albescens, margmem versus rivile luteum rel anramtium. Facies interna alba costas lalus plano-connexas sulcis angustis separatas ostendit. Margo forliter cremalus amramtius.

Specirs Cardis rugoso Lam. el subrugoso Sou, maximr affinis est.

Gehause dickschaligr, langlich gerundet, fast schief lierzormig, nach oben verschmälert, am rordern Schlossrande stark gebogen, mil runden dicken Rippen, wovon die mitleren am breilesten sind; die Zwischenfurchen ziemlich schmal; Wirbel aufgetrieben; Färbung eigell) und dunkel orangefarbig, zumal nach dem Rande hin. - Die Höhe des vorliegenden Exemplares beträgt Z Zoll. Das Verbălniss der llöhe zur Breite und Dicke entspricht elwa den Zahlen 100, 83, 73.

Neuholland. Mitgetheilt von Herru Consul Gruner in Bremen.

Unter den Cardien ist diese Art unstreitig eine der schönsten. An vorliegendem Exemplare zälılt man 28 oben gerundete, scillich elwas eingeschnirte Rippen, wovou die mittleren die breiteren und starkeren sind; nach den Seiten hin nehmen dieselben allmählich an Slarke ab. Die vorderen sind clwas
Coquille épaisse, oblongue arrondie, à peu pres obliquement cordiforme, rétrécie en baut, fortement courbée au bord cardiual antérieur. munie de còtes épaisses, arındies, dont les moyenues sont plus larges. Interstices assez étroits. Crochets renflés. Coulenr jaune doeuf et orange foncé, surtout vers le burd. Hauteur de notre exemplaire 2 pouces.

Ce Bucarde provenant de la Nouvelle Hollande, et communicué par Mr. le Consul Gruner à Brème est sans doute des phus beanx du genre. Sur l'exemplaire liguré l'on compte 28 côtes arrondies en laut, légỉrement comprimés latéralement; celles du milieu sont plus fortes et plus larges: elles décroissent insunsiblement vers les deux côtés. Les antérieures sont légèrement écailleuses. à peu pres imbriquées, les postérieures crénulées el celles du milieu rideuses et légèrement granuleuses. 
schuppig, fast wite mit Ihohlziegeh hedeckt, diu hinteren gesägl, die milteren breiteren runzelig und etwas gekörnt. Die Zwischeofurchen sind lief, ziemlich schmal und fein in die Qutere serunzell. Die Farbe ist nicht ganz constant, wie wil an anderen, zum Theil arosseren Exemplaren in der herrlichen Sammlung des Ilerrn H. Cuming in Loudon gesehen. Das vorliegende Kxpmplar, weiches sich durch besunders lebhalles Colorit auszeichnet, ist in der Mitte fast eigelb, nach oben lichler werdend, mach unten in dunkle Orangefarbe ubergehend. Die liörnclen und Rumeln anf den Rippen zeichuen sich durch noch dunklere Farlung aus. Die innere Seite ist weiss und zeigt breite, llache, durch schualo Furchen getrenute Rippen; der stark gekerble Rand ist orangefarben.

Diese Art qehört in die Nahe von Cardium rugusum, Lam. und subrugnsmm Sow.
Les sillons intermédiaires sont prolonds, atroits et ridés linement en travers. La couleur niest pas coustante, comme nous lavous ru sur des exemplaires de l'excellente collection de Mr. Cuming. Notre exemplaire, qui est bien vivement colorié. présente an centre une teinte jaune domal, devenant plus clair en haut el passaut it un orange foncé vers la base. Les rides el granulations des ciles se distinguent par une teinte encore plus foucée. La partie intérieure est hlanche et présente des cotes larges, peu saillantes, séparées par des sillons étroits; le borul fortement crénelé est de couleur dorange.

Cette espece doit ètre rangée an voisinge du C. rugusum Lam. et subrugosum Sow. 



\section{Mulinia Rodatzi Mhir.}

Tab. VIl. Fig. 1. 2 et 3 .

M. testa magna, solida, rotundato-trigona, tumida, aequilatera, roncentrice striata, antice rotundata, postice subito attemata, subangulata, basi fortiter cureata: umbonibus magnis turgidis prominenlibus subincuvis, antrorsum subinclinatis: area lanceolata, labiis magnis latis circumdata; lumula immessa subcordiformi; ligamento ommino occullo.

Mactra (Mulimia) Rodatzi Mlir. in Zeitseler. f. Mal. 1850. \%. 30.

Reportata est ex itinere Africano, ni fallor ex insula Zansibar, a beato Alb. liodats, in cujus memoriam eam nominati.

Species magna usque ad $75 \mathrm{~mm}$. longa, 0.5 alla, 43 crassa, ila ul longiludiuis, altitudinis el crassitulinis ratio circiter respondeat numeris 100,86 et $5 t$. Forma conchae fere eadem alque in Mactra stultorum Limmaei (Trigonclla Da Costa), sed mullo major ct solidior, languida, parum pellucida, sordide alba maculisque paucis fulcidis adspersa. Area pro magnitudine testae parta, urimque fulvo flammulata est. Epidermis temuis, pellucens pallide cornea, sublamellosa. Cardinis structura ul in reliquis Mactris, sed ligamentum cartilaginosum cum ligamento fibroso in fovea magna occultum, qua de causa species nostra Grayano generi Muliniarm admumeretur necesse est. Denles latcrales magni et crassi sicut in Mulinia typica Grayi, sed paullo longiores. Impressiones muscnlares magnac hand profundae et simus palliaris latus nitidi sum; praelerea faciem internam calcaream sine ullo splendore reperies.

Diese Muschel, welche, wenn wir nicht irren, von der Insel Zanzibar stammt, und sich unter den vielen von dem leider so frübe verstorbenen Capitain Alb. Rodatz von der Ostküste Afrika's mitgebrachten Conchylien befand, gehört zu den grössten Arten ihres Geschlechtes; denn ihre Länge beträgt 75 m.m., und ilre Dimensionen entsprechen ungefälr den Zahlen 100, 86 und 56. In ihrem Umriss erinnert dieselbe an Linués Mactra stultorum, doch ist sie weit grösser und dickschaliger. Unter der diinnen durchscheinenden etwas blätterigen, blass horufarbigen Fpidermis leuchten, zumal in der Gegend der aufgetriebenen Wirbel, röthlich braune Flecken hervor; in Uebrigen ist dic Schale schmutzig weiss, ziemlich matt und weuig durch-
Celte coquille s'est trouvée dans le grand nombre de celles, que feu le capitaine $A$. Rodatz a rapportées de la côte oricntale de l'Afrique, el probablement elle provient de l'ile de Zanzibar. C'est une des plus grandes especes de son gemre, puisqu' elle a une longueur de 75 millimères el ses dimensions répondent à peu près aux proportions de 100, 86 et 56. Par ses contours elle rappelle la Mactra stultorum de Lime, mais clle est bien plus grande el son test plus épais. A ravers lépiderme, qui est mince, couleur pale de corne, on remarque des taches roussâtres, principalement du còté des crochets renflés; les antres parties de la coquille sont d'un blanc sâle, assez teme et pen transparent. Laréa apparait pelit en comparaison de la laille; 
scheinend. Die Area erscheint im Verbältniss zur Grösse der Huschel klein; auf beiden Seiten derselben bemerki man undeutliche Flammenzeichnungen. Die Beschaflenheit des Schlosses ist im Wesentlichen ähnlich den übrigen Mactris, nur fehlt das äussere Liganent gänzliclı, indem das faserige sonst aussen liegende Band mit dem knorpeligen in der grossen Grube vereint liegl, weshalb dieselbe eben zur Abtheilung der Mulinien gezählt werden mus. Die Seitenzalıe sind gross und stark, fast wie bei Gray's 11 . typica, doch etwas Jänger. Die grossen und fachen Muskeleindrüke sowie die breite Mantelbucht zeichnen sich durch ilıren Glanz von der matten Innenfläche aus. Soviel uns bekannt, ist diese Mulinie die einzige der alten Welt. Das Colorit ist in der Alıbildung etwas zu lebhaft. des deux côtés l'on remarque des flammules obsolètes. Les caractères de la charnière en général sont semblables à ceux des autres Mactres, mais le ligament externe manque absolument - le ligament libreux qui en dantres cas tient sa place à l’exlérieur, étant uni à la partie cartilagineuse dans la grande fossette - et c'est pourquoi notre coquille doit être rapportée au groupe des Mulinias. Les dents latérales sont grosses et fortes, semblable à celles de la h. typica Gray, mais plus longues. Les impressions musculaires, grandes et plates, ainsi que le sinus palléal, qui est large, se distinguent de la superficie interne par leur splendeur.-Celte Mulinia paraît ètre la premièce connue de l'hémisphère orientale. - Le coloris est un peu trop vil dans notre ligure.

\section{Spondylus sanguineus Ilir.}

Tab. VII. Fig. 4. 5.

Sp. testa paene rotundato-trigona, obliqua, solida, subrentrosa, sanguinea, marginem lateraque versus sanguinen et castanco tincta lateribusque lineis fuscis intermptis ornata, concentrice rugosa, per longitudinem crebrisulcata el costata, costis inaequalibus maximam partem muticis, nomullis gramuliferis et subimbricatis; umbonibus valde inaequalibus: valva superiore concexa, umboncm parvun et subacutum versus subgibbosa; valoa inferiore apicem acutum versus profunda; area cardinali trigona albida plana valde prodncta sulco obliterato partita, striga subfusca utrinque signata; anriculis parvis.

Spondylus sanguineus Dhr. in Ztschr. f. Mal. 1852. p. 55.

Patria ignota est. Exstat in coll. beati G. Scheepmaker, Amstelodamensis.

Species cum forma, tum sculptura et colore valde insignis in coralio quodam affixa erat. Facies interna albida, margo ruber utrinque cremulatus, basin rersus plicatus. Cardo normalis. Testa ab apice ad marginom usque basalem $44 \mathrm{m.m}$. longa est, latitudinis plane eadem dimensio.

Diese sowolıl durch Gestalt als auch Färbung und Scujplur sehr ausgezeichnete Art gehört vielleicht als Varietät zum Spondylus nudns seu inermis Chemn.
Cette espèce biell distinguée par sa forme, ainsi que par sa sculpture et sa coloriation, pourrait être une variété du Spondylus nudus s. inermis Chemn. 
vol. XI. p. 235. Tab. 203. Fig. 1989. 1990, welcher am Strande der Antillen vorkommen soll; doch lässt sich darüler wegen der mangellaften Beselureibung und Abbildung nicht nit Sicherheit urtheilen. Im lnnern zeigt unsere Huschel eine weissliclıe Färbung mit rothem Rande, der beiderseits eingekerbt, unten dagegen gefaltel ist. Ilure Ilölıe beträgt $4+\mathrm{m} . \mathrm{m}$., die Breite genaı ebensoviel, doch mögen die Dimensionen wohl rariiren.
XI. p. 235. I. 203. f. 1989. 1990, qui vivrait aux côtes des Antilles, mais il est impossible d'en juger avec certilude, la deseription et figure de la coquille de Clsemnizz étant trop imparfaites. Notre coquille montre, à son intérieur, une teinte blanchâtre à bord rouge, qui est crenelé des deux eòtés et plissé à sa parlie inlérieure. La lıatcur de notre exemplaire est de it millimètres et sa largeur est exaclement la mème, cependant il est possible, que les dimensions sont variables.

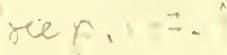

\section{Plicatula deltoidea I)kp.}

Tab VII. Fig. 6. 7 .

Pl. testa magna, ocato-subtrigona, crassa, albida, margine et superficie externa lineolis rufs irregularibus picta; costis magnis squamiferis simplicibus et furcatis.

Plicatula deltoidca D kr. in Ztschr. f. Mal. 1S48. p. 17 S.

Ilabitat in litore Africae orientalis teste beato Alb. Rodatz, qui eam attulit.

Testa 48 m.m. longa, 37 m.m. lata, forma subcristata delloidea et costis crassis rarietatis quibusdam plicatulae ramosae Lam. similis, sed multo major est. Character specificus forma deltoidea, magnitudo et lineolae rufae marginales et externae esse videntur.

Diese Muschel, welche von der Ostkiuste Afrika's slammt, ist $48 \mathrm{~m} . \mathrm{m}$. lang, $37 \mathrm{~m} . \mathrm{m}$. breit. Sie scheint sich durch ihre deltoiscle Form nnd ilıre starken nicht scharf gekichten Längsrippen ron gewissen Varietäten der P. ramosa Lam., die auch ungleich kleiner ist, wohl zu unterscheiden.
Celle coquille, qui provient de la côte orientale de l'Afrique, a me longneur de 48 , me largent de 37 millim. Elle parail suffisamment différer de cerlaines variélés de la Pl. ramosa Lam. (qui ell outre est bicu plus petite), par sa forme deltoide el ses còtes longiludinales fortes el non aigument carénées.

\section{Pintilia trigonimun Ilir.}

Tab. VIll.

P. testa triangula, subconvexa, in medio obtuse carinata, grisea nigrogne livida, per longitudinem costata, costis inaequalibus partim subumdulatis 24-26, totius marginis ventralis media parte panllulum simuata, oblique plicata; latere posteriore truncato el lamelloso. 
Pinna trigonium Dler. in Zeitschr. f. Mal. 1852. p. 60.

Specimen quod exstat maximum fere 190 m.m. longun, 75 latum et 25 crassum est.

Patria: Indiac orientales.

Species ul videtur lucusque plane ignola, forma fere regulari triangula insignis est. Valvae subcomexae, temes, nitidae diaphanae, subvitreac et, quod in permultis Pinnarm speciebus abservare potes, in medin abluse carinatae sunt, quae quidem carinae marginem posticum versus evancscunt. Margo dorsalis paene rectilineus ad apicem tantummodo subsinuatus; margo ventralis medio paullum sinuatus cum margine posteriore, qui eodem modo paullulum emarginatus est, prope angulum rectum format, angulus vero. quem lineae dorsalis et rentralis includunt, circa gradus 30 effcil. Color griseus, subruber, mediis in ralvis, praesertim latera versus, nigro-lividus. Testae superfecies costis longiludinalibus inacqualiter distantibus, partim subundulatis sculpta est, sed marginem ventralem et posticum rersus sensim obscuriores et obsoletae fiumt. Praeterea concha latere postico lamellis temissimis transersis, margine vero ventrali plicis obliquis instructa est.

Das Vaterland dieser eigenthümlichen Pinna, welehe ich bis jetzt nirgends abgebildet finde, ist Ostindien. Sie zeichnet sich besonders durch ihre regelmässig dreieckige Geslalt aus. Ihre Schalen sind wenig convex, dünn, stark gläuzend, fast glasartig, etwas durchscheinend und, was an selır vielen Stecksnuscheln beobaclıtet wird, in ihrer Mitte mit einem stumpfen lijel verselıen, der sich nach dem hinteren Rande hin allmálig verliert. Der Rückenrand erscheint fast geradlinig, nur an Vordertheil etwas gebuchtet. Die ziembich gerade Bauchseite bildet mit dem hinteren meist ansgeschweiflen Rande fast einen rechten Winkel, während der Winkel, den die Banch- und Rückenlinie einseluliesst, ein sehr spilzer ist und etwa $30 \mathrm{Grad}$ heträgt. Die Farbe ist ein röbliches Grau, welches beiderseits zumal in der Mitte des Banches in ein schwärzliches Blau rerlanft. Die Oberlliche wird con unregelmässigen, zum Theil etwas knotigen Längsrippen bedeckt, die nach dem hinteren Rande hin alluălig schwächer werden und zuletzt fast ganz verschwinden. Die Bauclıseite zeigı deutliche Querfalten und die ganze Oherflache is/ mit
Celte espèce singulière de Pinna, que je n'ai trouvé figurée nulle part, provient de l'Inde orientale. Elle se distingue particulièrement par sa forme régulièrement triangulaire. Ses valves sont peu eonvexes, minces, très-luisautes, presque vilracées, légèrement transparentes, et, comme plusieurs autres espèces du genre, munies à leur milıen d'une carène mousse, qui se perd insensiblement vers le bord postérieur. Le bord dorsal est presque rectilinéaire, excepté à sa partie antérieure, où il est légèrement sinueux. Le bord ventral est presque droit, et forme à peu près un angle droit avee le bord postérieur, qui géuéralement est simueux, tandis que l'angle formé par la ligne ventrale et dorsale, est très aign, d'environ $30^{\circ}$. La couleur est de gris rougeatre. passant des deux còtés, surtout au milieu du ventre, a un blen noiràtre. La surface esl converte de còtes longitudinales irrégulieres en partie tuberculifères, qui samincissent vers le bord postérjeur et finissent par disparaître presque absolument. Le côté veutral montre des plis transversaux bieu marques, el toute la surface est converte de stries fines daccroissement, qui, à 
feinen Wachsthumsansätzen bedeckı, die am Hintertheil der Muschel fast als sehr zarte Lamellen erscheinen. la partie postérieure, ont la forme de lamelles très-fines.

\section{Argonauta Girmeri Ilkr.}

Tab. IX. Fig. 1. 2.

A. testa parva, oxato-oblonga, celerrime accrescente, tenuissima, subdiaphana colore sordide lacteo, partim subrufo tincta; carina utrinque rufo-nigricante, lateribus convexis, radiatim costato-rugosis, rugis parum prominentibus undulatis, irvegulariter dichotomis; carina obtusa, mgosa, tubercutis minutis utrinque instructa; tota superficie testae granulis arenaeeis, in dorso frequentioribus, adspersa; apertura oblongo-subquadrata, antice amplificata. emarginata.

Argona u a Gruneri Illr. in Ztschr. F. Mat. 1S52. pag. 48.

Habitat in Archipelago Australi, ad insulas Marquesas dictas. Unicum hucusque vidimus specimen, quod exstat in collectione amici beati E. Chr. L. Gruner, Bremensis.

Testa hujus speciei singuluris parta elegantissima ab omnibus quae ad hoc usque tempus innotuere Argonautis praesertim spira celerrime accrescente nec non granulis arenaceis in superficie aspersis facile dignoscitur. - Diametros ejus maxima $50 \mathrm{~m} . \mathrm{m}$. adaequat, altitudo paene 28 , longitudo aperturae a carina usque ad simum anticum 25 , latitudo aperturae 2.1 .

Dieser kleine interessante Argonauta, welclier von den Harquesas-Inseln im australischen Archipel stanmt, zeichue sich von allen übrigen Arten zumal durch sein ungemein sehmell zunehmendes Gewinde sowic anch durch die feinen aul der ganzen Oberfläche der Schale zerstreuten sandarligen Körnchen aus. Der grösste Durchmesser der Schnecke beträgt $50 \mathrm{m.m}$., die Hohe derselben fast 28, die Länge der Mündung von der Carina bis zu dem vorderen Sinus 25, die Breite derselben 24.
Celte petite espèce curieuse provient des îles Marq̨uises el se distingue de toutes ses congénères principatement par sa spire accroissant rapidement, ainsi que par les graines sablonneuses dispersées sur toute la surface du test. Le plus grand diamètre de la coruille est de 50), la hauteur presque 28 millim. La longueur de l'ouverture (de la carène jusqu" an sinus antérieur) est de 2.5, sa largeur $2 \pm$ inillim.

\section{Argonauta Lodianus Dir.}

Tab. IX. Fig. 7. 8.

A. testa oxato-oblonga, rapide accrescente, tenui, lateribus comexa, radiatim rugata, mgis partim subfurcatis, partim pluries dichotomis, undulatis: carina lata plana, tuberculis acutis 
subcompressis mumerosis marginem anteriorem versus confertis sensimque demimutis ornata: apertura subquadrato-oblonga; axi quartam fere testae partem occupante; colore pallide fusco in tubcrculis majoribus nigricante.

Argonauta Kochiana Dhr. in Ztschr. f. Mal. 1852. pag. 49.

Mabitat in Mari Chinensi.

Specimen quod exstat, $64 \mathrm{~m} . \mathrm{m}$. longum, 37 altum; longitudo aperturae a carina usque ad spiram fere 37 , latit. circa 26 m.m. efficit.

Species nostra colore aliisque notis Argonautae hianti Dillwyn (Descr. Cat. of Shells, vol. I. pag. 334, Zool. of the Voyage of H. M. S. Samarang pag. 3. Tab. I. 2. Tab. 11. 2.) similis, sed tuberculis mumerosis marginem anteriorem versus demimutis et confertioribus, forma magis oblonga, mgis irregulariter dichotomis et marginem anteriorem versus distincte undulatis aliisque characteribus plane dirersa. Ab Argonanta gondola Dillsc. l. c. p. 335, Zool. Sam. p. 3 auriculis prolongatis plane deficientibus facile distinguitur.

Denominata est haec species in memoriam beati $\mathrm{Fr}$. Koch, seduli rerum naturalium investigatoris.

Das vorliegende aus China slammende Exemplar ist $64 \mathrm{~m} . \mathrm{m}$. lang und $37 \mathrm{~m} . \mathrm{m}$. hoch; die Länge der Mündung kommt beinahe der Höhe der Schale gleich und ihre Breite betrágt etwa $26 \mathrm{~m} . \mathrm{m}$.

Unsere Art gleicht anf den ersten Blick dem Argonauta hians Dillw. (Descr. Cat. of Shells, vol. I. p. 334, Zool. of the Voyage of II. M. S. Samarang p. 3. Tab. I. 2. Tab. Il. 2.) Dieselbe unterscheidet sich jedoch wesentlich durch die längere Form, durch die zahlreicheren nach dem vorderen Rande hin allmählig kleiner werdenden Knoten des Rückens, durch die unregelmässig dichotomirenden nach rorn hin deutlich wellenförmigen Rippen und andere Merkmale. Von Argonauta gondola Dillw. (l. c. p. 335, Zool. Sam. p. 3) ist dieselbe durch den gänzlichen Mangel der verlängerten Ohren leicht zu unterscheiden.

A n m. Was unsere Abbildung betrifft, so ist zu bemerken, dass dieselbe wie auch die der vorhergehenden Art etwas zu lebhaft colorirt ist.
Notre exemplaire, qui provient de la Chine, a une longueur de 64 et une hauteur de 37 millim.; la longueur de l'ouverlure égale à peu près la hanteur de la coquille, el sa largeur est de 26 millim.

Cette especce ressemble, an premier coup d'oeil, a l'Argonauta hians Dillw. (Voy. of Samarang. Zool. p. 3. pl. 1. 2. pl. 2. 2), mais elle s'en distingue essentiellement par sa forme allongée, par les tubercules dorsaux plus nombreux et s'amoindrissant peu à peu vers le bord antérieur, par ses côtes irrégulièrement dichotomes, qui sont distinctement onduleuses à la partie antérieure, et par d’autres caractères. On la distinguera aisément de l'Argonauta gondola Dillw. (Voy. Samarang p. 3) par le manqque absolu des oreilleltes allongées. - (Le coloris de notre figure, ainsi que de celle de l'espèce précédente, est un peu trop vili.) 


\section{2i. Cypraea gangrenosa Sol. var. Cypr. Reentsii.}

Tab. IX. Fig. 3. 4.

Jam anno 1852 in Commentariis malacosoologicis a viris clarissimis et doctissimis Mlenke et Pfeiffer editis p. 189. Cypracam quandam singularem in Tabula nostra nunc depictam nomine Cypraeae Reentsii, in honorcm clarissini G. Reents Ilamburgensis, Malluscorum seluli collectoris, nominatam, descripsimus, sed aliquot amos post Londini nobis persuasum est, hanc cochleolam, quamvis nimis discedat a forma vulgari Cypraeae gangrenosae non solum colore sed etian habitu, tumen al hanc ipsam cochleam adnumerandam esse, cum data fuerit occasio totam hujus speciei varietatum seriem inspicere, quae in colle-. ctione insigni clar. II. Cuming asservatur.

Im Jahre 1852 beschrieb ich in der Zeitschrift für Halakozoulogie S. 189 eine eigenthünliche Cypraea unter obigem Namen, wejche sich in der Sammlung des Herrn G. Reents in Hanburg befindet. Mehrere Jahre später habe ich mich überzeugt, dass diese, wenn auch in der Färbung sowohl als in Habitus ron der gewöhulichen Form der Cypraea gangrenosa ziemlich abweichende Schnecke dennoch dieser Art angehort, da es mir vergönnt war in der ausgezeichneten Sammlung des Herrn H. Cuming eine Reile von Uebergängen dieser Art zu betrachten.
Dans la "Zeitschr. f. Malakoz." 1852. p. 189 jai décrit une espèce singuliẻre de Cypraea, qui se trouvait dans la collection de Mr. G. Reents à llambourg, sous le nom de C. Reentsii. Plus tard, ayant joui de loccasion dexaminer, dans la superbe collection de Mr. Cuming, une série de formes de la C. gangrenosa Sol., je me suis persuadé, que cette coquille appartenait à la mème espèce, malgré ses différences de couleur et de lrabitus bien marquées.

\section{Cerithin!III stahlricosta Ilip.}

Tab. IX. Fig. 5. 6.

C. testu turrita, sordide alba fusco maculuta et irregulariter fammulata, submarmorata, costulis scabris aequalibus confertis cincta, anfractibus convexiusculis sutura distincta separatis, ultimo paulum inflato; apertura ovata patula in canalem brevem obliqum excunte; columella obliqua superne plica calida instructs; labro haud incrassato intus sulcato.

Cevilhium scabricosta Dlir. in Ztschr. f. Mal 1853. p. 110.

Patria ignota. Exstat in collectione ornat. Reents, Hamburgensis.

Cochlea parva fusco et albido variegata anfractibus $S$ convexinsculis formata est, ultimus paulo inflatus paene ${ }^{3}{ }_{7}$ totius longitudinis adaequat. Testa tota costulis aequalibus confertis 
granoso-scabris cingitur, costulae liris profundis et angustis divisae, in anfractu ultimo 14, in ceteris 7 tantun momerantur. - Forma singularis, praesertim insolito costularum ordine.

Auch diese kleine Sclonecke, deren Valerland unbekannt ist, gebört der Sammlung des Hern G. Recnts in Hamburg an. Sie zeigt eine rothbraune und weissliche Färbung, hat 8 ziemlich convexe Windungen, deren letzte elwas aufgetrieben ist und ungefälır ${ }^{3} ;$ der ganzen Länge einniınmt. Das Gehäuse wird von regelmässigen dicht stehcnden körnig-rauhen Querrippchen umgcben, die durch schmale tiefe Furchen getrennt sind, deren nuf dem letzten Umgange 14, auf den übrigen Windungen 7 sich belinden. - Es zeichnet sich diese Art zumal durch die grosse Regelmässigkeit der Rippchen aus.
Ainsi que la précédente, cette petite coquille, dont la localité est inconnue, appartient à la collection de Mr. G. Reents à Hambourg. Elle montre une teinte rousse et blanchâtre, el elle est composée de 8 tours de spire assez convexes, dont le dernier est un peu renflé et occupe à peu près ${ }^{3 / 7}$ de la longneur totale. Le test est entouré de nombreuses petites côtes tłansversales âprement granulées, qui sont placées régulièrement et séparées par des sillons étroits et profonds, dont il y a 14 sur le dernier, 7 sur les autres tours. Celte espece est distinguée surtout par la rẻgularité de ses côtes. 


\section{2!). Bullia valida Ilir.}

Tab. X. Fig. 1.?.

B. testa oblongo-turrita, apice acuminatu, valida et pomlerosa, unicolore pallide sordideque flava, striis incrementi longitudinalibus subtilissimis instructa, paene laevigata; anfractibus 11-12 sulшra haud callosa divisis, superne rotundato-angulatis, subgradatis, medio leviter excavatis, superioribus transversim bi-vel tristriatis, ultimo dimidian testae partem fere adaequante, basin versus transversim lineolato; rostro aculicarinato et lamelloso, late emarginato; apertura ovalo-oblonga, superne et inforne angustafa, in medio parum dilatata; labro simplici acuto; faucibus albis laevigatis; columella parum callosa. Long. 75 , latit. vel diams. max. $26 \mathrm{~mm}$.

Exstot in mus. clar. Reents Hamburgensis.

Ilabilat in Oceamo Pacifico?

Bullia ralida Dlir. in Zeitschr. f. Mal. 1852. pag. 191.

IIaec cochlea au Bullias, genus Grayamm inter Buccina quaedam et Terebras ambigume quasi intermedium admumeranda est, aul eas vero species pertinens, quae suturis callosis ommino carent, qua de causa affinitatem maximam praebet cum Terebris genuinis. Docet autem haec forma singularis Bullias, respectu habito testarum, a Terebris limitibus arctis haud separatas esse.

Diese eigentliumliche Schnecke, deren Vaterland nicht sicher bekannt ist, geliört zu der vou Gray 1839 Zoot. of Becch. Voy. pag. 125 aufgestellten Gattung Bullia, welche gewisse Buccina, im weiteren Sime genommen, mit Terebra verbindet. Unsere Aıl zahlt zu denjenigen Bullien, denen die schwielige Naht fehlt, wie solche so ansgezeichnet und gleichsam doppelt an Bullia coclulidium Kien. sich darstellt. Sie erinnert auch an die Gray'sclie Gattung Pusionella. - So I nge die Rewolmer dieser verschicdenen Schalen noch so unzureichend bekannt sind, lleibt die generische Bestimmmg derselben immer etwas zweifellati.
Celle coquille singulière, dont la patrie n'est pras bien connue, appartient au genre Bullia, fondé par Mr. Gray en 1839 (Zool. of Beeclı. voy. p. 125), qui forme un passage entre certaines espèces de l'ancien genre Buccinum arec le genre Terebra. Notre espèce apjartient au gruupe de celles qui sont dépourvues de la sulure calleuse, qui se présente en grade éminent el comme donblée chez la Bullia cochlidium Kien. Elle a aussi des rapports an genre Pusionella Gray. Tant que les mollusques inhalitans de ces diverses coquilles ne scront pas parfaitement connues, leur déternination générique restera toujours en quelque manière vague.

\section{Mitra arellacea Dir.}

Tab. X. Fig. 3. 4. Fig. 5 particula magnitndine aucta.

M. Lesta perlonge orata, subfusiformi, albida mfoque flammulata et rariegata; liris transcersis elevatis creberrimis granosis alternatim majoribus et minoribus sulcisque longitudinalibus 
confertis eleganter sculpta; anfractibus parum convexis ad suturam bene distinctam subangulatis; spira acuminata; apertura subangusta; labro absolete crenato; columella quinqueplicata. - Long. 35, lat. 10, 5, long. aperturae $15 \mathrm{~mm}$.

Patria ignota. Exstat in coll. beati L. Gruner, Bremensis.

Mitra arenacea Dkr. in Zeitschr. F. Mal. 1852. pag. 51.

Species elegantissima habitu ad Mitram scabriculam L. (Reeve Conch. icon. spec. 35) aliasque cognatas accedit, sed ratio anfractuun et superficiei indoles alienae sunt. Anfractus 10 usque ad 11, ultimus dimidiam fere testae partem adaequans; tota superficies transversim crebricostala sulcisque longitudinalibus confertis exarata, ita ut testa granosa quasi arenacea appareat. In anfractu ultimo costae transversae 32-34 usque ad canalem numerantur. Apertura subangusta, ad basin aliquantulum dilatata. Columella quinqueplicata,

- plica quinta minima et absoletissima. Pictura ut in aliis speciebus variabilis esse videtur. Spccimen quod exstat, in anfractu ultimo fasciam fuscam latam et obscuram ostendit, praeterea testa colore albo flammulisque longitudinalibus fuscis et croceo-ferrugineis variegata est.

Diese ungemein feine und elegante Mitra, deren Vaterland unbekanut ist, hat den Habitus der M. scabricula (Bucc.) L. (Voluta scabriuscula L. S. Nat. edit. XII.) doch ist das Verhältniss ilıres Gewindes ein anderes, auch weicht die Beschaffenheit ihrer Oberfläche ab. Sie hat 10 bis 11 Uingänge, wovon der letzte beinahe die halbe Länge des GeJäuses einnimmt. Jhre Oberfläche ist mit dicht gedrängten Querrippchen bedeckt, die ron feinen Längsfurcheı durchsclınitten werden, wodurch die Schale gekörnt ersclseint. Aul der letzten Windung zählt man 32-34 solcher Rippchen. Die Mündung jst ziemliclı eng, an der Basis etwas erweitert. Die Columella lat fünf von hinten nach vorn allmählig kleiner werdende Falten. Wie viele Mitrae, wird auch die gegenwärtige Art in der Färbung variabel sein, Das vorliegende Exemplar zeigt in der Mitte des letzten Umgangs eine breite rothbraune nicht scharf begränzte Binde; übrigens ist die Schale auf weisslichem Grunde mit rothbraunen Flammenzeiclinungen geziert.
Cette espèce extrêmement élégante et fine, dont la patrie est inconnue, présente l'habitus de la Mitra scabricula (Bucc.) Linn. (Voluta scabriuscula L. S. Nat. ed. XIJ.), mais la proportion de sa spire est tout à fait différente, ainsi que les caractères de sa surface. Ses tours de spire sont au nombre de $10-11$ et le dernier occupe à pell près la moitić de la longueur totale. La surface est couverte de fines côtes transverses très-serrées, coupées par des sillons longitudinaux, qui forment une sculpture granuleuse. Sur le dernier tour l'on compte $32-33$ de ces petites côtes. La bouche est assez étroite, légèrement élargie à sa base. La columelle est munie de 5 plis décroissant insensiblement de la partie postérieure jusqu' à l'antérieure. Comme chez beaucoup de Mitres la coloriation de notre espèce paraît être variable. L'exemplaire figuré est orné de flammules rousses sur un foud blanchâtre, et, au milieu dı dernier tour, d'une large bande rousse indistinctement limitée. 


\section{Hurex Belcheri llinds var.}

Tab. X. Fig. 6. 7.

Hanc cochlean eximiam clar. Ilinds in "the Zool. of the Voy. of H. M. S. Sulphur" jam amo 1543 descripsit et icone illustravit, pariter eam et in Conclyliologia iconica descriptam invenies. Specimen hic depictum statura quidem majore testaque solidiore excellit, sed squamis grandibus minus erectis instructum est. - Clar. Ilinds hanc specien Californianam Iluricibus adjungit, pro nostra rero opinione costae ejus imbricatae minime pro varicibus habendae sunt. Ad Ilemifusos potins pertinet, genus Swainsonianum.

Diese ausgezeichnete Schnecke ist bereits von Hinds in Zool. of the Voy. of Sulphur unter obigem Namen besclirieben und abgebildet; auch in der Conchyliologia iconica des Herrn Reeve findet sich dieselbe. Das hier abgebildete Exemplar zeigt uns eine grosse diclsschalige Varietät mit mehr abstehenden und minder in die Ilöhe gerichteten Schuppen. - Hinds bringt diese Art, deren Vaterland Californien isı, zur Galtung Murex, doch können ihre schuppigen Absätze eben so wenig als varices angesprochen werden wie die ähnliche Bildung an gewissen Trophonarten.

Es gehört diese Schnecke zur Gattung Hemifusus Sw.
Cette belle coquille a dẻjà élé décrite et ligurée par Mr. Hinds (Zool. of the roy. of Sulph.) et se trouve aussi dans la Conchyliologia iconica de Reeve. L'exemplaire figuré nous jrésente une variélé grande et à test épaissi, dont les écailles sont moins érigées et plus étalées.

Mr. Hinds retient cette espèce, qui provient de la Californie, dans le genre Murex; cependant ses prominences écailleuses ne sauraient être regardées comme des varices, mais plutôt comme des formations semblables à celles de certaines espèces de Trophon, et elle appartient au genre Hemifusus de Swainson.

\section{Cassis glabrata Dkr.}

Tab. X1. Fig. 1. 2.

C. testa ovata, temuicula, evaricosa, nitida, lactea, maculis nomullis pallide castaneis mope suturam ornata; spira subacuminata; apice obtusiusculo; anfractibus septenis concexis, sutura distincta divisis, superioribus transversim leciterque sulcatis, ultimo glabrato, fere ${ }^{2 / 3}$ totins longitudinis testae adaequante; colmmella ralde contorta superne laerigata, inferne subrugosa, ad basin triplicata; labro tenui reflexo acute dentato, dentibus superne et inferne evanescentibus; apertura oblonga, subarcuata. - Alt. 65, lat. $37 \mathrm{~mm}$.

Cassis glabrata Dkr. in Zeitschr. f. Mal. 1852. pag. 62, 
Ilanc speciem raram spira producta singularem beatus Alb. Radats ex insula Zanzibar quondam attulit. Cassidi turgidae Reevei proxime affinis est, sed habitu graciliare, spira multo langiore, apertura angustata, anfractibus superioribus transversim sulcatis et labra unicolore maculis castaneis omnina carente satis differt.

Diese seltene Cassis gehört zu den vielen Conchylien, die der leider su frülı verstorbene Capitain Alb. Rodatz von seinen öfteren Reisen uach der Osthüste Afrikas milgebracht hat. Sie ist der Cassis turgida Reeve zunächst verwand, aber durch schlankere Gestalt, viel längere Spira, engere Mündung, die quer gefurchten oberen Windungen und das gänzliche Fehlen brauner Flecken an Labrum hinreichend verschieden.
Celte râre espèce de Cassis appartient au grand nombre de coquilles, que Mr. le capitaine Alb. Rodatz, enlevé trop-tôt à la science, a rapportées de ses fréquens voyages à la côte orientale de l'Afrique. Elle a beaucoup de rapports avec la C. turgida Reeve, mais elle s'en distingue suffisamment par sa forme plus grêle, spire beaucoup plus alongée, bouclıe plus étroite, par les sillons transversaux des lours supérieurs et l'absence totale de taches brunes du bord droit.

\section{Nlarginella Burchardi Dlir.}

Tab. XI. Fig. 3. 4.

II. testa ovato-oblonga, basin versus parum attennata, crassa, solida, laerigata, Racescente subcarnea; spira brevissima conica obtusiuscula; labra albido valde incrassato, intus laevi, superne subsimato, ad basin excacato, varice parvulo lucteo adnato; columella quadriplicata; faucibus flavo aurantiis. - Long. 27 , lat. $15 \mathrm{~mm}$.

Patria ignata.

Marginella Burchardi Dkr. in Zeitschr. f. Mal. 1852. pag. 61.

Species quoad spiram Marginellae amygdalae Krieneri aliisque nonnullis similis, habith vero tato et magnitudine inter amnes quas novinus Marginellas cum subcoerulea Mart. (coerulescente Lam ) tantummoda comparari potest, a qua tamen testa multo solidiore, labro valde incrassato quasi bivaricoso nec non apertura angustiare satis differt.

Diese Art, deren Vaterland unbekanut ist, ähnelt in ihrer Spira eumal der Marg. amygdala Kiener, sie ist aber rücksichtlich ilırer ganzen Gestalt unter allen uns bekannten Marginellen nur mil der subcoerulea Mart. (coerulescens Lam.) zu rergleichen, von welcher sie indess durch weit stärkere Schale, sehr verdicktes Labrnm, das gleichsaın doppelt erscheint, und durch engere Mündung wesentlich abweicht.
Cette espèce, dont la patrie est inconnue, ressemble, quant à la spire, à la Margin. amygdala Kien., cependant ell considérant sa forme totale, nous ne saurions la comparer qu' avec la M. subcoerulea Mart. (coerulescens Lam.), dont elle differe essentiellement par son test beaucoup plus fort, par son bord droit fortement épaissi, presque doublé, et par sa bouche plus étroite. 


\section{Fasciolarlia tulipa (Murex) Lo var.}

Tab. XI. Fig, 5. 6.

Rariorem huins cochleae varietatem hic depinximus non solum testa solidiore, sed etiam sulcis costulisque irregnlaribus subgranosis insignem. - Quod attinet ad colorem et picturae indolem haec species maximopere variat; modo coerulescens vel alba est, modo cinerea vel olivacea, maculis rufis et spadiceis irregularibus flammisque pallidioribns varie picta, sed lineis transversis nigris continuis vel interruptis semper gaudet. Operculum crassum corneum subolicaceum ovato-lanceolatum.

Vurietas nostra ab amico $J$ Gundlach Die ad Matanas in insula Cuba lectum est, ubi suepius occurrit.

Wir haben hier ron dieser läufigen westindischen Schnecke, die in Beziehung anf Cirösse und Färbung ausserordentlich variirt, eine seltenere Abänderung abgebildet, die sich bei miltlerer Grösse durch stärkere und ziemlich schwere Schale, sowie zumal durch rauhe Oberfläche auszeichıel, während sonst die Schale glatt und nur von leichten Querfurchen umzogen zu sein pflegt und die Umgänge uur unmittelbar unter der Naht einige gekörnte Querrippchen Iragen, abgesehen von den Furchen, die anf der Spindel sich befinden.

Das abgebildete Exemplar stammt von Matanzas auf der lusel Cuba und wurde vou unserem Freunde Dr. J. Gundlach eingesandt.
Nous avons figuré une variété moins fréquente l'une coquille assez commune des Indes occidentales, qui est extrềnement variable quant à sa taille e sa coloriation. Cetle variélé, qui est de laille moyeune, se distingue par son lest plus épais et assez lourd, et principalement par sa surface àpre, taudis que dans les exemplaires typiques le test est lisse et seulement entouré de sillous transversanx peu marqués et de quelques cútes fines et granuleuses immédiatement au-dessous de la suture.

L'exemplaire figuré nous a été envoyé par. notre ami, le docleur J. Gundlach, yui l'a recueilli à Malanzas, île de Cuba.

\section{Q prog a iction $x$ \\ 35. Anomalocardia latrumcolaria Röm.}

Tab. XII. Fig. I. 2.3.

A testa corduto-trigona, tumidinscula, inaequilatera, antice parum producta, postice rotumdatoangulata; albido coerulea, maculis coeruleis subquadrangulis densis, cx parte in quincuncem ordinatis picta striisque densis radiantibus instructa, in medio et basin versus fere laevi, extremitate postica sulco lato obsoleto signata; umbonibus acutis coeruleis; margine dorsi antico subrecto, postico perparum fornicuto, margine ventris aequaliter currato; lunula ocato-cordata linea impressa distincte terminata; area canaliculata lanccolata; facie interna subriolacea marginem versus ventris crenulatum sordide alba; sinu 


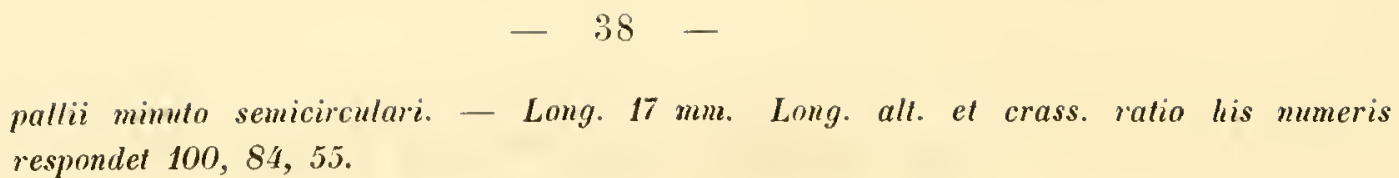
respondet $100,84,55$.

Patria ignota.

A. Latruncularia Rön. in Mal. Bl val. VII. pag. 162.

Diese kleine interessaute Musclıel, die uns Herr Dr. Römer zum Abbilden gïtigst milgelheilt hat, wird vou demselben I. c. folgendermassen beschrieben: Die latruncularia ist von den übrigen Arten wohl unterschiedę und zwar nächst der eigeuthüınlichen Färbung durch die Sculptur; die feinen, diclıteu Längs- und Querlinien siud nur in der Wirbelgegend, vorn und namentlich hinten deutlich ausgeprägı, der millere Theil der Schalen nach unten hin ist fast glall; in der Nille des Hinterendes zeigt sich eine breitere Furche, die von den Wirbeln zur Basis geht, neben welcher sich ein stumpfer Wulst erhebt, der den übrigen Theil dieser Extremität bemerklich absondert. Die Mantelbucht ist selır klein und laalbkreisförmig, sie stejgt fast senkreclit zun hintereu Muskelfleck heraul.
Cette petite coquille curiense, que $\mathbf{M r}$. Je docteur Römer a bien voulu nous confier pour la faire figurer, a été caractérisée par l'auteur de la manière suivaute: elle se distingue Irès bien des autres espèces uon seulement par sa coloriatiou, qui lui est propre, mais priucipalement par sa sculpture. Les stries longitudinales et transversales, qui sont fines et serrées, ne sout bien marquées que daus la région des crochets en avant et principalement en arrière; la partie moyenne des valves est presque lisse; près du bord postérieur l'on remarque un sillon plus large, qui s'étend des crochets à la base et à côté duquel s'elève une prominence obtuse, qui sépare distinctement l'autre partie de cette extrémilé. Le sinus pallial est très petit et de forme sémicirculaire; il s'elève presque perpendiculairement vers la tache musculaire postérieure.

\section{Tapes (Textrix) Carpenteri Rïm.}

Tab. XII. Fig. 4. 5. 6.

T. Iesta ovato-elliptica, inaequilatera, antice subattenuata, rotundata, postice panllo latiore oblique subtruncata parum convexa, tenui, liris transversis crassis rotundatis sulcisque angustis instructa, carneo-albida; macnlis pallide finscis distantibus, pracscrtim ad marginem ventris, picta; umbonibus acutis valde prominentibus laevigatis; lumula lancealata planiuscula, distincte circumscripta areaque angnsta fusco variegatis; ligamento temi subdepresso; facie interna sordide alba flavescente; simu pallii magno avali; dentibus valvulae dextrae antico et mediano bifidis. - Long. $27 \mathrm{~mm}$. Long. alt. crass. $=100: 60: 38$.

Patria ignota.

Tapes Carpenteri Röm. in Mal. Bl. vol. VII. pag. 156. 
Diese Art, welche ebenfalls Dr. Römer's SammJung angehört, ist eine Verwandte von Venus euglypta, exarata, lirata, semirugata Pliil., doch kleiner, dünner, gestreckter als alle diese, auch ist ihre Mantelbucht verhältnissmässig weit grösser.
Celte espece appartenant à la collection de Mr. le docteur Römer a des rapports avec les Venus euglypta, exarata, lirata et semirugata Phil., mais elle plus petite, plus mince et plus alongée, que toutes les espéces cilées, et son sinus pallial est proportionellement beaucoup plus grand.

\section{Cỵtherea (Tivela) arguta Rönll.}

Tal. XI1. Fig. 7. 8.9.

C. testa trigona fere aequilatera, tumidu, basin versus compressiuscula, utrinque attennata, rotundata; striis concentricis obsoletis instructa paene lateigata, pallide rabente, lineis radiantibus fusco maculatis subangulatis picta; umbonibus tumidis subrecte incurvis lividis fere contignis; margine centris antice curvato, postice subrecto, margine dorsi utrinque perdeclivi; limula subplana albida fusco venulata cordiformi, linea obsoleta termimata; area aulla; liganecnto breviculo parum prominente; pagina interna superius livido infecta inferius albida; siun pallii magno semiovato. . Cardinis structura eadem atque in Treela nuctroide Bornii. - Long. $2 ; \mathrm{mm}$. Long. alt. crass. $=100: 80: 66$.

Ilabital ad istlimum Panamensem (ex anct. merc. rer. rat.) Rom.

Cytherea argut a Röm. iu Mal. Bl. vol. VII. pag. 1.ts.

Diese interessante Form steht unter den bekannten Arten der Tivela mactroides Born am ıächsten, unterscheidet sich indessen von derselben wesentlich zumal durch weit geringere Höhe und mehr in die Länge gezogene fast gleichschenkelige dreieckige Gestalt sowie durch die nugleich grössere Mantelbucht, die fast bis zur Mitte der ScliaJen reicht. Die Art der Zeichnung ist allerdings etwas eigenthümlich, doch kommen Flecken und Zickzacklinien in und zwischen den braunen Strahlen auch bei T. mactroides vor. Uebrigens vergleiche man Römer's ausführliche Beschreibung.
Celte curieuse espèce a, parmi les espéces connues, ses plus proches rapports avec la Tivela mactroides Born, mais elle s'ell distingue essentiellement par sa hauteur moindre et par sa forme plus alongée, presque triangulaire, ainsi que par son sinus pallial beaucoup plus grand, qui alleint i peu près le milieu des valves. Le mode de coluriation est en général différent: cependant la T. mactruides présente aussi quelquefois des taches et des lignes ell zigzag dans el entue les rayons bruns. Du reste l'on peut comparer la déscription détaillée de lauteur.

\section{Cytherea (Liocontha) Limenial Röm.}

Tab. Xl1. Fig. 10. 11 .

C. testa subtrigono-cordata, crassa, inaequilatera, fere tumida, antice exacte rotundula, postice parum producta, mgis concentricis antice partim confluentibus instructa, rubente-alba 
$$
\text { - } 40-
$$

zonis pallide lividis cincta, lineis badiis subparallelis ablique ascendentibus postice inflexis orwata; umbonibus prominentibus acutis antrorsum inclinatis; lumula lanceolata parva, vix concava, conspicue terminata; area angusta livida maculata; facie interna alba medio et impressionibus muscularibus fusco variegata; sinu pallii brevissimo late aperto. - Long. $33 \mathrm{~mm}$. Long. alt. et crass. ratio zumeris 100, 90, 60 respondet.
\end{abstract}

Habitat mare rubrum.

Cytherea Limenia hom. in Mal. Bl. vol. VII. pag. 151.

-Unter den Arten der Gruppe Lioconcha Mörch ist es die kleine Altheilung der C. callipyga Born, welcher diese Species sich ganz anschliesst und besonders ist sie der C. lentiginosa Clemu. XI. f. 1963. fit (C. Pfeifferi Phil.) in Bezug auf Solidität der Schalen, Querreifung, Lunula, Mantelbucht nahe verwand, neigt aher wegen des abgerundeten Schnabels der Hinterseite melır nach manchen Formen der C. arabica Chemu. Die Wirbel springeı stärker vor und liegen weiter nach vorn, als in den genannten Arten; der Unriss neigt melır ins Dreieckige. Die eigenthümlichen braunen Parallellinien, welche ron vorn nach hinten ansteigen und in der Nähe der hinteren Extremität stumpfe, nach oben gerichtete Winkel bilden, zeigt, wenn anch anders geordnel, nur unch V. fuscolineata Brod. et Sow."
Parmi les espèces du groupe Lioconcha Mörclı c'est la petite section, dont Venns callipyga Born est le type, à laquelle notre espèce possède la plus grande affinité, et elle est surlout voisine de la C. leutiginosa Chemn. XI. f. 1963. 64 (C. Pfeifferi Phil.) par la solidité des valves, par ses stries Iransversales, par sa lunule et son simus pallial. Cependant par le bec arrondi de sa partie postérieure elle s'approche à certaines formes de la C. arabica Chemn. Les crochets sont plus saillants et sout placés plus en avant ụue dans les espèces citées; les contours ont une tendence à la forme Iriangulaire. Les lignes parallèles brunes, qui montent de la partie antérieure vers la poslérieure, et forment, près de l'extrêmité postérieure, des angles obtus, dirigés en haut, se remarquent, quoique en disposition dillérente, seulement dans la V. fuscolineata Broul. et Sow.

\title{
34. Gomphima Melanargis Rüm.
}

Tab. XII. Fig. 12. 13.

G. Lesta ovato-trigona compressa subaequilatera, antice rolundata, postice subrostrata, erassa et ponderosa, liris planis confertis concentricis fere aequalibus, nomullis utrinque confuentibus, instructa; umbonibus acutis obliquis valde prominentibus; latere dorsi antico subsinuato, postico subrecto, obtusangulo sulcisque nomullis ab umbonibus radiantibus signato; margine ventris aequaliter arcuato; lunula anguste lancealata concava indistincte terminata; area argusta haud limitata; albida, colore livido et subcano transversim fasciata et angulatim variegata. - Cardinis structura, impressiones musculares nec non linea pallii 
fere eaedem atque in Yenere donacina Chemnitzii. - Long $70 \mathrm{m.m}$. Long., alt. et crass. ratio muneris 100, 70, 40 respondet.

Patria ignota.

Am uäclısten verwandı dieser ausgezeichneten Art ist die Verus donacina Chemn., von welelser sie sich indesss namentlicls durch die spitzen, ziemlich stark hervortretenden Wirbel, durch die Concavität des vorderen Rückenrandes und die regelgelmässigen concentrischen Furchen sofort untersclieidet.

Leider ist das Vaterland dieser seltenen MIuschel unbekanut.
Cette espèce distinguée est assez voisine de la Venus donacina de Chemnitz, dont cependant elle se distingue au premier coup d'oeil par se's crochels assez fortement prominens et pointus. par la concavité du hord dorsal antérieur, et ses sillons concentriques et réguliers.

Nous regreltons de ne connaitre la patrie de cette coquille râre.

\section{Mactra rugifera Dlir.}

Tab. XIII. Fig. 1, 2. 3.

Testa ovato-trigona, subsolida, fere aequilateralis, parum concexa, posterius subcarinata, pallide flavescens, striis in mediis valvis concentricis, tenerrimis, obsoletis instructa, sed marginem versus inferiorem sulcis distinetis utrinque confuentibus, subdichotomis et rugosis exarata; margo dorsi mticus paene rectilineus, posticus parum curvus, margo ventris aequaliter arcuatus; extremitas antica subtruncata, postica attenuata; umbones parvuli acuti, violacei, nitidissimi; area lunulaque sulcato-rugosae, virgis luteis utrinque signatae. - Long. 50 m.m. Long., altit. et latit. ratio mmeris 100, 75, 42 respondet.

Habilat in flwio cygnorum Australiae (fide Henrico Dohrn).

Das Gehäuse ist für seine nicht beträchtliche Grösse ziemlich dickschalig, fast gleichseitig, wenig bauchig und ıälert sich im Unriss sehr der dreieckigen Gestalt. Der vordere Rückenrand ist fast geradlinigt, der hintere, ebenfalls nur sehr wenig gebogen, fällt fast eben so tief herab; der Basisrand bildet eine gleiche, ziemlich starke Curve. Die vordere Extremität ist etwas schief abgestumpft, die hintere ziemlich zugespitzt. Die kleinen spitzen, ungemein glänzenden Wirbel sind violblau, jı Uebrigen ist die Iluschel strohgelb und von sehr zarten concentrischen Wachsthumslinieu bedeckı, die
Cette coquille est assez solide en compraraison de sa taille médiocre, presque équilaterale, peu ventrue el se rapproche beauconp, dans ses contours, à la forme triangulaire. Le bord dorsal antérieur est presque rectilinéaire, le postérieur, qui est très peu arqué, descend presqu' au même niveau; le bord basal forme une courbure régulière, assez fortt. L'extrémité antéricure est tronquée subobliquement, la postérieure esı anguleuse. Les petits croehets pointus et très luisans, sont de couleur violacée, le reste de la coquille est couleur de paille et couvert de stries daccroissement con- 
nach dem Basalrande hin allmählig in starke an dem Vordertheil dichotomirende und runzelige Furchen ibergehen. Die durch eine stumpfe von den Wirbeln beiderseits luerablaufende Kante deutlich abgegränzte Lunula und Area sind ebenfalls von punzeligen Furchen bedeckt und nit orangefarbigen Stceifen gezeichnet. Die Schlosszähne haben in Wesentlichen die Beschaffenheit der meisten Mactra-Arten; die Mantelbncht ist ziemlich stark und nicht sehr seicht, daher leicht zu erkennen. Die innere Farbe ist milchweiss.

Diese Muschel, die wir nirgends beschrieben finden, unterscheidet sich auf den ersten Blick durch ihre zumal an ihrem Vordertheil dichotomirenden und runzeligen Furchen sowie durch die orangefarbigen Streifen zu beiden Seiten der violblauen Wirbel von allen uns bekaunuten Arten ihres Geschlechtes. centriques très-fines, qui vers le bord basal se changent peu à peu en sillons forts, dichotomes et lugueux à la partie antérieure. La lunule et laréole, qui sont bien circonscrites par un angle obtus descendant des deux côtes des crochets, sont aussi convertes de sillons rugueux et ornées de lignes orangées. Les dents de la charnière ont essentiellement les caractères de la plupart des espèces de Mactra; le sinus palléal est assez fort el assez approfondi pour être lemarqué aisénent. La couleur interne est blanc de lait.

Cetle espéce, que nous ne trowvons décrite nulle part, se distingue, à première vue, de toutes celles conuues par ses sillons dicholomes de la partie antérieure, et par ses stries orangées à chaque côté des crochets violacés.

\section{Cytherea umbonella Lam. var.}

Tab. XIII. Fig. 4. 5. 6.

Albam hujus conchae varietatem in dorsa coeruleo tinctam, ad Meretrices Lamarckii pertinentem, hic depingi curavimus, Cytheream scilicet niveam clar. Ianley. Non dubitamns quin Cytherea umbonella Lamarclii ad hanc ipsam speciem referatur, nam ejus magnitudo et verba: „testa cordata, tumida inaequilatera, antico (postico) latere laevi, postico (antico) transverse sulcato etc. optime in istam quadrant.

Haec concha haud frequens e Brasilia originem ducit; clar. Cuming affirmante et in mari erythraeo reperitu'.

Wir haben von dieser Mluschel, die zu Lamarck's Abtheilung Meretrix gehört, eine weisse auf dem Rücken blassblau gefärbte Varietät abgebildet, Hauley's Cytherea nivea (Spec. of Shells p. 97. Sow. Thes. Conch. vol. II. no. 37.). Es leidet wohl keinen Zweifel, dass dies eine Varietät der ächten Cytherea umbonella Lamarck's ist; deun
Nous avons figuré une variété blanche à dos bleuâtre de cette esjèce, qui appartient au groupe Meretrix de Lamasck; c'est la $C$. nivea Hanl. (Spec. of shells p. 97. - Sow. Thes. Conch, vol. II. nr. 37.) On ne peut guère douter, que cette coquille est une variété de la véritable Cyth. umbonella Lam., car les notices sur la taille et les 
die Angabe der Grösse und die Worte: ,Testa corlata, tumida, inaequilatera, antico (postico) latere laevi, postico (antico) transverse sulcato" etc., passen vollkommen auf das vorliegende Exemplar.

Es kommt diese in den Sammlungen nicht häıfige Art aus Brasilien; auch soll sie nach Herrı $\mathrm{Cu}$ ming's Angabe im Rothen Meere leben.

Das hier abgehildete Exemplar verdanken wir der gütigen Mittheilung des Herrn Riise in St. Thomas. Auf unserer Abbildung treten die concentrischen Wachsthumsansätze hinten zu stark hervor, dagegen erscheinen die auf der vorderen Hälfte der Schalen befindlichen starken Furchen wegen der Beleuchtung zu schwach. mots: , lesta cordata, lumida, inaequilatera, antico (postico) latere laevi, postico (antico) transverse sulcato, etc." s'appliquent parfaitement à l'exemplaire figuré.

Celte espèce, peu répandue dans les collections. provient du Brésil; daprès Mr. Cuming elle se tromverait aussi dans la Mer Rouge. Nons devous l'exemplaire figuré à la bienveillance de Mr. Riise à St. Thomas. Dans notre figure les stries d'accroissement concentriques sont trop marquées à la parlie postérieure, tandis que les sillons forts de la partie antérieure des valves apparaissent trop foibles, en suite de la position de la coquille vers la lumière.

\section{4\%. IDosinia Roemeri IDlir.}

Tab. XIII. Fig. 7. 8. 9.

Testa rotundato-cordata, subcompressa, valde inaequilateralis, alba, ad umbanes subrosea, ad aream lmmlamque badia, liris concentricis confertis regularibus utrinque aculis lanelliformibus, nonnullis interpositis et confuentibus, ad aream subcristatis instructa; umbones prominentes acuti appraximati, antrorsum valde inclinati; margo ventris fere exacte circularis, margo cardinis auterior valde simnatus, posterior perlongus declivis, parum fornicatus; lumula cordiformis medio porrecta, sulco profundc terminata; area lanceolata subplana, acute striata lamellis subcristatis circumscripta; ligamentum immersum; latus intermm albidum, medio subroseum; simus pallii linguaeformis permagnus. - Long. 32 m.m. Long., alt., crass. ratio $=100,90,40$.

\section{Habitat ad Guineam?}

Diese feine Muschel zeigt manche Analogie mit der Dosinia Carpentcri Röm., doch ist sie etwas flacher, minder boch, an der vorderen Extremität, wo der stark gebuchtete Schlossrand mit dem fast kreisrunden Bauchrande zusammentriff, winkelig, nicht gerundet, ihr hinterer Schlossrand ist minder gebogen und mehr abschüssig, abgesehen von der Färbung der Area und Lunula sowie der Wirbel. Das Schloss hat nichts Ausgezeichnetes und stimmt
Celte coquille élégante présente quelque analogie avec la D. Carpenteri Roem.; cependant elle est un peu plus aplatie, moins haute, anguleuse (non arrondie) à l'extrêmité antérieure, oủ le bord cardinal fortement sinueux se joint au bord basal, qui est presque circulaire; le bord cardinal postérieur est moins courbé et descend plus droitement. D’ailleurs la coloriation de l'aréole. de la lunule et des crochets est différente. La charnière 
mit der Bildung der mehrsten Dosinien übereia. Die Mantelbucht dagegen ist sehr tief und zungenförmig, sie ragt weit über die Mitte der Schalen hinaus. n'offre rien de particulier, elle est formée comme dans la plupart des espèces de Dosinia. Le sinus palléal, au contraire, est très profond et en forme de langue; il surpasse beaucoup le milieu des valves.

\title{
43. Fasciolaria Lischieana Dkir.
}

\author{
Tab. XIV.
}

Testa fusiformis, turrita, ventriosa, ponderosa, flavo-albida, lineis binis vel geminatis fuscis undique cincta, epidermide corneo-rufa laevi et frma vestita; anfractus novem convexi sutura hand profunda sejuncti, ultimus medio obsoletissime biangnlatus et subnodosus; spira acuminata tertiam tantummodo cochleae longitudinem occupans; cauda recta transversim plicata spira panllo brevior; apertura oblongo-ovata, intus albida, rufo lividoque variegata lineisque elevatis vel costulis fuscis parallelis sed interruptis ormata; labrum dentibus geminatis fuscis lineis externis respondentibus ornatum; colnmella hepatica basi plicis crassis tribus instructa, infima maxima, sequens minor, suprema minima. Long. 150, lat. circa $70 \mathrm{m.m}$.

Patria ignota.

Haec species insignis, quam mllibi depictam vel descriptam invenimns, Fasciolariam inermem Jon. (cfr. Phil. Abb. vol. 111. pag. 122. Tab. III. fig. 3) in mentem vocat; differt vero inprimis habitu majore, anfractibus multo tumidioribus, spira pro magnitudine testae breviore, anfractu nltimo obtusangnlo.

Diese ausgezeichnete grosse Fasciolaria, welchc wir nirgends beschrieben oder abgebildet finden, erinuert am meisten an die $F$, inermis Jonas Phil. Abb. vol. III. pag. 122. Tab. III. Fig. 3, sie ist aber durch bedeutendere Grösse, das weit bauchigere Gewinde, die verhältnissmässig kürzere Sjira, den schwach knotigen und etwas stumpfkantigen Jetzten Umgang, sowe durcl die stärkeren nicht weiss gelärbten Falten leicht zu unterscheiden. Dieselben treten jedoch in der soust sebr gelungenen Zeichung nicht hervor, weil sie ziemlich tief liegen.

Dieses gewiss seltene Stück gelıört der Sammlung des Herrn Regierungsraths Lischke in Elberfeld an. Leider ist das Vaterland desselben unbekannt.
Cette Fasciolaire grande et distinguée, que nous ne trowrons décrite ni figurée nulle part, a quelques rapports avec la $\mathrm{F}$. inermis Jonas (Phil. Abb. voll. 11I. p. 122. pl. 3. f. 3), mais elle s'en distingue aisénent par sa taille najeure, sa spire beaucoup plus ventrue et jroportionalement plus courte, par son dernier tour légèrement tuberculeux et muni d'une carène obtuse, ainsi que par ses plis plus forts, qui ne sont pas blancs. (Ces plis ne sont pas assez marqués dans notre figure du reste très caractéristique, parce qu' ils sont placés assez profondément.)

L'exemplaire liguré d'une espèce certainement bieı râre appartient à la collection de Mr. Lischke a Elberfeld. Nous regrettons de n'avoir nulle notice sur sa localité. 


\section{Mitra Sammelis Dohnm.}

Tab. XV. Fig. 1. 2. (Specimen majus.)

Testa oblongo-ovata, solida fulvo-viridis, spiraliter remote fusco lmata, subtilissime decussata; sutura marginata; anfractus 78 plani, ultimus antice ascendens; apertura angusta, intus coerulescens; labrum incrassatum album, denticulatum; columella quadriplicata. - Long. 28, latit. 10 ; apert. long. 15 , lat. 5 m.m.

Ilabitat ad insulas Sandwich.

Mitra Samuelis Dolem in Proc. Zool. Soc. of Lond. 1860. pag. 386.

Haec species cum Mlitra astricta Reeve saepins commixta, Hitrae pellis serpentis clar. Reevei affinis est; differt vero striis spiralibus tenerrimis sub epidermide olivacea occnltis. Magnitudine maximopere variat.

Diese Art erinuert sehr an Mitra pellis serpentis Reeve, vou der sie durch die olivenlarbige Epidermis, die darunter befindliche feine Spiralreifung und die glattere Oberfäche abweicht. Mit Mitra astricta, unter welchem Nanen sie mehrfach in Sammlungen liegt, hat sie der Reeve'schen Figur nach sehr weuig Achnlichkeit, und es kann nur die Angabe, dass diese ganz mit feiuen Spirallinien bedeckt sei, Veranlassung zu der Verwechselung gegeben haben. - Uusere Art variirt stark in der Grüsse.
Cette espèce a beaucoup de rapports avec la II. pellis serpentis Reeve, dont elle se distingue par sa surface plus lisse, couverte de stries spirales fines sous un épiderme de couleur olivacée. Ellc se trouve dans plusieurs collections sons le flom de 13. astricta, avec laqquelle, d'après la figure de lieeve, elle a pen de ressemblance, et prubablement la notice, que cette dernière et extiérement couverte de stries spirales, a été cause de la confusion des deux espèces. La taille de notre espèce est très-variable.

\section{Mlitra asperpillia Dohrm.}

Tab. XV. Fig. 3. 4.

Testa oblongo-ovata, per longitudinem rngoso-plicata et sulcata, spiraliter lirata, aurantia, ad suturam albisonata; anfrachs 5-6 ad suturam angulati, tuberculis obtusis coronati; anfractus ultimus basi subattemuatus et valde sulcatus; apertura coerulescentialbida; columella quadriplicata. - Long. 22, latit 9; apert. long. 11, lat. 3 m,m.

Patria ignota.

Mitra a sperrima Dohrn in Malak. Bl. vol. VIII. pag. 138

Species costis crassis nec non anfractibus ad sutmam obtuse angulatis tuberculiferis insignis est. Plicae a tuberculis obtusis et rotundatis incipientes, basin subattenuatam versus sensim 
evanescunt; praeterea cochlea carinis spiralibus cincta est, quae in parte testae antica sensin validiores funt. Color totus aurantius excepta carina alba.

Die Windungen dieser durch ihre selur grobe Sculptur ausgezeichneten Art sind in der Nähe der Naht stumpf gekielt, oberlıalb des Kieles fast lırizontal, dann vertikal absteigend; der Kiel ist mit rundichen Höckern besetzt, von denen aus Falten nach unten verlaufen; zwischen diesen befiuden sich ziemlich lief eingedrïckte Längsrinnen. Hierüber hinweg verlaufen erbabene Spirallinien, die namentlich an der Basis der letzten Windung selır krältig werden. Die Färbung ist orange; nur von der Naht bis einschliesslich der Höckerreilıe auf dem Ihel verlauft ein weisser Gürtel. Das abgebildete Exemplar befindet sich im Besitze des Herrn Sylvanus Hanley in London.
Les lours de cette espèce, qui se distiugue par sa sculpture grossière, sont pourvus d'une carène obtuse près de la suture, au dessus de la carène ils sont à peu près horizontaux, puis descendant verticalement; la carène est garnie de petits tubercules arrondis, qui donnent naissance a des plis décurrens, entre lesquels on remarque des sillons longitudinaux, imprimés assez profondément. Ces plis sont croisés par des stries spirales élevées, qui deviennent assez solides surtout à la base da dernier tour. La couleur est orangée, excepté seulement un cercle blanc, occupant l'espace de la suture et jusqu' à la série de lubercules de la carène. L'exemplaire liguré se trouve dans la colJection de Mr. S. Hanley à Londres.

\section{Nitra foveolata Mkir.}

Tab. XV. Fig. 5. 6. a. pars magn aucta.

Testa fusiformis, apice acuminata, basi attenuata; anfractibus $9-10$ parum contexis undique transversim costatis ornata; alba, maculis fammisyue ferrugineis picta; anfractus ultimus spira duplo fere longior; costae acutae aequidistantes; interstitia fovcolis plurimis linea medianu elevata divisis instructa; calumella quinque plicata; apertura langa angusta; labrum acutum simplex. - Lang. 25, lat. 10 m.m.

Patria ignota.

Haec Mitrarum species praesertim sculptura concinna excellit. Costis regularibus acutis aeque distantibus circa 14 cincta est. Interstitia foveolarum seriebus duabus linea elevata divisis, distincta et exornata sunt.

Diese Mitra zeichnet sich besonders durch ihre zierliche Sculptur aus. Sie ist von regelmässigen in gleicher Entfernung abstehenden scharfen Querrippchen bedeckt, deren an vorliegendem Exemplare auf der letzten Windung 14 vorhanden sind. Zwisclıen diesen Rippchen bemerkt man zwei Reihen dicht nebeneinander liegender Grübchen, die von einer feinen erhabenen linie getreunt werden.
Cette Mitre se distingue surtout par sa sculpture élégante. Elle est couverte de petites côtes transversales tranchantes, régulières et éqquidistantes, dont l'exemplaire figuré possède 14 sur le dernier tour. Entre ces côtes l'on remarque deux séries de fossettes très-rapprochées, séparées par une fine ligne élevée. 
Die vorliegende Schnecke hat viele Aelnnlichkeit mit Mitra flammea Quoy \& Gaim. (Voy. de l'Astr. vol. II. p. 659. Tab. 45. (bis) fig. 23-25), die jedoch keine vertieften Grübchen hat, sondern zwischen den Querrippchen läugsgestrichelt ist.
Notre espèce a beaucoup de rapports avec la 11. Alamea Quoy \& Gaim. (Voy. de l'Astrol. IJ. p. 659. pl. 45 bis. f. $23-25$ ), mais celle dernière n'offre point de fossettes, mais des lignes longitudinales entre ses côtes

\section{4i. Mitria Ilanleyi Doh''l.}

Tab. XV. Fig. 7. 8. magn. aucta fig. a. magn. naturali.

Testa pyramidali-ovata, per longitudinem sulcata, ad suturam plicis crebris in anfractibus mediis sulco unico spirali ornata, grisea, fulvo, vel fusco-macnlata, in medio late albisonata; anfractus 6 convexiusculi, ultimus basi dense plicatus et serie tuberculorum ornatus; apertura ovata; columella violacea quadriplicata. - Long. $5_{2}^{1}$, lat. 2; apert. long. $2_{2}^{1}$, lat. $I^{1}{ }_{4}$ m.m.

Patria ignota. Duo specimina in collectione Ilanleyana exstant.

Mitra II anleyi Dohrn in Malak. Bl rol. VIII. pag. 135.

Species singularis atque propria Mitrae Savigmyi Payr. e Mediterraneo labitu et colore quidem affinis, sed sculptura prorsus alicna. Superior anfractum pars superne fascia cineracea rel caesia fusco maculata cincta plicisque longitudinalibus confertissimis instructa est, medium fascia alba lata occupat.

Eine sehr ausgezeichnete kleine Art, die mit Mitra Savignyi Payr. verwandt ist. Die Form und auch die Färbung kommen dieser sehr nahe, doch weicht die Sculptur beträchtlich ab. Was ron den oberen Ungängen sichtbar bleibt, davon ist die obere Hälfte grau, braun gefleckt und mit dichten Längsfalten besetzt, die untere weiss, in deutlichen Zwischenräumen längsgefurcht und wieder in der Mitte durch eine spirale Furche getheilt. Am letzten Umgange folgt dann eine Reihe Höckerchen. Am Ende der Columella bemerkt man schliesslich enge Fältchen wie an der Nahı.
Perite espèce tres distinguée, qui a des rapports avec la M. Savignyi Payr. Je Ia luéditerranée. Sa forme ainsi que sa couleur lui ressemblent, mais elle en diffère considérablement par sa sculptnre. La partie visible des tours supérieurs est grise, tachetee de brun et muni de plis longitudinaux rapprochés à sa moitié supérieure, la moitié inférieure blanche, garnie de sillons longitudinaux distinctement espacés et divisée, à son milieu, par un sillon spiral. Une partie pareille est suivie, sur le dernier lour, d'une série de petits tubercules. Au bout de la columelle on remarque de petits plis semblables à ceux de la suture. 


\section{Mitra Mansi Donh'n.}

Tab. XV. Fig. 9. 10.

Testa solida, ovata, per longitudinem costellata, costis albidis, interstitiis fuscis spiraliter strigillatis; unfractus 7 convexiuseuli, ultimus ventricosior, medio faseia alba cinctus, basi spiraliter sulcatus; apertura intus livida, columella quadriplicata. - Long. 16, lat. 8; apert. long. $8^{1}, 2$, lat. $3 \mathrm{m.m}$.

Habitat ad insulas Sandwich? E collectione clar. H. Dolern.

Mitra Adamsi Dolern in Proc. Zool. Soc. of Lond. 1861. pag. 205.

IIaec Species Mitrae dermestinae Lamarchii (vol. X. pag. 340) similis est, sed costis planioribus et striis spissis intercostalibus praesertim differt.

Diese Art hat viele Aehnlichkeit mit Mitra dermestina Lam., doch unterschejdet sje sich durch die flacheren Rippchen und die dichteren dazwischen befiudlichen Querstrichelchen.
Cette espèce ressemble beaucoup à la $M$. dermestina Lam., mais elle s'ell distingue par ses petites côtes plus aplaties et les stries transversales iuterjacentes plus serrées.

\section{Nlitra Gimbiana Dotmrl.}

Tab. XV. Fig. 11. 1\%.

Testa fusiformis, spiraliter sulcata, ad suturam carinata, sub epidermide olivaceo-comea albicans vel flavescens; spira producta, acuta, anfractus 7-8 angulati, ultimus basi attenuatus; apertura intus alba; labrum simplex; columella quadriplicata. - Long. 20, lat. 6; apert. long. $10^{1}, 2$, lat. $2^{1}, 2 \mathrm{~m} . \mathrm{m}$.

Habitat in Senegambia. Exemplar depictum, magnitudine excellens, in collectione clar. Sylv. Ilanley exstat.

Differt a Mitra carinata Swains. sculptura, ceterum ei affmis est.

Die gegenwärtige Art eriunert an Mitra carinata Swains., doch unterscheidet sie sich zumal durch ihre Sculptur.
Cette espèce a quelques rapports avec la $M$. carinata Swains, mais elle s'en distingue par sa sculpture.

\section{Ilaliouis Dohrnilina Hkr.}

Tab. XV. Fig. 13. 14. 15.

Testa ovatomoblonga, subelliptica, parum convexa, colore albo roseoque variegata, maculis irregularibus magnis fuscis vel virideseentibus ad marginem saepius subquadratis picta; plicis rngisque obliquis, costulis spiralibus confertis $34-36$ subimbricatis nodosis transversimque 
striatis instructa; faramina 4 pervia subtubulasa; spira foramimu latiuscula subelevata apicalis; pars inter foramina et labium declivis subcavata; labium latum plamum; margarita argentea splendillissima, parum iridescens. - Lang. 40, lat. 28, alt. 10 m.m.

Ilabitat ad Novas IJebridas. Exstat in call. amici II. Dohrn.

Tria lujus speciei exemplaria exstant quae scnlptura et indole picturae satis itter se conveniunt. Spccimen tertium ambitu subelliptica excellit. Testa madice convexa castulis confertis subaequalibus transversim striatis hinc illic nodosis, marginem versus subimbricatis instructa est. Harga declivis medio cancavus, costulis $6-8$ cinctus. Foramina 4 subtubulosa; labium satis latum et plamum.

Es liegen drei Exemplare dieser Art vor, welche rücksichtlich der allgemeinen Form, der Oberfläche und Zeichnung ziemlich übereinstimmen; eines ist mehr elliptisch in Umriss. Die mässig gewölbte Schale ist mit $34-40$ dicht gedrängten spiralen Rippchen von ziemlich gleicher Stärke bedeckt, die nach dem Rande hin init aufgerichteten stumpfen Schuppen bedeckt sind und hin und wieder knot'g erscheineu. Der Rand ist ziemlich abschüssig, in der Milte concav und mit 6-8 Leisten von derselben Beschaffenheit wie die oberen Spiralreilchen umgeben. Es sind 4 Lücher oflen. Die Inuenlippe ist flach und ziemlich breit, die Perlenmutter weiss und ungemeiı glänzend, aber nur wenig irisirend.

Diese Art erinnert ziennlich an junge Exemvon Haliotis varia $L$.
Nous connaissons 3 exemplaires de cette espèce, presque égaux quant à la forme générale, la surface et le dessin; seulement l'un est d'un contour plus ellijtique. Le test médiocrement convexe est couvert de petites côtes spirales très rapprochées et assez égales entre elles, au nombre de 34-40, qui, vers le bord, sont garnies d'écalles érigées et obtuses, et apparaissent noduleuses en divers endroits. La partie marginale est inclinée, concave au milieu et entourée de $6-8$ stries semblables aux petites côtes spirales. On remarque quatre trous ouverts. La lèvre interne est aplatie et assez large, le nacre blanc et fortement luisant, mais très foibleinent iridescent. - L'espèce rappelle en quelque sorte de jeunes exemplaires de l'II. varia $L$.

\section{Cyclina intumescens Rïm.}

Tab. XVI. Fig. 1. 2. 3.

Testa orbiculata, paullulum quadrangula, crassa, inflata, striis tenuissimis radiantibus castisque vel rugis irregularibus concentricis marginem inferiorem versus validioribus remotioribus instructa, luteo albida, fasciis ferrugineis cincta, epidermide nitida pallide cornea decidua vestita; umbones tumidi prominentes incurvi, antrorsum inclinati super marginem anticum siti; lumula nimima, impressa, triangularis, subcordata; ligamentum angustum prafunde impasitum; calor internus albus medio pallide rubens; sinus pallii triangularis late apertus; dentes cardinales in utraque valva tres, posticus valvae dextrae subbifidus; margo acutus interne cremulatus. - Long. 38 mill. Long. alt. et crass. ratio mumeris 100, 90, 72 respondet. 
Patria Nova Caledonia fide ornat. Wessel Hamburgensis.

Cyclina intumesceus Röm. Malak. Bl. vol. VII. pag. 158.

Haec species quae Veneri Chinensi Chemu. cognata est, praesertim differt his notis: $1^{0}$ forma aliena, cum margo basalis posterior magis detractus sit, 20 mbonibus super marginem anticum ad perpendiculum sitis, si quidem concha apte posita, $3^{\circ}$ colore diverso.

Diese Art ist der Venns Chinensis Chemn., worauf D e s liay es seine Gattung Cyclina gegrïndet hat, zunächst verwandt; sie unterscheidet sich zumal durch etwas abweichende Form, indem der hintere Bauclurand sich stärker heruntersenkt, durch die noch melır nach vorn geneigten, in richtiger Stellung fast seukrecht über dem vorderen Schlossrande sich befindenden Wirbel sowie durch die abweichende Färbung. Uebrigens wird diese Muschel bedeutend viel grösser als sie unsere Abbildung zeigt. Ein 48 Millim. langes und fast eben so hohes Exemplar, welches wir von Herrn C. Wessel in Hamburg erhielten, soll von Neu-Caledonien stammen.
Cette espèce est très-voisine de la Venus Chinensis Chemn., sur laquelle Mr. Desh a yes a fondé son genre Cyclina; elle s' en dislingue principalement par sa forme différente, le bord ventral postérieur descendant plus fortement, par ses crnchets plus inclinés en avant, occupant leur place, en juste position, presque verticalement au dessus du hord antérieur de la charnière, ainsi que par sa coloriation différente.

Cette coquille acquient une taille beaucoup plus considérable que celle de l'exemplaire figuré. On assure, qu' un individu, que nous avous reçu de la part de Mr. Wessel à llambourg et qui a une longueur de 48 mill. et une hauteur presque égale, provieut de la Nouvelle Calédonie.

\section{Circe undata I)kr.}

Tab. XVI. Fig. 4. 5. 6.

Testa parvula, solida, complanata, subtrigona, postice trumcata, panllo inaeqnilateralis, costis crassis regularibus transversis aeque distantibns et interstitiis subtilissime striatis instructa, postice sublaevis, ad aream subnodosa, pallile rubra, macnlis obscurioribus ralliatim ordinatis picta; umbones peracnti, porrecti in $2 / 5$ longitudinis positi: margo dorsi anticus subrectus, valde declivis, posticus subcurvatus; margo ventris aequaliter rotundatus; lumla areaque lanceolatae, utrinque carinatae, haec plana, illa excisa; pagina interna livido-fusca, ad marginem obscurior; linea pallii a margine satis remota haud simusa; dens cardinalis valvae sinistrae anticus crassus, medius angustus. - Long. 14 mill. Long. alt. crass. $=100,80,40$.

Patria ignota.

Ilaec conchula Venerem scriptam Linnaei nondum adultam in mentem vocans, magnitudinem fere Circes minimae (Veneris) Mont. (= Cythereac apicalis et Cyrilli 
Pli il.) refert. Costis transversis crassis, parte postica inter costas et aream lapri, lunula plana argute terminata rugisque dichotomis ad apices deficientibus imprimis excellit.
\end{abstract}

Diese kleine Muschel, welche an junge Exemplare der weit grösseren Veuus scripta L. erinnert, hat ungefälır die Grösse der Circe minima (Vems) Mont. ( $=$ Cytherea apicalis et Cyrilli Phil.). Die verhältnissmässig sehr dicken Querrippen und die mangelnden Gabelfurchen zı beiden Seiten der spitzen Wirbel sind sehr aulfallend, sowie das glatte Feld, welches die Querrippen von der durch unregelmässige Knötchen besetzten Area trenut. Nicht minder ausgezeichnet ist die ebene bis zu den Wirbelspitzen reichende Lunula, die beiderseits durch die plötzlich abgeschnittenen Querrippchen scharf begrenzt wird. Uebrigens gehen auf unserer Zeichnung Fig. 4 die Querrippchen zu weit nach hinteı, daher das glatte Feld am Ilintertheil der Muschel nicht deutlich hervortritt.
Cette petite coquille, qui a quelque ressemblance avec des individus jeunes de la Venus scripta, qui est bien plus grande, est à peu près de la taille de Circe minima (Vemus) Mont. (三Cytherea apicalis et (yrilli Phil.) Ses côtes transversales, proportionalement trés-grosses et le defaut des sillons furqués des deux còtés des crochets aigus sont des caractieres bien saillans, ainsi que lespace lisse qui sépare les côtes transversales de l'aréa, qui est munie de petits tubercules irréguliers. Un autre caractère remarquable est fourni par la Iunule, qui est plaine et atteint le sommet des crochets; alle est distinctement bordée des deux côtés par les côtes transversales découpées subitement.

Dans notre dessiu (fig. 4) les côtes transversales sont trop prolongées en arrière et ne lont pas ressortir assez clairement l'espace lisse de la partie postérieure de la corjuille.

\title{
53. Nurcia semsilis Rüm.
}

Tab. XVI. Fig. 7. 8. 9.

Testa orato-cordata, alba, paene aequilatera, tumida, solida, antice rotundata, postice subattenuata, costis concentricis rotundatis crassis utrinque subrugosis et confluentibus instructa; margo ventris valde curvus, margo cardinalis anticus simatus; lumula orata pallide fusca, sulco angnsto argute circumscripta; area lanceolata. lincis nommullis fuscis signata; umbones tumidi, subacuti antrorsum inclinati; ligamentum angustum profunde immersum; pagina interna alba; simus pallii brevis; dentes valde comergentes, primus et secundus valvae sinistrae crassi bifidi. tertius angustus; margo interior denticulatus, sub lunula subtilissime cremulatus. - Long. 27 mill. Long. alt. crass. $=100,80,56$.

Patria ignota.

Murcia scansilis Röm. Malak. Bl. vol. VII. pag. 161. 
Diese Arl gehört in die Nähe der Verus gallina L. - Römer hebt noch besonders hervor, dass die dicken Querreifen beiderseits ihre Hölıe und Breite fast beibelalten und nirgends blättrig werden, und dass die Schlosszälıne, zumal in der linken Schale, stark divergiren, da der erste Zahn fast die Richtung des Lunularrandes, der letzte die der Nymphe besitze.
Cette espèce est voisine de la Vemus gallina L. - Mr. Römer mentionne spécialement, que les côtes transversales grosses retiennent à peu près leur Iongueur et leur largeur des deux côtés et qu'elles ne deviennent nulle part foliacées, et que les dents cardinales sont fortement divergentes, surtout dans la valve gauche, puisque la dent première suit à peu près la direction du bord lunulaire, et la dernière celle de la nymplie.

\section{Ilercenaria paucilamellata Ilkr.}

Tab. XVI. Fig. 10. 11. 12.

Testa trigono-cordata, solida, inaequilateralis, tumida, concentrice tenerrimeque striata, striis nonnullis incrementi fortioribus lamellisque paucis in antico latere instructa, antice parnm producta rotundata, postice altenuata, in margine dorsali antico sinuata, postico fornicata; colore griseo-rubente tincta radiisque tribus latis internuptis pallide fuscis ornata; umbones magni antrorsum versi; lumula oblonga striota, linea distincta circumscripta; ligamentum subimmersum angustum; latus internum lacteum opacum, sinus pallii late apertus et impressiones musculares mitidissimae; dentes cardinales erecti, medius valvae dextrae angustus bifidus, sinistrae pariter bifidus sed multo latior; margo snbtiliter cremulatus. - Long. speciminis unici 54 mill. Long. alt. et crass. ratio numeris 100, 52, 68 respondet.

Patria Nova Hollandia. Exstat in coll. clar. Lischke.

Diese schöne und interessante Art, welche uns Herr Regierungsrath Lis chke in Elberfeld zum Abbildelı gütigst milgetheilt hat, gehört in die Gruppe Mercenaria Schum., die sonst nur durch wenige unansehnliche Arten repräsentirt wird.
Celte espèce belle el curieuse, que Mr. L is chke à Elberfeld a bien voulu nous communiquner pour être figurée, appartient au groupe Mercenaria Schum., représenté d'ailleurs par un petit nombre d'espèces peu apparentes.

\section{Cytherea semiarata Dkir.}

Tab. XVII. Fig. 1. 2. 3. variegata, Fig. 4. 5. 6. unicolor.

Testa ovata plus minusve inaeqnilatera, modice convexa, crassa, concentrice striata, in antico latere sulcis fortioribus striis concentricis paene parallelis instructa, grisea, maculisque fuscis irregularibus radiatim ordinatis picta, vel unicolor pallideque fusca; lunala 
oblonga, striata, subconcava, linea impressu terminata; umbones parruli, subaculi approximati; pagina interna albido-coerulescens, vel rubens; margo integer; sinus pallii minimus. Cardinis structura eadem atque in Cytherea callipyga Bornii. - Long. maximi quod exstal speciminis 44 mill. Long. alt. crass. $=100: 76: 50$, sed ratio mensurae in aliis speciminibus variare solet.

Patria ignota.

Hacc species ad Lioconchas clar. Morchii pertinus. quoad picturam et colorem pervariabilis est, ut icones in Tabula nostra XVII. docent. C'nm Venere callipyga Bornii maxime convenit, sed ambitu et sculptura crassiore differt.

Es liegen von dieser zu Mörch's Abtheilung Lioconcha gehörenden Muschel zwei in der Zeichnung sehr auffallende Varietäten vor, wovon die eine grössere auf licht graulichem Grunde hellund dunkelbraune wellenförmige, zum 'Theil in Zickzack gebogene, meist aber ganz unregelmässige und in Strahlen geordnete Flecken besitzt, während die andere kleinere einfarbig lıellbraun ist. Sie steht der Venus callipyga Borris (Mus. pag. 66. Tab. 5. I. 1) die ebeufalls in Zeichuung und Farbe variirt, sehr nahe, unterscheidet sich jedoch namentlich durch abweichenden Umriss und die stärkeren Furchen auf der vorderen Schalenhälfte. Weit entferuter steht sie der Cyth. florida Lam. (E pulchra Gray Wood Suppl. Tab. 2. fig. 16), die nur rücksichtlich der Oberfläche ilırer Schalen an unsere Art erinnert.

Das Vaterland dieser interessanten Conchylie, die der Sammlung des Herrn Regierungsrathes Lischke in Elberfeld angehört, ist unbekanıt.
Cette coquille appartient an groupe Lioconcha de Mörch. Nous en connaissons deux variétés remarquables par la différence de leur coloriation, dont l'une, qui est plus grande, est garnie, sur un foud clair grisâtre, de taches brunes plus on moins foncées, ondulenses, fléchies çi et là en zigzag, mais en général irrégulières et disposées en rayons. L'autre, plus petite, est couverte d'un brun clair uniforme. Elle est très-voisine de la Venus callipyga Born, qui n'est pas moins variable pour son dessin el ses conleurs; mais elle s'en distingue principalement par ses contours et par les sillons plus forts de la partie antérieure. Ses rapports avec la Cyth. Alorida Lam. ( $=$ pulchra Gray, Wood sujpjl. pl. 2. f. 16) sont beaucoup plus éloignés, puisque celle-ci ne rappelle notre coquille que par la superlicie des valves.

Nous ne connaissons pas la patrie de celte coquille remarquable, qui appartient à la collection de Mr. Lis chke à Elberfeld.

\section{Heretrix attenuata Dlir.}

Tab. XVlI. Fig. 7. 8. 9.

Testa ovato-trigona, solida, parum convexa, compressiuscula, valde inacquilateralis, antice rotundata, postice attenuata, in margine cardinali utrinque declivis el subrecta, in margine ventrali aequaliter curvala, concentrice tenerrimeque striata paene malique laevigata, flacida, fasciis obscurioribus concentricis lineisque plus minusce angulatis picta, in 
inferiore parte alba, postice coerulescens; umbones acuti, porrecti, approximati; hmula lanceolata canali levi utrinque terminata in medio prominula; area lata, plana; labia prominentia; ligamentum crassum productum; latus internum lacteum, in tergo violaceum; sinus pallii permagnus; nymphae tenerrine granulatae nec denticulatae. - Long. specimimis naximi 53 mill. Long. alt., crass, ratio mumeris 100, 80, 48 respondet.

Patria ignota. Exstat in collect. clar. Lischke.

Eine sehr eigenthumliche zur Gruppe Meretrix gehörende Art, lie in die Nälse der Mer. Lamarckii Desh. (morplina Sow. non Lam. Sow. Thes. Conch. pag. 620. Tab. 129. Fig. 59) gehört. Sie zeichuet sich besonders aus durch die dreieckige Form, den ziemlich gesaden linteren Rükkenrand, den zugespitzten Hinterllueil, die stark hervorspriugenden Wirbel, von denell eine stumpfe doch deutliche Kante nach dem hinteren Ende verlauft, ferner durch lie ungemein grosse Mantelbuclıt und die feiı gekörnten nichı gezälınteı Nyınphen.

Ein etwas kleineres, sonst im Wesentlichen übereinstinmendes Exemplar ist mit hellhornfarbiger dümner glänzender Epidermis überzogen.
Espèce très singulière appartenant au groupe Meretrix, et voisine de la Mer. Lamarchii Desh. (morphina Sow. non Lam. Sow. 'Thes. Conch. p. 620. pl. 129. 1. 59). Elle se distingne surtout par sa forme triangulaire, son bord dorsal postérieur presque droit, sa partie postérieure atténuée, ses croclsets fortement saillans, desquels descend, ver's la partie postérieure, un angle bien apparent quoique émoussé, enfin par son sinus pallial extrêmement grand et ses nymphes finement granulées, mais uon pas denticulées.

Un exemplaire plus petit, mais oflrant les mêmes caractères essentiels est unni d'un épiderme mince et luisant de conlenr claire de corne.

\section{5\%. Bursa tuberculata Brod.}

Tab. XVIll. Fig. I, 2. var.

Eximiam lic depinximus rarietatem ad collectionem clar. Il. Cuming pertinentem, quae, excepta superficiei indole, pictura et colore, non solum tuberrulis multo minoribus, sed etiam spira. magis prodncta a forma vulgari differt.

Von dieser Art baben wir hier eine ansgezeichnete Varietät von Bombay abgebildet, die der Sammlung des Herrn H. Cuming in London angehört. Dieselbe unterscheidet sich von der gewöhnlichen Form zumal durch weit feinere Irnotenreilıen und ein böheres Gewinde. Inı Uebrigen ist die Beschalfenheit der Oberfliche sowie der Charakter Jer Zeichnung und Färbung der Nor-
Nous avons liguré une variété très-remarquable, provenant de Bombay et appartenant à la collection de Mr. II. Cuming. Elle diffère de la forme typiqque principalement par ses séries de tubercules beancoup plus lins et par sa spire élevée; les autres caractères ainsi que la coloration sont les mêmes. D'après des exemplaires, que nous reçumes de la prart de Mr. de Cochenhansen et de Mr. 
mallorm ganz analog. Nach Exemplalen, die wir von den Herren ron Cochenhausen und $\mathrm{Z}$ elebor erhielten, wehche sie von China mitbrachten, ist diese Arl mit eimer schwachen braunen etwas wolligen Epidermis überzogen und einem verlualtnissmássig kleinen Deckel verselsen.

Jerr 0. Märch giebt in seinem Cat. coll. Yoldi p. 1106 lolgende Synonymie dieser Alt:

Apollon Montf. (Gyrina Schum.)

olivator Meusclı. Mart. C. C. fig. 122!), 1230. Gyriueum natator (Trit.) Boli. Lisk.

Ran. tubesculata Brod. (J'roc. Zool. Soc. Lond. 1832. p. 179.;

Sie ist in den Verken ron Sowerby jun. (Coucl. III.) lieeve (Conch. icon.) und kien. (Cou. viv) gut abgebildet.
Zelebor, yui les avaient remporlé de la Chine, l'espèce est munie d’uı épiderme mince peu laineux et d'un brun chir, et d'un opercule petit en proportion de l'ouverture.

Mr. O. Märh, daus son Catal. Yold. P. 1165 dome la synonymie suivante de celle espèce, trèsbien ligurée dans les ourrages de Sow e rby jun. (Conch. Ill.), lieeve (Conclı. ic.) et líener Coq. vir.).

Apollon Montf. (Gyrina Sclum.)

olivalor Meusch Mart. C. C. IV. fig. 1229. 1230.

Gyrineum natator (Trit.) Bolt. Link.

Ran. tuberculata Brod. (Proc. zool. soc. Lond. 1832. p. 179.)

\section{5s. Bursia concinna Dhr.}

Tab. XVIII. Fig. 3. 4.

Testa ovato-conica, c colore pallide fusco vel livido subrosea tincta; anfractus $8-9$ modice concexi sutura distinctu sejuncti seriatim granosi et striati, ultimus seriebus granorum 7 cinctus, quarta series alba; varices subobliqui albi luteo maculati; canalis brevis rccurtus, apertura parva; labrum album incrassatum denticulis septenis muntum; columella subrugosa. - Alt. 22, lat. $14 \mathrm{~m} . \mathrm{m}$.

Hab. Mare erythraeum.

Haec species yarta concinna Ranellam roseam Reeve ex Philippinis insulis in mentem vocat, quae vero colore coccineo in ruborem roseum transeunte, an/ractibus superwe angulatis nec non sculptura crassiove satis superque differt.

Diese zierliche Art erinnert sehr an die $R a-$ nella rosea von den Philippinen, die jedoch, abgesehen von der etwas abweichenden Fäbung durch die gewickelten Umgänge, die melır gedrungene Gestall, stärkere Schale und gröber'e Skulptur hinreichend verschiedell ist.
Cette espece jolie rappelle la Ranella rosea des iles Philippines, qui est cependant assez dilférente par sa coloriatiou, par ses tours enroulés, sa lorme plus raccourcie, son test plus fort el sa sculpture grossière. 


\section{Bursa lamellosa Dkrr.}

Tab. XVIIl. Fig. 5. 6. magn, aucta, Fig. 7. magn. nat.

Testa parvula angusta sublanceolata, alba, nitida, anfractibus septenis modice accrescentibus transversim granoso-striatis sutura profunda divisis lamellisque erectis instructa; colu-. mella laevigata; canalis brevis recurvus; apertura parva ovalis. - Alt. 15, lat. vix $6 \mathrm{m.m}$.

Hab. Japonia.

Ilaec species parvula et singularis varicibus quinis erectis lamelliformibus cum suturis conjunctis excellit. Spira anfractu ultimo fere duplo longior est.

Diese eigenthümliche weisse glänzende kleine, sehr schmale Art zeichnet sich besonders durch ihre lamellenartigen aufgerichteten Varices aus, wovon auf jeder Windung fünf sich belinden. Zwischen denselhen bemerkt man auf der letzten Windung einige gekörnte Querrippchen. Die Spira ist fast doppelt so hoch als der letzte Umgang. Im Habilus erimnert diess Sclneckchen an Bursa (Murex) anceps Pfr.
Celte espèce singulière, petite et très-étroite, de couleur blanche el luisante, se distingue surtout par ses varices érigées en lamelles, dont il y a cintf sur chaque lour. Entre elles on remarque, sur le deruier tour plusieurs côtes transversales fines el granulées. La spire a la hauteur presque double du dernier tour. Lhabitus de cette coquille rappelle la forme de Bursa (Jurex) anceps Pfr.

\section{Bursa tumida Dkir.}

Tab. XVIII. Fig. 8. 9.

Testa orata subconica, tmmida, vix depressa; anfractus 7 valde comexi, ultimus costulis lineisque elevatis densissimis aculis sub vitro undulatis undique cinctus, fasciis angustis castaneis aequidistantibus lineisque flavidis elegantissime pictus; fasciae anfracturm superiorum undulato-nodiferae; varices superiores appressi haud regulares, penultimus panllo listans; apertura ovata; columella medio laerigata, superne tuberculo crasso plicato. inferne rugis nonnullis signata; labrum paullo incrassatum, intus plicato-dentatum; fances laevissimae lacteae. - Long. 93, lat. $56 \mathrm{m.m}$.

Hab. Nova Seelandia.

Ilaec species insignis Bursae Z Clebori Dkr. (Novara) respectu labito sculpturae tam affinis est, ut pro varietate tantum haberi possit. Cum vero specimen quod exstat unicum collectionis Cumingianae testa temiore leviore ralde inflata nec non spira multo breviore minum in modum differat, adluc secernendum esse putavimus. 
Diese ansgezeichnete Alt steht der B. Zelebori Dhr. sehr nahe und ist vielleicht nur eine Varietät derselben. Da sich jedoch das vorliegende Exemplar von Neusecland durch dünnere Schale, sehr aufgetriebene Windungen und küzere Spira von der $B$. Zelebori anffallend unterscheidet, so glanbten wir sie unter obigem Namen so lange trennen zu müssen, bis Uebergangsformen gefunden sein werden.

(Diese, wie Bursa Zclcbori, vexillum und Argus bilden eine selu natiorliche Grupus: der Gattung Bursa Bolt.)
Celle espèce singulière est très-voisine de la Bursa Zelebori Dhr. et n'en constitue peut-être qu'une variélé. Mais comme notre exemplaire de la Nouvelle Seelande differe essentiellement de la B. Zelebori par son test plus mince, par ses tours fortement renflés et par sa spire plus courte, nous croyons pouroir la séparer sous le nom de lamida, jusqu’à ce que peut-ître des folmes intermédiaires se seraient ollertes.

Celte espèce, jointe anx B. Zelcbori, vexillum et Argus, forme avec elles un grompe tres-naturel du genre Bursa Bolt.

\section{6). Bursil linconcostata Ilip.}

Taf. XIX. Fig. 1. 2.

Tesla parra, ovala, sublepressa, Ravila, Iransversim denseque striala, coslis longitudinalibus luberosis fuscis ormala; anfrarlus 8 comexi; varices vix obliqui; anfractus ultimus spira pacne duplo major; canalis angustus fere rectus; columella plicala; labrum incrassatum, intus sulcalum; fances albae. Long. 22, lat. $14 \mathrm{~m} . \mathrm{m}$. - Ilabilat ad Californiam.

Bursa fusco-costata Dlir. in Proc. Zool. Soc. of Lond. Nov. 1962. 1. 239.

Species elegans Bursae bilmberculari Lam. hand dissimilis, habilu minore, costis luberosis longitudinalibus fuscis, varicibus vix obliquis aliisque nolis bcue differt.

Diese zierliche Art hat einige Aehnlichkeit mit Bursa bitubercularis Lam.. doch ist sie viel kleiner und zumal durch die knotigen gleichnässig rohbraun gelärbten Längsrippen, die auf dem Riicken der letzten Windung besonders stark hervortreten, hinreichend verschieden. Die Oberfläche erscheint dırch feine Längs- und Qnerfurchen gegittert.
Cette espèce jolie a quelque ressemblance avec la Bursa bilubercularis Lam., cependant elle est beaucoup moins grande et se distingue suffisamment par ses còtes longitudinales noduleuses uniformément rousses, чui paraissent plus fortement saillantes sur le dos du dernier tour. La surface est comme treillissée par des sillons lins, longitudinaux et transversaux.

\section{(i2. Bursa asperrima ldil'.}

\section{Taf, XIX, Fig. 3. 4.}

Testa ocata, crassa, vix deprcssa, alba, maculis punctisque fuscis conspersa, anfractibus septenis comexis angulalis granosis et nodiferis instrncta; anfractus nltimus spira vix duplo 
major, costis transversis majoribus nadiferis et rugoso-granosis nee non pluribus minoribus quasi margaritiferis cinctus; varices recti crassi distantes; columella fortiter rugasoplicata, valde simata; canalis curvus, paullo adscendens; labrum expansum dentatum et plicatum; apertura parva subrotunda, superne canali brevi profundo terminata. -- Long. 40, lat. $30 \mathrm{~m} . \mathrm{m}$. -- Ilab. Clima.

Bursa asperrima Dlir. in Proc. Zool. Soc. of Lond. Nov. 1862, p. 238.

Haec species ad gems "Lampas" Schum. pertinens et magnitudine ad Bursam cruentatam Sow. prope accedens, superficie sua rugosissima excellit. Anfractus ultimus costis duabus crassis nodosis ac rugiferis, inferiore paullo angustiore, instructus est; costae quae seqummer minores, cx parte moniliformes.

Diese Art, welche zur Gattung Lampas Schmm. gehört und in der Grösse ziemlich mit B. cruentata Sow. übereinstimmt, zeichnet sich hesonders durch ihre selır knotige und rnnzelige Oberflache ans. Auf der letzlen Windung befindet sich zu oberst eine starke knotige und runzelige Querrippe, darunter eine etwas schwächere, auf welche mehre feine, fast perlenschnurartige Rippchen folgen, wovon eine an dem Varix besonders stark hervoltritt, und an der Stelle endet, wo der innen stark gezälınte, aussen faltige Mundsaum am meisten ansgedehnt ist. Auf der Columella befinden sich starke Runzeln. Die Mündung ist klein und länglich rund; der dünne Deckel hat eine blass kastanienbraune Färbung.
Cette espece, qui appartient au genre Lampas de Schumacher et qui prosséde à peu près la taille de la $B$. cruentata Sow., se distingue surtont par sa surface très rugıeuse et noduleuse. En haut du dernier tour l'on remarque nne côte transversale forte, rugueuse et tubercnlense, puis une seconde plus faible, et alors plusieurs très-lines, ressemblant à des cordons de perles, dont lune est plus fortement saillante du cóté de la variee et se termine à l'endroit, où le péristome, fortement denté en-dedans et plissé à l'extérieur, atteint sa plus grande extension. La columelle est garnie de rides fortes. Louverture est pelite el de forme oblongue arrondie. L'opercule est mince ef de couleur claise de marron.

\section{Bursit Grayana Mhir.}

Taf XIX. Fig. 5. 6.

Testa ovata, solida, alba vel gilca. maculis fuscis irregularibus parvis variegata, anfractibus senis concexis angulatis, prope suturam corrugatis, mndique granosis, rugiferis transversimque costatis instructa; anfractus ultimns interdum gibbosus, $2 / 5$ totins longitndinis adaequans, costis majoribus tribns nodiferis snbcompressis et nommllis mimoribus cinctus; variccs crassi, vix obliqui; columella valde simuata rugoso-plicata; canalis brevis curvus; labrum incrassatum, dentatum; apertura oxata, superne canali profundo quasi fistulato terminata. - Long. 29, lat. $22 \mathrm{~mm}$. - Hab. Mare Erythraeum.

Bursa Grayana Dkr. in Proc. Zool. Soc. of Lond. Nov. 1862. p 238. 
IIaec cochleola undique rugosa, granosa et tuberosa, plerumeque costis tribus crassioribus cincta, ad eas Bursarum species pertinet, quae in superiore peristomatis parte canali fistuluto gandent, qui et in anfractibus superioribus observatur.

Diese kleine, überal! runzelige, mit stäkeren und leineren knotigen Querrippen bedeckte Scluecke gehört zn denjenigen Bursaarten, die oben an ter Mündung einen rölırenarligen Cana! besitzen, Jer auch an den varices der ibrigen Windungen, welche die verschiedenen Wachsthumsstadien andeuten, noch beobachtel wird. Besonters charakterislisch ist ein zwischen der unteren Rippe und dem stark gebogenen Canal befindlicher warzenoder knotenartiger, einem eingeklemmten Steinchen ähnlicher Auswuchs. Rücksichılich der Beschalienheit der Oberflache variirt ubrigens unsere Schnecke zienılich. Ein Exemplar unserer Sammlung zeigt nur schwache Rippen, dagegen ziemlich flache Erloöhungen in der Mitte der Windungen.

In der Form erinnert unsere Art an B. cruentata Sor., Iuberusissima Reere etc.
Celle petite coquille, dont toute la surface est rugueuse et couverte de côtes transversales tuberculeuses plus ou moins fortes, appartient à un groupe du genre Bursi, dont les espèces sont pourvues, en haut de l'ouverture, d'un canal tubuleux, que l'on remarque anssi à l'endroit des varices des autres tonrs, démontrant les diverses éporjues daccroissement. Eutre la côte iuférienre et le canal, yui est fortement courbé, il se trouve une protnbérance en forme de verrue ou de tubercule. La condition de la surface est assez variable: un exemplaire de notre collection ne posséde que de laibles cûtes et des saillies assez plates au milieu des tours. Quant à la forme générale notre espèce ressemble à la $B$. cruentata Som., tuberossissima Reeve etc.

\section{Litrsil Cumingiallat Dhir.}

Taf. XIX. Fig. 7. 8.

Testa ovata, subdepressa, solidiuscula, pallide fusca, albida lividoque vuriegatu, apicem rersus rubida, anfractibus septenis convexis instructa; anfractus ultimus spira duplo fere longior, nodorum grandium seriebus duabus nee non granorum minorme seriebus senis cinctus; nodi majores verrutosi, minores irregulares; vurices crassi, undique graniferi; columella ragoso-plicata alba; apertura orata, superne simata et canaliculata; labrum album incrassatum, dentatum; canulis brecis, profundus, subobliqus. - Long. 47, lat. 32 mm. Hab. Nove Caledonia.

Bursa Cumingiana Dlir. in Proc. Zool. Soc. of Lond. Nov. 1862. p. 238.

Species nostra Bursae affini Brod. similis nodorum grandium nernesorum seriebus duabus cingulisque senis granorum minorum insignis est. Varices crussi ut solent laterales.

Wir finden diese interessante Arl, welche einige Analogie mit Bursu affinis Brod. zeigt, nirgends
Cette espèce, que nous ne trouvons décrite ni figurée nulle part, a quelque analogie avec la $B$. 
beschrieben oder abgebildet. Besonders cluarakteristisch sind zwei Reihen theils runder, theils länglicher mit feinen Wärzchen bedeckter Knoten. die auf dem Rücken der letzten Windung sehr stark liervortreten. Ausserdem ist die Schnecke noch mit 6 Reilsen feinerer Knötchen von ungleicher Grösse umgeben, wovon zwei schwache fast rerwischte oben, eine ebenfalls schwache zwischen den grossen linoten und drei unler denselben sich belinden. Diese letzteren treten stärker hervor als die oberen. besonders die mittlere, deren línotchen durch ungleiche Grösse und durch Unregelmässigkeit sich auszeichnen. Die Varices sind stark und bilden beiderseits ziemlich regehmässige Reihen Der Canal ist kurz und tief, aussen gänzlich granulirt, der rechte Mundsaum verdicht und oben mit einer starken Bucht versehen. affinis Brod. Un de ses caractères principaux consiste en deux séries de tubercules arrondis on oblongues couverts de fines granulations et forteinent saillants sur le dos du dernier tour. D'ailleurs la coquille est entourée de six séries de tubercules plus lins de grandeur inégale. Deux de ces séries, qui sont placées en haut, sont presque imperceptibles, la troisième, également très-faible, se trouve entre les grands tubercules, et les trois autres au-dessous des mèmes. Ces dernieres sont plus fortement saillantes que les supérieures, principalement celle du milieu, dont les petits tubercules sont très-irréguliers et de taille inégale. Les varices sont fortes et forment, des deux côtés, des séries assez régulières. Le canal est court el profond, également granulé en dehors, le bord droit du péristome est épaissi et fortement sinueux ell lıut.

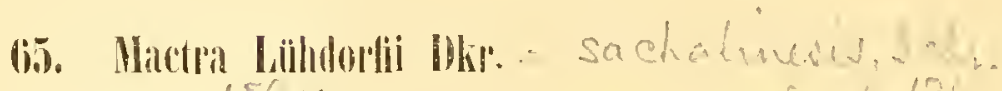

Taf. XX. Fig. a, valva sinistra, b. latus internum valvae dexirae, c. tergum.

Testa turgida ovato-trigona, inaequilatera, crassa, postice paullulum hians, sordide alba, striis obsoletis sulcisque incrementi concentricis fortioribus instructa, carina oblusissima ab umbonibus prominentibus magnis tumidis incurris ad latus posticun decurrente signata, epidermide cornea vel olicacea rugosa et lamellosa vestita; latus conchae anticum paullo attenuatum productum, subtruncatum; extremitas postica dilatula et rotundata; margo ventris fortiter curvatus; sinus pallii magnus, rotundatus profundus; impresszones musculares magnae subovalae; dentes laterales crassi, forea ligamenti magna obliqua. - Long. speciminis quod exstat majoris 95 mill. est. Long., alt. et crass. muneris 100, 85 et 62 respondent.

IIabitat in freto Sangar ad insulame Jesso Japoniae. Exstat in collectiune Molluseormm clar. Lischlie

Haec cancha forma peculiari et imsitata insignis, colore opaco langnido Muliniis antarcticis similis est, sed cardinis stmctura Mactris veris respondet. Valvae ejus magnae crassae, tumidac, epidermide olivacea ex parte rugifera obductae, latere postico panllo hiant.

Diese grosse Mactra, von welcher zwei vollständige Exemplare vorliegen, ist ron allen bis
Cette grande espèce de Mactra, dont nous avons devant nous deux exemplaires complets, se distingue 
jetzt bekannt gewordenen Arten verschieden. Sie hat rüeksichtlich ilırer matten unansehnlichen Färbung mit den antaretisehen Mulinien viele Aehnlichkeit, doch entspricht ihre Schlossbildung ganz derjenigen der gewölulichen Mactraarteu. Sie ist dickschalig und aulgeblaht, mit concentrischen feinen Reilchen und tieferen Furchen versehen und mit einer ziemlich dünnen, doch runzeligen und am unteren Rande blatterigen olivenfarbigen, bei jüngeren Exemplaren melır gelblichen Epidernis uberzogen. Die etwas eingerollten Wirbel sind stark anfgetrieben, überragen weit den gewölbten Schlossrand und stossen nicht aneinander. Der Vordertheil ist etwas verschmälert und gerundet, bei dem grösseren Exemplare ein wenig abgestutzl; der breite und zugleich gerundete Hintertheil schliesst sich dem ebenfalls gerundeten linteren Bauchrande ziemlieh gleichmässig an. Von den Wirbeln lauft beiderseits nach hinten eine slumpfe fast verwisclite Kante herab, auch an dem Vordertheile der Wirbel bemerkt man beiderseits eine sehr schwache nur durch eine lıelle Linie angedeutete Carina. An dem grösseren Exemplare endigt dieselbe in einer sehr seichten Rinne.

Es gewährt uns Vergnugen diese ausgezeichnete Art nach Herrn Consul Lülıdorf in Nikolájew zu benennen, welcher dieselbe aus Japan gebracht hat. de toutes les espèces connues jusq̨u’à prẻsent. Sa coloriation mate et peu apparente lui donne beaucoup de ressemblance aux Mulinies antarctiqnes, mais la formation de sa charnière est tout-à-fait la mème, que celles des Ilactres typiques. Elle est épaisse et renflée, marquée de stries fines concentriques et de sillons plus profonds, et couverte d'un épiderme assez mince, inais rugueux et foliacé au bord inférieur, de couleur olivacée, qui est plutôt jaunâtre daus les exemplaires plus jeunes. Les crochets légèrement enroulés sont fortement renflés, dépassent beaucoup le bord cardinal convexe, et ne se toncheut pas. La partie antérieure est légèrement atténuée et arrondie, légèrement tronquée chez le plus grand exemplaire. La partie postérieure large et arrondie se joint régulièrement au hord ventral postérieur, qui est de mème arrondi. De chaque côté il y a nu angle obtus peu marqué, descendant des crochets en arrière; une autre carène très-faible, marquée seulement par une ligne claire, se trouve ì la partie antérieure des crochets, et se termine, dans l'exemplaire majeur, en une rigole peu profonde.

Nous avons le plaisir de dédier cette espèce distinguée à Mr. le consul Lui hdorf à Nikolajew, qui l’a rapporté du Japon.

\section{6ij. Pecten Yessuensis Jay.}

Taf. XXI. valva superior vel sinistra.

Testa maxima solida orbicularis inaequivalvis, costis radiantibus 22 rrassis rotundatis striisque incrementi concentricis marginem inferiorem versus subimbricatis instructa; interstitia valcae superioris parnm concexae, costis latiora, apicem tersns gramulis seriatim ordinatis signata; costae valvae dextrae conrexioris latiores, fere ommes aequidistantes; auriculae magnae, in valra sinistra paene aequales, in dextra inaequales, auricula antica subtus emarginata; color utrinsque valvae cxternus dispar, sinistrae, (adspice iconem nostram) viride purpurens alboque variegatus. dextrae albus et pallide rubellns; valcarum 
pagina interna prorsus alba; focea ligamenti pro magnitudine et vastitate valvarum parva; impresitio muscularis magna subelliptica. - Alt. testae $150 \mathrm{~mm}$.

Pecten Ircssoensis Jay Report on the shells collected by the Japan Expedition under the command of Commodore 1\%. C. Perry, U. S. N. pag. 293. Taf. III. Fig. 3. 4. Taf. IV. Fig 1. 2.

Ilabitat laec species permagna prope IIakodade vel ut alii dicunt, Hakodadi in insula Japonica Yesso ad fretum Sangar, unde eam misit omat. Lüldorf. Exstat in collectione clar. Liscllie.

Von dieser grossen interessanten Art liegen zwei nicht zusammengehörige, leider etwas beschädigte Sclıalen vor, die uns Herr Geheime-Regierungsratlı Lischke in Elberl'eld zum Abbilden guitigst mitgelheill hat. Die obere flachere von einem etwas kleineren Exemplare herrührende Schale zeichnet sich durch ihre zum Theil sehr lehhafte, fast purpurrothe, hin und wieder, namentlich auf einigen Rippen ins IVeisse übergehende Färbung, besonders aber durch ilıre eigeutbümliche fein granulirte Oberfläche zwischen den Rippen aus, die nach dem unteren Schalenrande bin allmählig verschwindet. Die Rijpen sind meist gleich weit von einander entlernt, auch im Allgemeinen von ziemlich gleicher Stärke. Die fast gleichen Obren sind mit einigen stärkeren und schwächeren ausstrahlenden Rippchen verseben, zwischen denen man unter der Loupe hin und wieder ebenfalls eine Andeutung feines liörnchen bemerlit. In Inneru ist dic Schale ganz weiss und zeigt sehr deutlich, zumal uber dem grossen fast elliptischen, ziemlich glatten Muskelfleck eine krystallinische, wie auch krcideartige Beschaflenheit, wie solche überhaupt oft an den Ostraceen angetroffen wird. Die rechte ungleich gewölbtere Schale besitzt elwas breitere Ripuen und folglich anch schmalere Zivischenräume, die jene feinen Körnchen nicht erkennen lassell. Auf weissem Grunde zeigt sich eine blass röthlich braune concentrische Zeicbnung, die auf den Rippen etwas dentlicher
Nous avons sous nos yeux deux valves solitaires de cette espèce grande et intéressante, que Mr. Lischke à Elberfeld nous a communitjuées pour les faire figurer, quoiqu'elles soient un peu endommagées. La valve sıpérieure, appartenant à un exemplaire de taille moindre, est remarquable par sa coloriation partiellement très-vive, presque pourprée, passant au blanc çà et là, principalement sur plusienrs côtes, mais surtout par la sculpture de sa surface, qui présente une granulation fine dans les interstices des côtes, s'ellaçant peu à peu vers le bord inférieur. Les côtes sont, pour la plupart, placées en distances égales, el, en général, également fortes, les oreillettes à peu près égales sont munies de plusieurs côtes rayonnantes, plus et moins fortes, entre lesquelles l'on remarque, à l'aide de la loupe, des vestiges de granulation. A l’intérieur la valve est parfaitement blanche, et montre très-distinctement (surtout au dessus de la tache musculaire, qui est grande, presque elliptique et assez lisse) une structure crystalline et crétacéc, que l'on remarque sumvent chez les Ostracées. - La valve droite, qui est beaucoup plus voutée, posséde des côtes un peu plus larges et en conséquence des interstices plus étroits, qui ne laissent pas apercevoir la granulation de l'autre. Sur un fond blanc l'on voit un dessin concentrique de coultur pale rougentre passant au brun, un peu plus marqué sur les còtes. 


\section{- $63-$}

hervoltritt. Die grössere Schale misst etwa 150 mill. Höhe nud bieite sind fast gleich.

Im Ilabitus älınelt unsere Art dem fossilen Pecten solarium Lam. aus dem Tertiargebirge, sowie dic Könchen zwischen den Rippen der oberen Schale an den Pecten bifrons Lam. erinnern. Der sehr grosse ebenfalls von Japan stammende Pccten nobilis Reeve ist gleiclsschalig und hat sehr ungleiche Ohren.

Wir haben diese grosse Kammmuschel hier a])gebildet und ausfulurticlıer beschrieben, weil sowohl die citirten Abbildungen bei Jay als auch desseı Beschreibung kein recht dentliches Bild von dieser Arl geben, mamentlich weder die feine Granulation zwischen den Ripjen der oberen Schale, noch auch die Färbung erwähnt ist. Wahrscheinlich sind, wie das so oft rorkommt, beide Schalen stets ungleich gefärbt. Obgleich diese Art nach Ja y's Bemerkung an der genannten Localität sehr lıäufig vorkommt, so scheint er doeh bis jetzt ausser den vorliegenden beiden Schalen noch nicht nach Europa gekommen zu sein.
La valve majeure a une hauteur el largeur à peu près égales d'environ 150 millim.

Par son habitus notre espèce ressemble au Pecten solarium Lam., fossile de la Jormation tertiaire, et les gramulations entre les cotes de la valve superieure rappellent le $P$. bifrons Lam. Le $P$. nobilis Reeve, espèce très-grande et proveluant également du Japon, est équivalve à oreillettes très-inégales.

Nous avons donné la figure et déscription détaillée de ce grand Peigne, parceque les ligures citées de Jay ne donnent pas me idée claire de lespèce, el parcequ'il n’est lait mention ni des gramulations fines de la valve supérieure, ni de la coloriation. Probablement les denx valves sont loujours de couleurs différentes, comme il y a beancoup d'autres exemples. Quoique notre espece est, d'apres une observation de $\mathbf{J}$ a $\mathbf{y}$, assez abondante à la localité citée, il paraìt qu’à l’exception de nos denx valves elle n'est pas encore parvenue en Europe.

\section{(bi. Voluta Kiulpii IDkr.}

Taf. XXIl. Fig. 1. 2.

Testa avato-oblonga, antice attenuata, crassiuscula, laevis, gilea, subalbicans, maculis fermgineis irregularibus ex parte subtesselatis variegata; spira breviuscula conica, ad apicem obtusa, submamillaris; anfractus sex parum convexi, infra suturam subcarati et irregulariter plicati. ultimus maximus, subangulatus; apertura magna; labrum paullo incrassatum postice subalatum; columella perparme simuata, plicis quaternis crassis instructa. - Long. testae $56 \mathrm{~mm}$., ejus latit. $25 \mathrm{~mm}$. Long. aperturae $45 \mathrm{~mm}$. - Habitat ad novam Seelandiam?

Voluta Ka upii Dhr. in Malak. Bl. vol. X. pag. 145.

IJaec cachlea ad minores Volutas pertiners, a reliquis speciebus facile distinguenda est testa laevi, ovata-oblonga, spira breviuscula conica in anfractibus embryonalibus obtusa submamillari, columella partm curvata quadriplicata nec non apertura longa et angusta. Labrum vix incrassatum subalatum. Aufractus infra suturam parum concavi irregulariter 
plicati. In fundo pallide rubido subalbicante maculis ferrugineis irregularibus ex parte subquadratis marmorata est.

Hanc speciem in honorem amici J. J. Kaup palaeologi perillustris denominavimus.

Diese Schnecke gehört zu den kleineren Arten ihrer Gattnng, und ist durch ihren ganzen Habitus von allen bekannt gewordenen Voluten leicht zu unterscheiden. Das glatte Gehäuse hat eine lang eiförmige Gestalt, eine knrze konische am Enbryonaltheil warzenförmig abgerundete Spira, eine nur sehr wenig gebuchtete Columella, auf welcher sich vier starke Falten von ziemlich gleicher Grösse befinden, und eine lange schmale Mündung, die etwa Dreiviertheil der ganzen Schalenlänge einnimmt. Der rechte Mundsaum ist inuen nur wenig verdickt, oben, d. h. hinten, elwas flügelartig ausgedehnt, wie dies in noch lö̈herem Grade an manchen Exemplaren der Voluta scaplia bemerkt wird. Unter der Naht sind die Umgänge mit Ausnahme des warzenförmigen Embryonalgewindes mit unregelmässigen Fältchen besetzt und schwach ansgekehlt. Die letzte Windıng erscheint stumpfwinkelig. Auf blass gelblichrothem ins Weissliche übergehendem Grunde ist diese Voluta mit grossen unregelmässigen rustfarbigen Flecken gezeichnet, die ihr zum Theil ein marmorirtes Ansehen geben.
Cette coquille de taille moyenne se distingue aisément de toules les Volutes connues par son habitus total. Le tesi lisse a me forme ovoïde allongée, la spire courle el conique, arrondie en papille à sa partie embryonale, la columelle trèsfaiblement sinneuse, portant 4 gros plis à peu près également grands, et la bouche longue et étroite, occupant environ les trois quarts de la longneur totale. Le bord droit de la bouche n'est que légèrement épaissi en-dedans; en haut, c'est à dire en arrière, il est légèrement élargi en aile, comme l'on remarque, en degré plus haut, chez quelques exemplaires de la Voluta scapha. Tous les tours, excepté la partie embryonale, sont, audessus de la suture, légèrement cannelés el garnis de petits plis irréguliers. Le dernier tour est obtusément auguleux. Notre Volnte est marquée, sur un fond pâle janne-rougeâtre passant au blanc, de taches grandes el irrégulières coulenr de rouille, qui lui donnent, en plusieurs endroits, ın aspect marbré.

\title{
(is. Hurex longicornis Mlir.
}

\author{
Taf. XXII. Fig, 5. 6.
}

Testa ovato-fusiformis, flava alboque variegata, anfractibus 8-9 convexis, transtersim granoso liratis et striatis, trifariam varicosis, perlonge cormutis instructa; apertura ovato-rolunda, columella alba simata, superne tuberculo crasso munita; canalis longus, curvus, subobtectus; labrum crenatum; fauces albae. - Longit. testae 70 mill., longit. a tuberculo inde usque ad finem canalis 48 mill., latit. anfr. ultimi 28 mill. Anfractus ultimus a tergo visus, $7 / 10$ totins longitudinis aequat. - Habitat ad Amboinas insulas. Exstat in musco IIasso-Darmstadiensi.

Cochlea certe rarissima, nullo loco descripla, habitu fere Muricis cervicornis Lam., formam valde 
singularem prae se fert cornibus duobus canaliculatis longissimis in quavis anfractus ultimi varice; cormu primum erectum paululum longius est altero. Praeterea laminae nonnullae deflexae aculeiformes interpositae sunt.

Testa undique costulis crassioribus et angustiaribus plus mimusve granosis cincta est, ita ut crassiores in aculeos vel cornua transeant. Color flavus, passim albidus, in spira costisque paullo vividior.

Das Gehäıse dieser eigenthumlichen Sclinecke hat 8-9 convexe durch eine tiefe Naht getrennte, fast treppenförmig abgesetzte Umgänge, die 3 starke varices tragen, auf deren jedem ? lange Hörner stehın; zwischen diesen befinden sich noch einige kleinere etwas niedergebogene Stacheln. Das vordere stärkere der beiden Hörner, welehes auf dem vorletzten varix fast senkrecht steht, misst 35 mill.; doch sind alle Hörner ein wenig verletzt, so dass man eine etwas beträchtlichere Länge derselben annehmen darf als sie unsere Zeichnung angiebr. Auf dem ganzen Gehüuse betinden sich feinere und gröbere gekörnte Rippchen, welch letztere in die Stacheln verlaufen und an der Spira in stärkeren linotenrehen herrortreten. Die Farbe der Schnecke ist bräunlich gelb, an der Spira und auf den stärkeren Rippchen etwas dunkeler.

Le test de cette espèce singulière posséde $8-9$ tours convexes, séparés par une suture profonde et détachés l'un de l'autre en forme d'escalier. Chaque tour est muni de trois varices fortes, portant deux cornes allongées, entre lesquelles se trouvent plusieurs épines, légèrement décourbées et de taille moindre. La corne antérieure et plus forte, qui est placée à peu près verticalement sur la varice avant-dernière, a une longueur de 35 mill.; cependant toutes les cornes ne sont pas parlaitement conservées, de sorte qu’il faut présumer une longueur un peu plus considérable que dans notre figure. La surface entière est couverte de petites côtes granuleuses, plus ou moins saillantes. Ces petites côtes forment les epines et, dans la spire, des séries de noeuds sailiantes. La couleur du test est d'un jaune brunâtre, un peu plus foncé à la spire et sur les côtes majeures.

\section{Mn!ex trigonulus Ialll. var?}

Taf. XXII. Fig. 3. 4 .

Muricem eximium hic depinximus ad Pteronotos Swainsoni pertinentem, quem pra varietate lluricis trigonuli habemus. Icon apud hienerum, (Coquilles vivantes Tab. 40 Fig. 3) qui hanc speciem et Muricem triquetrum Burnii confudit, nec non Fig. 1. tabulue 417 in Eneyclop. méthodique specimina minora repraesentant detrita et appendice pimata in varicibus prorsus carentia. Icones nro. 102 in Sowerbyi Conch. Ill. a nostro specimine praesertim differunt testa angustiore spiraque magis producta; ratio inter spiram et anfractum ultimum numeris 38 et 62 respondet, in nostro vero specimine est 30 ad 70 . Cochlea denique in Reevei Concl. iconica Tab. XII. Fig. $\mathbf{S 7}$ depicta pariter formam paullo diversam ostendit; est enim minor, canalis pro statura ejus longior magisque curvus, praterea peristoma paullulum differt. Cum vero varicum et sculpturae natura et color testae satis conveniant, nostrum specimen pro varietate Muricis trigonuli habendum essc putames, nisi 
forte Murex Barclayi Reevei (Proc. Zool. Soc. of Lond. 1857. pag. 209) huc pertinet, qui vero nnu depictus est, quamobrem de eo certe dijudicare non possumus.

Wir haben hier einen ausgezeichnet schönen ebenfalls im Darmstädter zoologischen Museum befindlichen Murex abgebildet, den wir für eine Varietät ron Lamarck's $M$. trigonulus halten. Die Abbildung bei Kiener, (Iconogr. des Coq. viv. Taf. 40. Fig. 3), welcher diese Art mit Mur. triqueter $\vee$. B orn verwechselt, sowie diejenige in der Enc. méth. Taf. 417. Fig. 1 sind offenbar uach kleinen beschädiglen und abgeriebenen Exemplaren angeferligt, an welchen zumal die Lamina über den fast geschlossenen Canal ausgebrochen, auch der blätterige flossenartige Anlang am unteren Theile der Varices sehr beschäligt ist, und heinahe gänzlich fehlt. Die beiden unter Nr. $102 \mathrm{ge-}$ gelenen Figuren in Sowerby's Conch. Ill. sind von unserem Exemplare hauptsachlich dadurch verschieden, dass ilır Gehäuse schunaler und die Spira mehr vorgezogen ist, denn diesellse verhält sich zum letzleı Umgang wie 38 zu 62 , während das Verluältniss bej vorliegendem Exemplare elwa den Zahlen 30 zu 70 entspricht Die Schnecke endlich, woron sich in Reere's Conch. icon. Taf. XXII. Fig. 87 eine Abbildung lindet, zeigt wieder einen anderen Habitus; sie ist kleiner, ihre Mündung hat einen etwas abweicluenden Umriss und der Canal ist verhältnissmässig länger und auch mehr gekrümmit. Die Beschallenheit der Varices, die Oberfäche und Färbung stimmen indess ziem]ich überein, so dass wir nach dem uns vorliegenden Material zu urtheilen, die gegenwärtige Sclınecke fïr eine Varietăt des Murex trigonulus Lam. halten mïssen. Von Murex Barclayi Reeve (Proc. Zuol. Soc. of Lond. 185\%. pag. 209) ist leider keine Abbildung vorhanden, und dalıer niclıt mil Sicherheit darüber zu urtheilen. Jedenfalls steht derselbe der gegenwärtigen Form sehr nahe, wenı er nicht damit identisch ist.
Nous avons figuré un Murex de beauté extraordinaire, appartenant au Musée zoologique de Darmstadt, que nous considérons comme variété du 11. trigomulus Lam. La figure de Kiener (Icon. d. coq. viv. pl. 40. f. 3) qui confond celle espèce avec M. triqueter Born, ainsi que celle dans l'Encyclopédie métlı. pl. 417. f. 1 sont faites évidemment d'après des exemplaires petits el endommagés, chez lesquels la lame au-dessus du canal presque fermé est cassée et l'appendice foliacée (semblable à une nageoire) de la partie inférien'e des varices est usée ou manque presqu'entièrement. Les deux ligures de Sowerby (Conch. IIl. Nr. 102) diffèrent principalement de notre coquille en se qu'elles présentent le test plus étroit et la spire plus allongée; la proportion entre la spire et le dernier tour est $=38: 62$ : tandis que dans notre exemplaire elle serait plutôt $=30$ : 70 . Enfin la coquille figurée par Reeve (Conch. icon. pl. 222. lig. 87) montre encore un labitus différent: elle est plus pttite, sa bouche a un contour différent, et le canal est plus long en proportion et plus fortement courbé. Cependaul les caractères des varices, la surface et la couleur sont à peu près les mèmes, de sorte que, à en juger daprès les ouvrages comparés, nous somınes forcés, de considérer notre coquille comme variété du Hurex trigonulus Lam. Malheureusement il n'existe aucune ligure du M. Barclayi Reeve (Proc. Zool. Soc, Loud. 1857. p. 209), et l'on ne peut en juger avec certitude. En tout cas celle espèce est très-voisine de la forme figurée sur notre planche, si elle n'est pas absolument identique avec elle. 


\section{io. Paten multisquamatus Ilkr.}

Tab. XXII. Fig. 1 latus externum, Fig. 2 iat. internum, Fig. 3 particula magn, aucta.

Testa ovata, temis, paullo pellucida, valde compressa, obliqua, inaequivalvis striis rostulistue ab apice radiuntibus numerosissimis eleganter confertimque imbricatis instructa, narie picta, pallide fulva, fusco purpureoque variegata, ad apicem citrina, valva dextra interdum tota citrina; ralva sinistra dextra paullulum converior; auriculae valde inatquales striatae, anricula valvae dextrae major pro bysso emiltenda late sinnaia; simus inferne denticulutus; latus conchae internum sulcis pluribus costulis externis respondentibus insigne, ceterum lavigatum, nitidum, pallide purpureum, albo luteoque rariegatum; margo temiter sulcatus; fovea ligamenti parva. - Alt. testae 6i, latit. 58, crass. 11 mill.

Pecten mulisquamatus Dhr. in .Halak. Bl. XI. pag. 100.

Ilabital in simn ad Habanam.

Haec species pulcherrima ab amico J. Gundlach Dre. delectu, Lum habilu, quam striis numerosissimis squamulisque erectis totam testam occupantibus insiymis esi.

Dr. J. Gundlach, dessen Forschungen die zoologische Kenntniss der Insel Cuba ungemeiu bereichert haben, entdeckte diesen schönen Pecten im Hafen von Habana. Es erimnert derselbe an einige fossile Arten. Unter den Arten der heutigen Schöpfung kenneı wir keine, womit er verwechselt werden könnte.
Munsieur le docteur Gundlach, qui par ses voyages scientiliques a déjà enrichi éminemment uotre connaissance zoologique de l'île de Cuba, a trouvé ce beau Peigne daus le port de la Havane. Il est voisin de quelques espèces fossiles, mais parmi les vivantes nous ue connaissons aucune, avec laquelle il pourrait être confondu.

\section{i. Pecten sulcicostatus G. B. Sow.}

Tab. XXIII. Fig. 4 valva superior. Fig. 5 el 6 varr. valva inferioris.

Quamvis clar. Sowerby in Thesauri Conchylormm volmmine 1. pay. 7 hanc speciem jam descripserit et in Tab. XIII. Fig. 35 et 36 detineaverit, tres huius conchae valoas in Tabula nostra iterum depingi curavimus, yuae ratione habita costarum, picturae et coloris satis differunt. Icones nustrae refwesentum calvas colore rosen vel subpurpureo tinctas, albo variegatas; pictura valvae superioris concavae rubro marmorata est. Costae numerantur 14-17 (neque 12, ut Sou. ail) - in valva comexa "rimque subangulata, inlerstitiis iriplo latiores; tota testa sulcis densis radiantibus instructa; costae valvae superioris angustiores magis elatae. Sub vitro striae concentricae subimbricatae confertissimae, in interstitiis clariores, ubique cognoscuntur. Awriculae paene aequales cavatae. in latere externo oblique sulcatae: impressio muscularis magua subreniformis. 
Haec species ad Volas Kleimii vel Janiras Schumacheri pertinens, in Porlu Natalensi Africae australis habitat. Certe eadem est concha, quam Clar. Ferdinandus Krauss in opere suo de molluscis Africae australis pag. 29 sine nomine breviter commemaravit.

Obgleici Herr G. B Sow e rby in ersten Band seines Thes. Conch. pag. 7 diesen Pecten ohne Angabe des Vaterlandes bereits besclurieben und Taf. XIll. Fig. 35 и. 36 abgebildet, so habell wir doch nochunals eine Abbildung von drei Schalen dieser Art gegeben. nicht nur wegen der Veränderliclkkeit in Färbung und Zeichnung, sondern auch weil dieselben rücksichtlich der Zalıl und Beschaflenheit der Rippen etwas abweichen. I)ie $1+$ bis I7 Rippen sind niclıt gerundet, sondern beiderseits stumplkantig, die der Oberschale weit schmaler, dagegen beträchtlich höher als die der Unterschale. Unter der Loupe bemerkt man überall feine concentrische Linien, die in den Furchen wie feine Schüppchen erscheinen

Es gelı̈rt dieser Pecten, welcher von der $\mathrm{Na}-$ talküste stammt. zur Gattung Vola Klein oder Janira Schumacher.
Ce Peigne a été décrit (sans indication de locabité) et figuré dans le premier volume du Thes. Conclı. pag. 7, planche XIII. Fig. 35. 36; néanmoins nous donnons les ligures de trois valves de cette espèce, non seulement dans l'intention de démontrer sa variabilité de coloriation, mais aussi parceque nous tronvons quelques différences quant an noubre et la formation des côtes. Nos valves sont munies de It 17 côtes, qui ne sont pas arrondies mais obtusément anguleuses des deux côtés. Les côtes de la valve supérieure sont beaucoup plus élevées et plus hautes que celles de l'inférieure. A l'aide de la loupe on remarque partout des lignes fines concentriques, qui, dans les sillons, apparaissent en forme de fines écailles.

Ce Peigute, qui se trouve à la côte de Natal. appartient au genre Vola Ílein ou Janira Sclımacher.

\section{洼. Tivelia subglobosia 1)kr.}

Tab. XXIII. Fig. 7 latus internum valvae dextrae, Fig. 8 latus externum valvae sinisirae,

Fig. 9 dorsum conchae.

Testa trigona, subglobosa, altissima, paene aequilateralis, crassa, tota albida, concentrice obsaleteque striata, epidermide tenui pallide corneu restita; marga dorsi utrinque subrectus, valde declixis; umbones incurvi prominentes inflati paene contigui. margo rentris antice rotundatus, postice parum attemuatus; area lata subcordiformis indistincte terminata; limula cordiformis in medio subranaliculata. linea elevata terminata; ligamentum partulum promimhlum; calar internus cretaceus marginem versus lacteus: sinus pallii magrus; cardo dentibus utrinque sulcato-rugosis munitus, medins valvae siristrae crassus, reliqui compressi; dens lateralis ejusdem valoae magnus valde prominens compressinsculus. Long. 30 mill. Lang. altit. crass. ratio mumeris 100,100 et 80 resnondet.

Tivela (Trigona) subglobosa Ilir. in Mal. Bl XI. pag. 100.

Patria ignotu. 
Species singularis paene globosa, valvis erassis altis insignis, Cythereae Itindsii (Hanley sp of Shells Wood Suppl. Tab. 15. Fig. 35) affinis est, sed ambitu alieno differt.

Eine sehr eigenthümliche last kuglige, durch starke Schalen und sehr bedeutende llöhe ausgezeichnete Art, die wohl der Cytherea Hindsii (Hanley Sp. of Shells Wood Suppl. Taf. 15. Fig 351 am nächsten verwandt ist. doch namentlich durch abweichenden Umriss sich unterscheidet.
Espèce très-singulière de forme presque globuleuse et se distinguant par ses valves fortes et sa hauteur considérable. Sa plus proche voisine parait être la Cytherea Hindsii (Hanley Sp. of shells, Wood Suppl. pl. 15. fig. 35), mais elle s'en distingue entre autres par ses contonrs différens.

\section{i3. 'Tivelat Vatalensis liki'}

Tab. XXIII Fig. I0 dorsum conchae. Fig. 11 valva dextra, Fig. 12 eadem latere interno.

Testa trigonu paene uequilatera, crassa, postice canvexa declivis, basin marginemque anticum versus compressa, nitida. laevigata striisque concentricis tenerrimis obsoletis postice paullo fortiaribus instructa, unicolor alba vel subcana, vel lineis umdulatis et angulatis pallide fuscis picta: umbores acuti parum incurvi, fere contigui; marga dorsi utrinque valde declivis, antice subrectus, postice paullo fornicutus, margo ventris aequaliter arcuatus; extremilas unticu parum producta; lumla lanceolata, linea levi circumscripla; area mulla; ligamentum breve prominevs: latus internum album; sinus pallii magnus semiovatus; impressiones musculares fortes bene distinctae; dentes cardinales valvae dextrac anticus et posticus valde divergentes. dens medins paullo obliqnis, fossula et dens lateralis comfressus vialacei. - Long. 55 mill. Long. alt. et crass. $=100,86,46$.

Habitat in port" Natalensi Africae anstralis. Amicus llẹnnemann testas mecum cammunicavit.

Tivela (Trigona) Natalensis Mlir. in Mal. Bl. XI. p. 101.

Haec concha Cytheream planulatam Brod. et Sow. in mentem vocat, speciem quidem pernariabilem, sed valvis compressioribus, tenuioribus, mimss altis, ambitu alieno. colore externo et interno nec non picturae indole satis diversam.

Diese Art gehört ganz in die Nähe von Cytherea planulata Brod. Sow. die zwar sehr variirt. aber stets durch flachere, dünnere und schwächere Schalen, durch geringere Höhe, überhupt abweichenden Umriss . durch verschiedene äussere wie innere Färbung, anderen Charakter der Zeichnung etc. elc. von uuserer Art abweicht.
Celte espèce doit ètre rangée tuut près de la Cytherea planulata Brod. \& Sow., qui est en vérité très-variable, mais se distingue de la nôtre constammant par ses valves plus aplaties. plus minces et laibles, par sa hauteur moindre, en général par ses contours différens, par sa coloriation extérieure et intérieure et le caractère différent de son dessin, etc 


\title{
i4. Sulen Lischlieanus IJkr.
}

\author{
Tab. XXIV. Fig. I.
}

Testa linearis brevis, perparum curvata, plano-convexa, temnissime striata, paene laevis, lactea, subpellucida, epidermide pallida tennissima, nitidissima vestita; extremitas antica abrupte truncata in superiore et inferiore parte obtusa; extremitás postica rotumdata; margines. subparalleli.

Habitat mare erythraewn.

Species praesertim testa temi luctéa subpellncida insignis. Specimen qnod pertinet ad collectionem Molluscormm eximiam Clar. Lischke multo majus est.

Dieser interessante Solen zeichnet sich besonders durch seine dünnen fast milchweissen durchscheineaden Schalen aus. Das aboebildete Exemplar ist noch nicht völlig erwachsen Nach einem Stücke, welches der ausgezeichneten Sammlung des Herm Geh. Regierungsrathes Lischke in Elberfeld angehört, wird diese Art ziemlich viel grösser.
Ce Solen curieux se distingue surtout par ses valves minces of transparentes de couleur presque blanche laiteuse. L'exemplaire figuré n'est pas complêtement adulte. Un autre exemplaire appartenant à la riche collection de Mr. le Conseiller intime L is clıke à Elherfeld, démontre, que cette espèce atteint des dimensions beancoup plus considérables.

\section{i5. Solen Woodwardi I)kt'}

\section{Tab. XXIV. Fig. ?.}

Testa linearis brevis, paullo currata, plano-convexa, laevis, antice abrupte truncata, postice rotundata, sordide alba, epidermide cornea nitida induta; murgo dorsi et basis paene ommino paralleli.

Solen Wooduardi Whr. in Proc. Zool. soc. of Lond. 1861. pay. 420.

Species parva 53 mill. longa, 12 alla, 7 lata. unicalor, ad eos Solenes pertimet, qui canaliculo levi in margine antico instructi sunt.

Habitat ad insulam Zebu Philippinarum. (H. Ciming.)

Diese kleine Species ist 53 Mill lang, 12 hoch und 7 breit. Sie ist einfarbig weiss, von einer glänzenden hornfarbigen Epidermis überzogen und vorn mit einem schmalen und seichten Canal versehen.
Cetle pelite espèce a une longueur de 53 , une hauteur de 12 et une largeur de 7 millin. Elle est de couleur uniforme blanche, couverte d'un épiderme corné et luisant, et munie, à son extrémité antérieure, d'un canal étroit et peu profond. 


\section{iti. Solen gricilis Phil.}

Tab. XXIV. Fig. 3.

Testa linearis, sub epidermide cornea albida, in area dorsi pallide rufo strigata; latus anticum ucute abrupteque truncatum, latus posticum paullo rotundatum; margines paene exacte rectilinei et paralleli.

Solen gracilis Phil. in Zeitsch. fur .Malak. von Wenke und Pfeifler. 1847. pag. 72.

Testa depicta 85 mill. longa, 12 alta et 8 lata est, sed panllo major fit. Snecies tota forma singularis jam pridem lescripta, ad hanc usque diem nondum depicta esse videtur.

Habitat ad insulas Plitippinas.

Das abgebildete Exemplar misst 85 Mill. in der Länge, 12 in der Höhe und 8 in der Breite, doch wird diese durch ihre schmale Form ausgezeichnete Art noch etwas grösser Dieselbe wurde schon vor längerer Zeit beschrieben, doch ist uns eine Abbildung bis jetzt nicht bekannt geworden.
Liexemplaile figuré a une longueur de 85 , une halleur de 12 et une largeur de 8 millim. Cependant cette espèce distinguée par sa forme étroite atteint quelquefois des dimensions plus considérables. Il y a assez long tems, qu'elle est décrite, mais nous n'en connaissons jusqu'aujourd'hui aucune figure.

\section{Solen grandis Ilki.}

Tab. XXIV. Fig. 5.

Testa linearis, rectu, magna, salida, striis incrementi obsoletis et epidermide laevi cornea instructa; extremitas antica acute marginata. oblique t'uncata, neutiquam sulcata, extremitas postica rolundata, haud angusta. Color sub epidermide albus, strigis roseis, ex parte subfuscis, striis increnenti parallelis picta; pagina interna alba, posticum marginem versus rosea.

Solen grandis Dhr. in Proc. Zool. Soc. of Lond. 1861. pag. 418.

Concha usque ad 144 mill. longa, 32 alta et 21 lata, quasi intermedia inter solenem ceylaneusem et brevem. A Solene ceylanensi praesertim differt latere postico plus minusve rotundato. a Solene brevi pictura aliena, margine dorsi et basis prorsus parallelis, ita ut testa postice hand angustata appareat . Practerea angulus, qui furmatur linea basis cum margine oblique truncato plerumque acutior est quam in illa specie.

Habitat ad Philippinas insulas.

Diese Art, welche eine Länge von 144 Mill. erreicht, dabei 32 Mill hoch und 21 breil ist, steht gewissermassen zwischen solen ceylanensis
Cette espèce, qui atteint une longueur de 144 , une hauteur de 32 et une largeur de 21 millim., est en quelque sorte intermédiaire entre les Solen $10 \%$ 
and brevis in der Mitte. Vou ersterem uaterscheidet sich dieselbe zumal durch die mehr oder minder gerundete hintere Seite, von letzterem durch abweichende Zeichnung und den vollkommen parallelen Rücken- und Bauchrand. Ausserdeon pflegt der Winkel, den die Bauchlinie mit dem schief abgestutzten Vorderrande bildet. spitzer zu sein, als beim Solen brevis. ceylanensis et brevis. Elle se distingue du ceylanensis surtout par sa partie postérieure plus ou moins arrondie, du brevis par sa coloriation et le paraliélisme parfait de ses bords supérieur et ventral Outre ces différences, l'angle formé par la ligne ventrale avec le bord antérieur obliquement tronqué. est communément plus aigu, que chez le brevis.

\title{
78. Sulen Malaccensis Dhir.
}

Tab. XXIV. Fig, 6.

Testa linearis, recta, utrinque truncata, angusta, obsoletissine striata, epidermide tenni pallide olivacea obducta, alba, maculis nomullis flammisque lividis perpendiculatis variegata; extremitas antica sulco levi siguata.

Solen Malaccensis Dkr. in Proc. Zool. Soc. of Lond. 1861. pag. 419.

Testa 115 mill. longa, 17 alta, 11 lata. (Specimeu depictum paullo majus est.) A Solene vagina Limaei latere antico acute marginato abrupte truncato, sulco multo minore et leviore nec non pictura differt.

Habitat ad Malaccam.

Das Gehäuse ist 115 Mill, lang, 17 hoch und 11 breit (das abgebildete Exemplar hat etwas grössere Dimensionen). Von Solen vagina $L$. unterscheidet sick unsere Art zumal durch den scharl abgestutzten Vordertheil und eine viel schmalere und seichtere Furche, sowie durch die Zeichnung. Aus Versehen wurde die Abbildung rom Lithographen verkelırt gezeichnet.
La coquille atteint en général one longenr de 115 , une hauteur de 17 et une longueur de 11 millim, cependant ces dimensions sont plus considérables chez plusieurs exemplaires. comme dans celui, que nous avons fait figurer. Notre espèce se distingue du Solen vagina $L$. surtout par sa partie antérieure brusquement tronquée, par un sillon beaucoup plus étroil et moins profond et par sa coloriation. Par une erreur du lithograpliste la figure est dessinée en sens invers.

\section{9). Cultellus attemuatus IMir.}

\author{
Tals. XXIV. Fig. 4.
}

Testa ovali-oblonga. utrinque rotundata, subrecta, postice sensim attenuata, temuis, concentrice obsoleteque striata, in speciminibus jumioribus paene laevis, tota alba. epidermide olivacea nitida evanida, totum marginem involvente obtecta. 
Cultellus attenuatns Dkr. in Proc. Zool. Soc. of Lord. 1861. pag. 422.

Concha 110 mill. Longa, 30 alta, 14 tantum lata, in antica longitudinis parte altissima, extremilatem vero postican versus sensim coarclata. Denles in valua sinistra duo observantur. amticus partus simplex, posticus magnus valde resupinatus. late fissus, ita ut cardo tridentalus appareat. Dentes valvae dextrae pariter duo sed simplices. anlicus magmus compressus erectus. Liganentum pro magnitudine testae brere.

Valrae ante umbones compressae in extremitate amtica hiantes.

Habitat ad Mhilippinas insulas.

Diese ausgezeichnete Art ist in der Gegend der Wirbel am höchsten, nach hinten verschinàlern sich die Schalen allmälılig. Dieselben sind verlıältnissmässig dünu und weiss, aber nit einer olivenfarbigen Epidermis bedeckt, die den unteren Schalenrand überragt und sich an demselben umgebogen hat. Die linke Schale besitzl zwei Zälne, wovon der vordere einlach und klein, der lintere stark zurïckgebogen und weil gespalten ist. Die gegeniuberliegende Schale trägt dagegen zwei einfache Zälıne, deren vorderer ungleich grosserer, schmal und ziemlich stark aufgerichtet ist. Vorn im ersten Viertel der MIuschel sind die Schalen ziemlich stark zusammengedrückt, doch gehen dieselben am Rande weit auseinauder. Das Ligament ist im Verhältniss zur Grösse dieser Art ziemlich klein.

Die in den Proceedings I. c, beschriebenen Exemplare sind der Jugendzustand dieser interessanten Muschel.
Cette espéce distinguée a sa plus grande hauteur près des crochets et les valves deviennent inseusiblement plus étroites vers la partie postérieure. Les valves sont proportionellement minces et blanches, mais couvertes d'un épiderme olivacé, qui surpasse le bord inférieur, où il s'enroule. La valve gauche montre deux dents, dont lantérieure est simple et petite, l'autre fortement reclinée et largement fendue. Au contraire la valve droite possède deux dents simples, dont l'antérıeure est benucoup plus grande, étroite et médiocrement érigée. En avant, daus le premier quart de la coquille, les valves sont assez fortement comprimées, cependant elles s'éloignent beancoup à leurs bords. Le ligament est assez petit en proportion de la taille de cette espèce.

Les exemplaires décrits dans les Proceedings I. c. représentent l'élat de jeunesse de cette coquille curieuse.

\section{S0. Callista Gotthardi INkr.}

Tab. XXV Fig. 1. latus extermum valrae sinistrae, Fig. 2. latus intermm ralvae dextrae, Fig. 3. dorsum conchae.

Testa ovata, oblique subcordata, basi aequaliter curvata, ntrinque rotundata, striis concentricis lirisque inaequalibus plus minusve distinctis, umbones versus regularibus instructa, pallide flava, radiis nommllis latis obscurioribus haud regulariter fusco muculatis ornata; unbones tumidi antrorsum inclinati, subacuti; lumla ovato-lanceolata vix excavata, pallide 
rosea; impressiones musculares leves; simus pallii latus, subito attematus; color interms albus, in margine cardinis antico roseus. - Long. 50 mill. Long. alt. latit. ratio fere laec est: $100.78,48$.

Ilabitat Upolu. Exstat in Mus. clar. Godeffroy Hamburyensis.

Diese interessante Muschel hat eimen ähnlichen llabitus wie Callista Chione L. und Ilayenorii $D k r$, doch unterscheidet sie sich ron beiden durch die Färbung und den Clarakter der Zeichunng, durch die Sculptur und die geringere Grösse.
Cette coquille curieuse ressemble, par son habitus. aux Callista Chione $l$ et Hagenovi Dhr.; cependant clle se distingue de ces deux especes par sa stature moindre, sa sculpture, sa coloriation et le différent caractère du dessin.

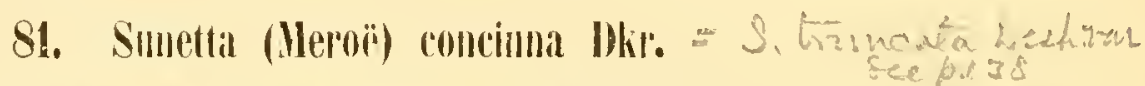

Tab. XXV. Fig. \& latus extermm valvae dextrae, Fig. 5. dorsum conchae, Fig. 6. latus intermum valvae sinistrae.

Testa subovata, albida lineis acutangalaribus subundulatis lividis vel fusco-violaceis eleganter picta, laevissima, epidermide nitida pallide cornea pellucida vestita, paene aequilateralis, utrinque rotundata, postice panllo altior; margo cardinis anticus subsimatns, posticus parnm arcuatus; nubones acuti approrimati, lividi; lunula lanceolata, linea impressa terminata; area, ut in Sumettis solet, profundissima, utrinque sulcata; ligamentum immersum; color internus fusco-violaceus; margo dense cremulatus; simus pallii latus. - Long. 20 mill. Long. alt. lat. ratio numeris $100,80,35$ respondet

Ifabitat ad Moluccas insulos (Amboinam). - Satis bene delineata est haec conchula elegantissima in Rumplii Amb. Rar. T. NLIII. Fig. IH.

Diese kJeine ungemein zierlich gezeichnete. glänzende, fast ganz glalte, uur zu beiden Seiten der tiefen Area gefurchte, Art ist der Sumetta scripta (Donax) L. am meisten verwandt, aber, abgeselıen von der weit geringeren Grösse, im Umriss wesentlich verschieden, da der hintere Rand gerundet, nicht zugespitzt ist; auch liegeı die Wirbel bei unserer Muschel fast in der Mitte der Schalen. Die innere Farbe ist ein etwas in's liräunliche spielendes blasses Vıolblau; die Mantelbucht ist verlältnissmässig breit, der Rand der Schalen fein gekerbt. - Von der scharf eharakterisirten interessanten Galtung Sunetta Link sind zur Zeit 11 Arten bekannt geworden.
Cette petite espèce, dessinée très-délicatement, juisante. presqu' aplatie, sillonnée seulement des deux cùtés de laréa enfoncée, est assez voisine de la Sumetta scripta (Donax) L., mais outre sa taille bien moindre elle en differe essentiellement par ses contours, puisque le bord postérieur n’est pas pointu, mais arrondi. Les crochets de notre coquille accupent à peu près le milieu les valves La couleur de l'intérieur est un bleu pâle violacé, tirant légèrement an brunâtre. Le sinus pallial est comparativement large, le bord des valves crénelé. - Nous connaissons aujourd'hui 11 espèces de Sunetta, formant un genre très-curieux et nettement caractérisé. 


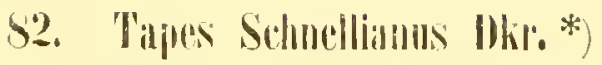

Tab. XXV. Fig. 7. latus internm valvae dextrae, Fig. 8. latus extermm valvae sinistrae, Fig. 9. clorsum conchae.

Testa ovato-oblanga, subelliptica, inaequilateralis, pullide flava, lineis obscuris angulosis hand regulariter reticulata, radiis quaternis obsoletis latis interruptis subreticulatis picta, liris transversis regularibus planis nec non sulcis angustis et profundis instrncta; margo ventris aequaliter arcuatus antice ascendens; margo dorsi anticus simulus; area lanceolatu; lumula ovato-lanceolatu excavata, sublaerigata, fusco-lineata, labiis parum elevatis terminata; umbones parvuli subacuti approximati; cardinis dentes utrinque tres, medius perspicue bifidus; sinus pallii magnus ascendens; color intermus prorsus albus. - Long. speciminis quod exstat unici. 85 mill. Long. altit. el latit. ratio mmeris I00, 62 el 39 respondet.

Habitat in litore Japonico.

Diese Art gehört ganz in die Nahe der Jenus ala papilionis rhemn. $=V$. papilionacea Lam. (Venus rotundata Gmel. non L. *), mit welcher sie auch die aufsteigende Manlelbucht gemein lat; sie unterscheidet sich aber durch lıöhere, gewölbtere, fast elliplische Schalen, sowie durch regelmässigere und stärkere Furchen: auch an Tapes (Venus) amabilis /Nil. Abb. vol. III. pag. 75. Tab. VII. Fig. 2 erinnert unsere Muschel auf den ersten Blick.

Wir erlielten diese ausgezeichnete neue Arl durch die Giite des Herrn Eduard Schnell in Nangasaki; sie slamınt von Japan.

*) Lirme's Vermes rohundata ist eine ziemlich zweifelhafte Art, zu dereu kurzer Beschreibung, die auf andere Arteu ebenso gut passeu könnte, weder im Syst. Nat. ed. X. (1758) pag. 690 , poch im Mus. Ludovicae Ulricae leg. (1761) pag. 509, noch auch in der letzten vou Linné selbst besorgten Ausgabe des Natursystems (1767) das Citat einer Abbildung sich findet.
Cette espèce est très-voisine de la Venus ala papilionis Chemn. $=V$. papilionacea Lam. (Venus rotundata Gmel., non $L . *$ *), avec laquelle elle a aussi de commun le sinus pallial ascendant; mais elle s'en distingue par ses valves plus hautes, plus convexes, presquelliptiques, ainsi que par ses sillons plus réguliers et plus forts. De même notre coquille rappelle, ả première vue, le Tapes (Vemus) amabilis Pleil. Abb. vol. III. 1).75. pl. 7. f. 2.

Notre espece nouvelle et curieuse provient du Japan, et nous l'avous reçu par la bienveillance de Mr. Ed. Schnell à Nangasaki.

*) La Fernes rotunchatu de Lmme est une espèce assez douteuse, dout la courte déscription, qui est igalement pratiquable pour différentes espices, n'est éclaircie par aucune figure citce, ni dans le Syst. nat. ed. X. (1755) p. 690, ni dans le Mus. Lud. Ulr. (1764) p. 509, ni dans la deruière édition du Syst. nat. (1767) proveuant de Linné lui-même.

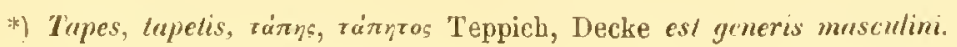




\section{S3. Diplodonta bullatia IOkr.}

Tab. XXVI. Fig. 1. latus intermum valvae sinistrae, Fig. 2. dorsum conchae, Fig. 3. latus extermum valvae sinistrae.

Testa magnu, sordide alba vel flavescens, valde tumida. paene globosa, striis concentricis densissimis inaequalibus subrugosis instructa; mbbones tumidi sc invicem tangentes, antrorsum inclinati; areu lumulaque hand distinctae; ligamentum profunde impositum: dentes ntriusque valvae duo, antirus sinistrae et posticus dextrae bifidi; impressiones musculares magnae ablongae nitidae, margini ventris acuto approximatae, cum linea pallii simplici conjunctae. - Long. 35. mill. Long. alt. lat. = 100, 85, 80 .

Habitat ad litus Ceylonicum.

Ex itinere reportament Asiatico hanc nirabilem concham clar. fratres de Schlagintweit.

Die vorliegende Art zeichnet sich zumal durch ilre bedeutende Grösse und die sehr aufgetriebenen Schalen ans. Der Rand derselben ist fast elliptisch, die gerundeten Wirbel neigen sich nach vorn und stossen dicht zusammen, die grossen langen glänzenden, durcls eine einfache Mantellinie verbundenen Muskelflecken liegen selır dem Rande genähert 1)as Schloss zeigt ganz die Charaktere der Gattung.

Der vol Bronn iı „Italiens Tertiärgebilde* (1831) und in Jer Lethaea geognostica wohl begründele Gatungsname verdiest vor der verschieden gedeuteten Bezeichnumg Mysia Leach, einem blossen Manuscriptnamen, wohl jedenfalls den Vorzug. Cfr. Lncina undata (Jemus) Pemant in L a marck"s Syst. des an sans vert. VJ. pag 229. He rma n n s e I Ind. Gen. Mal. I pag. 392. Plilippi Handb. der Conchyl. und Malakoz. pag. 342.
Notre espèce est sourtoul distinguét par sa taille considérable et ses valves fortement renflées. Ses contour's sont à peu près elliptiques, les crochets arrondis sunclinent en avant el se touchent. Les impressions musculaires grandes. allongées, luisantes et jointes par une ligne palliale simple, sont très-rapprochées au bord. La charnière présente parfaitement les caractères du genre.

Le noun générique fondé exactement par B ron n (Italiens Tertiaergebilde 18:31 et Lethaea geognost.) doit être préferé alı nom manuscript: Mysia Leach, qui a été expliqué en différens sens. Voyez Lucina undata (Venus) Pennant in Lam. Syst. all. saus vert. VI. p. 220, Helrmannsen lind. Gen. Mal. I. p. 3:2, Philippi Handb. Conchỵl. n. Malac, p. 34 ?.

\section{S4. Lucina carmosa Dhis}

Tab. XXVI. Fig. 4. latus externum valvae sinistrae, Fig. 5. latus internum eiusdem valvae, Fig. 6. dorsune.

Testa suborbicularis, paullum altior quam longa, solidula, plus mimusre tumida, subgibbosa, tota carnosa, postice sulco lato levi signata, liris concentricis rotundis inacqualibus cincta; 
umbomes parvuli antrarsum inclinati. incurvi. paene rostriformes; lumula ovata, sulco distincto terminuta; area lanceolata; ligamentum angustum infossum; denticuli cardinis mediani duo internales. granosi. laterales valeat dertrae remoti et erecti fove is simistrae correspondentes; pagina interna opaca, subaspera, punctulis nomullis leviter stigmosa: pallium tenuiplicatum; impressiones musculures haud profundae. -- Long. Is mill. Long. alt. crass. ratio his mumeris respondet 90, 100, 60 usque ad 70.

Putria: Portus Nutalensis. Falvas clar. Heynemam Francofurtamis benevole dedit.

Nostra concha habitn Lucinam columbellam Lamarckii refert, sed ejus valvae intus extusque carnosae, minus globosae, tenuiores nec non minores sunt. Vertices specimimum exactae jam aetatis saepe decorticati sum, unde patet, testas duobus constare coriis.

Die Form dieser Lucina erimuert sehr an $L$. columbella Lam., doch ist sie anssen und innen fleischfarben, dünnsclıaliger, nicht so kugelig, auch elwas kleiner. Besonders merkwärdig ist es, dass diese kleine Muschel zwei Schalenschichten besitzt, wie man an alten Exemplaren, deren Wirbel entrindet sind, deutlich sielit. Die untere Schicht ist an vorliegenden beiden Schalen glatt und lebhafter gefärbt als die obere. - Obgleich die Furche, welche beiderseits von den Wirbeln nach dem hinteren Rande der Muschel sich herabzieht, nur seicht ist, so müsste sie auf unserer Zeichunng doch ileutlicher hervortreten.
La forme de celte Lucine ressemble à la $L$. columbella Lam., mais elle est de couleur carnée en dehors et en dedans, plus petite, plus mince et moins globuleuse. Il est surtout remarquable. que cette petite coquille est formée de ileux couches, ce que l'on observe clairement chez les individus vieux, dout les croclıtes sout usés. La couche inférieure est, chez nos deux valres, lisse et coloriée plus vivement que la supérieure.

Quoique le sillon qui des deux còtés descend des crochets vers le bord postérieur, est pen apparent, cependant il n'est pas assez distinct dans notre figure.

\section{Lulcina mirabilis Ioki. $=\alpha$}

Tab. XXVI. Fig. T. dorsum conchae. Fig. 8. Latus externum valvae sinistrae. Fig. 9. ejusdem latus intermum.

Testa magna, oblique ovata, transversa, subpellucens, valde compressa, paene aequilateralis, concentrice striata et rugoso-sulcala, plicis duabus obsoletis ad latus posticum decurrentibus strigillisque radiuntibus hand regularibus tenuissimis, sub vitro tantum conspicns instructa, antice rotundala subattemuata, postice latior; margo dorsi posticus curvalus, pone declivis, maryine dorsi untico paene rectilineo altior; margo ventris medius valde curvatus; umbones peracuti. erecti, se invicem tangentes, mediam fere testam tcnentes; lunula minima anguste cordiformis, simuata, valde impressa; ligamentum profunde situm snboccultum; cardo vulrae simistrate binis denticulis divergentibus muntus, antico bifido breviore, dentibus lateralibus nullis. Pagina interna, nt in Lucinis solet, opaca, subaspera. impressime musculari antica 
longissima, striata, magnam testae anticae partem tenente excellit. - Long. 102 mill. Long. alt. crass. his mumeris respondet: $100,80,25$.

Patria ignota.

Diese seh. eigentlümliche grosse Lucina, wovon Jeider nur die linke Schale vorhanden ist, belindet sich im Besitze des Herru Christoph Reents in Hamburg. Da uns weder eine Beschreibuug noch Abbildung dieser Art bekannt geworden, so geben wir von derselben bier eine Zeichnung. Sie wirde zu einer besonderen Altheilung der Lucinen gehören, da ihr die Seiteuzähne gänzlich fehlen; doch ist eine Eintheilung mancher Acephalen bloss nach der Beschaffenheit des Schlosses misslicl, wenn nicht noch andere Merkmale hinzukommen, da mitunter eine und dieselbe Arl je nach dem Orte ihres Vorkommens mehr oder minder ausgebildete Zähne hat, sogar die Zähne zuweilen ganz verschwinden, wie bei Lucina jamaicensis (Venus) Chem. Bei näherer Kenntniss der Thiere mancher Gattungen würde man sicher auf gewisse $\mathbf{A b}$ weichungen in der Schalenbildung, die uns bis jetzt noch unwesentlich erscheinen, ein grösseres Gewicht legen.

Unter den Arten der jetzigen Schöpfung kemuen wir keine der gegenwärtigen verwandte; doch kommen im Tertiärgebirge einige älnnliche aber kleinere Formen vor.
Celte Lucine grande et très-singulière, dont malheureusement nous riavons vu que la valve gauche, appartient à la collection de Mr. Chr. Reents à Hambourg et nous en donnons la ligure, n'ayant trouvé nulle part ni déscription ni figure s'accordaut avec elle. Elle partiendrait à une section particuliẹre des Lucines, puisqu'elle est entièremeut dépourvue de dents latérales: mais il est difficile, chez certains Acéphales, d'établir une division unique me ut sur les caractères de la charnière sans le concours d'autres caractères, puisque quelque-lois la mềne espèce, selon sa localité, a des dents plus ou moins dévelopées, 0 ! même nulles, comme p. ex. Lucina jamaicensis (Venus) Chemn.

Si nos connaissances des animaux de plusienrs genres seraient plus completes, certainement lon mettrait plus de prix sur certaines différences dans la formation des coquilles, qui maintenant nous paraissent être peu essentielles.

Parmi les espèces vivantes nous ne connaissons aucune voisine de la nôtre; mais dans le terrain tertiaire se trouvent quelques formes analognes, quoique plus petites.

\section{S6. Donax englyptus Dhil.}

Tab. XXVII. Fig. 1. latus externum valvae dextrae, Fig. 2. latus intermum valvae sinistrae, Fig. 3. dorsum conchae, Fig. 4. particula lateris postici magnifndive aucta delineata.

Testa trigona, alta, brevicumeata, valde inaequilateralis, tennis, in lateribus lineolis lirisqne undulatis et flexuosis haud regularibus instructa, in parte postica abrupte truncata, gramulis seriatim ordinatis in liras transenntibus ornata; alba, marginem versus pallide livescens. pagina interna rosea, postice subcoerulea; margo posticus malulatim excisus; 
umbones parouli; ligamentum prominulum; cardinis dentes exigui, laterales compressi, remaliusculi, anticus longior; linea pallii el impressiones musculares leves, simus latus. - Long. 25 mill. Long. ult. lat. ratin mueris $100,85,50$ respondet.

Habitat ad .lloluccas insulas.

Hacc species inprimis sculptura yemina et elegantissima insignis est. Latera maximam partem sulcis confertis undulatis et flexuosis obducta sunt, pars vero postica abrupte truncafa, rugis granulisque ordinatim seriatis excellit Marginis postici inferior pars, quacume valvae complectutur, undatus est.

Diese Art zeichnet sich besonders durch ihre eigeuthümliche Oberfläche aus Der bei weitem grösste Theil der Schalen ist mit dichten feinen, unregelmässig wellenförmig gehogenen Furclien bedeckt Auf den stumpfen bis zu dem unteren Rande verlaufenden Kiele gehen die durch die Furchen gebildeten Rippclien in feine Runzeln und Köornchen über, welch' letztere die schräg abgestutzte hintere Fläche in dichten Lieihen bedecken. Der untere Rand ist innen mikroskopiscl, fein gestrichelt, linten wellenförmig gebogen, so dass die Schalen aı diesem Theile wie eine gefaltete Auster in einander greifen.

Uuter den vielen bekanuten Donax-Arteu kemnen wir keine, mit welcher die vorliegende verglichen werden könute.
Cette espèce se distingue surtout par sa surface particulière. La plus grande partie des valves est couverte de sillons fins et rapprochés, irrégulièrement ouduleux. Sur la carcire: émoussée et descendaut jusquau bord inférieur, les petites côtes formées par les sillons se clangent ell rides et granulations fines, couvrant en séries rapprochées la partie postérieure obliquement tronquée. Le bord inférieur est presı̨u' insensiblement striolé en-dedans et onduleusement plissé en arrière, de sorte qư’à cette partie les valves ressembleut à une huitre plissée.

- Parmi le grand nombre d'espèces de Donax nous ne connaisons aucune, qui pourrait être comparée avec la nôtre.

\section{8\%. IDonax splendens Dhi.}

Tab. XXVIl. Fig. 5. latus valvae dextrae externum, Fig. 6. latus sinistrae intermu, Fig. 7. dorsum conchae, Fig. 8. particula lateris postici magmitudine aucta delineata.

Testa ovato-trigona, cuneiformis, compressa, solidula, splendens, alba cel pallide coerulescens, intus radiis nonnullis violaceis picta; concentrice tenerrimeque striata, marginem inferiorem versus sulcata, postice truncata, crispato-rugosa, ragae lineis subtilibus ab apice radiantibus decussatae; umbones parvuli subacuti; linea pallii impressa, simus latus, semiovatus. - Long. 24 mill. Long. alt. crass. $=100,68.38$.

Habitat ad ostium fluminis cygnorum, fide ornat. C. Wessel.

Concha in lateribus ventris et dorsi aequaliter curvata, antice productu, lingulata vel cuneiformis, postice truncata brevissima, rugis concentricis striisque radiantibus sub vilro 
tantummodo conspicuis pracsertim insignis est. Ligamentum, ut in genere Donacis solet, breve et paullo porrectum. Specimen nostrum albidum zonisque nommulis subcoeruleis cinctmm est; latus intermm radiis pallide violaceis pictum, sed color in Donacibus pervariabilis.
\end{abstract}

Die ziemlich starken, ungemein glänzenden, keilförmigen Schalen sind ziemlich flach und besonders durch die am abgestutzten Hintertheil befindlichen unregelmässigen Runzeln ausgezeichnet, die von mikroskopisch feimen Längslinien durchschnitten werden
Les valves assez fortes, très-luisantes, cunéiformes sont assez aplaties, et se distinguent surtout par les rides irrégulières de la partie postérieure tronquée, qui sont découpées par des lignes longitudinales microscopiques.

\title{
85. Dosimia temuilirata INkr.
}

Tab. XXVII. Fig. 14. lahs calvae dertrae extermm, Fig. 15. ejusdem latus internum. Fig. 16. dorsum concluae.

Testa suborbicularis solida, tota sordide alba vel straminea, comexa. inaequilateralis. liris concentricis temibus regularibus confertisque cincta: margo dorsi anticus simuatus brenis, mosticus longus valde declivis, parm fornicatus cmm margine ventris exacte circulari angulum format ralde obtusum; umbones acuti involuti antrorsum inclinati; lumula cordiformis sulco profundo terminata; area lanceolata; ligamentum angustum profunde imposilum; sinus pallii longus, angustus, lingnlatus, antice subobtusus, vix ascendens, ultra medium testae productus. - Long. 33 mill. Long. alt. et crass. ratio est 100, 95. 50.

Habitat ad litus Ceylonicum.

Diese Art ähnelt an meisten der Dosimia Adansoni Phil. (Abb. vol. I. pag. 3. Tab. 2. Fig. 2.), doch unterscheidet sie siclı besonders durch den vollkommen cirkelrunden Bauchrand und die weit grossere, nur sehr wenig aufsteigende Mantelbucht, deren stumpfe Spitze bis in die Nälue des vordereu Muskeleindrucks reicht.

Wir verdanken mehrere Schalen der Gijte des Herrn Prof. Rob. von Schlagintweit, der sie von seiuer Reise nach Indien mitgebracht.
Cette espèce ressemble à la $D$. Adansoni Hil. (Abb. I. p. 3. pl. 2. f. 2), mais elle s'en distingue surtout par son bord ventral parfaitement circulaire, et par son sinus pallial beaucoup plus grand, légèrement ascendant, dont l'extrémité émoussée se rapproche à l’impression musculaire antérieure.

Nous devons plusieurs valves de cette espèce à Mr. Rob. de Schlagintweit, qui les a rapporté de son voyage à l'Inde. 


\section{8!. Inosinia cubdichotoma Ithr.}

Tab. XXV1I. Fig. 9. latus extermm valvae dextrae, Fig. 11. latus intermum valvae sinistrae, Fig. 11. dorsum conchue. Fig. 12 et 13. particulae magn, ancta delineatae.

Testa solida, suborbicularis, inaequilatera, habitu fere Dosinia e altae, sed paullo major et convexior, liris concentricis densis utrinque subdichotomis undulatis, quasi ramosis instructa, luteo alba, fasciis nonullis rufescentibus cincta: umbones parvuli subacuti, prominentes paene rostriformes; maryo dorsi posticus arcualıs, parum declivis; lunula cordiformis. valde impressa. obvallata et sulco profundo circumscripla; area auguste lanceolata, striata; labia protuberantia: ligamentum profunde impositmn; dens cardinis anticus vel lunularis crassus, obtusus; simus pallii usque ad medium testae productus, late anertus, lateribus subrectis inclusus. - Long. 2.5 mill. Long. alt. crass. $=100,96.58$.

Habitat ad litus Ceylonicum.

Haec species ab ommibus cognatis superficie singulari externa facile distinguenda est; lirae enim densae, rotundalae in utroque valvarum latere undulatae sulcis passim interpositis subdichotomae, quasi ramosae apparent. Cardo tribus constat denticulis, medio valido, lateralibus compressis, tuber lumularis, vel dens valvae sinistrae quartus magnus et oblongus.

Diese Art ist durch ihre eigenthümlichen zu beiden Seiten wellenlörmig gebogenen und uuregelmässig gespaltenen Rippchen von allen übrigeu bis jetzt bekannt gewordenen Dosinieu leicht zu unterscheiden. Das etwas vergrösserte Stück Fig. 13 giebt kein deutliches Bild von den verzweigten etwas runzeligen Rippchen; besser stellt Fig. 12 dieselben dar.
Cette espèce est facilement à distinguer de toutes les autres connues par ses petites côtes onduleusement courbées des deux côlés et irrégulièrement f'endues. La petite partie Fig. 13, legèrement grossie, ne représente pas distinctement les côtes ramifiées et ruguleuses, nieux visibles dans la Fig. 12.

\section{Dosinia Ceylonica IDkl'.}

Tab. XXVII. Fig. 17. latus extermu valvae sinistrae, Fig. 18. latus ejusdem imternum, Fig. 19. dorsum conchae.

Testa suborbicularis, convexa, crassa, sordide alba, valde inaequilatera, postice paullulum producta, liris concentricis temuibus utrinque lamellosis cincta; umbones tumidi involoti, promi; margo dorsi anticus linea exacte circulari cum margine inferiore conjumctus; dorsi postica pars longa, curva valde descendens; lunula canaliculo levi terminata cordiformis vix expressa; area lanceolata; labia parum prominentia; ligamentum immersum; cardinis dentes valvae dextrae mediani duo crassi subbifidi divergentes, anticus tertius obtusus; posticus quartus compressus; sinus pallii late apertus, brevis ascendens, lateribus rectis inclusus. - Long. 35 mill. Long. alt. crass. mumeris $100,94,56$ respondent. 
llabitat ad litus Ceylonicum. Plures testas ex itinere Asiatico attulit clar. Robertus de Schlagintweit.
\end{abstract}

Haec concha singularis ad eas Dosinias pertinet, yuae lunula distincte circumscripta carent, e.r. gr. Dosinia excisa Chemn., trigona Reevei aliaeque.

biese eigenthỉmliche Muschel gehört zu Römer’s Gruppe der Dosinia excisa Chemn. (voi. VIh. pag. 17. Tab. 38. Fig. 400 : 401.), deren wenige Arten durch bauchige Schalen und den fast ganzlichen Mangel einer scharf hegräuzten I.unula sich anszeichnen. Charakteristisch fiil die vorliegende Art sind unter anderen Merkmalen die ziemlich scharfen concentrischen Rippen, deren breitere Zwischenräume unter der Loupe feine concentrische Linien zeigen.
Cette coguille singuliere appartient au groupe établi par Mr. Römer pour la D. excisa Chemu. (VII. p. 17. 1 38. 1. $400.4(1)$ ), dont les especces peu nombreuses se distinguent par ses valves renflées et par l'absence presuue absolue de lunule marquée. Parmi les caractères de l'espèce l'un des plus saillans est fourni par les côtes concentriques assez tranchantes, dont les interstices plus larges, vuos à l'aide de la loupe, montrent de fines lignes concentriques.

\title{
91. I'osinia reunlaris IMli'.
}

Tab. XXVII. Fig. 20. latus extermu valrae dextrae, Fig. 21. latus internm valvae sinistrae. Fig. "'?. dorsum conchae.

Testa orbicularis, connexiuscula antice, subcompressa, inaequilateralis, concentrice confertimque striata et lirata, lirae in media testa et praesertim marginem inferiorem versus paene exacte circularem sublanae et latiores, in margine antico et postico sublumellosae, passim haud regulariter fissae; color ex albo flavescens, intus cretaceas; umbones tumidi, subacuti, antrorsum inclinati; margo dorsi anticus brevis valde sinuatus, margo posticus longus parum curvatus; lumula cordata, dense striata, sulco profundo terminata; area lanceolata tenuistriata: liganentum subimmersum; dens anticus rel lunularis obtusus. cardinulis valvae dextrae medius crassus, posticus bifidus; sinus pallii parum asceudens ultra medium testae moductus. - Lony. 38 mill. Lory. altit. et crass. ratio mumeris $100,100,48$ respondet.

Patria ignota.

Concha peculiaris Dosiniam (Cyth.) scabrinsculam Phil. (Abb. vol. II. pag. 229. Tab. VI. Fig. 2) in mentem vocat. Margo dorsi pasticus satis longus est et parum declivis, margo anticus perbrevis excavatus cum latere antico alam parvulam format. Simus pallii angustus rel acutangulus, antice obtusus est.

Diese Art, welche in $\mathrm{K} \ddot{0} \mathrm{~m}$ er's Abtheilung de. Uosinia scabriuscula gehört, zeichnet sich zmmal durch ihren sehr regelmässigen fast kreisrunden
Cette espèce appartenant à la section de la D. scabriuscula, établie par Mlr Römer, se distingue surtout par ses contours très-reguliers 
Umriss aus, so dass die Höhe der Breite gleich kommt. Der luintere Rückenrand ist ziemlich lang und wenig abschüssig, die vordere sehr kurze Rückenseite bildet gewissermassen einen kleinen Flügel mit dem Vorderrande. Die Mantelbucht reicht etwas über die Mitte der Schalen hinaus, ist schmal und vorn gerundet. - Unsere Muschel befindet sich in der Sammlung des Herrn E. Hartvig in Herruliut. presque circulaires, la hauteur égalant la largeur. Le bord dorsal postérieur est assez allongé et peu incliné, le bord dorsal antérieur très-court forme, avec le bord antérieur, une sorte de petite aile. Le sinus pallial dépasse légèrement le milieu des valves; il est étroit el arroudi en avant.

La coquille décrite se trouve dans la collection de Mr. E. Hartvig à Herrnhut.

\section{Anomblocardia subrubra I)kir.}

Taf. XXVIII. Fig. 1 latus internum valvae sinistrae, Fig. 2 latus extcruum valvae dextrae, Fig. 3 dorsum conchae.

Testa ovata, parum obliqua, subrubra, intus alba, unbones versus flavescens, valde tumida, epidermide fusca villosa, in sulcis setigera obducta, costis 36-40 subgranosis exceptis posterioribus latioribus sulco mediano bipartitis, instructa; umbones tumidi remotiusculi, subcancellati, paullulum incurvi, antrorsum inclinati; area ligamenti subcavata magna, impressiones musculares leves, postica panllo major; cardinis denticuli inaequales haud obliqui; linea pallii satis impressa. - Long. 42 mill. Long. alt. crass. ratio his numeris respondet $100,60,60$.

Habitat ad Philippinas insulas teste beato H. Cuming.

Das eiförmige, nur wenig schiefe, ziemlich dünnschalige Gehäuse ist mit 36 bis 40 nicht sehr erhabenen Ripplien rerselıen, die mit Ausnahıe der hinteren durch eine Furche gelleilt und durch concentrische Reifchen fein gekörnt erscheinen. Die Farbe ist blass rostbraun, die Epidermis, wie bei einer ganzen Reihe von Arten, blätterig und in den Furclien zwisclien den Rippen borstesartig vertängert.

Diese wic mehrere andere Formen sind nicht vollkommen gleichschalig; sie näherı sich daher der Gatlung Scapharca, welche bei der grossen Menge und Mannigfaltigkeit der Arcaceen zur Novitates 11. A. XX. Mai 66 .
Coquılle ovoïde, légèrement oblique, assez nince, garnie de $36-40$ petites côtes peu saillautes, qui paraissent, à l’exception des postérieures, divisées par un sillon et finement granulées par des stries concentriques. Couleur de rouille pale; l'épiderme comme chez plusieurs espèces, foliacé et alongé en soies dans les sillons entre les côtes.

Cette espèce, ainsi que quelques autres, n'est pas parfaitement équivalve; ainsi elles s'approchent du genre Scapharca, qui à cause du grand nombre et des diverses modufications des Arcacées et pour faciliter leur revue, saurait être adopté 
leichteren Uebersicht wohl als Abtheilung benutzt werden kann, aber zur Aufstellung als Gattung keine hinreichende Begrüudung findet. conme section, mais ne parait pas suffisamment fondé comme genre.

\section{Anomalocardia rugilera I)kr.}

Tab. XXVIII. Fig. 7 latus externum valvae dextrae, Fig. 8 dorsum conchae, Fig. 9 latus internum ralvae sinistrae.

Testa suboblique ovala, crassa el ponderosa, tumida, epidermide fusca sublamellosa vestita, utrinque subaurita, margine antico valde aequaliterque curvata, postice praducta subattenuata, albida, costis radiantibus crassis subplanis transverse rugosis 38-40 instructa, costae anticae fissae vel canaliculatae, costae posticae planiores, interstitia transversin sulcata costis ter angustiora; umbones valde tumidi parun incurvi prominentes, satis distantes; area cardinalis prafunda; cardo denticulis 62-66 inaequalibus medianis minoribus ex parte dichotomis instructus; impressiones musculares magnae haud profundae. - Long. $76-78$ mill. Long. altit. et lat. ratio mumeris $100,78,70$ respondet.

Habital in Indiis.

Diese schwere dickschalige Art, welche in die Nälse der A. scapha Chemn. gehört, variirt ziemlich im Umriss. Ein Exemplar unserer Sammlung, welclies von Zanzibar stammen soll, ist nach hinten etwas gestreckter und am Bauchrande minder gebogen. Besonders charakteristisclı für diese Muschel sind die starken quergerunzelten Rippen, wovon die rorderen mehr oder minder deutliche Furchen zeigen. Die Zwisclienräume zwischen den Rippen sind quer gefurcht. In denselben bemerkt man Spuren der dinnblätterigen braunen Epidermis. Die sehr aufgetriebene» Wirbel liegen ziemlich nach vorn, und besitzen eine gelblicbe Färbung, auch sind an dem einem der beiden vorliegenden Exemplare die Schalen innen unter den Wirbeln gelblich.
Celte espèce lourde el épaisse, voisine de l'Arca scapha Chemn., est très-variable dans ses contours. Un exemplaire de notre collection, provenant vraisemblablement de Zanzilsar, est plus élancé à sa partie postérieure et moins courbé au bord ventral. Notre coquille est principalement caracterisée par ses côtes fortes, transversalement rugueuses, dont les antérieures présentent des sillons plus ou moins apparens. Les interstices entre les côtes sont sillonés transversalement et l'on y lemarque des traces de l'épiderme brun, foliacé et mince. Les crochets fortement renflés sont situés assez en avant el sont de couleur jaunâtre. De même dans les deux exemplaires, que nous avons sous nos yeux, les valves sont jaunâtres à l'intérieur sous les crochets. 


\section{Anomalocardia oblonga Phil.}

Tab. XXIX. Fig. 7 latus externum valvae dextrae, Fig. 8 dorsum conchae, Fig. 9 latns intermum valvae sinistrae.

„Arca testa ablanga, fere aequilatera, utrinque rotundata, tumidissima, aequivalvi, alba, versus apices rufescente; epidermide tenni obtecta; costis circa 20 elevatis, gramulatis, interstitia aequantibus; area mediocri declivi."

Arca oblonga Phil. Abb. u. Beschr. etc. vol. 11l, pag. 85. Tab. V. Fig. 6.

Patria: Mergui in ditione quondam Birmanorm.

Diese ausgezeichnete, nicht häufige, ungemein aufgetriebene, im Verhältniss zu ihrer geringen Grösse ziemlich dickschalige, Art scheint in mehrer Beziehung nicht unbetrachtlich zu variiren; namentlich zeichnet sich das hier abgebildete Exemplar von dem ron $\mathrm{Philip}$ i beschriebenen durch etwas breitere minder knotige und unregelmässige Rippen aus. Eiu anderes der Cuming'schen Sammlung angehöriges Exemplar von Bombay zeigt anf dichter liegenden Rippen nur feine Körnchen.

Anmerk. Area oblonga Goldf. ist eine fossile Cucullaca Mill. Sow., Areacites oblongus Sehl. Petr. I. p 204 eine zweifelhafte Art; daher kann der I'hilippische Name fuir gegenwärtige Art verbleihen.
Celte coquille distinguée et pen commune, fortement renflée et assez épaisse en comparaison de sa petitesse, parait être très-variable dans plusieurs caractères. L'exemplaire figuré se distingue de celui, que Philippi a décrit, par ses côtes un peu plus larges, moins noduleuses et irrégulières. Un autre exemplaire de Bombay, appartenant au Musée Cuming, ne montre que de fines granulations sur ses còtes plus rapprocliées.

Note Area oblonga Glat. est une espèce fossile de Cuenllaea Mill. Sow., Areacites oblongus Sehl Petı. I. p. 204 est une espèce douteuse; ainsi le nom donné par Philippi peut être conservé pour notre coquille.

\section{Anomalocardia panciglanosa Ilir'.}

Tab. XXIX. Fig. 10 latus extermm valvae dextrae, Fig. 11 dorsum conchae, Fig. 12 latus internum valvae sinistrae.

Testa oblonga, subaequilateralis, haud ponderosa, utrinque rotundata, postice perparum producta, valde tumida, tota alba, epidermide temi vix lamellosa, viridi-cinerascente decidua obducta, costis circa 20 crassis, elatis, rotundatis instructo, costae distantes interstitiis cavatis panllo angustiores, exceptis posticis nodos singulos prominentes irregulares ferentes; umbones submediani, crassi, distantes; areae parum cavatae antica pars a ligamento nigro utrinque nudata. - Long. 60 mill. Long. alt. crass.ratio haec est 100, 70, 66.

Habitat in sinu Siamensi. 
Diese Art unterscheidet sich von der vorhergehenden durch viel bedeutendere Grösse und verhälınissmässig stärkere und mehr vereinzelte Knoten, auch sind die Dimensionen etwas verschieden. Die sehr häufige ebenfalls indische $A$. gramosa $L$, welcher sich diese und die vorhergehende anschliessen, ist dickschaliger, mit mehr Knoten besetzl und durch die sehr aufgetriebenen starken Buckel bedentend höher.
Cette espèce se distingue de la précédente par son volume beaucoup plus grand et ses noeuds proportionalement plus forts et plus épars. De même les dimensions sont différentes. Arca granosa $L$., espèce des Indes très commune, dont notre espèce et la précédente sont voisines, est plus épaisse, garnie d'un plus grand nombre de tubercules et parait beaucoup plus haute à cause du renflement considérable de ses crochets forts.

\section{Anomalocardia Carpenteri Ilir.}

Tab. XXX. Fig. 7 latus valvae sinistrae externum, Fig. 8 dorsum conchae, Fig. 9 latus internum.

Testa oblongo-ovata parum ventriosa, extremitate antica rotundata, postica producta attenuata, superne obtusangula, albida, haud ponderosa, costis crebris (32-34) subrugosis, anticis bifidis granosis, posticis integris planis sublaevibus instructa, interstitia costis triplo paene angustiora, epidermis fusca lamellosa, in sulcis posticis setosa; umbones parum prominentes; area ligamenti angusta, profunda; cardo angustus denticulis parvis instructus. Long. 57 mill. Long. alt. crass. $=100,55,40$.

Ilabitat ad litus Novae Hollandiae australe.

Habitu haec mea species cum Arca setigera Dkr. (Moll. Guin. pag. 45. Tab. IX. Fig. 16-18) interdum paullo contracta, manca ac debilis paullulum convenit. Hoc loco notandum est, Arcam setigeram cl. Reevei ad Barbatias pertinere.

Die Schalen dieser Art sind ziemlich lang und sclımal, wenig aufgetrieben, nicht selsr stark und mil 32 bis 34 flachen Rippen versehen, wovon die vorderen etwas schmäleren in ihrer Mitte eine seichte Furche zeigen. Sämmtliche Rippen sind etwa dreimal breiter als deren Zwischenräume. Der Schlossrand bildet mit der hinteren Extreunität einen stumpfen Winkel. Der schwach gebogene Bauchrand geht allmälig in die regelmässige Rundung des Vordertleils ïber. Das Schloss ist schunal und mit entsprechenden kleinen vertikalen Zähnclen besetzt. Die Wirbel ibberragen nur wenig den Schlossrand. Die Blälterlagen der Epjdermis gehen in den Zwischenräumen zwischen den
Les valves de celte espèce sont assez longues et étroites, peu renllées, de substance médiocre et garuies de 32-34 côtes aplaties, dont les antérieures, qui sont un peu moins larges, présentent à leur milieu un sillon léger. Toutes les côtes ont une largeur à peu près trịple de celle des interstices. Le bord cardinal forme un angle obtus avec l'extrêmité postérieure. Le bord ventral, faiblement courbé, se perd insensiblement dans la partie antérieure régulièrement arrondie. La charnière est étroite et garnie de petites dents verticales. Les crochets sont peu saillants au dessus du bord cardinal. Les couches foliacées de l'épiderme se changent en écailles acuminées 
Rippen in borstenförmig zugespitzte Schuppen uber. Das Arealfeld ist ziemlich vertieft und fast gänzlich vom selıwarzbraunen Liganent eingenommen. en forme de soies dans les interstices entre les côtes. L'aréa est assez approfondie et presqu' entièrement occupé par le ligament de couleur brune noirâtre.

\section{Arca bistrigata I)kil.}

Tab. XXX. Fig. \& latus intermum valvae dextrae, Fig. 5 lalus externum valvae sinistrae, Fig. 6 dorsum conchae.

Testa oblonga subquadrangula, temuicula, antice rotundata, interdum subtruncata, postice obliqua, in margine ventris subsinuata, costulis latis rugosis, mnticis usque ad mediam testam canaliculatis et gramulatis instructa, albida, ad umbones parvos aculos parum porrectos subincurvos strigis binis cinereo-viridescentibus signala; epidermis in interstitiis setosa; cardo perangustus, linearis, denticulis plurimis munitus; area angusta plana, subprofunda, a ligamento paene omnino occupata; pagina interna lactea sub umbonibus virescens. Long. speciminum quae exstant mujorum 43 mill Long. alt. crass. $=100,48,42$.

IIabitat in litore Indico prope Bombay H. Cuming, China, de Cochenhausen.

Eine kleine ausgezeichnele, ziemlich diinnschalige Arca, die durch zwei von den spitzen Wirbeln ausstrahlende aber beim weileren Wachsthum der Schalen verscluwindende graue oder grünlich graue Streifen sofort kenntlich ist. Ihr Umriss ist fast reclangulär, an den Ecken gerundet, am hinteren Bauclirand etwas verlängert, mehr nach vorn, gegenüber den Wirbelı elwas ausgebuclılet. Die Rippchen sind flach, vorn bis zur Mitte, zuweilen über die Mitte der Schalen hinaus, tief gefurcht und daher zweitheslig und durch vertiefte concentrische Linien, welche darïber hinweglaufen, granulirt, hinten erscheinen die Rippchen breiter und gewöhnlich ungetheilı; an einem der vorliegenden Exemplare bemerkt man jedoch eine zweiund dreifaclse leichte Furchung der hinteren Rippchen. Die braune leicht zerstörbare Epidermis ist dün und in den sehr schmalen und tiefen Zwischenräumen zwisclıen den Rippchın borstenförmig. Die innere milchweisse Farbe lässt in der Nälıe der Wirbel die oben erwähntengraugrünen Streifen durchleuchten.
Pelite espèce, distinguée, assez mince, aisément reconnaissable par deux rayons de couleur grise ou grise-verdâtre sortant des crochets aigus, mais s'effaçant par l'accroissement ultérieur des valves. Son contour est presque rectangulaire, arrondi aux angles, légèrement allongé au loord ventral postérieur, légèrement sinueux en avant, vis à vis des crochets. Les petites côtes sont aplaties, en avant jusqu' au milieu des valves et quelquefois plus loin, profondément sillonées, divisées en deux et granulées par des stries enfoncées concentriques. A la partie postérieure les côtes sont plıs larges et en général non divisées; cependaut dans l'un de nos exemplaires nous remarquons un sillonnement léger double et triple des côtes postérieures L'épiderne brun el caduque est mince et allongé en soies dans les interstices entre les côtes étroits et profonds. A l'intérieur au voisinage des crochets l'on remarque les rayons grisátres mentionnés plus-laut sur le fond blanc de lait. 


\section{S. Area Adamsianal I)kr.}

Tab. XXIX. Fig. 4 latus externum valvae dextrae, Fig. 5 latus internum valvae sinistrae, Fig. 6 dorsum conchae.

Testa ablonga, plerumque subquadrangula, utrinque subtruncata, in margine dorsali antice et postice angulata, convexa, tenuicula, albida, costis angustis confertis $28-30$ granulatis anticis bipartitis, posticis simplicibus latioribus instructa; epidermis fusca subfinbriatolamellasa, in interstitiis setigera; margo ventris paullulum sinuatus cum $m$. dorsali paene parallelus; umbones prominuli antrarsum inclinati; area cavata, antice a ligamento haud plene accupata. - Long. speciminis depicti 26 mill. Long. alt. crass. his mumeris respondent $100,50,50$.

Habitat in Mari Chinense. Ed. Belcher. Exstat in coll. Cumingiana.

Diese Muschel ist der vorhergehendeı ähnlich, aber oben an beiden Extremitäten dentlich gewinkelt, auch zeigt die Beschaffenbeıt der Oberfläche Verschiedenheiten. Die ziemlich breiten, oben kaum merklich ausgebuchteten 'Wirbel ragen nur wenig über dem Schlossrande herror. Von denselben strahlen 28 bis 30 flache Rippchen aus, deren vorderen getheilt und körnig, die linteren dagegen etwas breiter und platter sind. Die Epidermis geht in den sclımalen Furchen in kurze Borsten über. Innen sind die Schalen gelblich weiss.

In Form und Dimensionen variirt ïbrigens die vorliegende Art ziemliclı; sie besitzt zuweilen einen mehr bogigen Bauchrand und wird auch beträchtlich grösser.
Celte coquille ressemble à la précédente, mais elle est distinctement anguleuse en haut aux deux extrêmités et les caractères de la surface présentent plusieurs différences. Les crochets assez larges, irsensiblement simueux en haut, surpassent à peine le bord cardinal, qui donne origise à 28-30 petites côtes aplaties, dont les antérieures sont divisées et granulées, les postérieures un peu plus larges et lisses. L'épiderme se cliange en soies courtes dans les sillons étroits. L'intérieur des valves est blaıc jaunâtre.

Notre espèce varie considérablement en forme et dimensions: quelquefois elle devient beaucoup plus grande et son bord basal est quelquefois plus arqué.

\section{Barbatia pectunculiformis Dhr.}

Tab. XXVIII. Fig 4 latus externum valvae dextrae, Fig. 5 latus internum valvae sinistrae, Fig. 6 dorsum conchae.

Testa tenuicula, subovata, antice producta et rotundata, postice brevior, paene oblique truncata, striis incrementi concentricis costulisque radiantibus confertim decussata, albida, epidermide atro-fusca temui, sed firma obtecta; umbones parvuli subacuti, antrorsum inclinati, 
paene mediani; cardo curvatus, denticuli sub umbonibus minimi; area brevis valde angusta. - Long. 28 mill Long. alt. et crass. ratio numeris 100, 75, 50 respondet.

Habitat ad litus Borneense, teste beato H. Cuming.

Haec species singularis formam Pectunculi cujuslam minoris refert, testaque tenuicula, umbonibus parvulis submedianis, cardinis structura aliisque notis ab ommibus ceteris Barbatiis, quae hucusque imotuere, bene distinguenda est.

Diese sehr interessante eigenthümliche Art erinnert in ilhrem ganzen Aeussern an die Galtung Pectunculus Lam., zumal auch wegen der Schlossbildung und der fast in der Mitte der Schalen liegenden Wirbel. Die Oberfläclse der weissen von einer dunkelbrannen Epidermis bedeckten Sclualen erscheint wegen der scharfen concentrischen Wachsthumsteifchen, die von dichten strahlenföruigen Rippchen durchkreuzt werden, wie gegittert. Der innere Schlossrand ist gebogen, wie bei Peclunculus, unter den Wirbelı sind die Zähnchen sehr klein. Das Schlossfeld ist schmal und klein.
Cette coquille singulière el curieuse rappele par l’ensemble de soll extérieur, ainsi ıue par la formation de la charnière et les crochets silués presqu' an milieu des valves, le genre Pectunculus Lam. La surface des valves blanches, recouverte d'un épiderme brun foncé, parait treillissée à cause des stries d’accroissement concentriques et aiguës, croisées par les petites côtes rayonnantes et rapprochees. Le bord cardinal interne est courbé comme chez les Pectunculus, et les dents sont très-petites sous les crochets. L'aréa cardinale est étroite et detite,

\section{Rarbatia Rodatzi Dlir.}

Tab. XXIX. Fig. 1 latus intermum ralcae sinistrae, Fig. 2 dorsum conchae, Fig. 3 latus extermum valvae dextrae.

Testa crassa ovato-oblonga, subelliptica, concexa, fusca, ad umbones tumidos albo variegata, costellis radiantibus confertis ina equalibus striisque incrementi undique gramulata, epidermide obscure fusca setigera plerumque plus mimusve obliterala, obducta; cardo denticulis utrinque inflexis instructus; area ligamenti sulcata profunda acutangula; color internus albidus et rufescens; margo conchae paene laevigatus, fuscus, obvallatus. - Long. speciminis depicti 38 mill. sed multo major fit. Long. alt. et crass. ratio haec est 100,68,54.

IIabitat ad insulam Zanzibar in litore Africano orientali. Beatus R. Rodatz.

Diese Species gehört in die Nähe der Barbatia (Arca) cruciala Phil. und der fusca des Brug., doch unterscheidet sie sich von der ersteren hinreichend durch die Beschaffenheit der Rippen, da bei der Philippischen Art in der Mitte des Ge-
Celte espèce est voisine des Barbatia (Arca) cruciata Phil. el fusca Brug., mais elle se distingue sullisanment de la première par ses côtes, puisque dans l'espèce de Philippi au milieu de la coquille deux côtes plus fortes sont régulière- 
häuses regelmässig zwei stärkere mit sechs schwächeren abweclsseln, Barbatia fusca hat dagegen eine viel gestrecktere, minder elliptisclue Form und auch leiclitere Schalen. ment alternantes avec 6 plus faibles, tandisque Barbatia fusca a une forme beaucoup plus élancée, moins elliptique et les valves plus minces.

\section{0!. Barbatia eximia Oki".}

Tab. XXX. Fig. I latus internum valvae sinistrae, Fig. 2 latus externum valvae dextrae, Fig. 3 dorsum conchae.

Testa ovato-oblonga, valde compressa, in medio ventris margine coarctata et sinuata, utrinque rotundata, postice latior, alba fusco variegata, costulis radiantibus parum granosis densissimis instructa, epidermide atro-fusca setigera induta; area ligamenti angusta, valde declivis, profundissima, utrinque angulatim sulcata; umbones parvi subacuti; cardo denticulis utrinque obliquis, medium versus sensim obliteratis instructus; color internus lacteus, in regione impressionum muscularium rufus. - Long. 82 mill. Long. alt. crass, ratio his circa numeris respondet 100, 44, 26.

Patria ignota. Exstat in coll. beati H. Cuming.

Eine grosse ausgezeiclnete, uugemein flache Muschel, die auf den ersten Blick von allen bislang bekanut gewordenen Arten ihres Geschlechtes sich unterscheidet, auch, so viel mir bekannt ist, kein Analogon unter den vielen fossilen Arcaceen hat. Die Schalen sind lang eiförmig, unten, etwa in der Mitte des Bauches, eingebuchtet und eingeschnürt, vorn etwas verschmälert, hinten dagcgen ziemlich erweitert und von zahlreichen fast glatten Rippchcı bedeckt, dere॥ Zwischenfurchen dicht aneinander liegende vertiefte Punkte zeigen mit noch theilweise erbaltenen starken Borsten der Epidermis. Das Arealfeld ist winkelig gefurcht, selir vertieft und abscluüssig, so dass beide Seiten desselben in einem spitzen Winkel sich vereinigen. Die Wirbel treten nur wenig hervor. Die selır genaue Abbildung maclıt eine weitere Beschreibung überflïssig.
Coquille grande, très-aplatie, se distinguant au premier coup d'oeil de toutes les espèces connues du genre, et ne possédant pas d'analogue parmi le grand nombre d'Arcacées fossiles qui nous sont connues. Les valves sont ovales allongées, sinueuses et étranglées en bas à peu près au nilieu du ventre, légèrement retrécies ell avant, élargies ả sa partie postérieure et couvertes de petites côtes nombreuses presque lisses, dont les interstices unontreut des points enfoncés et très-rapprochés. sur quelques-uns desquels se sont conservé de fortes soies de l'épiderme. L'aréa est anguleuse, sillonée, fortement cnfoncée et inclinée, de manière que ses deux côtés se joignent en angle aigu. Les crochets sont peu saillants. Par notre figure parfaitement exacte une déscription détaillée est rendue superflue. 


\title{
102. Barbatia venusta I)kr.
}

\author{
Tab. XXXI. Fig. 1.
}

Testa oblique ovata, tenuis, subtrigona, aequivalvis, valde inaequilatera, tumidiuscula, subgibbosa luteo alba, ad umbones aurantia, radiatim costata et striata, latere antico brevissimo subattennata et rotundata, postico producta, dilatata, compressa; margo cardinalis et posticus linea curvata conjuncti; umbones prominuli, approximati, antrorsum inclinati. Long. 25 mill., alt. maxima in ${ }^{2}{ }_{3}$ longitudinis testae sita, 14 mill.

Arca venusta Dkr. Zeitschr. F. Mal. 1852 pag. 5\%.

Patria ignota. Extat in coll. clar. Fr. Pätel Berolinensis.

IIaec Arcarum species singularis praesertiun forma sua oblique ovata subtrigona, valvulis valde inaequilateris et carinis omenio deficientibus facile dignoscitur. Testa tenuis costis radiantibus untice gracilibus et confertissimis, latus posticum nersus sensim crassioribus et distantibus circa 39 instructa est. Interstitia subtilissime et elegantissine striata sunt. Color luteo-albus, ad umbones aurantius; ligamenti area angustissima. Cardo denticulis gracilibus utrinque obliquis munitus. Totam testam nudam esse et epidermide omnino carere dolendum est. Specimen depictum fortasse ad aetatem adultam nondum perrenit. Unicum est, quod unyuame ridi.

Diese kleine Arca zeiclınet sich durch ihre schief eiförmige an Modiola oder Volsella erinnernde Gestalt, die kleinen weit ıach vorn liegende॥ Wirbel, den sehr breiten Hintertheil, den gänzlichen Mangel einer Carina, düne Sclale und eigenthümlicle elegante Sculptur vor allen anderen Arten aus. Dieselbe kömnte mit demselben Rechte wie gewisse andere Arcaformen als Typus einer besonderen sogenannte॥ Untergatlung der Arcaceeı angeschen werden; doch labeu solche Gruppirungen "olıne anatomische Untersuchung der Thiere nur einen geringen Werth, la sie höchstens zur Jeichteren Uebersicht der vielen Arten dienen können.

Die vorliegende Art ist mir bis jetzt nur in dem einzigen hier abgebildeten Excmplare zu Gesicht gekommen, so riele lebende wie fossile Arcaceen mir auch durclı die Hände gegangen sind.

Nosilates II A. Mai Gi
Cetle petite espice se distingue de toutes les autres par sa forme oblique oralaire, rappelant celle des Modiola ou Volsella, par ses petits crochets placés en avant, par sa partie postérieure trèsJarge, labsence parfaite de carènes, par son test mince et sa sculpture élégante. On pourait la regarder, avec le mêne droit comme plusieurs autres espèces da genre Arca, comme lype d’un sous-gentre des Alcacés; mais ces divisions ne possédent, saus l'examen anatonique des mollusques, yu'une valeur subordonnée, puisqu'elles peuvent tout au plus servir à faciliter la revue des espèces nombreuses

Malgré la quantité immense d'Arcacés récents et fossiles, qui ont passé par mes mains, l'exemplaire liguré est Je seul de son espèce que j’ai su. 


\section{0\%. Barbatia mollis 10ki.}

- Tab. XXX. Fig. 2, 3,4.

Testa oblonga, alba, tenuis, valde inaequilatera, antice brevis rotnudata, postice producta infra paullulum attenuata pariterque rolundata, basi vix curvata, striis radiantibus temuissimis, mumerosissimis partim dichotomis instructa, striis nomullis incrementi concentricis signata, epidermide tenuissima fusca, in costarum interstitiis brevipilosa, obducta; umbones obtusi, approximati, antrorsmn inclinati; cardo pertennis, linearis, denticulis minimis utrinque divergentibus munitus; ligamenti area angusta lanceolata. - Long. 26 mill. Long. alt. crass. ratio mumeris $100,62,60$ respondet.

IIabitut ad insulas Fidschi (Viti Levu). Misit clar. Graefe Dr. Exstat IIamburgi in Museo clar. Godeffroy, nec non in nostra ipsa Molluscorum collectione.

Diese sehr dünnschalige Art zeichuet sich besonders durch die ungemein feinen und regelmässigen von den stumpfen Wirbeln auslaufenden und meist dichotomeu, lin und wieder schwach gekörnten Rippclsen aus. Die brame Epilermis isi schr zart und zwischen den Rippchen kurz und weich behaart. Der Uniriss der Schaleu ist oval; der Schlossrand bildet mit dem vordern und binteru Theil derselben sehr stumpfe Winkel. Die kleinen Zähnchen divergiren beiderseits.
Cette espèce très-mince se distingue surtout par ses côtes extrêmement fines et régulières q̨ui descendent des crochets oblus et sont, en général, dichotomes et légèrement granulées ęi et là. L'épiderme est brun et très-mince, garni, entre les côtes, de poils courts et moux. Le contour des valves est ovalaire et le bord cardinal forme, avec leurs extrémitės antérieure et postérieure, des angles très-obtus. Les petites tents sont divergentes des deus côlés.

\section{IBarloatia Giliyana IVkr.}

Tah. XXXI. Fig. 5, 6, 7 .

T'esta oblonga, subcompressa, solidiuscula, alba, parum inaequilatera, antice rotundata, postice oblique truncata, interdum paullo enarginata, margine rentris subsinuata, costulis radiantibus confertis striisque concentricis eleganter sculpta, epidermide fusca setigera marginem posticum versus lamellosa et lacerata vestita; umbones obtusi approximati, cardo denticulis parvis anticis et posticis paullo divergentibus instructus; ligamenti area angusta profunda, lanceolata - Long. 35 mill. Long. alt. crass. $=100,50.40$.

Patria. Ex Indias misit clar. lirüre Mus. Godeffroy. 
Diese Art erinnert in mehrfaclser Beziehung an Barbatia Ilelblingii Chemn., doch ist der Umriss, zumal durch den gewinkelten Hintertheil, etwas abweichend, die Sculptur feiner und die Beschaffenheit der Epidermis verschieden. Aussen ist dic Muschel sclmutzig weiss, innen milchweiss, in der Gegend der Wirbel gelblich.
Celle espece s'avoisine, par plusieurs caractères, à la Barbatia Helblingii Chemm., mais elle en dillëre par son contour qui préseute la partie postérieure anguleuse, par sa sculpture plus fine et par son épiderme. Les valves sont d'un blanc sâle à l'extérieur, en-dedans elles sont d’un blane de lait et jaunâtre sous les croclıets.

\section{Area angusta I)kis.}

Tab XXXl. Fig. 8, 9, 10 .

Tesia ablonga, angusta, inaequilateralis, solidinscula, sordide alba subcinerea, radiatim costata. concentrice denseque striata, antice rotmdata, postice producta, emarginata, carina obtusa sed satis expressa ab umbonibus ad latus posticum decurrente signata; margoventris perparum curvatus; mbones pareuli incurvi, subacuti; area ligamenti excavata haud lata; cardo linearis denticulis minimis instructus. - Long. 27 mill. Long. alt, et crass. ratio mumeris 100, 40, 40 respondet.

Ilabitat ad Viti insulas. Coll. frat. Godeffroy.

Species testa angusta insignis, convexa, costulis radiantibus coufertis striisque incrementi concentricis concinne cancellata; carina postica obtusa subimbricata, carina antica nulla; margo posticus oblique emarginatus; impressiones musculares et linea palliaris satis distinctae.

Diese Art zeichnet sich Jurch ihre schmalen, ziemlich gleichmässig gewölbten Schalen und die fein gegitterte Oberfläche besonders aus. Die Farbe ist schmutzig weiss, elwas graublau, inuen, besonders an den Muskeleindrücken, bräunlich. Von der Epidermis ist am vorliegenden Exemplare kaum eine Spur vorhanden.
Les caracteres principaux de cette espèce sont les valves étroites, assez également convexes et la surface finement treillissée. Elle est d"un blanc sâle, tirant sur le bleu grisâtre, en-dedans brunâtre, surtout dans les impressions musculaires. L'exemplaire figuré ne montre qu'un vestige de l'épiderme.

\section{Arca insignis Dkr.}

Tab. XXXI. Fig. 11, 12, 13.

Testa oblonga valde inaequilateralis, antice gibbosa, postice oblique truncata, emarginata, pallide fusca, costis sulcisque radiantibus confertis, supra carinam latioribus instructa, epidermide 
lamellosa et hirta obducta; umbones prominentes, valde remoli; area ligamenti plana latissima, albida, rhombus sulciferus latus, corio fusco-nigricante oblectus, strigis vel flammis pallide fuscis circumdatus; cardo linearis denticulis plurimis munilus; fissura mediocris. - Long. 68 mill. Long. all. et crass. ratio $=100,45,58$.

Patria ignota. Exstat in coll. beati II. Cuming Londini.

Testa rugoso-costata el sulcata; carina paullo curva usque ad angulum ventris posticum perspicua. Area latissima altitudinem testae multo superat. Valvae lam inaequilaterae, ut umbones prominentes sextam totius longitudinis partem teneant.

Die vorliegende Art gehört in die Nähe der Arca Noae C., von welcher sie sich indessen durch minder spitzen Vordertheıl, feinere Rippen, blassere Färbung und abweichende Art der Zeichnung unterscheidet.
Celte espèce est voisine de IA. Noae; elle s'en distingue par sa partie antérieure moins acuminée, par ses côtes plus fines, couleur plus pale et caractère différent du dessin.

\section{0\%. Fasciolaria pur'purea Jonas var.}

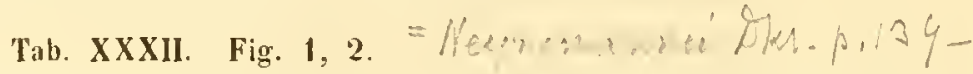

Tesia crassa unicolor rulra, anfractibus $8-9$ anyulatis, in angulo nodiferis instructa, ultimus spira duplo longior, transcersim late planeque coslalus et liralus, superne cavalus, in carina obtusangula nodis crassis distantibus 9 coronatus; apertura ovato-oblanga alba; labrum intcrmum lacteum lacvissinum; columella alba cylindracea, superne costa crassa nunita, inferne triplicata, rostrum subrectum. - Loug. testae 82 mill., lat. 42 mill. Long. apert. 55 mill., ejusque lat. 17 mill.

Ilabitat in portu Natalensi Africae australis.

Diese ausgezeichnete Fasciolarie, für welche indessen der obige Name wenig passt, da ihre Farbe ein reines Braunroth ist, wurde bereits $18+9$ im 3. Bande von Plilippiss "Abbildungen und Beschreibungen neuer oder wenig gekannter Conchylien ${ }^{\star}$ pag. $7 t$ beschrieben und Tab. 1 Fig. 2 abgebildet. Da jedoch das vorliegende Exemplar, welches leider elwas verrieben und an der Mündung beschüdigt ist, in mehrfacher Beziehung abweicht, namentlich die knoten desselben sehr stark hervortreten, auch nicht in der Mitte der oberen Windnnoen, sondern dicht ibler der tiefen Naht liegen,
Cette Fasciulaire distinguée, dont le nom n'est pas bien signifiant, puisqu'elle possede une couleur purement rousse, fut déjà décrite et figurée en 1849 dans le troisième volume de l'ourrage iconographique de Philippi (p. 74 pl. 1. f. 2). Mais comme notre exemplaire, légèrement roulé et imparfait à sa partie orificiale, nontre plusieurs différences du type, nous l'avons figuré comme variéló assez marquée d'une espèce, qui n'est pas trèscommune. Les différences consistent en ce que les tubercules sont fort saillants et placés, non au milieu des tours supérieurs, mais immédiatement 
rerner das Gehäuse mit flachen aber selır deutlichen breiten Querrippen versehen und unter der Naht stark gebuchtet ist, so haben wir dasselbe als eine ziemlich abweichende Varietät der eben nicht häufigen Fasc. purpurea abgebildet.

Fasciolaria lugubris Reeve $=F$. badia Krauss, welche ebenfalls an der Küste Siidafrika's vorkommt, hat ungefähr dieselbe Grösse, weicht aber specifisch sehr ab.

Die Farbe ist auf unserer Zeichnung elwas zu dumkel aufgetragen. au-dessus de la suture profonde el que d"ailleurs le test est entouré de coles larges, peu élevées mais bien marquées, et fortement sinueux au-dessous de la suture. La coloriation de notre figure est un peu trop foncée.

Fasciolaria lngubris Reere $=F$. badia Krauss, qui provient également de la côte de l'Afrique méridionale, est à peu près de la même taille, mais elle montre d’importantes différences spécifiques.

\section{Fasciolaria Aulouini Jonas var.}

\section{Tab. XXXII. Fig. 3, 4 .}

Tesia fusiformis subventrosa, glabra, pallide rubra, in anfractu ultimo albescens, fasciis fuscescentibus cincta, epidermide obscure cornea coriacea laevi et nilida obducta; an/iractus 9 convexi, nodosi, ultimus spira duplo longior, superne nodis valde prominentilus 8 instructus; rostrum mediocris longitudinis subrectum; apertura oblongo-ocata; labrum intus laevissimum albescens; columella superne costa crassa signata, inferne triplicata, colore hepatico tincta; canalis latus pariter hepaticus. - Long. 122 mill, diam. 55 mill. Long. apert. So mill. ejusdem lat. $26-27$.

llabitat Mare Rubrum. Exstat in coll. clar. F. Paetel Berolinensis.

Das Geläuse ist niclıt sehr dickschalig. fast ganz glatt, und nur am Rüssel sclıwach quergefurcht, blassröthlich, auf dem letzten Umgang mehr weiss, von einer glatten glänzenden lederarıgen braunen und fest aufsitzenden Epidermis iberzogen, welclie, gogen das Licht geltalten, blassbraune Querbinden dẹ Schale durchleuchlen lässı. Die inncre Lippe ist durchaus glall; die Spindel trägt gleich melıreren anderen Arten oben eine ziemlich starke Querfalte, unten befinden sich deren drei. Spindel und Canal sind blass leberbraun gefärht.

Das rorliegende Evemplar weicht von der Beschreibung und Zeichnung, die Philippi im dritten Bande seiner Abbildungen ${ }^{*}$ etc. Fasciolaria Tab. III. Fig 1 gegeben, ziemlich ab, zumal durch
Le test n’est pas très-épais, presputue lisse, légèrenıent sillonné transversalement ì la queue. Sa couleur est pale rougeâtre, presłue blanche sur le dernier tour, el il est couvert d'un épiderme lisse et luisant, coriacé, brun, qui laisse a peine apercevoir des bandes transversales din brun pale. La lère intérieure est parfaitement lisse, la columelle est, comme chez plusieurs autres espices, munie en haut d'un pli transversal assez fort: il y en a trois à la partie inféricure. La columralle et le canal sont de couleur de foie pale.

Notre exemplaire diffère de la déscription et le la figure publiées par Philippi daus le vol. Ill. de ses ${ }_{\text {Abbild. Fasciolaria pl. } 3 \text { f. } 1}$ par sa forme plus grêle et par sa lèvre intérieure 
schlankere Gestalt und vollkommen glatte Innenlippe. Was diese letztere Abweichung betrifft, so ist es mögliclı, dass die für gewisse Fasciolarien so charakteristischen inneren Furchen bei der gegenwärtigen Art erst in höherem Alter siclı ausbilden.

Zu dieser von Jouas in der Zeitschrift für Malak. 1846 pag. 63 zuerst beschriebenen Art ist die Figur 17 auf Tab. IV, der Descriplion de l'Egyple citirt.

Bekanntlich sind die Tafeln dieses Werkes theilweise leider gar nicht, zum Theil nur ungenijgend erklärt. Vergl, die treffenden Bemerkungen über Audouin's Bearbeitung der Savigny'scheu Tafeln von Dr. L. Pfe iffer in der Zeitschrift für Malak. 1816 pag. 67. lisse. Quant à sc dernier caractère il serait possible, que les sillons intérieurs, qui sont si caractéristiques pour certaines especes de Fasciolaires, ne se développent, daus notre espèce, qu'à un âge plus avancé.

Mr. Jonas est le premier qui a décrit cette espèce (Zeitschr. f. Malak. 1846 p. 63). II cite la figure 17 de la planche IV. de la Description de l'Egypte. L'on sait, qu'une partie de ces planches n'ont trouvé aucun commentaire et une autre partie est imparfaitement connue. Comparez les remarques de Pfeiffer sur le commentaire d'A udoui u pour les planches de Savigny: Malak. BI. 1846 p. 67.

\section{Nassa (Buccinum) semisulcata Ikrr.}

Tab. XXXIl. Fig. 5, 6.

Testa solidula, nitida, ovato-lurvita, albo luteoque rariegata, fascia lata fusca infia suturam cincta lineolisque transversis fuscis eleganter picta, anfractibus convexiasculis senis, sutura incisa separatis per longitudinem plicatis instructa; plicae breves mox cvanescentes, plurimae ad suturam albidae ct crenatae; anfractus ultimus reliquis panllo breviar, ad basin transversim liratus; apertura otata; labium dextrum incrassatum album, intus obsolete sulcatum; columella arcuata, superne denticula absaleto munita; canalis brevissimus; fances fuscae. - Long. 19, diam. max. 8 mill.

Patria ignota, Exstat in coll. ornat. Christophori Reents Ilamburgensis.

Buccinum semiplicalum Dhr. in Zeitschr. f. Mal. 1853 pag. 59.

Species elegantissima, spira valde exerta abtusa, plicis brevibus ad suturam nodulos albos et coerulescentes formantibus cancinnc sculpta; anfractus ultimus pro testae statura brevis lineolis 8 aurantis-fuscis cinctus, superiores paullo distantes, inferiores tres modice incisae, canalis truncalus brevissimus in margine superiore castaneo tinctus.

Diese zierliche Art zeichnet sich aus durch ihre lang gezogene Spira mit gerundeter Spitze, die kurzen Fältchen, welche an der Nalıt in Knötchen oder Papill $e_{n}$ endigen, die feinen besonders auf
Cette espèce élégante se distingue par sa spire élancée à sommet arroudi, par les petits plis qui se terminent, près de la suture, en petits noeuds ou papilles, par ses lignes transversales fines, 
der letzten Windung deutlichen Querlinien und den sehr kurzen abgestutzten Kanal. Sie hat einige

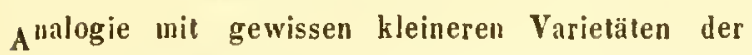
Nassa suturalis Lam. zumal wegen der Querlinien, doch ist ihr Habitus ein ganz anderer; auch erinnert sie an Nassa gaudiosa Hinds.

Da A. Adams bereits 1851 in den Proc. of the 200l. Soc. of Lond. p. 107 eine Nassa semiplicata beschrieben, so ist der Name in semisulcata umgeändert worden. visibles surlout sur le dernier lour et par son canal raccourci et tronqué. Elle montre quelque analogie avec certaines petites variétés de la Nassa suturalis Lam., principalement à cause des lignes transversales, cependant son labitus est entièrement différent. Elle est aussi roisine de Nassa gaudiosa Hinds.

Nous avons changé le nom de semiplicala en semisulcata à cause de la Nassa semiplicata Adams, décrite dans les Proceed. of the zool. Soc. of Lonion 1851 p. 107.

\section{Nassa coturnix Dkir.}

Tab. XXX11, Fig. 7,8 .

Testa ovato-conica, acuta, glaberrima, nitidissima, lurida, luteo et fusco variegata saepius albo conspersa, anfractibus 7-8 convexiusculis, supremis subtissime gramulato plicalis instructa, ultimus ceteris paullulum major lineisque 10-12 transversis fuscis subtilibus cinctus; labrum intus sulcatum; columella arcuata supra denticulo munita, infra fere uniplicata yramulisque nonnullis signata; apertura ovata; canalis brevis valde emarginatus. - Long. 18, diam. max, 9 mill.

Ilabitat insulas Philippinas.

Nassa colurnix Dls. in Zeilschr. f. Mal. 1853, pag. 59.

IIaec species elegantissima peraffinis est Buccino (Nassae) picto Dkr. (Phil. Ablild. vol. III. p. 65 Tab. II. Fig. 6), a quo tamen differt fasciis duabus articulatis et fuscia nigro-castanea in suprema faucis parte plane defcientibus, sutura minus profunda. gramulis columellaribus et fauce subfusca neque alba.

Das Gelı̈̈use isı ziemlich słark, glänzend, gelblich und rötlılich gefärbt, häufig weisslich gespreukelt. Die 7-8 Umgänge sind schwach convex, die obersten mit feinen Längsfältclıen versehen, die ubrigeı glatt, der letzle ist etwas grösser als die Spira und mit 10-12 feinen bräunlichen Linien umgeben. Das Labrum ist innen gefurcht, die Columella gebogen, oben mit einem kleinen Höcker, unten mit einer kleiuen Falte und mit einigen löruchen verselıen.

Diese Art ist der Nassa picta Dkr. zunächst
Le test est assez solide, luisant, de couleur jaunâtre oul rougeâtre, souvent parsemé de taches blanclies. Les lours de spire, au nombre de 7 à 8 , soul légèrement convexes, les suprèmes garuis de plis fins longitudinaux, les autres lisses, le dernier un peu plus grand que la spire et entouré do 10 - 12 lignes fines brunâtres. La lèvre extérieure est sillonnée en-dedans, la columelle courbée, munie en haut d'un petit tubercule, en-bas d'un pli inince et de plusieurs gramulations. 
verwandt; doch fehleu ihr die beiden unterbrochenen Bindelı und das dunkel kastanienbraune Band oben in der Miundung, auch ist die Naht minder tief, der Schlund bräunlich, nicht weiss und die Columella gekörnt.
Cette espèce est roisine de la Nassa picta $D k r$., mais elle ne possède pas les deux fascies interrompues et la fascie d'un marron foncé à la partie supérieure de la bouche. La suture est moins profonde, l'intérieur de la bouche brunâtre et la columelle granulée.

\section{Fusus tenuiliratus Dhir.}

Tab. XXXIII. Fig. 1, 2.

Testa crassiuscula, gracilis, fusiformis, alba strigis fammisque nonmullis pallide fuscis picta, anfractibus 8-9 aequaliter convexis sutura distincta sejunctis, costulis crebris rotundatis glabris inaequalibus cincta; costarum interstitia subtilissime cancellata; anfractus ultimus spira satis longior, $3 / 5$ scilicet totius testae longitudinem aequans; anfractus primordiales per longitudinem plicati; rostrum allenuatum; canalis angustus; labrum internum sulcatum albmin. - Long. 72 mill., diam 24 mill.

Patria ignota.

Species habitu et sculptura genuina insignis in collectione moll. clar. Paetel Berolinensis exstat.

Das Gehäuse dieser bis jetzt unbeschriebenen Schnecke ist schlank spindelförmig, weiss mit einigen blass bräunlich rollıen Längsstreifen und Flammenzeichnungen geziert. Die 8 bis 9 durch eine deutliche Naht getrennten Windungen sind gleichmässig ziemulich stark convex und werden von runden, glatten slärkeren und feineren Rippchen unguirttet der Art, dass jc zwei stärkere Rippchen eine bis zwei feimere fadenförmige einschliessen, was besonders deutlich auf der letzten Windung hervortrilt. Die schmalen Zwischenrăume zwischen den Rippcheu erscheinen unter der Loupe fein gegittert. Die ersten 4 bis 5 Umgänge tragen feine Längsfalte». Die Mündung ist länglich eiförmig, an dem innern Mundsaume gefurclıt, der Canal schmal und lief, der Rüssel
Le test de cette espèce indécrite jusqu' a présent est grêle, fusiforme, blanc, orné de plusieurs lignes longitudinales et flammules pâles roussâtres. Les tours de spire, au nombre de 8 a 9 , séparés par une suture biell marquée sont également assez convexes et sont cerclés par des petites côtes arrondies et lisses, plus ou moins prominentes, de manière que deux côtes plus fortes ont entre elles 1 à 2 qui sont plus minces el filiformes, ce que l'on remarque surtout sur le dernier tour. Les interstices étroits entre les côtes sont finement treillissés vus à la loupe. Les $4-5$ tours premiers sout munis de plis fins longiludinaux. La bouche est oblongue ovalaire, sillonnée à son hord interne, le canal étroit et profond, la queue ınédiocrement allongée, assez fortement retrécie en 
massig lang, nach vorn ziemlich stark verschmälert. Die Mündung bis zum Ende des Canals heträgt ${ }^{3}{ }_{5}$ der ganzen Schalenlänge.

lch kenne keine Art, die mit der vorliegenden verwechselt werden könnte. avant. La bouche jusqu' an bout du canal formo $3 / 5$ de la Ionguenr totale.

Je ne connais aucune espèce, qui pourrait êtro confonduc avec la nôtre.

\title{
11\%. Fusus nodoso-pliratus Itrr.
}

Tab. XXXIll. Fig. 3, 4.

\begin{abstract}
Testa magna, crassa, solida, alba, in apice fuscescens, inter costas interdum fusco strigata, anfractibus 9 ad 10 valde convexis, nodoso-plicatis undique transversim sulcatis aculeque liratis instructa; epidermide tenui lamellosa pallide cornea facile dehiscente vestita; anfractus ultimus, $3 / 5$ totius testae longitudinem adaequans, nodis crassis 11 cinctus; rostrum longum rectum, ad canalem intcrdum colore fusco tinctum; apertura ovala alba; labrum intus sulcatum. - Long. 146 mill., diam. circa 50 mill.
\end{abstract}

llabitat mare Japonicum.

A Fuso (.Wurice) longissimo Gmel. haec nostra species stutura multo minore, rostro breviore, costis spiralibus crassioribu mimus acutis costisque tuberosis facile distinguenda est. Praeterea anfractus sutura multo profundiore disjunguntur. A Fuso ventricoso Beck niss., mus. regis Daniae, Reeve Conch. icon sp. 34. anfractibus omnibus fortiter undosoplicatis, minus ventrosis, suturae indole aliisque notis differt.

Diese Art, welche zu den grösseren ihrer Gattung gehört, zeichnet sich besonders durch ihre starke feste Schale und die etwas oberhalb der Mitte aller Windungen befindlichen faltenartigen Knoteı aus, über welche scharfe stärkere und schwächere Rippen hinweglaufen. Die Farbe der Schnecke ist weiss, zwischen den Knoten des oberen Gewiudes schimmern braunrothe Längsstreifen unter der dïnnen blättrigen Epidermis hervor; zuweilen ist auch der lange gerade Rüsel am Canal ahulich gefärbı

Nusiate I1. 1. Mai 67.
Celle espèce de taille considérable se distingue surtout par son test fort et solide et les noeuds pliciformes remarquables un peu au dessus du milieu de tous les tours, qui sont croisés par des côtes aiguës plus ou moins fortes Sa couleur est blanche; entre les tubercules de la spire l'on remarque à travers l'épiderme mince et foliacé, des stries longitudinales roussâtres, quelquefois aussi la queue allongée et droite est teinte intérieurement de la même couleur. 


\section{Fusus Pacteli IDkr,}

\section{Tab. XXXIII. Fig. 5, i.}

Testa gracilis fusiformis crassiuscula, alba strigis rubro fuscis per longitudinem picta, anfractibus 9-10 convexis fortiter plicatis transversim crasse acuteque costatis insiructa; anfractus ultimus ${ }^{3}$; longitudinis testae occupans; rostrum mediocris langitudinis rectum antice altenuatum, transversim crasse costatum: labrum crenatum allum intus sulcatum. Long. 65, dian. 22 mill.

Putria iynota.

Speciem genuinam quantum scio ad how nsque tempus nec descriptam neque depictam in honorem clar. Pactel Berolinensis denominavi.

Dieser zierliche, mïssig dickschalige Fusus, zeichnet sich besonders dureh regelmissige ijherall gleich starke Längsfalten sowie lıreite, dabei aber scharfkantige Querrippen aus, die über die Langsfalten hinweglaufen und in der Hitle der Windungell besonders hervortreten. Hin und wieder bemerkt man in del Zwischenriumen feine Querrippchen. An vorliegendem Exemplars befinden sich auf dem letzten Umgang 13 Längsfalten. Ganz übereinstimmend isı eiu etwas kleineres Stiok. Die Epidermis, welche alogesprungen ist. scheint dünn gewesen zu sein.

Im Ilabitus erinnert diese Schnecke an Fusus strigatus Phil. Abb. vol. IIl. pag. 116. Tab. V. Fig. 3. Dieser hat jedoch ein melır winkeliges und gedrängteres Gewinde; auch ist der liüssel desselben etwas kürzer und die rothbraunen Streifen liegen auf, nicht zwischen den Laugsrippen.
Celle espèce élégante, médiocrement solide se distingue surtout par ses plis longitudiuaux réguliers et partout également forts et par ses côtes transversales larges mais anguleuses, jui surpassent les plis longitudinaux et sont plus saillantes au milieu des tours Dans les imterstices l'on remarque çà et là de petites eôtes transversales. Notre excmplaire possède, sur le dernier lour, 13 plis longitndinaus. Un' autre exemplaire un peu plus petit est tout-i-lait égal II parait que l'épiderme, yui ne s'est pas couservé, a été mince.

Le habitus de celte coquille rappelle le Fusus strigatus Phil. Abbild. Ill. p. 1[6. 1. 5 f. 3. Cependant celui-ci a la spire plus anguleuse et raccourcie, sa queue est un peu plus courte el les bandes rousses sont placées au laut des plis longitudinaux et non entre ceux-ci.

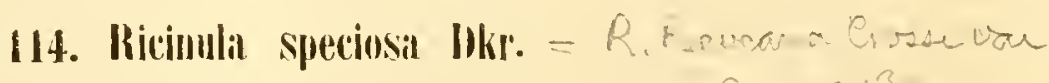 Tab XXXIII. Fig: $\mathfrak{i}, 8$.}

Testa oxato-globosa, solida, alba, anfractibus 7 insiruch, ultimus spira ter longior, costis quinis spiniferis, plicisque longitudinalibus instructus nec non costulis minutissime den- 


\section{$-101-$}

seque squamatis undique obtectus; spira conica acula, tuberculifera; labrum incrassatum denticulis albis 7 munitum, colunella inferne triplicata, superne obsolete miplicata, medio cavata et laevigata; peristoma vivide purpureum, subroseum - Long. 25, diam. 19 mill. Habitat ad Philippinas insulas teste beato II. Cuming.

Ricinula clathrata Lam. var. Ps testa parva spinis brevioribus, albida intus vivide purpurea. Re eve Conch. icou. Mon. of the gen. Ricinula spec. 90. a.

IIanc speciem pulchran et insignem jam in clar. Reevei opere supra laudato bene depictam invenies, sed auctor ejus naturam prorsus ignoranit, hanc cachleam mo varietate tantummodo Ricinulae clathratae Lam. declarans quae vero plurimum differt. Cum specimen nostrum optime conservatum, nulla loco Bryozois aliiste corporibus marinis obductum sit, praeterea habitu paulla differat, iconem iteratam Tibi l. b. hic offero.

Das Gehäuse ist eiförnig, etwas kuglig, ziemlich dickschalig, weiss und auf der letzlen Windung von 5 Querrippen ungebell, die vou neun varixartigen 1 egelmässigen Läugsrippe॥ durschnitten werden. Auf dem Durchschnitts-, oder lireuzungspunkle befinden sich ziemlich spitze in die Höhe gerichtete stachelartige Silnuppen, die nach vornhin, in der Waclısthumsrichtung, geöffnet sind wie bei Murex und andern Scbnecken. Ausserdem laufen ỉber dıs ganze Gebäuse, wenu dasselbe unverletzt ist, dichte Reihen lejuer in die Höhe gerichleter Sclü̈ppchen. Die Spira tritl ziemlich stark hervor und ist mil Knölchen ungebeu, die beim Verlaufe des Wachsthums der Schuecke allmälig in die erwähnten Stachelı übergehen. Schon am Embryonalgewinde zeigen sich unter der Loupe die Andeulung feiner linötchen. Auch auf der letzten $\mathbf{W}$ indung sind unmittelbar unter der Nalıt einige Kinoten bemerkbar. Die Müudung and übrige Beschallenheit der Schnecke ist aus der Zeichunng ersichtlich. Diese Art gehört in die Nähe der Ricinula ricinus L. (arachnoides Lam.), globosa Mart. elc.
Le lest est ovoide, subglobuleux, assez épais, blanc et entouré, sır le dernier lour, de 5 côtes Iransversales, qui sont croisées prar \$ còtes longitudinales variciformes et régulières. Sur les points de croisement se trouvent des écailles érigées spiniformes assez pointues, qui sunt ouvertes en avant, dans la direction de l'accroissement, comme clıez plusieurs antres coquilles. Tout le test, s'il esı parfait, est garni de séries rapprochées d'ècailles lines et érigées. La spire assez saillante est entourée de petits noeuds, qu avec l'acroissement progressif forment les épines imenliunnées. Les tuurs embryonaux, regardés à la loupe, montrent déjả des vestiges de noends fins. Sur le dernier tour l'on remaripue de mème quelques noeuds au-dessus de la suture La bouche el les autres caractères de l'espece sont bien recontuassables par la ligure.

L'espèce est voisine de la Ricinula ricimus $L$. (arachoides Lam.), globosa Mart., etc. 


\section{5. 'Turritellat ('Torcula) catelata Mörch.}

Tab. X\XIV. Fig. 1, 2.

Testa ralde crassa. conico-turrita, colore badio, apicen versus pallidiore tincta, aper ipse paene albus, anfractus circa 15 planiusculi sutura distincta sejuncti, inferne angulati, subimbricati transversimque rugoso-costati, costae validiores duae rugoso-nodosae, costae angustiores ad suturam papilliferae; aufractus ultimus obtuse angulatus, inferne planus liris obsoletis 4 bi-vel tripartitis exaralus; striae incrementi retroflexae confertae; interstitia impresso-punctata; apertura obliqua subquadrata. - Long. circa 90 mill., diam. 30 mill., apertura 14 mill.

llabitat in sinu Guineensi?

Diese zu Grays Gattung Torcula gehörende Sclinccke, welche IJerr Dr. O. Mirch in Copenhagen zum Abbilden gütigst mitgetheilt, zeichnet sich besonders durch ilıre dicke feste Sclate und eigenthünliche rauhe. runzelige und fein gcstrichelte Oberfläche aus. Die fası llachen iiber der Nalı! dachlörmig lıervorragenden Windungen tragen unten zwei starke. aul den mitlleren Gewinde selır deutliche knotige und runzelige Rippen. iber welchen an vorliegenden Exemplare vier diclıt gedrängte schmalere Rippen liegen. Unter der Naht befinden sich zum Theil stark hervortretende Fapillen, die naclı unten in mehr oder minder deutliche Fältchea verlaufen. Der lelzte Ungang ist stumpfwinkelig und gerundet, die Basisfläche rauh und fein geslrichelt. Das Innere ist weiss und porcellanarlig, die Columella brann.

Unter deu bis jetzt bekannt gewordenen lebenden Arlen befindet sich keine einzige, die rücksichtlich ihrer Oberfläche mit der gegenwärligen verglichen werden kömnte, doch zeigt die tertiäre Turritella (Turbo) varicosa Brocchi (Conch. subapp. II. p. 371. Tab. 6. lig. 15, hoenig icon. sect. 96.) mit gegenwärliger Art einige Inalogie.
Espece appartenant an genre Torcula deGray et communiquée par M. le Dr. O. Mörch à Copenlageı pour être figurée Elle se dislingue surtout par son test épais el par sa surface singulière àpre, rugueusc el finement slriolée. Les tours de spire, prominents au-dessus de la suture, sont munis, à leur parlie inférieure, de deux côles tortes tuberculeuses el rugueuses, au dessus desquelles se trouvent, dans notre exemplaire, 4 còtes plus étroites, très rapprochées. Au dessous de la suture nous remarquons des papilles, en partie fortement saillantes, prolongées en-bas en petits plis plus ou moins visibles Le dernier tour est obtusément anguleux et arrondi, sa partie basale âpre et tinement striolée. L'intérieur est blanc et ressemblant à la porcelaine, la columelle brune.

Parmi les espèces vivantes connues jusqu' a présent il "’ y a aucune, dont la surface pourrait être comparée ar c la nôtre; seulement uue espéce tertiaire: Turritella (Turbo) varicosa Brocchi (Conch. subapp. V. p. 374. pl. 6. f. 15, König icon. sect. 96) présente quelque analogie avec elle. 


\section{6. 'Turritella dura Hörch var.}

Tab. XXXIV. Fig. 3,4 .

Testa dura gracilis, pallide cinereoque fusca, apicem versus obscurior, fascia lata mediana fusca flammisque longitudinalibus obsoletis variegata; anfractus 20 subplani inferne carinati, sutura profunda divisi, costis nomullis acutis inaequalibus lineisque interpositis cincti; basis multilirata. - Long. 82, diam. 18 mill.

Patria Realejo. Mörch Mal. Bl. vol. YII. pag. 78.

Differt a T. Cumingii Reeve Conch. icon. sp. 13. Lesta dura, carina acuta, "lineis spiralibus aurantio-maculatis" prominentibus, fascia lata mediana riolacea-fusca etc. Cfr. M ïrch l. c.

Der Habitus dieser Art entspriclıt vollkommen der Turr. Cumingii. Die ersten Windungen sind dunkler gefärbt und eriunern sehr an Turritella bacillum Kiener. Nach Mörch haben die Spiralreifen rothgelbe Flecken wie Dulium maculatum. An vorliegendem, von Herrn Morch zum Abbilden gütigst mitgetheilten Exemplare, wonach die Diagnose entworfen ist, vermisst man jedoch dieselben, und scheint daher diese Scluecke in der Farbung ziemlich zu variiren.
Par son habitus celte espèce est parfaitement analogue à la Turr. Cumingii. Les premiers tours sout de couleur plus foncée el font songer à la $T$. bacillum Kiener. Selon Morch les cotes spirales portent des taches d'un jaune rougeâtre comme le Dolium maculatum, yui cependant n’existent pas dans l’exemplaire figuré communiqué par lauteur, daprès lequel la phrase diagnostique a élé faite. Ainsi il paraît, que la coloriation de cettc coquille est assez variable.

\section{F'usus pirmlitus Recve varr.}

Tib. XXXIV. Fig. 5, 6.

Testa ovato-fusiformis, ventrosa, tenuis, ulba, flamuis strigisque pallide fuscis picta, unfractibus $S$ convexis per longitudinem plicatis transversimque costatis instructa; unfractus uttimus inflatus ceteris duplo fere longior, rostrum breviusculun subcurvum; columella media sinuata; apertura oblongo-ovata alba; labrum tenue intus sulcatum; canalis late apertus - Long. 85 mill, diam 35 mill.

Habit. litus ins. Van Diemen teste Reeve.

Testa tenuis costis rotundis inaequalibus subglabris undique cinctu et plicis costus decussantibus ornata; plicae anfractuum superiorum crassiores, in anfractu ultimo obliteratae; rostrum 
breviculum apertum. Sub nitra lineae absoletac incrementi et transversae in tota testa conspiciuntur.

Quamers specimen depictum a forma typica (cfr. Reeve. Conch, icon. Monogr. of the Gen. Fusus spec. 50) testa majore, tenuiore, habitu paullo alieno, aperturae ambitu, nec non plicis in anfractu ultimo obsoletis paene evanescentibus satis abhorreat tamen pro variotate tantum habendum esse puto.

Das hier abgebildete Exemplar usterscheidet sich vou der Iypischen Form bei Reeve (Conch. icon sp. 50: pyrnlatus) in mehrfacher Beziehung ziemlich beträchtlich. Jie Schale ist grösser und verhälınissmässig dünner, der letzte Ungang gleichmässiger gewölbt und etwas breiter, auch sind die Längsfalten auf demselben sehr schwach, fast verwischı, während sie auf dem oberen Gewinde slark hervortreten. Dennoch halte ich diese Form uur für eine ausgezeichnetc Varielät der obigen Art. Die Furcheu in Innern, welche den äusseren spiralen Rippen entspreclivn, hat Reeve nnerwälııt gelassen, auch sind sie in seiner Zeichnung nicht zu erkennen. Als Fundort giebt Reene die Küsle von Van Diemens Land an.
Liexemplaire liguré se distingue sous plusieurs rapports considérablement de la forme typique (Reeve Conch. icon. sp. $\mathrm{j0}$ : pyrulatus). Le lest est plus grand et proportionellement plus mince, le dernier tour plus également convexe el un peu plus large, presłue dépourvu des plis longitudinaux, qui sont très marqués sur la parlie supérieure de la spire Néanmoins je ne regarde celle forme que comme une variété de l'espèce citée. Les sillons à l'intérieur, qui correspondent aux côtes spirales externes, ne sont pas mentiounés par Reeve, ni visibles dans sa figure.

Selon Reeve cette espèce provient de la côte de Vandiemensland.

\section{Doliun Japonicum Dkr. = 2 , Cuic as trman inst Tab. XXXV und XXXVI.}

Testa pergrundis, subglobosa, anguste umbilicata, albida, colorc fulvo-rufescente tincta maculisque irregularibus, plurimam parten subquadratis variegata, anfractibus senis vel septenis valde tumidis transversim lateque costatis instructa, epidermide temuissima pallide cornea decidua vestita; costae promineutes in anfractu ultimo 16-17, interstitiis concavis liratis et striatis duplo paene latiores; spira depressa; apcx (vel anfractus embryonalcs) nt in Doliis solet, corneus; sutura prafundissima; apertura ablonga; labrum dentatum paullo incrassatum, flavescens vel albidum; fauces colore nuceo tinctae; umbilicus lamina magna alba paululum abtectus. - Long. testae fere 180 mill., ejusdem latit. 155 mill.

Habilat mare Japonicum. 
Diese selir grosse und ausgezeichnete Toumenschnecke erinnert im Habitus an das grosse mittelmeerische Dolium (Bucc) galea L.; dieselbe ist jedoeh ziemlich viel dickschaliger, noch bauchiger und nit braunen Streifen und Flammenzejchnungen, auf den breiten Rippen dagegen mit unregelunässigen quadraticchen castanienbramen Flecken verselsen. Aul de! letalen, oben besonders aufgelriebente. Windung befinden sicl 16 bis 17 solcher Querrippen, die ziemlich erhaben und etwa doppelt so breit sind als die concaven Zwischenräune biese schliessen auf der oberen Hälfte der Windung eine schmale Rippe ein. auf deren beiden Silen lin und wieder noch leinere Rippchen sich eirschieben.

Das Neuholländische Dolinm variegatum Lumarck, welches mıt usserer Art nocls verglichen werden kann, hat eine weit stärker hervortretende spira, ist minder banchig, aueh dumsehaliger und anders gezeichuet.

Es licgen drei wohl erhallene durehaus ubereinstimmende. Theilweise noeh mit der dunuen braunen Haut bedeckte Exemplare ror. - Das Original zu unserer Zerclınung belindet siclı in der Sammlung des Herrn Fr. Fätel in Berlin.

Diese Art wie auch das $D$. galea mögen wohl von allen die bedeulendste Grösse errejelıen

Die bis jelzl lekanm gewordenten Speeies dieser fratlung sind folgende.

Dolium gulea Bucc. L. = D. costatum magmus Mart. juv. D. lenue Mhe. Hitlolmeer.

2. D. ampullaceum Phal. Stiller Ocean. - 3. D. Japonicum Dhr. Japaı. -- 4. D. variegutum Lam. = hieneri Phil. Neuholland - j. D. melanostama Jay. Freuudscluaftsinseln. $-6 . D$. amphora Phil. Vaterland unbekannt - $7 . D$. Clinense Dw = Bucc. Australe sen Chirense Chemn $=$ D. variegatum Phil. Ion Lam. China. - 8. D. olearium (Bucc.) Brug. Ostindien.
Cette espèce très-grande el distinguée montre, par son habitus; quelque analogie avec Je grand Dolium (Bucc) galea $L$. de la Médilerranée, mais elle est beaucoup plus épaisse, encore plus ventrue et garnie de bandes et flammules brunes, et de taehes irrégulièrement quadrangulaires couleur de marrou sur ses coles larges. Le dernier lour, qui est parliculièrement renllé en luau, porte $16-i 7$ de ces côles transrersales, qui sont assez saillantes et de largeur á peu près double de celle les inlerstices concaves. Ceux-ci renferment, sur la moilié supérieure du tour, unt eôle étroite, aux deux côtés de laquelle se trouvent ça et là de pelites eoites encore plus fines.

Une autre espèce, arec laquelle notre espéce pourrait être comparée, est le D. variegatum Lom. de la Nouvelle Hollande. mais celle-ci a la spire beaucoup plus saillante. elle est moins ventrue. plus mince et do coloriatiou différente.

Nous avous sous nos yeux trois exemplaires bien conservés el parfaitement égaux, monlrant encore une parlie de lépiderme mince el brun. L'exemplaire figuré appartient à la collection de Mr. Fr. Patel a Berlin.

Les espèces du gen'e Dolium connmes jusqu' à présent sont les suivanles: I. galea L. costatum magnum Mart. jur. D. tenue Illie Méditerranée. - 22, ampullaceum Phil Océan pactique. - 3. Japonicum Dhr. Japon. -- 4. cariegatum Lam. = hieneri Phil. Nouv. Hollande.

5, melunostoma Jay. lles d'Amitié. - 6 . amphora Phil. Localité inconnue $=\underset{7}{ }$. Chinense Dw. = Buce. australe s. chinense Chemn. = variegatum Phil., non Lam. China - 8. vleurium Brug. Indes orientales, Mer Rouge. (Bucrum olearium $L$ parait être un 1 , yalea jeune) 9. zonatum Green _- crenulatum Phil China. 10. fasciatum Murt. Bucc. = fasciatum Brug. 
Rothes Meer. (Bucc. olearium $L$ soll ein junges Dolium galea sein.) -- 9. D zanatum Green. = cremelatum Phil. China. - 10. D. fasciatum Mart. = Bucc. fasciatum Brug. Ostindien. 11. I lactescens Mart. = costatum Desh. = fasciatum var. Kiener Ostindien. - 12. D. Cassis Bolt. = maculalum Lam. Ostindien. 13. D tesselatum Lam. = minjac Adans et Desh. fmbrialum Sou. = Bucc. dolium L. Ostindieu. Guinea. - 14. D. Cumingii Hanl. Reene sp. 13. Philippinen - 15. D. Deshayesii Reeve sp. 15. Philippinen. - 16. D. Favannei IIanl. P..Z. S. 1859. Mus. Cunı. Vaterlaud unbekannt. - 17. D. Dunkeri Hanl. ibid. Port Natal. - 18 D perdix (Bucc.) $L=$ Cochlea pennata Rumph. A. R. = D. plumatum Green. Ostindien. Die westindische Form mit verhältnissnässig dickerer Schale ist stets kleiner und tiefer gefurclst. - 19 . D. pomum (Bucc.) L. = Cassis labrosa Mart. Ostindien, Rothes Vleer. - 20. D. dentatum Barnes. Panama -- 21. D. ringens (Cassis) Sw, = Malea latilabris Val. Peru. Diese drei letzteren zur Gattung Cadium Link oder Malea Valenc, gehörig.
Indes orientales. - 11. lactescens Mart. $=c o-$ statum Desh. = fasciatum var. Kien. Indes orientales. - 12. Cassis Bolt = maculatum Lam. Indes orientales. - 13. Iessclatum Lam. = minjac Adans. et Desh. = fimbriatum Son. $=$ Bucc. dolium L. Indes orient, Guinèe. 11. Cumingii Harl., Reeve sp. 13. Iles Plilippines. - 15. Deshayesii Reeve sp. 15. Philippines. - 16. Favannei Hanl. P. Z. S. 1859. Mus. Cun. Localité inconnue, - 17. Dunkeri IIanl. ibid. Port Natal. - 18. perdix. (Bucc.) L. = Cochlea penuata Rumph. $\mathbf{A}-\mathbf{R} .=D$. plumatum Green. Indes orient. La forme, qui provient des Indes occidentales à test propurtionellement plus épais est tonjours plus petite et plus profondément sillonnée. - 19. D. pomum (Bucc.) L. = Cassis labrosa Mart. Indes orient., Mer Rouge. 20. dentatum Bames. Panama. - 21. ringens (Cassis) Sw. = Malea latilabris Val. Pérou. Les trois dernières appartiennent au geure Cadium Link ou Malea Valenc. 


\title{
11!. Barbatia Adolphi IDkl.
}

\author{
Tab. XXXVIl. Fig. 1. 2. 3.
}

Testa ocalis. utrinque rotundula, basi subsimuala, solidula, albofuscescens, postice fusca, costulis confertissimis radiantibus et concentricis decussata tenniterque granosa, epidermide fusca setigera decidua induta; cardo temis denticulis paucis utrinque divergentibus munitus; umbones parvi prominuli; area ligamenti profunda: color internus postice fuscus. - Long. 20 mill. Long. alt. crass. $=100,60,50$.

Ad Novam Mollandiam legit b. Preiss.

Haec species quod attinet ad ambitum et staturam Barbatiae molli similis est, sed ejus valvae crassiores colore albido fuscescente postice fusco nec non sculptura valde aliena satis differunt.

Gehäuse oval, vorne und hinten ziemliclı gleichmässig gerundet, an der Banclıseite etwas eingebogen, vou feinen concentrischen und ausstrahlenden Rippchen dicht bedeckt und daher gegittert und zugleich fein gekürnt. Die Wirbel sind klein und treten nur wenig hervor. Das Schloss zeigt beiderseits wenige divergirende Zahuclien, Aussen und innen sind die Schalen weisstich, hiuten braun. Die Epidermis, wovon noch Spuren vorhanden siml, ist braun und kurz borstig.
Coquille oralaire, presque régulièrement arrondie antérieurement et postérieurement, légèrement échancrẻe à sa partie ventrale, couverte de petites côtes très-rapprochées, fines, eoncentriques et layounautes, réticulée et en même tems finement granulée. Les croclsets sont petits et peu prominents. La charnièe montre, de chaque côté, quelques petites dents divergentes. Les valves sont blanchâtres extérieurement et à l'intérieur, brunes à la partie postérieure. L'épiderme, dont des vestiges se sont conservé, est brun et muni de soies courtes.

\section{Barbatia oblonga Dkir.*)}

Tab. XXXVIl. Fig. 4. 5, 6. Fig. 7 particula magn. aucta.

Testa oblonga alba, temicula, valde inaequilatera, antice brevis, rotundata subventrosa, postice producta, basi arcuata, extremitatem versus attenuatam subsinuata, striis radiantibus confertissimis lineisque incrementi coneentricis decussata et subgranosa, costulis crassioribus in postice parte signata; umbones parvuli suberecti, modice distantes, antrorsum inclinati; cardo linearis dentienlis medianis minimis obliteratis, utrinque majoribus, divergentibus

*) Arca oblonga Goldf. = Cucullneu oblonga Müll. Sow. est speries quaedam fossils. 
munitus; ligamenti area satis profunda latiuscula. - Long. 28 mill. Long. alt. et crass. ratio numeris 100, 50, 42 respondet.

Ad Philippinarum insulas habitare dicitur.

Barbatiae trapezinae similis est, sed sculptura subtiliore, ligamenti area majore, latiore totoque habitu differt.

Die Schalen dieser Art sind gewöhnlich lang eiförmig, selten etwas verkürzl, ungleichseitig, am Vordertheil gerundet und kurz, da die Wirbe! sehr nach vorn liegen, hinten verlängert und verschmälert. Der Schlossrand hildet mil dem schräg abfallenden Hintertheil eine hervortretende Rundung. Die liauchseite ist vorn gebogen, hinten schwach gebuchtet, übrigens variirt der Unriss dieser Huschel zuweilen ziemlich beträchtlich. Die Schale isı überall mit feinen ron den Wirbeln ausstrahleuden Rippclien bedeckt, die ron concentrischen Wachsthumsreifchen durchschnitten werden, wodurch eine cancellirte und körnige Oberfläche entsteht, die bei so vielen Barbatien angetroffen wird. Am Hintertheil der Schalen sind die Rippchen stärker. Die Farbe ist durchgehends weiss, die Area tief und winkelig gefurcht und für die Gattung durchaus nicht schmal. An einigen Stellen bemerkt man noch Spuren von einer braunen borstigen Epidermis.

Von anderen ähnlichen Arten unterscheidet siclı die gegenwärtige zumal durch feinere Sculptur und breitere Area.
Les valves de cette espèce sout, en général, de forme ovalaire allongée, rârement raccourcies, inéquilatérales, arrondies et raccuurcies à leur partie antérieure, parceque les crochets sont situés forternent en avant, allongées et alténuées vers l'extrémité postérieure. Le bord cardinal forme, avec la partie postérieure descendant obliquement, un contour arrondi et prominent. Le bord ventral est courbé en avant, légèrement sinueux en derrière, mais les contours sont quelquefois assez variables. La coquille est couverte partout de petites côtes rayonnantes, coupées par les stries d'accroissement concentriques, ce qui produit mıe surface cancellée et granuleuse, comme elle se trouve chez beaucoup d'espèces de Barbatia. Les côtes sont un peu plus fortes à la partie postérieur des ralves. $\mathrm{L}^{\mathrm{a}}$ couleur est blanche partout, l'aréa garni de sillons profonds et anguleux, et proportionnellement assez large. Dans quelques endroits on remarque des vertiges d'un épiderme brun et hérissé.

Cette espèce se distingue des autres, auxquelles elle est semblable, principalement par sa sculpture plus fine el par son aréa plus large.

\section{Scapharca prmila Dkir.}

Tab. XXXVII. Fig. 8. 9. 10.

Testa ovato-globosa, parmm inaequivalvis, solidula, antice rotundata, postice paullo longior inferneque perparume producta, albida, costis $26-27$ rugosis subnodosis instructa, epidermide lamellosa fusco-rirescente induta; umbones fere mediami obtusí; area angusta a ligamento prorsus occupata; margo internus paullo incrassatus, profunde sulcatus. Long 22 mill. Long. alt. crass. circa 100, S0, 70. 
Patria ignota.

Species statura pumila subglobosa, costis rotundatis rugosis, passim subnodosis, umbones cersus planis, medio imo etian canaliculatis signata est. Linea cardinalis cum lateribus antico et postico angulum obtusum format. I/argo internus paullo incrassatus, profunde sulcatus costatus est: costae medianae canaliculo excellumt.

Das kleine unansehnliche bauchige Geliäuse ist fast gleiclsseitig, da die breiter aufgetriebenen Wirbel beinahe in der Mitte der Schalem liegen. Yon denselben lauft eine stumpfe Kante nach dem hinteren nur wenig herrortretenden Theil der Bauchseite herab Die 26 bis 27 Rippen haben ziemlich gleiclıe Stärke, sind auf der etwas verwitterten Obertläche der Wirbel flach, in der Mitte sogar elwas verlieft, werden aber allmahlig rund, runzelig und hin und wieder knotig. Die Epidermis ist blätterig, zunal zwischen dell Furchen, die ungefälır voll gleicher Breite der Rippen sind.

Von Scapharca (Arca) compacta Reeve unterscheidet sich die gegenwärtige Art durch geringere Grösse, mehr gleichseitige Schalen, kürzeren nicht geflügelteu Hintertheil; auch ist die Bildung der Rippen eine andere.
Cette petite coquille ventrue est à peu près équilatérale, parceque les crochets larges et renflés sont situés presqu'au milieu des valves. L'on remarque un angle obtus, descendant des crochets vers la partie postérieure, peu éminente, du bord ventral. Les côtes, au nombre de 26 à $\mathbf{2 7}$, sont á peu près égales, aplaties à la surface légèrement rongée des crochets el même enfoncées au milieu, mais peu à peu elles deviennent rondes, ridées et noduleuses çà et là. L'épiderme est foliacẻ, surtout entre les sillons, qui ont à peu près la même largeur comme les côtes

Notre espèce se distingue de la Scapharca (Avca) conpacta Reeve par sa taille moindre, ses valves plus équilatérales, sa partie postérieure plus courte, non ailée, et par la formation de ses côtes.

\section{2'2. Anomalocardia aefuilatera I)kr.}

Tab. XXXVll, Fig. 11. 12. 13.

Tesia crassa, globosa, ambitu subquadrato, aequilatera, antice rotundata, basi perparum curcata, carina obtusa at umbonibus crassis incurvis medianis prominentibus decurrente insignis costisque crassis 24-25 instructa; costae anticae et medianae concinne nodosae, posticae paene nodosae, interstitia striata obsoleteque squamosa; cardo robustus multidentatus, paullo curvus; ligamenti area latiuscula, rhomboides; color sordide albus, umbones versus pallide fuscus subcinereus; margo incrassatus profunde sulcatus; latus internum ut in hoc genere solet, tenuistriatum. - Long. 28 mill. Long. alt. crass. his circiter numeris respondet $100,90,80$.

Ilabitat in Oceano Indico. 
Diese Alt zeichnet sielı dureh ilı" ziemlich gleichseitiges dickschaliges Gehänse, die stark hervortretenden Wirbel, von welchen beiderseits eine deutliche Kante nach Ilem hinteren Theil der Banchseite verlauft und besonders durch die eigenthïnliche Oberfäche aus. Die vorderen Rippen tragen näılich regelmässige glatle perlenähnliche Knoten, die gegen die Mitte der Schalen hin minder regelmässig erscheinen und fast in Rumelı ibergehen. abel auf der Kante fast rerschwinden, wälırend die Rippen aul dem hinteren abgestuzten Theil ziemlich glatt sinı. Zwischen den Rippen, zumal in der Nähe der Wirbel, bemerkt man undeutliche Querschuppen und auf der rechten Schale blassgellye Fleckchen. Die Schlossfläche ist ziemlich breit und mit langen Zähnchen dieht besetzt; die scluwache Krümmung des unteren Schlossrandes erinnert an dic betreffende Bildung der Pectunculi. Das Liganeuteld ist ziemlich breit und beinalse rhombisch. Die erhabenen eingerollten Wirbel stelsen ziemlich weit von einander entfernt. Von der Epidermis ist keine Spur vorhanten; sie wird wohl düıı und braun gewesen seiı.
Cette espece se distingue par sa coquille épaisse, à peu près équilatérale, par ses crochets fortement saillants, desquels descend, de chaque côté, un angle marqué vers la partie postérieure du bord ventral, el prineipalement par sa surface. Les còtes antérieures sont garnies de tubercules lisses en forme de perles, qui deviennent plus irréguliers ct semblables à des rides vers le milieu des valves el disparaissent presque tolalement sur l'angle, taudis que les còtes de la partie postérieure tronquée sont assez lisses. Entre les côtes, priıcipalement au voisinage des crochets, Jon remarque des écailles transversales peu risibles, et sur la valve droite, de petites taches d'un jaune pale. Le plan de la charnière est assez large et munj de petites dents allongées et très-rapproehées; la courbure légère dı bord eardinal inférieur rappelle la formation aualogue des Pétoncles. L'aréa du ligament est assez large, presque rhombique. Les croehels saillants et enroulés sont assez éloignés lun de l'autre. II n'y a plus aucun vestige de l'épiclesme, qui probablement aura été mince et brun.

\section{Aru maculata Reeve.}

Tab. XXXVIJ. Fig. 14. 15. Fig. 16 particula magn, aucta.

Haec species oceani australis ambitu satis variabilis, interdum tam irregularis est, ut forma Arcarum genuina fere sublata appareat. Tale specimen non exigmum tabula nostra exhibet una cum particula per vitrum aspccta. Nota huius speriei singularis maculis partis dorsi posticae nititur, ab initio vividis, sensim vero evancscentibus.

Diese Art ist in ilurem Unriss ziemlich veränderlich und lıäufig unregelmässig, so dass die Arcaforn im engeren Sinue sich fast verwiseht. Ein solches unregelmässiges, ziemliclı grosses Exemplar ist auf unserer Tafel von zwei Seiten dargestellt, zugleieh mit einem vergrösserlen Theil
Cette espèce est assez variable dans ses contours; et snuvent irrégulière, de manière que la forme typique des Arca soit peu apparente. C'est un tel exemplaire irrégulicr, et assez grand, dont nous avons donné sur notre planche deux vues et une partie grossie de la surface. Un caractère 
der Oberflaclse. Besonders charakteristisch sind die Flecken, welche auf der hintern Seite der Wirbel neben der liante beginnen und auf dem hinteren Felde blasser werdend allnälılig verschwinden. particulier est lourni par les taches, qui commencent à la partie postérieure des crochets à côté de l'angle et pâlissant sur la moitié postérieure linissent par être invisilıles.

\title{
124. Arca constricta IDkr.
}

\author{
Tal, XXXVlI. Fig. 17 et 18.
}

Testa oblonga, tmmida, mediis in valvis coarctata, paene aequilateralis, sumerne utrinque obtusangula, antice rotumlata prodncta valde declivis, postice brevis prome truncala, in margine rentris medio simata, costulis radiantibus mumerosissimis densis striisque concentricis cancellata plus mimusre granosa, carina crassa prominente ad latus posticum decurrente insignis: umbones magni valde obtusi, depressi, incurvi; area ligamenti profunda carata; ligamentum subrhombeum. brcve; costae inter carinam et aream costnlis ceteris radiantibus multo crassiores imbricatae et subnodosae; color albus postice fuscus. - Long. 40 mill. Long. crass, alt $=100,60,58$.

\section{Patria ignota.}

Diese Art ist durcl ihren eigenthümliclsen Halbitus, die fast gleichseitigen bauchigen in der Miite zusammen geschnürten und mit dicht gedrängten köınigen Rippchen bedeckten Schalen ausgezeiclınet. Die Wirbel, welche fast in der Mitte des Gehäuses Jiegen, treten slark hervor, sind aber breit, oben niedergedruckt und ziemlich nahe gegen einauder geneigt. Beiderseits zielıt sich von denselben mach dem Ende der Basis hin eine stark lıervortretende Kante. Zwischen derselben und der Area befinden sich mehre stärkere knotige nnd hohlziegelartig schuppige Rippen. Die dichten hinteren Längsrippen, welche die Seiten und den vorderen Theil der Schalen bedecken, werden von concentrischen Wachsthumsreifen durchschnitten, wodurch eine gitterartige, zum Theil auch sehr deutlich gekörnte Oberflache gebildet wird, besonders an der hinteren Seite, die wie auch das luinterc Feld castanienbrauı gefïrbt ist. Die ziemlich breite Oellnung
Cette espèce est bien distincte par son habitus particulier et par ses valves à pen près équilatérales, ventınes et retrécies au milien, munies de petites côtes granulcuses très rapprochées. Les crochets, occupant presque le milieu.de la coquille, sont tres-saillants, mais larges, déprimés en haut et assez rapprochées l'un de l'autre. Un angle fortement saillant descend des croclsets jusquà l'extrémité de la base; entre celui-ci et J'aréa on remarque plusieurs cotes plus fortes, ubberculeuses et imbriquées. Les côtes longitudinales postérienres rapprochées, qui occupent les parties latérales et antéricures des valves, sont coupées par des stries daccroissement concentriques et produisent une surface treillissée, quelquefois distinctement granulée, surtout à la parlie postérieure, qui est d'un brun de marron. Louverture assez large, desliuée pour la sorlie dı pied corné, est située un peu devant le milieu lu bord ventral. La 
zum Austritt des hornigen Fusses liegt etwas vor der Mitte des Bauchrandes. Das Schloss ist schmal wie bei allen ächten Archen und dicht mit Zähnchen besetzt, das Ligament ungemein stark.

Diese Art gehört in die Verwandtschaft der Arca cunealis Reeve und mubilis Sow. charnière est étroite, comme chez toutes les vraies Alqques, et garnie de denticules très-serrés; le ligament est très-fort.

L'espèce est voisine des Arca curealis Reeve et mutabilis Sow.

\section{Ar'a Martensii Dhr.}

Tab. XXXVIII. Fig. 1, 2.

Testa oblonga paene aequilateralis, antice producta declivis rotundata, postice abrupte truncata, in margine ventris postico leviter sinuata, costulis radiantibns densis striisque incrementi concentricis gramosa, carima prominente ab umbonibus crassis latis paullulum curvis ad latus posticum decurrente insignis; area profunda cavata, a ligamento prorsus obtecta, linea rhombiforme excisa; color totius testae fuscus; epidermis lamelloso-laciniata. Long. 40 mill. Long. alt. et crass. ratio $=100,60,50$.

Patria ignota.

Eine sehr ausgezeichnete Form, die durch die beiden Ansichten anf unserer Tafel gut dargestellt wird. Die grösste Wölbung der Schalen befindet sich in der Mitte der stark hervortretenden Kante. Die äussere Farbe ist bei unverletzten Exemplare॥ dunkelbraun. Das Original der Zeichnung, welches dem zoologischen Museum zu Berlin angehört und mir von Herrn Dr. v. Martens anvertraut wurde, ist beiderseits der Wirbel abgerieben und zeigt an diesen Stellen eine untere lichtere Schalenschiclit.
Forme très-distinguée, fort bien réprésentée par les deux vues sur notre planche. La plus grande convexité des valves se trouve au milieu de l'angle fortement saillant La coloriation extérieure est d'un brun foncé chez les exemplaires frais. L'original de notre figure, qui appartient au Musée zoologique de Berlin et me fut confié par Mr. le docteur de Martens, est roulé des deux cùtés des crochets et montre, à ces endroits, une couche infẻrieure plus claire.

\section{Arca signata Dkr.}

Tab. XXXVIII. Fig. 3. 4. 5.

Testa oblonga cymbaeformis, inaequilatera, tumida, tenuicula, in medio ventris leviter sinuata, in latere antico rotundata, superne angulo paene recto terminata; valva dextra pro bysso vel pede cornea emittendo satis emarginata; sculptura singularis: costae ubique granosae, nedianae simplices angustae, anticae et posticae vero sulco divisae; area ligamenti plana 
latiuscula; color albidus, pagina interna sub umbonibus utriusque valvae macula aurantia signata; epidermis lamellosa fusca. - Long. 34 mill. Long. alt. crass. circa 100, 56, 50.

Patria ignota.

Diese Art scheint im Umriss ziemlich zu variiren, wie das überhaupt bei allen Arten der Fall ist, die zur Gruppe der Arca Noae gehören. Das abgebildete Exemplar ist übrigens am hinteren Bauchrande elwas abıorm gelsildet; bei normaler Schalenbildung würde der hintere Theil der Basis schwach gebogen seirl, wie die Wachsthumsansätze am oberen Theil der Schalen zeigen. Besonders charakteristisch ist die Sculptur und ein orangefarbiger Fleck innen unter den Wirbeln, welche auch aussen etwas röthlich erscheinen.
L'espèce paraît être assez variable dans ses contours, ainsi que toutes celles appartenant au groupe lle l'A. Noae. L'exemplaire figuré est un peu déformé à la parlie postérieure du bord ventral: ipuand la formation de la coquille était normale, la partie postérieure de la base serait légèrement courbée, ce que démontrent les stries d'accroissemeut sur la partie supérieure des valves. Un caractére bien marqué est fourni par la sculpture et une tache orangée, placée en-dedans sous les crochets, et apparaissant à l'extérieur comme tache rougeâtre.

\section{Anomalocardia pulchella Dkir.}

Tab. XXXVIII. Fig. 6. 7. 8. Fig. 9 particula magn. aucta.

Testa oblonga, parva, fere aequilateralis, utrinque aequaliter rotundata, superne angulata, hand tumida, albidoflava, costis $22-23$ crassis acutis subimbricatis et granosis paene aequalibus sulcisque costis angustioribus transversim striatis ornata, epidermide tenui laevi fuscescente obducta; apices parvuli submediani imoluti; area angusta plama hand profunda. - Long. 15 mill. Long. all. crass. circa 100, 60, 50.

Patria ignota.

Differt a pullis Anomalocardiae oblongae Phil. et A. granosae L. praesertim costarum numero earumque structura.

Diese kleine, ungemein zierliche Art könnte auf den ersten Blick für des Jugendzustand der Anomalocardia oblonga Phil. oder auch der $A$. granosa $L$. gelialten werden; bei näherer $\mathrm{Be}-$ trachtung derselben ergiebt sich indess, dass die Oberfläclue eine ganz andere ist; auch der Umriss weicht ab. Die 22 bis 23 zienlich gleichen Rippchen sind scharf oder spitz dachförmig und mit in die Hölse gerichteten Schüppchen besetzt,
A première vue l'on pourrait prendre cette espèce petile et très-jolie pour l'état de jeunesse de l'Anomalocardia oblonga Phil., ou de la granosa L., mais en regardant plus proche on voit que la surface est bien différente et que les contours sont aussi différents. Les petites côtes au nombre de 22 à 23 , assez égales, sont en forme de toit aigu et munies de petites écailles érigées, qui forment des tubercules aigus, Les 
die als spitze Knötchen hervortreten. Die kleinen efwas eingerollten Wirbel sind ziemlich einander genähert, da das Ligamentfeld nicht breit ist. Dieselben liegen fast in der Mitte der Sclialen und es erscheint daher die kleine Muschel beinahe gleichseitig. Innen und aussen ist dieselbe gelblich weiss. petits crochets, légèrement enroulés sont assez rapprochées, puisque laréa lu ligament est étroit. Les crochets occupent à peu près le milieu des valves, ce qui fait paraitre la petite coquille à peu près équilatérale. La coloriation interne et externe est d'un blanc jaunâtre.

\section{Barbatia solidula Itkr.}

Tab. XXXVIII. Fig. 10. 11. 12. Fig. I3 particula per vitım aspecta.

Testa ovata, solidnla, compressiuscula, inaequilatera, antice rotumdata brevis, postice producta linguiformis, in dorso fornicata, costulis radiantibus confertis inaequolibus striisque concentricis concinue granuloso-cancellata, epidermide setigera obducta, fusco alboque variegata; apices prominentes acuminati approximati, antrorsum inclinati; lamina cardinis lata denticulis confertis longis irregularibus munita; margo centris parum aequaliterque carinatus, haud crenatus. - Long. vix 20 mill. Long. all. crass. $=100,70,50$.

Ilabitat in sim Californiano, fide H. Landauer Francofurtano ad Moenum, qui venalem habuit.

Der Rücken dieser kleinen dickschaligen Art ist stark gewölbt, dagegen ilır Bauchrand gleichmässig schwach gelrogen; vorn sind die Schalen gerundet, nach hinten zungenförmig vertängert. Die kleinen spitzen Wirbel neigen nach vorn und liegen im ersten Drittel der Schalen, daher dieselben sehr ungleichseitig erscheinen. Die Oberfliche ist durch feine von den Wirbeln ausstralilende Rippchen und concentrische Reifchen gegittert und gekörnt. Die Rippchen sind aber von ungleicher Stălke, da zwei bis drei feinere mit zwei dicht neben einander liegenden stärkeren wechseln. Zivischen diesen letzteren entspringen kleine Borsten der braunen Epidermis. Das vergrösserte Stück Fig. 13 auf unserer Tafel hat ülrigens der Zeichner nicht ganz richtig dargestellt. Innen und aussen sind die Schalen kastanienbraun ins Weisse verlaufend, der innere Rond ist
Le dos de cette espèce petite et épaisse est lortement vouté, landis que le bord ventral est également et légèrement courbé; en avant les valves sont arrondies, en arrière elles sont allongées en forme de langue. Les petits crochets pointus šinclinent en avant et sont situés au premier tiers de la coquille, ce qui la fait paraitre très-inéquilatérale. La surface est treillissée et granulée par des cỏles lines et rayonnantes et des stries concentriqques. Mais ces petites côtes sont très-inégales, puisque 2 ou 3 plus fines alternent avec deux plus fortes immédiatemeut rapprochées. De petites soies de l'épiderme brun prennent leur origine entre ces dernières. La partie grossie (fig. I3 de notre planche) n'est pas dessinée assez exactement. En-dedans et en dehor's les valves sont d'un brun marron, passant insensiblement au blanc; le bord interne est lisse, 


\section{$-115-$}

glatt, die Schlossplatte verhältnissmässig stark und mit langen unregelmässigen Zähnchen dicht besetzt

Diese kleine Muschel gebört zur Gruppc Larbatia fusca Brug. le plan cardinal proportionnellement fort et muni de petites dents allongées, irrégulières et Irèsrapprochées.

Cette petite coquille appartient au groupe de la Barbatia fusca Brug.

\section{Anomalocardia Lischkei Ilkr.}

Tab. XXXVllI. Fig. 14. 15. 16.

Testa ovata, obliqua, crassiuscula, inflata, antice ratundata brevis, postice paullo producta, linea obliqua parum curvata cum margine cardinis angulo obtussissimo conjuncta, costis 29-30 radiantibus crassis planis, in valva dextra sublaevibus, in sinistra subrugosis, instructa, epidermide fusca lamellosa, in sulcis lateris postici setigera vestita; area latiuscula sulcata, a ligamento crasso omnino occupata; umbones prominentes involuti, antrorsum inclinati; lamina cardinis multidentata solida, inferne leviter curvata; color albus, in speciminibus integris sub epidermide virescens. - Long. $50-60$ mill. Long. alt. crass. $=100,78,70$.

Patriam ignoro.

Hacc species ab Anomalocardia urapygimelana Bory, quae est holoserica Reevei, satis differt sculptura et epidermidis indole.

Gehäuse fast eiförmig, ziemlich dickschalig, aufgetrieben, mehr oder minder schief, vorn kurz und gerundet, der hintere schwach gekrümmte Theil mit dem geraden Schlossrande in sehr stumpfem Winkel verbunden. Die 29 bis 30 von den starken, etwas nach vorn geneigten Wirbeln ausstrahlenden Rippen sind zieınlich flach und beiderseits kantig, auf der rechten Schale fast glatt, auf der der linken dagegen gerunzelt, die Furchen schwach quer gestreift. Frische Exemplare erscheinen in der Nähe des Bauchrandes unter der braunen Epidermis grünlich. Die Area ist gefurclit und wird vom starken Ligament fast ganz eingenommen. Unter den bis jetzt bekannt gewordenen Anomalocardien steht die gegenwärtige der urapygimelana Bory wohl am nächsten.

Novitates 111. Marz 68 .
Coquille à peu près ovoïde, assez épaisse, renflée, plus on moins oblique, courte et arrondie en avant, la partie postérieure légèrement courbée, formant un angle très-obtus avec le bord cardınal rectilinéaire. Croclsets forts, légèrement inclinés en avant. Les côtes rayonnantes, au nombre de 29 à 30 , sont assez aplaties et anguleuses des deux côtés, presque lisses sur la valve droite, ridées sur la valve gauche, à sillons légèrement striés transversalement. Les exemplaires ont, sous l'épiderme brun, un aspect verdâtre au voisinage du bord ventral. L' aréa est sillonné et presqu'entierement occupé par le ligament lort.

Parmi les espèces conuues d'Anomalocardia c'est la uropygimelana Bory, à laquelle la nôtre s'approche le plus. 


\title{
130. Anomalocardia Ehrenbergi Dhr.
}

Tab. XXXVIII. Fig. 17 valvae dextrae facies interna, fig. 18 eiusdem valvae latus externum.

Testa ovato-oblonga, gibbosa, tunida, crassa, alba, antice subattenuata, postice latior, superne utrinque angulata, concentrice striato-rugosa, subundulata costis radiantibus 27-28 latis planis, in dextra valva striatis obsoleteque rugosis instructa, costae alterius valvae paullo angustiores, concinne crenatae subnodosae; interstitia transversim lamelloso-striata; umbones crassi involuti, submediani; ligamenti area cavata longa, a sulco rhombiformi circumscripta; lamina cardinis angusta, subrecta multidentata; latus internum radiatim sulcatum. - Long. majoris quae exstat valvae 76 mill. Long., alt. crass. circiter his numeris respondet $100,60,55$.

Singulas valvas e Mari Rubro attulerunt viri celeberrimi Hemprich et Ehrenberg.

Diese sehr ausgezeichnete Art liegt nur in zwei Schalen vor, einer rechten und linken, die dem Berliner zoologischen Museum angehören. Die rechte grössere Schale, welche die Abbildung darstellt, zeigt breitere und, namentlich in der Mitte, plattere Rippen, wogegen auf einer kleineren linken Valve die Rippen etwas schmaler und ron starken dicht gedrängten Rumzeln bedeckt sind, die auf dem vorderen und miltleren Theil der Schale wie glänzende Körner erscheinen. Eine solche ungleiche Beschaffenbeit der beiden Schalen kommt selır bäufig an Arcaarlen vor, zumal solchen, welche den Abtheilungen Anomalocardia und Scapharca angehören, die übrigens in einander ühergelıen. Von der Epidermis isl auf den beiden vorliegenden Exemplaren keine Spur vorhanden
Nous ne connaissons que deux valves de cette espèce distinguée, une droite et une gauche, appartenant au Musée zoologique de Berlin. La valve droite, plus grande (figurée sur notre planche) est munie de côtes plus larges et, surtout au milieu, plus lisses, tandis que sur une valve gauche plus petite les côtes sont un peu plus étroites et couvertes de rides fortes et très-rapprochées, qui produisent. sur la partie antérieure et médiane de la coquille. l'aspect de grains luisants. Une qualité aussi inégale des deux valves, a été très-souvent observée chez les Arques, priucipalement chez celles qui appartiennent aux sections Anomalocardia et Scaplıarca, qui à peine penvent être séparées. Les deux exemplaires ne montrent aucun vestige de l'épiderme.

\section{Solen exigums Dhir, var.}

\author{
Tab. XXXIX. Fig. 1 .
}

Testa parva, brevis, linearis, solidula, unicolor alba, epidermide cornea subolivacea induta; margo anticus abrupte truncatus, superne et inferne paullo rotundatus, margo posticus rotundatus, subobliquus; linea dorsalis basi exacte parallela. Long. testae 40 mill., alt. vix 10, lat. 4,5 . 


\section{$-117-$}

Solen exiguus Dkr. Proc. Zool. Soc. of London 1861. pag. 419.

Habitat litus Borneense fide beato Cuming.

Varietatem huius speciei parvulae, quam videndi causa amicns 0 . Mörch nihi misit, Tab. nostra exhibet.

A forma normali paululum differt praesertim marginis antici formatione. In Museo augustissimi Daniae regis asservatur.

Die Figur 1 auf Tab. XXXIX. stellt eine Varietät dieser kleinen ostindischen Art dar, welche zumal durch die Bildung des vorderen abgestutzten Theils etwas abweicht.
Notre figure représente une variété de l'espèce citée, provenant des Indes orientales, qui diffère principalement par la forme de la partie antérieure tronquée.

\section{Solen acutangulus Ilir.}

Tab. XXXIX. Fig. 2.

Testa linearis recta, convexiuscula, albida, ad apices interdun subrosea, epidermide cornea vestita; margines ventris et dorsi fere paralleli; pars antica intus paullulum incrassata, oblique truncatu cum basi angulum format acutum, extremitas postica subrotunda. Long. testae 54, ejusdem altit. 11 mill.

Llabitat ad Philippinas insulas.

Der spitze unten im Vordertheil dieser Art liegende Winkel erinnert an die älunliclue Bildung des weit grösseren Solen Timorensis Dkr.
L'angle aigu situé en bas de la partie antérieure de cette espèce rappelle la formation semblable chez le S. Timorensis Dunk., qui est beaucoup plus grand.

\section{Siliquaria nitidissima Dkir.}

Tab. XXXIX. Fig. 3.

Testa oblonga, solidula, concentrice striata, alba, utrinque pallide livescens, linea brevi fusca ab umbonibus decurrente lineolisque nonnullis medias valvulas tenentibus signata, epidermide tenui pallide cornea, pellucida constante et nitidissima abducta; umbones submediani obtusi; basis et linea dorsi paullo curvatae; extremitates rotundatae, postica subattenuata. - Long. 43, alt. 15, lat. 7 mill.

Siliquaria nitidissima Dkr. Proc. Zool. Soc. of London 1861. pag. 426.

Habitat in litore Peruano fide beato H. Cuming.

Differt a Siliquaria polita Carp. testa majore solidiore, pictura languida, epidermide pallidiore et lineolis istis fuscis medias valvas accupantibus. 
Diese ungemein glänzende verhältnismässig ziemlich dickschalige Art, welche unter der durchscheinenden blassen, zarten, fast glasartigen Epidermis beiderseits bläulich, in der Mitte weiss erscheint und unter den Wirbeln mit einem stärkeren und mehren feineren rothbraunen Strichen gezeichnet ist, hal eine gewisse Analogie mit Carpenter's Siliquaria polita; ihr Gehäuse ist jedoch stärker und ihre Färbung blasser, auch fehlen bei jener die braunen Strichelchen auf der Mitte der Schalen.
Celle espèce extrèmement brillante et proportionnellement assez épaisse, qui apparaît, sous un épiderme transparent, pale, mince et presque vitracé, bleuâtre des deux côtés et blanche au milieu, et qui est dessinée, sous les crochets, d'une ligne rousse forte et de plusieurs autres plus fines, a quelque analogie avec la Siliquaria polita Carp.; cependant sa coquille est plus forte et sa coloriation plus pale; aussi l'espèce de Carpenter n'a pas les lignes rousses sur le milieu des valves.

\section{Pharella ovalis Dkr.}

Tab. XXXIX, Fig. 4 .

Testa ovalis subelliptica, complanata, tenuis, lineis incrcmenti concentricis plus minusve expressis instructa, epidermide tenui pallide cornea langnida haud nitente valvarum margines late excedente obducta; umbones obtusi, perparm prominentes, ad $2 / 7$ longitudinis testae siti; liganentum breve, latiusculum; cardo dentibus quinque munitus, in valva dextra duobus longis angustis divergentibus, antico subbifido, in valva opposita tribus, duobus posticis basi conjunctis. - Long. 74, alt. 26, crass. 14 mill.

Pharella ovalis Dkr. Proc. Zool. Soc. of London 1561. pag. 432.

Eine sehr ausgezeichnete Art, die breiteste von allen bis jetzt bekannt gewordenen, welche elwas an die Gattung Glauconome erinnert.
Espèce très-distinguée, la plus large parmi toutes celles, que nous connaissons aujourd'hui et rappellant en quelque sorte le genre Glauconome.

\section{Aulus fasciatus Spengler.}

Tab. XXXIX. Fig. 5, 6. 7.

Testa parvula tenuis paene elliptica, postice attemuata, complanata, valde inaequilateralis, nitida, striis incrementi tenuissimis instructa, albida, radiis latis 4 fusco-violaceis ornata; umbones minimi, subacuti; cardo valvulae dextrae dente valido erecto inferne bifido, $v$. sinistrae tuberculis 3 irregularibus munitus; pagina interna lamina crassa lactea insignis. - Long. 16 mill. Long. alt. crass, ratio $=100,50,30$. 
Specimen depictum ad Museum Augustissimi regis Daniae pertinet. Clarissimo Mörch affrmante Solen fasciatus Spengleri haec ipsa est species.

Der Unriss dieser kleinen slark glänzenden flachen Muschel ist fast elliptisch, jedoch nach hinten etwas zugespitzt. Das Schloss bestelıt in der rechten Schale aus einem aufgerichteten nach unten in zwei Sclıenkel getheilten Zalıne, welcher sich auf einer mit der starken innern weissen Rippe verwachseneu Lamelle belindet. Das Scbloss der linken Schale hat drei unregelmässige Zähnchen, zwischen welche der gespaltene Zahn der rechten Schale eingreift. Die innere Rippe leuchtet als der vordere vou den kleinen Wirbeln herablaufende weisse Streifen durch dic dünne Schale stark hervor. Das Ligament entspricht der Kleinheit der Muschel. Auf dem Rücken befindel sich beiderseits eine schmale bis zu dem zugespitzten Hintertheil verlaufende Falte, ebenso bemerkt man vor den Wirbeln beiderseits eiu Fältchen.

Burch ihre vier breiten bräunlich violetten Strahlen erinnert diese eigenthümlichc Art an Aulus radiatus $L$. Dieselbe wurde mir nebst anderen Solenaceen von Herrn O. Höl ch zur Ansicht gittigst zugesandt. Sie wird zuerst von Spengler: Genauere Bestimmung und Erweiterung der Linnéschen Gattung Solen vom 22. Febr. 1783 in Skrivter of Naturh. Selsk, vol. IlI., pars 2, 1794 unter der Nummer 12 als Solen fasciatus lesta ovali, minuta, extremitate postica linea transversa candida aufgeführt, doch mit Unrecht dazu Chemn. VI., Fig. 40 citirt, welche sowolsl im Umriss, wie auch in der Grösse wesentlich abweicht und ohne Zweifel eine zweistrahlige Varietät des Solen radiatis $L$. darstellt. Spenglers Angabe, dass diese kleine Muschel bei Tunis gefunden werden, beruht vielleicht auf einem Irrthume.
Le contour de celte petite coquille fortement luisante et aplatie est à peu près elliptique, mais légèrement acuminé vers l'extrémité postérieure. La charnière de la valve droite est formée par une dent érigée, divisée en bas en deux rameaux et placée sur une lamelle qui est affichée à la côte interne forte et blanche. La charnière de la valve gauche possède trois petites dents irrégulières, entre lesquelles se place la dent fendue de la valve droite. Ia côte interne est bien visible à travers la coquille mince et forme la première des bandes blanches partant des crochets petits. Le ligament est eu proportion de la petitesse de la coquille. Sur le dos on remarque, de chaque côté, un pli étroit prolongé jusqu'à l'extrémité postérieure acuminée, et un autre petit pli se trouve à chaque côté devant les crochets.

Les quatre rayons larges d'un violacé brunâtre de notre espèce lui donnent quelque ressemblance avec l'Aulus radiatus $L$. Elle me fut envoyẻe pour l'examiner, conjointement avec plusieurs autres Solénacés, par Mr. O. Mörch Le premier quj en a fait mention, est $\mathrm{Spengler}$ dans son travail sur le genre Linnéen: Solen, 2? Febr. 1793 in Skrivter af Naturh. Selsk vol. III pars 2, 1:94, Nr. 12: ,Solen fasciatus testa ovali minuta, extremitale postica linea transversa candida." Mais c'est à tort, qu'il cite pour cette espèce Chemn. VI., Fig. 40, qui en diffère essentiellement par ses contours et par sa taille, et qui représente sans doute une variété à deux rayons du Solen radiatus $L$. - Spengler dit que la petite coquille a été trouvée à Tunis, mais cette indication pourrait être erronée. 


\section{Aulus Winterianus Dkr. \\ Tab. XXXIX. Fig. 8. facies interna, 9. f. externa.}

Testa avali-oblonga antice paulo latior, utrinque rotundata, concentrice striata, lactea mediis in valvis subdiaphana, costa crassa abliqua usque ad impressionem pallii decurrente insignis; apices prominuli tertian testae partem occupantes; liganentum prominens; epidermis temis decidua. - Lang. speciminis quod exstat maximi 80 mill. Dimensionum ratio plane haec est: long. alt. crass. $=100: 40: 20$.

Habitat in litore Javanica.

Aulus Winterianus Dkr. Zeitschr. für Mal. 1853. pag. 57.

Cardo in utraque valva bidentatus, in dextra dens anticus compressus ovatus subrectus, posticus productus valde obliquus, in sinistra dentes eadem fere forma divergentes irregulariter fovealati ut recipiant dentes valvae sinistrae. Nymphae prominentes. Costa erecta valde crassa cardini adnata, oblique decurrit usque ad impressionen pallii. Impressiones musculares leves antica avato-acuta, aream ante costam fere omnino occupat, postica ovatotrigona. Simus pallii magnus rotundatus paene usque ad mediam testam productus. Angulus palliaris acutus ut linea margini ventris parallela in quinta fere testae parte desinit

Das Schloss trägt in lıeiden Schalen zwei Zähne, der rordere der rechten Schale ist länglich, zusammengedrïckt und aufgerichtet, der hintere dagegen selır schief und verlängert. Die divergirenden Zähne der linken Valve sind ähulich gestaltet und mit Vertiefungen versehen, in welche die gegenüberliegenden Zähne eingreifen. Die mit der Schlossleiste verwachsene sehr starke Rippe zieht sich in schiefer nach vorn geneigter Richtung herab und endet an der Mantellinie, oder überschreitel etwas diese Grenze. Die Muskeleindriicke sind flach; der vordere spitz eiförmige nimmt beinahe die ganze Fläche vor den Rippen ein, der lintere gerundele ist dreiseitig. Die Mantelbucht ist gross und gerundel, und zieht sich fast bis zur Mitte der Muschel. Dieselbe endigt hinten, etwa im fünften Theil der Schale in einer schmalen dem Bauchrande ziemlich parallelen Linie.
L.a charnière est munie, dans chaque valve, de deux dents; la dent antérieure de la valve droite est oblongue, comprimée et érigée, l'autre au contraire très-oblique et allongée. Les dents divergentes de la valve gauche sont formées semblablement pourvues de fossettes pour recevoir les dents opposées. La côte Irès-forte, counée avec la plaque de la charuière descend obliquement en avant et se termine à la ligne palliale, ou surpasse légèrement cet endroit. Les impressions musculaires sont peu enfoncées; l'antérieure, qui est ovalaire et pointue occupe presque tout l'espace devaut les côtes, la postérieure est arrondie, triangulaire. Le sinus pallial est grand et arrondi, il se prolonge presque jusqu'au milieu de la coquille, et se termine en arrière, environ à la partie cinquiéme de la longueur, en ligne étroite, presque parallèle au bord ventral. 


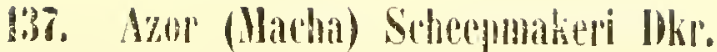

Tab. XXXIX. Fig. 11). 11. Facies externa et interna.

Tesha ovali-oblonga, solida, cone xa, medio coarchata, utrinque rolundata, concentrice rugosostriata, plicis radiantibus obsoletissimis nec non sulo levi mediuno obliqno ad neniris marginem decurrente instructa; umbones antemediani obtusi paullo mominertes ; ligamentun crassum.

Long. S2 mill. Long. all. crass. ratio fere est 100, 4.5, 28.

Ilabitat ad Hhilppinarum insulas (JI. Cuming). Specimen depichm quondam misit beatus Sekeepmaker Amsleladamensis.

Hacha Schepulateri Dlir. in Zeilschr. für Mal. 1552. pag. 56.

f'ario hand mediasus, margini anlico paulum approximatus; in valca dexlra dentes duo valde crecti aculi, posticus mngis obliguns, in sinistra umus commessus. Nymphae prominulue. Impressiones masculares fere ocato-rolundatae, antica minor subprofmula, sunne came impressio parou sublrigona; impressio palliaris paene eadem alque in Solene strigilalo Linnaei, sed magis a margine rentris distans. Striae incrementi euncentricae inatynales ad lateru partime rugulosue el confluentes, a strits obsoletissimis radiantibus decnswatae sumt, ilt ut superficies testae subcoriacea apmareat. Color testae albus; epidumis subolicurea.

Die Wirbel liegen etıa iı $2_{5}$ der Sclalen, deren rechle zivei anfgerichtete spitze, schief stehende Zilıne enthält, die linke dagegen nur eineı lamellenförmigen, welcher zwischen die gegenüberliegenden eingreift. Die ituskeieindriicke sind unregelmàsig länglich rund, der vordere lileinere elwas vertieft. Die Mantellinie ist von ähnlicher Beschaffenleit wie bei Macha strigilala L., nur liegt sie etwas entfernter rom Bauchrande. Die concentuschen Wachsthumsansälze sind mngleich und etwas runzelig, vom und hinten an stäristen. Vou den etwas erhabenen Wirbelı strahten sehr schwache, fast rerwische Rippchen aus. In der Hitte der Schalen befindet sich eine seichte Rinne. Die Farbe der Muschel ist weiss, die zarle, düne rauhe Epidermis olivengriin. An dem abgebildeten Exemplare ist sie abgesprungen.

Novitates 1:1. April 69.
Les crochets sont silués à peu pres aux deux cinquiemes de la longueur. La valve droite poseide deux dents érigées, pointues et obliques, la valre gauche n’ en a quine seule, Jamellilonue, qui se range dans linterstice des deux oppusées. Les impressions musculaires sont irrégulieres, de forme arrondie allongée, l'antérieure plus petite et légèrement enfoncée. La ligne palliale est semblable à celle de la Macha strigilata L., seulement elle est un peu plus éluignée du bord ventral. Les stries daccroissement concentriques sont inégales, légèrement ridées, plus fortes aux extrémités anlérieure el postérieure. Les crochets légèrement saillants émettent de petites côles rayonnantes, très-faibles, à peine perceptibles. Au milieu des valves se trouve un sillon peu imprimé. Ia coloriation de la coquille est blanclse, l'épiderme, qui n' existe plus dans l'exemplaire figuré, est mince et âpre, de couleur verte d'olive. 


\section{1:3. Aromalocirdia subgranosa Dlir.}

Tab. XL. Fig. 1. 2, 3.

Testa ovato-oblonga, compressiuscula, alba, subtenuis, valde inaequilatera, antice brevis rolundata, supcrne paene rectangula, postice extensa, paullo dilatata, angulo valde obluso signata, costis radiuntibus $38-40$ rotundatis sublaevigatis, marginem versus subgranosis instructa, epidermide fusco-cornea decidua vestita; ligamenti area angusta; cardinis lamina mullicrenata; umbones oblusi, paullulum sinuatim depressi. - Long. 48 mill. Long. altit. crass. ratio fere haec est: $100,62,48$.

llabilat litus Jatanicum.

Syecies toto habilu atque structura singularis, nullo loco descriptam vel depictam invenimus. Tesla pro magnitudine tenuicula tota alba aequivalvis, costis radiantibus simplicibus et regularibus paene glabratis, marginem versus tamtunmodo subgranosis insignis est.

Die lüngliclı eiförmigen, ziem'ich dünnen, weissen sichalen sind sehr ung'eichseitig und nur wenig gewöllt. Der gerundete kurze Vordertheil verrinigl sich mil den elwas geneigien Schlossrande in einem stumpfen dem rechlen genäherten Winkel, Jer Hintertheil ist verlängert, fast zungeuförmig, und bildet mit dem Schlossrande einen kleinen : iump̧fwinkeligen Flügel. Die gauze Schale ist mit :3-40 gerundeten, am Schlossrande flachen, ziemlich diclıt neben einander liegenden Rippen bedeckt, die nach der Peripherie der Muschel hin mit schwachen linötclien besetzt sind. Die Area is schmal lanzetiformig und wird vom schwarzkrauneu Ligameut ganz eingenommen. Die Wirbel sind stumpf und erscheinen oben durch eine schwache Bucht elwas niedergedrückt. Die braune Epidermis ist düun und zart und löst sich leicht ab; am Rande zeigt dieselbe eine Anlage zur b!ättrigen Structur.
Cette espèce à contour oblong ovalaire possède des valves minces et blanches, Irès-inciquilatérales et peu convexes. La partie antérieure qui est abrigée el arrondie se juint au bord cardinal légèrement incliné en angle obtus, presquue droit; la partie postírieure est allongée, presque linguiforme, et produit, avec le bord cardinal, une petite aile obtusangle. Tuute la surface de la coutulle est garnie de 38 - 4n cotes arrondies, qui sont aplaties et assez rapprochées près du bord cardinal, munies de petits tubercules vers la piriphérie. L'aría est étroitement lanciolée et presqu enlièrement occupée par le liganent brun noirâtre. Les crochets sont émoussés et une sinuosité légère les fail paraître faiblenent déprimés en haut. L'épiderme est brun el mince; il se détache facilement et montre, au hord, des vestiges d'une structure foliacée.

\section{Noetia contraría Reeve var.}

Tab. XL, Fig. 4. 5.

Testa oblique ovata, crassa, turgida, antice rolundata, postice praducta, paullo atlenuata, costis. 
tricenis latis lacvibus vel obsolete rugosis, sulcis angustis divisis instructa; ligamenti area profunda, latiuscula, sulcata; umbones crassi porrecti, contrarie contorti.

Arca contraria Reeve Proc. Zool. Soc. 1844. pag. 45; Conch. ic. sp. 5.5.

Patria ignota.

Ich gebe hier die Abbildung einer kleinen sehr dickschaligen Varietät, deren Rippen keineswegs glatt, sondern etwas runzelig sind. Im Innern zeigen dic Selaten ziemlich starke und dichte radiale Reifen. In der Mitte tritt an dell abgebildeten Exemplare eine etwas stärkere Rippe hervor. Die beiden starken Muskeln liegen auf einer erhöheten Lamelle.
Notre figure représente une petite variété trèsépaisse, dont les cỏtes ne sont pas lisses, mais légèrement ridèes en avant. A l'interieur des valves on remarque des stries rayounantes assez lortes et rappruchées. Au milieu de l'exemplaire liguré il y a une côte un peu phus saillante. Les deux muscles sont situés sur une lamelle élevée

\title{
140. Barbatia erythraecusis Jonas.
}

\author{
Tab. XL. Fig. 6. 7. 8.
}

Testa ocato-oblonga, crassiuscula, albida, ad apices subflava, epidcrmide fusca lamellosa in costarum interstitiis subsetigera obducta, costis planis 38-40, anticis et medianis dichotomis subcrenatis, posticis simplicibus sublaevibus instructa; interstitia costis multo angustiora; apices remoti, antrorsum inclimuti, utrinque subsimuati; area profunda sulcata a ligumento crusso atro occupata. - Long. specininis quod exstat maximi 90 mill. Long. alt. crass, ratio plerumque numeris 100, 60, 40 respondet.

Arca erytleraeonensis Jonas in lit. Philippi Zeitschr. fur Malakoz. v. Menke u. Pfeiffer $185 t$.

Illabilat Mare Erythraeum; multa specimina legit beatus A. Rodatz navarchus. Nargo testae anticus aequaliter rotundulus, posticus oblique descendens subrostratus, margo ventris parum arcuatus, nomnnquam subsinuatus. Umbones in 1/3 areae siti aliquantulum distantes impressione vel simu levi signati sum. Costae planae sulcis angustis dividuntur, anteriorcs et medianae bifilae crenatae, posteriores obsolete rugulosae. Species singularis primo intuitu ad Anomalocardias pertinere videtur, scd omnia specimina in ventris latere hiant. Quod attinet ad costarum indolem Anomalocardiam secticostatam Reevei in mentem vocat.

Da diese ziemlich ansehnliche und eigenthümliclse Arche, welche hänfig im Rolhen IIcere vorzukommen scheint, noch nirgends abgebildet worden, so gebe ich davon eine genane Zeiclunung in drej Ansichten, welche eine detaillirtere Beschreibung zu der obigen Diagnose überflüssig machen Nur bemerke ich, dass das Zahlenverhältniss der Dimensionen von dem gegebenen mitunter elwas abweiclıt. Die kleine
Cette Arque assez distinguée, qui paraît être fréquente dans la Mer Rouge, n’étant encore figurée nulle part, nous en donnons un dessin exacte en trois vues, qui, jointes à la phrase diagnostique, rendent superflue une déscription plus détaillée. Seulement je remarque, que la proportion numérique des dimensions présente quelquefois de légères modifications. La petite sinuosité près des crochets 
Bucht in der Gegend der Wirbel Irill an dem abgebildeten Original weniger heivor als an den übrigen vorliegenden Exemplarion

Der schlecht gebildete Name erythraeensis oder erylhraeonensis soli das Vorkommeı dieser Muschel in Rothen Bleer (mare erylliraeum) andeuten. est moins prononcée chez l'exemplaire liguré que chez les autres.

Le nom mal formé: erythraeonensis ou erythraensis doil indiquer la provenance de l'espece de la Mer Rouge (mare erythraeum'.

\section{Barbutia velata Sow. vall.}

Tab. XLI.

Testa praegranlis, ovata, solidinscula, compressa, tota alba, antice declivis prodncta, attenuata, lisea nequaliter rotundata terminata, pastice extensa dilatata, in dorso parm fornicala, margine ventris sinuata lateyne hians, costis radiantibus inaeqnalibus granosis sulcisque incremcnti concentricis instructa, epidermide atra-fusca dense lamellosa el laciniosa velala; umbones magni obtusi; ligamenti area utrinque declivis valde profunda, sulcis mnmerosissimis densis subundatis signata; facies interna obsolete radiata; impressiones musculares plunate et obliteratae. - Specimen quod adest naximum epidermide inclusa lengitudinem 134 mill. allingit.

Simm Siamensem habitare dicilur.

I:yssoarca velata Sou. Proc. Zool. Soc. 1833. - Arca velata Reeve Conch. icon. sp. 79.

IIaec species cerle maxima est Barbatiarum huc nsque notarum. Specimen meae collectionis unicum depinxi ab icone Receana non solum forma multo majore, sed etiam ambitu vel lineis e.rtremis satis liversum.

Das Gebäuse dieser Art ist selar gross, im Unriss lang eiförmig, ziemlich flach, nicht sehr stark, vorn ahschüssig, am äussersten Rande gerundet, hinten verlängert und verbreitert. Der Rücken bat eine schwache Wölbung. Die gerade Schlusslinie schliessl sich dem vorderen und hinteren Muschelrande in einem selır stumplen Winkel an. Die Bauchseite ist vorn ausgebuchtet. Von den breilen slumpfen Wirbelı laulen unregelmässıge dichte Rippen aus, die von concentrischen zum Theil als Furclen sich darstellenden Wachsthumslinien durchschnitten werden, wodurch eine gekörnelse, hin und wieder gegitterte oherflache entsteht Die Epidermis stellt sich linten in dichten breiten Blällerlagen dar, dic ausgeschlitzt und ge-
La coquille de celle espece est trés-crrande à contour ovalaire allongé, assez aplatie, médiocrement épaisse, oblique en arant et arrondie à son extrémité, allongée el élargie à sa partie postérieure. Le dos présente une légère convexité. La ligne cardinale droile se joint aux bords antérieur el postérieur en angle très-oblus. La partie ventrale est sinueuse en avant. Du haut des crochels larges el ćmoussés un ruil partir des côtes rapprochées el irrégulières, croisées par des lignes concentriques d'accroissement, dont une partie forme des sillons, d'où résulte une surface granulée el treillissée çà et là. L'épiderme est composé de couches foliacées el larges, qui apparaissent laciniées el serrulées à l'extrénité postérieure, 
Eägı, am vorderen Theil der Muschel dagegen hin und wieder borstig erscheinen. Die Area ist beiderseits sehr abschiissig und tief und mit dichten etwas wellig gebogenen Liganentfurchen versehen. Innen und aussen ist die Muschel weiss, alugesehen von einer zufälligen grünlichen Färbung an einzelnen Stellen, die von Conferven herrührt.

Von allen Barbatien ist die gegenwärtige die grösste, die ich je gesehen. Es fragt sich übrigens ob wir hier nicht eine Riesenform der Arca candida Helblingii des Chemnitz vor uns haben, die so sehr variirt. Es ist bei dieser wie anderen ähnlichen Barbatien, die man zum Theil als selbstständige Species aufgeführt hat, in der That äusserst schwierig, ja unmöglich zu entscheiden, was als Species oder als Varietät angesehen werden muss, wenn nicht ein sehr reiches Material von möglichst vielen Localitäten zur Uutersuchung vorliegt. mais hérissées dans quelques parties de l'antérienre. L'aréa est des deux côtés très-oblique et profond, et présente des sillons ligamentaux rapprochis et légèrement ondulenx. Excepté une tciute partielle verdâtre, produite par des conferves, la coquille est blanche ent-dedans et en-dehors.

Parmi toules les espèces de Barbatia, que j'ai vues, celle-ci est la plus grande. Cependant if est douteux, si elle " est pas une lorme gigantesque de l'Arca candida Ilelblingii Chemn., qui est extrêmement variable. En effet pour cette espèce comme ponr plusienrs autres semblables désignées comme bonnes espèces il est très-difficile ou presque impossible de décider, lesquelles doivent être considérees comme espèces ou comme variétés, lorsqu' on n' a pas à examiner des matériaux riches de différentes localités.

\section{Murex crispus Brod.}

Taf. XLII. Fig 1. 2.

Brod. Proc. Zool. Soc. 1832. - Reeve Conch. icon. 67.

Cochleam hanc rarissimam et singularem Hnsei Hauburgensis hic depinximus a beato Hugone Cuming in litoris Peruani fundo petroso olim captam. Testa ejus ovato-piriformis anfractibus 7 ad suturam late canaliculatis, liris alternis majoribus transversis varicibusque 20 squamosis compressis crispatis instrucla est.

Clarissimi II. et A. Adams Fratres hanc cochleam ad Phyllonotos Swainsoni referunt.

Notandum est Murici cuidam alii telluris tertiariae fossili valde diverso jam antea a Lamarckio (Ann. Mus. II. pag. 224. Desh. Tert. II. pag. 589. Tab.81. Fig. 7-12) hoc idem nomen impositum esse, qua de causa hanc nostram speciem Muricem multicrispatum nominaverim.

Von dieser eigeutlü̈mlichen äusserst seltenen Sclinecke, die Cuming an der liüste von Peru auf felsigem Grunde in einer Tiefe von 25 Faden entdeckle, habe ich hier ein sehr ausgezeichnetes Exemplar abgebildet, welches dem Musenm in Hamburg angehört. Seine Länge beträgt 63 mill. bei einer Breite von 38 mill.
Celte espèce extrêmement râre, énumérée, par les frères Adams, dans la section Phyllonotus Szoains., fut déconverte par H. Cuming à la côte de Pérou, sur un fond pétreux, dans une profondeur de 25 brasses. Nous en avons figuré un exemplaire très-beau, appartenant au IIsée de Hambourg. Sa longueur est de 63 , sa largenr de 38 mill. 
Die Gebrüder H. und A. Adams bringen diese interessante Art in Swainson's Abtheilung Phyllonotus.

Murex crispus Lam. ist eine ausgestorbene von gegenwärtiger Schnecke sehr verschiedene Art des unteren Tertiärgebirgcs. Da der Lamarck'sclse Name das Prioritälsrecht hat, schlage ich für gegenwärtige Species die Bezeichnung Murex multicrispatus vor.
Murex crispus Lam. est une espèce fossile des couches tertiaircs inférieures, très-dif̣cirente de l'espèce de Broderip. L'espèce de Lamarck ayant la priorité je propose pour l'autre le nom de $\boldsymbol{M}$. multicrispatus.

\section{Murex depresso-spinosus Dlir.}

Tab. XLIl. Fig. 3. 4.

Testa ooata, turbinata, ventrosa, subfuviformis, crassa, fusco alboque zonata, transversim sulcata et costata, granoso-rugosa, anfractibus $6-7$ angulatis varicibusque totidem crassis squamato-spinosis instructa; spinae, imprimis superiores, recurvae valde depressae; spira parum exserta conica; canalis brevis lamina alba depressa paene clausus; cauda recurva umbilicata; apertura ovata; labrum crasse dentatum; fauces albae; aperturae margo aurantius. - Altitudo testae 73 mill., ejusdem latit. maxima paene eadem.

Patria ignota.

Haec species forma, pictura, varicumque numero variat. Specimen depictum majus varicibus 7 crassis spinisque longioribus e.rcellit, specimen quod cxstat minus, 6 tantummode varices ostendit brevispinosas et in anfractibus superioribus plicam inter varices intermediam. Cochlea spinis depressis habitun prae se fert valde singularem ab omnibus reliquis Muricibus aliemum, sed forma generatim atque universe spectata, Muricis trunculi varietates quasdam in mentem vocat.

Das Gehäuse dieser eigenthümlichen dickschaligen Art erimnert auf den ersten Blick an gewisse Varietäten des Murex trunculus $L$. aus dem Mittelmeer, auch in Bezielsung auf die Beschaffenheit der Oberfläche; doch ist die Spira kürzer, überhaupt die ganze Form der Schnecke gedrungener. Die Windungen sind unterhalb der Naht etwas wulstig und hier nicht eingeschnürt; der rechte Mundsaum ist stark gezahnt u. s w. Das wichtigste Unterscheidungsmerkmal sind jedocls die herabgeneigten und rückwärtsgebogenen Stacheln der varices, wodurch sich unsere Art überhaupt von allen übrigen Stachelschnecken unterscheidel Es
Le test de cette espèce singulière et épaisse rappelle, a première vue, certaines variétés du $.1 \%$. trunculus $L$. de la Méditerranée, auquel la surface est semblable. Cependant la spire est plus courte et la forme totale plus ventrue, les tours sont légèrement bouffis et non rétrécis au-dessous de la suture, le bord droit est fortement denté. Mais le caractère le plus important qui la distingue du M. trunculus, ainsi que de tous les autres Murex, consiste dans les épines des varices défléchies et recourbées. Il y a $6-7$ rangées de ces épines et la base des épines suprêmes qui sont les plus longues porte une petite appendice épineuse. 
sind dieser Stachelreilien 6 bis 7 rorluanden; an der Basis der obersten, längsten und am meisten herabgeneigten Stachehn hefindet sich nocls ein kleinerer stachelartiger Anhang. Dor liefe Nahel wird volı 6 hohlziegelartigen, in dir llähe gerichteten Schuppen umgehen, jedr einst das Encle des lianals der früheren varices oder Wachsthumstadien. Ein kleineres Exemplar mit verhälnissmissig kürzeren Stacheln besitzt eine lohlıaftere kastanienbraune Färbung olune die beiden weissen Biuden in der Mitte des Gewinles.
L'ombilic profond est entouré de 6 écailles imbriquées et érigées, dont chacune à son tour a été l'extrèmité du canal des varices précédentes. - Un exemplaine plus petit el garni d'épines proportionellement plus comtes a me teinte de marron plus vive el ne montre pas lus denx bandes blanches au milieu de la spire.

\section{Peristermia (latirus) gemmata Reeve.}

Tah. XLII. Fig. 5. 6.

Turbinelta gemmata Reeve Conch. ic. Tab. 1I. fig. 5. Tah. YII. fig. b1.

Ex icone Recreana Fig. 5 hujus cochleae natuia non satis elucet; icones 51 a. b. figuras meliores exhibent. Testu singuluris humectuta splendore iridescente refulget pulcherrimo, Buccino quoque prismatico Mart. proprio, que colorum varietas cum splendore rivido mixta e.r epidermide hydrophana oritur.

Habitat ud insulas Sandwirhenses.

Die lieeve'sclue Abhildung Fig. 5 gibbt lieine deutliche Ansicht von dieser interessimten schupche, besser ist schon die auf 'Talı. Xll. Fig. 61 gegehorne Zeichnung. Diess merkwürdige Sht zerigt eivenso wie Peristemia Prismatiea (Bureimem) Drertyn Lniv. Conch. vul. II. Talb. 2 dias Eigenthümliche, dass sie angefeuchtet mit den schönsten Farben schillert gleich dem Labradorfeldspath, eine Erscheinung, die meines Wissens mur an diesen beiden Sclunecken beobachtet worden.
La figure 5 de Reeve ne donne pas une idée chaire de cette rspece curieuse; le tlessin publié sur la planche 12. 8. 61 est un peu meilleur. Un caractere particulier de l'espèce, ainsi que de la Peristemia prismatica (Burrimum) Murtyn Univ. conch. Il. t. 2 est que le test humecte clange dans les couleurs les plus helles, semblable au Labradorite, caractère qui, à ce pue je crois, n’a encore èté observé que cluez ces deux cotjuilles.

\section{Fusus Heyeri Ilis.}

Tab. XLIII. Fig. 1. 2.

Testa magna, gracillima, tota nivea, anfractibns 10-12 valde convexis, superne paullo caratis, sutura profunda sejunctis, fortiter nodoso-plicatis, trunsversim crasse acuteque costutis instructa; eostae transversae impares, costulis incrementi olsoletis decussutae; anfractus ultimus $3 / 5$ Novitates II. 
totius testae aequans; rostrum longissimum latiusculum, anlice attenuatum; canalis late apertus; apertura oblonga; labrum intits sulcatum. - Long. testae 176, lat. max. 46, long. apert. 98 mill.

Patria huius cochleae in honorem Adolphi Meyer doctoris Hamburgensis nominatae, ignota est. Exstut in Museo Hamburgensi.

A Fuso longicauda Bory Encyclopédie méthodique Tab. 423. Fig. 2, Reeve Conch. icon. $s p .13$ nostra cochlea praesertion differt anfractibus supra paullulum caratis, plicis longitudinalibus nodosis costisque transversis crassioribus, sculptura omnino asperiore et vostro latiore.

Das Gehäuse ist gross, schlank, ziemlich dickschalig, einfarbig weiss und nit 10 bis 12 selur conrexen Winlungeu verselsen, die durch eine tiefe Naht getremut und unter derselben etwas ausgeschweift sind. Die oberen Umgïnge tragen starke knotenartige Löngstallen, dle nach unten hin allwälig schwächer verden und aul der letzlen Windung ganz verschwimlen. Erhabene scharfe Querrippen mil feineren dazwischen liegenden Rippchen umgeben las ganze Geluäuse, dessen Lünge an vorliegendem Exemplare 176 Mill. missl; doch dürfte dieselbe an 180 Vill. betragen labeu, da die Spitze verletzt ist. Der Rüssel ist breit und lang, vorn versclumälert, der Kanal ziemlich breit.

Von den vielen bis jetzt bekannt gewordenen Spindelsclunecken steht gegenwärtige Art dem Fusus longicanda Bory, Encyclopédie méllodique Pl. 423, Fig. 2, Ri e eve Conclı. icon. sp. 13 wohl am nächsten, doch sincl ihre Windungen unter der Naht etwas ausgebuclıtet, die knoligeı Längsfalten, sowie die Querrippen sind erbahener und schärfer, der Rüssel ist viel breiter; aucls kann ilsre Schale nicht dünn genannt werden.
Cette coquille est grande, grêle, assez épaisse, de coulen blanche uniforme, composée de 10-12 tours très-convexes, separés par une suture profonde, au-dessus de layuelle ils sont légèrement eufoncés. Les tour's supérieurs sont munis de plis longitudinaux forts et noduleux, qui s'amincissent insensiblement sur les suivants et disparaissent sur le dernier. Tont le test est eutouré de cóles transserses aignuës et de petites côtes interposées. La longueur totale de untre exemplaire a ėlé probablement de 180 millim., le sommet n'ètant pas parfaitement complet. La queue est large el allongée, atténuée en avant, sou canal assez large.

Parmi le grand nombre de Fuseaux connus notre espèce s'avoisine priucipalement au $F_{\text {usus }}$ longicanda Bory, Encycl. méll. !)l. 423. fig. 2. Reeve Conch. icon. spec. 13, mais elle s'en distingue par ses tours enfonces au-dessous de la suture, par ses julis longitudinaux et ses cóles transverses plus aiguës, sa queue beancoup plus large rt sa solidité.

\section{Fusus Rudolphi Illir.}

Tab. XLIII. Fig. 3. 4.

Testa ovato-fusiformis, ventrosa, solidiuscula, strigis maculisque pallide fuscis vel ferrugineis per. longitudinem picta, anfractibus 8 convexis transversim inaequaliterque costatis lineisque increnenti obscuris instructa; anfrectus ultimus inflatus $3 / 5$ totius testae adaequans; rostmm 
breviusculum, subcurvum, truncatum, columellae media pars parum sinuata; canalis antice late apertus; labrum tenue, crenatum, intus sulcatum. - Long. testae paene 90 mill., diam. max. 35 longa, diam. aperturae 51.
\end{abstract}

Patria ignota. Exstat in Museo Hamburgensi.

Hubitu et picturae indole nostra cochlea Fuso pirulato Reeveano similis est, sed distinete differt testa paullo solidiore, spira longiore, costis planioribus plicisque longitudinalibus prorsus deficientibus: praeterea rostrum paullo brevius et canalis latior est.

Dieser eigenthümliche Fusus erinmert anf den ersten Blick an $F$. pirulatus Reve, docls sind die Umginge desselben minder stark aufgerriehen, die mughelien Spiralreifen flacher, überhanpt ist die Sculptur feiner; auch feblen die Längslatten, welche zumal auf den oberen Windungen des $F$. primblutes sely stark hervortrelen, hier gänzlich; die Spira ist langer, anderer kleinerer Abweichnngen niclut zu gedenken.
Cette espece singuliere rapurete, à première vue, le $F$. pirulatus Reeve, cependant ses tour's sont moins renllés, les strits spirales inégales moins sailantes, en general sa sculpture plus fine; les plis longitudinaux, qui sont très-silllants surtout sur les tours supérieurs du pimlatus, manquent entièrement; la spire est plus allongée, ptc.

\title{
147. Solen Lappeanus Dlit.
}

\author{
Tal. XLIY. Fig. 1.
}

Testa angusta linearis, sulvylindriea. postice namm attenuata, solidula, alba nicolor, striis incrementi obsoletis instructa, epidermidr olirucca-comea restita; margo unficus peroblique truncatus, canaliculatus, inferne paullo rotundutus: margo lateris postici contracti subrotundus, perparum obliguus; dentes pro exiguitate testue crassi; nmbones vix prominuli; dorsum rentri paene exacte parallelum. -- Long. testae 7.2 mill., alt. 11, j. lut. 10.

Habitat Hare dietillam fide ornat. Theoloro Lappe.

Gehäuse schmal, gerade, sohr gewiilbt, fast cyliudrisch, ziemlich dickschalig, weiss mit schwachen, doch deullichen Wachsthumsansäizen, der Vordertheil mil riner sclmalen Furclie ouler limme sohr schief trunkrirt, ein wenig nach aussen umgalogen, mulen clwas germulet; der IJintertheil nu rin Weniges verschmälut und ziemlich germulet. bie Wirbelchen treten kaum liervor. Das Schloss zeigt vorn an joder Schale riuen verhibltnissmässig starken Zahn, lat also die Beschaffenheit der Fattung Solen im engeren Sinne. Die Epidermis ist holnhlahen, fast blass olivengrün, und ragt rorn elwas, hinton
Cmpille etroite, rectilinime, tris-convexe, presque cylindriuge, assez épaisse, blanclie, marquée de stries d'accroissement faiblos mais bien visibles; la partie anterieure montre $\mathrm{mn}$ sillon ftroit, elle est trompuée tres-obliquement, legèrement évasée en dehors, nédiocrement arrondir en bas; la partie postérienre rst insemsiblenent annincie et bien arrondie. Les petits crochets sont á prine saillants. La charniere nontre, dans claque valve, en avant une dent proportionellement forte, carractire du gente Solen rétréci. L'épillerme est corné de couleur pale légérement verditre, et il dépasse le bord de 
jedoch melır über den Schalenrand livaus, als das bei Solen der Fall zu sein pllegt. Die fast cylindrische Form, varhältnissmãssig starke Schale, der sehr schief abgestutzte Vorderlueil mit der Rinne, die hintere verschmälerte Extremität und die ziemlich writ den etwas gerundeten hinteren Schalenrand n̈berragende Epideruis sind Merkmale, die diese Art vou den ïbrigen bislang bekannt gewordenen Solenen leicht unterscheiden. la coquille, surtout à la partie postérieure, plus lasgement que cliez les autres Solens. La forme à $p$ tu près cylindrique, la solidité comparative des valves, la partie antérieure sillonnée et très-obliquement Ironquèe, l'extrémité posterjeure amincie et l'èpiderme fournissent des caractères, qui distinguent aisement notre espèce de toutes les autres connues jusc|u’à prèsent.

\title{
148. Siliquaria centrialis Contrid.
}

\author{
Tab. XLIV. Fig. 2.
}

Specimen hic depictum, ad collectionem ornat. Fr. Pätel Berolinensis pertinens, pro mea opinione Siliquariam (Tagelum) centralem Conna di veram rejert. E litore Georgiae originem ducit. Perafinis est Soleni gibbo Spengleri, qui est S. Caribaeus Lamarikii.

Das licr aligebildete Evmplar, welches in der Sammlung des Iluru Fr. Pä al in Berlin sich belimlet, ladts ich bür die echle Siliqueria centralis Conrad's. Dassplle stammt von der liiiste Georgiens.

Diese Art ist dem Solen gibbus Spengl. (S. Caribaezs (am.) zunächst verwandt.

\section{Siliquaria Califormiana Comr.}

\author{
Tab. XliV. Fig. 3.
}

Varietas huius speriei hic ante oculos posita est colore pallide mijo lineisque duabus radiantibus magis ut solent perspicuis insignis. Epidermis comea plemmque obliterata jacile deliscit. - Species S. Dombeyi Lam. affinis, sed anbitu rel axtrema linea, valvis tenuioribus alïsque notis satis clifiert.

Conferatur Gultellus Californianus Conr. Joum. A. N. S. Phil. 7. p. 233. t. 18, f. 3. Hanley an illustr. and descript. Catalogue of recent Shells I. p. 16. t. 10. f. 4.

Wir haben hier eine Varietät der Siliquaria Californiana dargestellt, welche sich durch eine etwas ungewölsuliche Förbung, sowie auch durch die bejolen vom hinteren Theil der Wirbel ausstralılenden Linien auszeichnet, die lebhafter litervortretem, als dies ge-
Nous avous tiguré une variété de la Siliquario Californiana, qui se distingue par une coloration anomale el par les denx ligues rayomnantes de la partie postéricure des crochets, plus marqués que dans les exemplaires typiques. L'épirlerne corné brunàtre 
wöhnlich der Fail isl. Die hornbranne Epidernis ist meist zerstïrt, da sie leitut abspringt. Vun Solen rufus Bosk (Dombeyi Lam.), welcher einen abweichenten Umriss und tickerm Schalıu hat, muterscloridet sich vorliegende Art leicht. rst trés-fragile et detruit dans la flupart. On la distingnera aisement dn Solen mijus Bosk (Dombeyi Lam.), qui a des conton's diflerents et un test phus épais.

\section{Solen Mörchii Mkr.}

Tit). NLIV. Fig. 4.

Testa lata pamm concexa albida latere interno medio mubicundu, striis inerementi tenuibus, in area trigonali fortioribus subrugosis instructa, epidermide temui flavilu abducta; margo anticus abrupte truneatus, superne infirneque rotundatus, plano-canaliculatus, in pagina interna subinerassatus, margo postiens rotundato-truncatus; umbones piunissimi; lineae dorsi et reutris extremitatem rersus posticam pauhhom diveryentes. - Long. 7', alt. lateris antici $1 \bar{j}$, postici 17 mill.

Patria ignota. Exstat in Museo Regio Inafniue. Perserutandi causa hune speciem amicissimus O. Möreh misit.

A Solene vagina Linnaei nostra slecies testa multo lireviore et latere postico altione facile distinyeuenda est.

Schiten wenig convex, weisslich, inuen in der Mitte blassı̈̈lılich, mit feinen denı Bauchramle parallelen Limen, aul Jem drejeckigen Felule mit stïlkeren faltenartigen Reifen. Der Vorderrand ist steil ablallend, oben unt unten gerumdet mat mit ejoer seichten linue versedern, imnen etwas rendickt, die

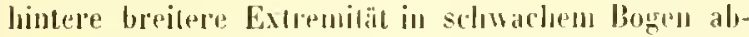
gesturz. Die bassloranne Epidermis ist zart, dïm und glinzend. Das Schloss hat die gevö̈luliche Beschalfenheit der Solenen im engenen simne.

Von dem entupriischen Solen vagina $L$. ist unsese Art zumal dorch kürzrle, linten hreitre Schalen lejcht. zı interscheiden.
L's valves sout légèrement convexes, blanchâtres, d l'intérienr rougeâtres au milieu, garnios de lignes fines parallèles au bord venual et de stries plus fortes pliciformes sur l'aréa triangulaire. Le bold antériem. descend subitement, il est arromdi en haut et en bas, muni d'un sillon peu eufonce, legèrument epaissi a l'interienr; l'estremite postriente plus Jarge est tronquée en arc faible. L'épinternes d'un lırun pale est mince et luisant. La charniere a l's caracteres accoutumés des Solens proprement dits.

On distinguera notre espece aisement du S. va-

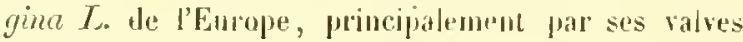
plus raccourcies et plus larges vers l'extrénté postérieure.

\section{Alea Hmbonitit Lillm.}

Till, NlilV. Fig. 5. 6. 7.

Icones nostrae exemplar exhibent integmu et regulare, eqidemide bene servata obuluctum. intillarmu maris incola satis jrequens forma suc pervariabilis est. Sulptura cancellata plus minusve granosu. 


\section{$-132-$}

Epidernis lamellis constat squamaeformibus sululiuphunis striatis sultiliterque plicatis, marginibus acute lariniosis, in carina praesertim expressis. - Le Loussole Adansonii (Ifist. du Sénégal Tul. 18, Fig. 9.), quem Lamarckius laudat, fortasse al Aream Noae L. pertinet; Area vero Americana d'Orbignyi (Cuba vol. II. pag. 317, Tab. 29, Fig. 1. 2.) nil est nisi Area um lionat a deprilata.

Diese drei Ansichten stellen ein umerletzlrs, regelmässigg ausgebildetes, mit vollstăndiger Epidermis bekleidetus Beispled dieser iusser'st wandebaren Art dar, welche ins Antillenumeere selır verbreitel vorkomm. Die gegitterte Oberfliche ist auf den Durchselnittspmkten der kippchen stets mehr oder minder körnig. Die braıne Epidermis besteht aus zarten, durchseheinenden sehuppigen Blättern, die fein gefaltet und an Rande scharf áusgezackt, auf der Carina besonders dentlieh lervortreten. - Ob der von Lamalek (Ilist. des an. s. vert. ed. II. rol. Vil. pag. 462) citirte Moussole Adanson's (Hist. du Sénégal Pl. 18, ligg. 9) liipther gehört, ist selu fraglich. Derseltse scheint der verwandtons Area Noae I. anzugehören. Doch dörfte jedenfalls die Arca Americana d'Orlugry's (Cula II. pag. 317, Pl. 28, fig. 1.2.) die normale, freilich der Epidermis berauble Area umbonatu Lam. sein.
Nos trois figures représentent un exemplaire parfait et régulièrement formé, vétu de son épiderme complet, d'une espèce très-variable et très-répandue dans la mer des Antilles. La surface treillissée est toujour's plus ou moins granuleuse sur les points de croisement des petites cỏtrs. L'épiderme lrun est composé de lames éeailleuses minces et iransparentes, fincment plissées et frangées, saillantrs prineipalement sur la caréne. Il est très-doutenx, si le Moussole d'Adanson (Hisl. du Sénégal pl. 18. f. 9) cite par L am a pek (Ilist. des anim. s. vert. ed. Desh. VII. p. 462) est la mème espèce. je crois gu'il correspond pủntôt à l'Area Noae $L$. An contraire il parait, que l'A. americana Orb. (Cuba I1. p. 317. p. 28, f. 1.2) n'est antre chase que l'A.umbonata Lam. normale, mais déjponillée de son épiderme.

\section{Barbatia harhata L. Varr.}

Tab. XliV. Fig. 8. 9.

Cum haec species Maris mediterranei frequentissima lulitu muximopere variet, duo specinina inter se valde discrepantia lic adumbraxi, alterm patene cylindrinu, alterum prope accedens ad formam nomnulem.

Da diese sehır lıănlige Art des Mittelmeeres ansserordentich variirt, zumal in ihrem Umriss, so habe ich hier zwei Exemplare abgebildet, wovon das eine (Fig. 9) mit sehr gewölbter Schale last cylindriseh erscheint, das andere dagegen mehr die gewöhnliche Form zeigt.
Celle espece très-fréquente de la Méditerranèe étant extrêmement variable surtout dans ses contours, j’ai fait dessiner deux exemplaires, dont l'un (fig. 9) se distingur far une coquille fortement convexe et presque cylindrique, l'autre s'approche davantage à la forme ordinaire. 


\title{
15\%. Barbatia Adolphi Ilkl.
}

\author{
Tab. XIJIV. Fig. 10-13.
}

Hane speciem ad divisionem Barliatia fuscae, eruciatce atiarumque pertinentem. jom in pagina 107 Novitatum descriptem et in Tal. XXYIII. Fị. 1-3 depietam invenies; nenc vero icones speriminis mujoris, epudermide prilosa obulucti nec non varietatem minorem in latere interno vivide coloratam (Fig. 13) adjieio, naturam Barbatiae Adolphi melius illustrantes. - Ienominatio Barbatiae Reentsii in Tubula nostra in crrore nititur.

Von dieser in die Gruppe der Barbatiu fusca, cruciata u. s. w. gelbörigen Art ist bereits aul' Seite 107 der Novitates eine Besclureibung und 'Tall. NXX'il. Fig. 1-3 Abbildung gegeben worden, doclı liïge ich hier noch dhei Ansichten (Fig. 10-12) bei, welche naclı rinem grösseren, meist noch mit der laarigen Epidermis verselienen, Exemplare genommen sind, sowir auch die innere Seite einer kileinen ledsuaft rothlbraun gefärbten Varietät. - Die Bezeichnung Barbatia Reentsii auf unserer Tafel 44 beruht anf einer Verwechselıng.
Cente espèce appartenant an groupe des $Z_{\text {. }}$ cruciata, fusca elc. a déjá été décrite dans les Novitates pag. 107 rl figures ph Xxxvu. lig. 1-3; voici l'illustration en trois vues (lig. 10-12) d'un exemplaire plus grand, muni, dans sa plus grande partie, de son épiulerme velu, et relle de la face interirure d'une petite variete dre coulempr rousse. Le nom de Barbatia Reentsii sur motru phanche 44 s'y trouve en suite d'une confusion.

\section{Arcil Mirtinii Reciuz.}

Tal. XIS. Fig. 1. 2. 3 it 4 particula lateris magnitudine aucta delineata.

Testa orato-ollonga, aequivalvis, githosa, antuce brevis rotundata, postice producta angrestata, inde valde inaequilatera, costis racliantilus subaequalibus 26-30 costulisque multo angustiorilus interpositis, ommitus transcersim striato-grenosis instrueta; color allielus rel sulfflarms, in umboribus saeprins mulidus; epudermis fusco-nigricans, lanellosa et hispiela, postice setigera: unlones crecti, sulwemoti, veversi; area lenecolate directe sulcata, a ligamento nigro crasso prorsus feve occuprate; impressiones musculures leminam oblongam umhones versus angustatum et acuminatam a margine acuto terminatam formant. - Long. 30-32 mill. Long. alt. cruss. ratio $=100,55,50$. Ilubitut ad insulum Sentue Cathurinae Brusitiue, unde misit eluer. Dr. Fr. Mäller.

Arca (Byssoarea) Martinii Recluz in Journ. de Conchyliologie 1852. pag. 409. Tub. XII. Fig. 3.4. 5.

Diese selır eigenthünliche Art ist meist vollkommen gleichschalig. aber ungleichseitig, vorn kurz,
Cette espèce très-singulière est, en génèral, parlaitement équivalve, mais inéruilatérale, contre, ar- 
gerundet umd aufgetriplen, linten verlängert und nular orler minder vaselımälert, zuweilen auch schräg alorestulzt und alsdamn himten etwas breiter. Die Selsalen sind mit dichten, abwechselnd breiteren und suhr schmalen, schuppig körnigen Rippeben beleckt. llir Wirbel ragen weit hervol und sind gegen alie gewölunliche Regel rinckwairts gebogen. Von denselben lãuft ein selıarfir, nach dem llintertheil der Huseluel stumpf werlender Kial herab. The Farbe ist gewölulich weiss, imnen und an den Wirheln zuweilen gelblich; anch liegt ein Exemplar vor, welches aussen den concentriseluen Schalenansälzen parallele rothbraune Bainder besitzt. Die seluwäzlich bramn Epidermis lat eine dicht blättrige Beschaffenleit und endel, mamentlich gegen d+o Rand lin, in feinen Borsten. Dits Area ist lanzetffirmig und auf der vorderen Iälfte mit 12 bis 14 tieferen, hinten dagegen mit schwächeren und feineren Furchen versehrn, die rechtwinklig $7.1 m$ Schlossande gerielstet sind. Las scliwarze I igament nimmt das Frall beinalue ganz ein. Die Muskeln betinden sich auf einer etwas erhöheten hallssehicht, die spitz zulaufend unter den Wirbehn sich verliert and von einer anfgerichteten Lamelle begrenzt wird, eine Bildung, die vollkomuen analog bei Lrea reversa, sowie in wejt ansgezeichuetrem lirarle hei Cumblaea rorkommt. Unsere kleine Vusclul wïrde zumal anch wegen der rückwärts gelogenen Wirbel und der eigenInümlichen Berselualfumbrit dres Schlossfeldes der Gray'schen Gatung Noctir angehören, welche aul' die Arca reversa gegründet ist.

Bei diesin Gelegenleit möchte ich fragen, was ist Area bisulcata Lamarel's? (Anim. sans vert. VI. j. 475.) Die freilich selır kurze Diagnose: „Testa transversim oblonga, antice angulata, longitudinaliter sulcata, suleis transverse striatis, alternis minoribus" sowie die Bemerliung ,.Halite les mers de la Guyane et dı Brésil. Larg. 30 mill." passen ziemlich gemau. Es wäre sehr zu wünsclıen, dass Mr. B. Delessert rondie et renflée en avant, allongée et plus ou moins rétrécir a sa partie postérienre, yuelquefois ohliqurment uronquée et dans ce eas plus large. Les valves sont couvertes de cotes frérpuentes, alternativement plus laroges et très-étroites, écaillenses et granuleuses. Les crocliets sont furtement saillants et (en contradiction à la regle ordinaire) recourbes en arrière. Une carène tranchante, plus émoussée vers la partie postérieure de la coquille, descend des erochets. La couleur est dans la plupart blanche, quelquefois jaumatre en-dedans et aux crochels; un autre exemplaire montre, à l'extérirur, des bandes rousses palallèles au stries d'accroissement concentriques. L’épiderue lorun noirâtre est éjais el foliacé; il se termine. surtout vers le borl, en soies fines. L'aréa est lancéolée et garni, à sa partie antérieure, de 12-14 sillons profonds, plus fins vers lin partie postérieure, formant on angle droit avec le bord cardinal. Le ligament noir occupe l'aréa presqu'rntiérement. Les muscles sout placés sur unt couche calcaire èlevée, qui s'atténuant en pointe se perd sous les croelıets et est bordée par une lamelle élevée, formation qui se retrouve en parfaite analogie chez l'Area reversa et eu lien plus haut degré chez Cucullaea. Notre espece appartiendrait, a eause des crochets recourbés et de la condition singulière de l'aréa cambinal, au genre Noetia, foudé par Mr. Gray sur l'A. reversa.

Nous profions de celle occasion pour demander: qu'est ce l'A. bisuleata Lam.? (Anim. s. vert. VI. j. 475.) La phrase courte: "testa rausversim oblonga, antice angulata, longitudinaliter sulcata, sulcis transverse striatis, alternis minoribus" ainsi que lindication "haluitr les mers de la Guyane et du Brésil. Larg. 39 mill." correspondent assez bien. Il serait à désirer que lourrage de Mr. H. Delessert "Thecueil de Copuilles décrites par Lamarck et non encore figurees" se fut horné pour les espèces lamarckiennes, pour lesquelles il n'y a pas de ligure 
in seinem Recueil de Coyuiles decrites par Lamarck et uon encore figurées statt mancluer bekammlen vou Anderen publicirten Arten mur anf diejenigen Lamarck'sclien Ajten Rücksicht genommen lrätle, zu welchen kine Abbiklungen rilirt sind. citér, au lieu d'autres deja publices el bien connues.

\section{Barlatia Petersii lokr.}

Tab. XIV. Fig. 5. 6. 7 .

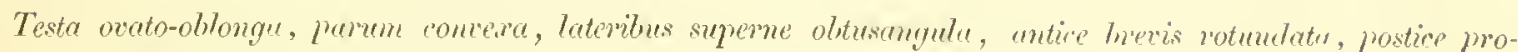

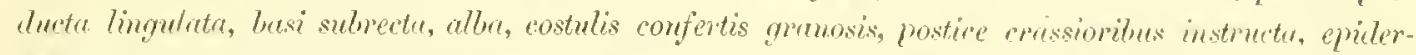

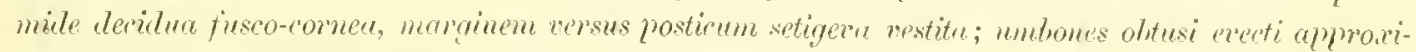

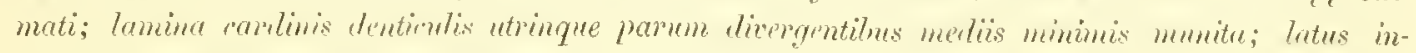

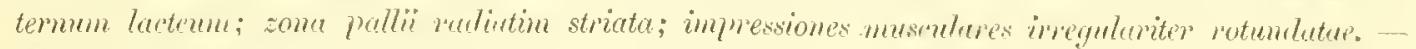
Long. speriminis depieti 50 mill. Long. altit. cress. ratio $=100$. j2, sis.

Habitat in litore Malugaseriensi.

Gehäuse länglich, vorn kum und gerundet, hinten zungenförnig verlängert, dej Schlossuand fast gerade, mit dem vorderen und hinteren Rande stumpfwimkelig verbumlen und hinten einen lileinen Flügel bildend; Jer Banchraul in dre Milte kaum merklich gebuchtet. Die stmmpfrn mul anfgetriebenen einander ziemlich geuährnten Wirbel liegen etwa im ersten Drittel der Schalenlänge; run denspllsen laufen dichte gekömste Rippches aus, die hinten brejtes. werden und zumal aul dem kleinen hinteren flüge!artig ver]ängerten Theil besonder's deutlich herrortreten. Die Suhale ist innen und aussen bläulich weiss und von einel braunen, dümmen, leicht abspringendes Epidermis bedeckt, die am Rande der Auschel, namentlich hinten, horstig ersclıeint. Die Schlossleiste ist zu beiden Seiten mit etwas divergil'enden Zähuchen besetzt, die unter den Wirbelı sehr klein sind. Das Schlossfeld ist schmal und wird rom Ligament fast ganz eingenommen. Die flachen, glänzenden Muskelnalben sind unregelmässig gerundet; oberhall, de Mantellinie bemerkt man feine raviale Reifchen.

Novitates II
Coquille ohlongur, comrte et arrondie en avant. allongéc en arrièe en forne de langue; bord casdinal presque droit, joint au hord antérieur et postérieur en angle obtus et formant en arrière nne petite aile; hord rentral presyu'insensillement sinueux au milieu. Les crochets émoussés et jenllés, assez rapprocliés sont placés à pen près an premiej tiers de la longueur; de petites cótes granuleuses descendent des crochels, s'élargissent en arriere et sont particulièrement marquées sur la petite partic postérieure allongèe en aile. La coquille est blanche bleuâtue an dehors et en dedans, et couverte d'nu épiderme hrun, mince et caduc, qui apparait hérisse au bord. principalement en arrière. La plaque carliuale est garnie, des deux cótés, de dents légèrement divergrentes, qui sont tres-petites sous les crochets. L'aréa cardinal est étroit et presynentièrement occupé par le ligament. Les cicatrices musculaires, aplaties et lınisantes, ont une forme circulaire irrégulière; au dessus de la ligne palliale l'on remarijue de fines stries rayonnantes. 
Diese Art ist Reeve's Barbatia (Arca) decussata verwandt, aber minder bauchig, anch in Umriss versehieden.
Cette espèce est voisine de la Barbatia (Arca) decussata Reeve, mais moins ventrue el à contours dilferente.

\section{Area Crossei Dkr.}

Tab. XLV. Fig. 8. 9. 10. 11.

Teste oblonga, subquadratu, tota alba vel postice fuseo tincta, plus minusve aequilatera, solidiusula, aniece rotundata, postice oblique ubmupteque truncata, basi cix simuata, carina crassa ab umbonibus ad latus posticum. utrinque decurrente insignis, costulis radiantibus et concentricis eleganter cancellata, sulimbricata; umboncs subacuti; area subangusta profunda a ligamento omnino fere occupata; costae inter carinam et aream sen crassae subimbricatce; cardo crassiusculus fuscus, denticulis utrinque divergentibus munitus; vima pro pede enittendo angusta; margo internus plenemrque fuscus. Long. maximi quod exstat speciminis 20 mill. Long. altit. cretse cinca 100, 60, 48.

Matitut in sinu Mazatlani o.

A. pullis Arcae umbonatae Lam. tostre regulari haud tumile, sculpture cancellata costisque in area postica crassis imbricato squamosis prasertion differt.

Dirse Alt hat Aelunlichlieit mit jungen Exemplaren der Arca umbonata Lame, doch sind ihre Schalen nicht aufgetrichen und melır gegittert, auch trägt das hintere, schief alygestutzte Feld 6 bis 7 starke, schuppige Rippen. Die Farbe dieser kleinen Muschel pllegt weiss und hinten braun gefleckt zn sein. Ibas verhültnissmässig'starke beiderseits mit etwas divergirenden Zälmelten besetzte Schloss ist brauu. llie Oell'nung fiir den Fuss ist schmal. - Iliu und wieder bemerkt man Spuren einer hramen blätrigen Epidernis.
Cette espece ressemble is de jeunes exemplaires de l'A. unlionate Lam., mais ses valves ne sont pas renflées, alles sont plus fortement treillissérs ot la partie posterieure obliquement tronpuẻe est munie. $6-7$ còtes fortes et écailleuses. La conleur est en gínéra! blanche avec drs taches brunes à sa partie postérieure. La charnière proportionellement fort: et garnie des deux côtés de petites dents légèrement divergentes est brune. La partie baillante pour le pied est ètroite. Des vestiges d'un épillerme foliacé et hrun se trouvent ẹà et la.

\section{5\%. Area fusco marginata Olir.}

Tals. Xl, V. Fig. 12, 13, 14.

Testa valde ventrosa, subtrigona, crassiuscula, alba, strigis fuscis angulatis et undulatis pieta, costis radiantibus inapqualitus instructa; costae anticae crassae, posticae plus minusve obliteratae; unbones sacpine obtusi late distantes; carina obsoleta paene.nulla; area ligamenti latissima sulcis im rhombos

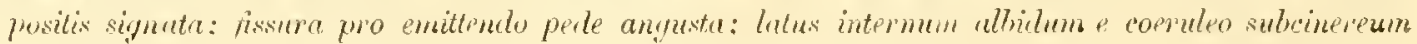


maroo concher internus incrassatus vivide fuscus. - Longit. sper. marimi bä mill. Long. alt. crass. ratio muneris $100,55,52$ respondet.

Habitut ad litus Maclagascariense, teste mercutore, qui venalem hubuit.

Eine sehr eigenthümliche, zirmblich dickschalige, zur Gruppe der Area Noae gehöremle Art, die sich namentlich durch iluen fast dreiseitigen Umriss und ihre ungemrin bauchigen schalen auszricluet, dren beträchtlichste Höhe im Hintertheil sich befindet. Der Charakter der äusseren Zeichnung entspriclit dem der verwanden Arten. Innen ist die Vuschel weisslich, etwas in ein bläuliches Grau verlanfend aber-am verdickten hatule lelhaft rollhoraus gefïrbs. Die vorderen Rippen treten stark hervor, werden jedoch nach tler Mitte hin allnälige feiner und schlirssen hier noidh schunatere Rippehen rin, die Ileeilweise mit kleinen schuppen bedeckt sind. Am Hintertheil ist die Seltale, wrinn nicht verridhen, grobblätlerig. Die Epictermis, wovon usur șpuren vorhandeu sind, ist lichthraun, dūunblatterig usul seidenglänzend. Die weit abstehenten Wirhel sind an den drei vorliegenden in Westutlichen vollkommen ühereiuslumeroden Exemplatren "twas algerielen.
Especer très-singulirre, assuz solide, apprartenant au groupe de l'A. None, qui se distingue principalement par son conton presıue triangulaire et ses valves extraordinairement ventrues, dont la plus grande lauteur se troure a la prarlie postérieurp. Le caractere de la coloriation pxtérieure correspond a celui les especes voisines. A l'interieur la coquille est blanche, tirant sur un gris bleuâtre, main vivement rousse au bord éprissi. Les cotes antérieures sout fortement saillantrs, s'anincissmu insensiblement vers te milieu, ou entre elles se trouvent des côter encore plus étroites, jui en partie sont couvertes de prtites écailles. La partir postériemre est grossièrement loliacée. L'épiderme, dont il n'y a yue des vestiges, est d'un hrum clair, composé de lames minces et luisant comme de la soye. Les crochets fortement divergents, sont légèrement usés dans lus trois exemplaires essentiellement égaux, que nous avons sous maill.

\section{Cor rigenda quaedan et addenda.}

3. Die als Cytherea cordiformis Dhr. pag. 11 beschriebene und Tab. IV. Fig. 1. 2.3. abgebildrte Nuschel stellt eine ausgezeichnete, fast kugelige Varirlät der Cyth. obliquato Hanl. dar, wie eine Reilse von Urbergängen, die ich später zu vergleichen Gelegenheit hatte, beweist. Es ist diese Art zumal in Beziehung auf Stärke der Schalen und deren Umriss sehr variabel. Nach M $\mathbf{a r}$ ch soll dieselbe übrigens Cyth. (Cardium) albida Martyn sein. Vgl. Cat. Yoldi JI. Lioconcha 317.

2. Zu Spondylus sanguineus Dkr. pag. 26 ist hillzuzufügen, dass anch eine blassrothe mit dunkeln breiteren und schmäleren Strahlen gezierte Varietat vorkommt.
1. La coquille dicrite sous le nom de Cytherca ccrligorm's Dkr. pag. 10 el ligurée pl. IV. f. 1.2.3, represente une variaté remarquable, presque globuleuse de la $C_{3}, h$. obliquaia Mlanl., ce qui est prouvé par un série de formes intermédiaires, que plus tard j'ai ell occasion de comparer. Celte espece est treis variable surtout par rapport de l'épaisseur et des conton's des valves. Selon Mörch elle serail identique avec la Cyth. (Cardium) albida Martyn. Comparez Cat. Yoldi II. Lioconcla 317.

2. Spondylus sanguineus Dkr. pag. 26. Ajoutæz, qu'il existe une variété d'un rouge pale, ornée de rayons plus fonces plus ou moins larges. 
3. Fiil Anomalocandia latruncularia Röm. pag. 37 ist Coyptogramma latruncularia zu suzen.

4. Lubre Muctra Lailulorfii Dhr. = sachativensis Schrenck vergl. I.ischkı's Japanische Meeres-Conchylien pag. 182.

5. Wiewolı von Sumptta (Meroë) coneinna Dhr. pag. 74 trei im Unriss, Zeichnung und amderen Nerkmalen vollkummen ïbereinstimmende Exemplare vou Ambuina rorliegun. so zeigen rloch die ron Römer in seiner Mononpaphie ler Molluskengatıng Venus neurdioh gegebrur Abbildungen, dass diese Art im Unurss kejueswros so constant erschrint, weshalb die unserige voln mur als cine am Vorder- mul Hintertheil stark aburerumlete larietät der Sunetta (Meroë) truncata Lesh. zu belrachten sein diirfie.

6. Lucina mirabitis I/kr. jag. 77 ist schon in Journ. de Conchyliologie 1857 pay. 106 unter dem Vamen L. Voomoeree von Desliayes lueschrieben, was ich keider äbersehen habe. Diese Art soll von ver Kö̈ste von Mozambique kommen.

7. Anomalocardia paucigranosa Dhr. pag. 85 ist wach der Mittleilung dre llerrn von Jartens Areu nodifera v. Mart. I'roc. Zool. Soc. 1860 pag. 17.

8. Zu Barbatia erimia Dkr. jag. 90 Tab. XXX. Fig. 1. 2. 3. aus des seligen Herrn Cuming's Sammlung ohne Angabe des Vaterlandes labe ich naclıuräglich zu bemerken, dass dieselbe vielleicht zur Area nagellanica des Chemnitz (Vol. VII. pag. 192. Taf. 53. Fig. 539) gehört. Diese bislang zweilellaft gebliebene, jedenfalls seltene Art wirl memes Wisseus neurlich weiter nirgends erwäht als in Pliilippi's Abb. und Beschr. vol. III. jag. 88. 20) der sie fïr eine monströsn Form von Area barbata $L$. häh.

9. Zu der als eine Varietät der Fasciolaria purpurea Jonas auf pas. 94 dieses Bandes der Novitates beschrielienen Schnecke muss ich nachtrigglich hemerken, dass dieselbe, nachdem ich Gelegemheit gehabt das Jonas'sche Originalexemplar, welches sich im Hamburger Zunlogischen Huseum befindet, genauer
3. Au lieu de Anomalocurdia latmuncularia Röm. pay. 37 lisez Cryptogramma latruncularia.

4. Mactra Liihdorfi Dkr. = sachalinensis Schrenck. Comparez Lischlie Jap. Meeres-Conch pag. 182.

5. Sunetta (Meroë) concinna Dkr. jag. 74. - Nous avous sous mains 3 exemplaires d'Amboina, parfaitement egaux quant a leur's contours, colorisation et autres caractères. Neanmoins les figures publiées récemment par Kö mer laıs șa لlonographie du genr Vemus, demontrent que cette espece n'est pas jarfaitement constamte tuant a ses contours, et que la môtre doit plutôt être considéree comme varièté dt. la Sunctu (Meroü) truncata Desh., fortement arrondie à sa partie andérieure ansi qu’a la posterrieure.

6. Lucina mirabilis Dl\%. pag. 77. Cette esprece a ete lecrite par Y. Heshayes dans le Jourmal de Conchyliologie 1857. jag. 106 sous te nom de L. Voorhoevei, nolice yui à mon grand rrogrot m'a echappe alors. Ello doit provenir de la cous: de Nozambique.

7. Anomulocadia puncigranosa Dur. pas. 85 . Cette espéce est, d'après les cummunications de لlr. E. de $M$ a I'uns, identipue avec I'Arca modiferce Hart. in Proc. Zun]. Soc. 1860. pag. 17.

8. Barbatia eximia Dkr. pag 90. pl. XXX, fig. 1. 2. 3. J'ai remarquer, que cette espèce, decrite d'aprés des exemplaires de la collection de feu H. Cum ing sans indication de localité, appartient peut-ètre à l'Area magellanica Chemn, (vol. VIl. pag. 192. pl. 53. lig. 530.) Cette espèce certainement urès-rare est r'usté douteuse jusqu'à présent, et je ne commais aucmue notice recente sur elle excepter celle de Jhilippi (Abbilu. und Beschreil. III. pag. 88. 20), qui la regarde comme lorme monstrueuse de l'Area barbata Limn.

9. Fasciolania purpuxea Jon. var? pag. 94. Apres voir eu l'occasion l'examiner soignensement le type do: l'espéce de J o n as, qui se troove daus. le Jusée zoolo- 
zu vergleichen, docl zu selur abweicha, un als blosse Varietät jener Art angeselıen werden zu können. Unsere Schurede ist weit dickschaliger, ilne Windungen sind moter der Naht viol contaver und mit

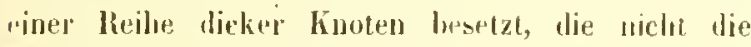
Wiur der obernn Windumgen rinnelmmen, sondern dicht über der Naht sich bufunden und auf der belzten Windung am stäıksten ersclıeinen, "älırend ant Fasc. perperea die linoten beim Wacloshlum der schale allmälig schwäclser werden. The letzl. Mindung ist unter der Konotenreihe mit ziemlich starken, "loch ungleichen Querrippen verselıen, wälund fasc.purpurea überall schmale Querreifchen zeigt. Ein wesentlicher Unterschied hesteht noch in innem ganz glatten Labrum. In der donas'schen Beschreibung wirl zwar ebenlabls die äussere Lippe als immen glatt lezeichnet, Joch besuht diesa: Angabe auf rinem Irrhum, denn das Original zeigt innen slarke (luelfurchen. Dieses wesentliche Merkmal dünlte allein schon herechtigen, unsere Arl vou der Joras'schen zu Iremmen. Ich nenne dieselbe Fasciolarit Heymemanni nach llern H. Ileynuma II in Frankfurt a/M., dem eifrigen Forscher der Linatriden.

10. Ricinula speciosa Dhr. pag. 100 ist eine kleine, aber volstündig ausgebilute Varietït ron der R. Reeveana Crosse. (Joum. de Cumch. 1862 pag. 47.

11. Dolium Japonicum Dhr. pas. 104. Tah. XXXV. XXXVI. and D. luteostomm Kïst., beide in der Zeichnung wesentlich verschieden, gehören einc: Art an, wie ich mich durch Ansidıt des im Besitze des Ilerrn Gelı. Regierungsiatls Lisclike befindliclıen Exemplares, welches der lin̈ster'schen Beschruilung zu Grunde liegı, überzugt labe. Der Kïster'sclıe Nane loat die Prioriıäı. Vergl auch Lischkp's Japanische Mecres-Conchylien pag. 65.

12. Anomulocardia pulchella Ukr. pag. 113 erhielt ich mittlerweile in twas grösseren Exemplaren von Cluina. giqne de llambourg, j’ai remarque que l'exemplaire liguré en differe par des caractèces trop tranchants pour pouvoir ètre considéré comme simple variete de l’autr". Notre roquille esi beaucoup phus epaisse. ses tont's de spire sont bien plus concaves au-dessous de la sulmue el garnis d'une série de gros tuberoules, qui n'ucenpent pas la partie moyenne des loms supvirieurs mais se trourent inmediatrment au-dessus de lat suture, et yui sont plus forts sur te drmin" lon", tandis yue clez la $F$. purpurea les tuherenles deviennent inspnsilhement plus petits en mesurn de l'accroissentem du test. Ine autre diffërence essentiell, consiste lans le labrum, qui est entierement lisse tn-tledans. II est vrai que la déscription de do llas desigut aussi comme lisse la face interme the la livere "xperipur", mais cette indication est erronè, phistue l'exemplaire typique montre en-dodans de forts sillons transversaux. Ce caractere important sultirail a lui seul, pour séparer notre coquille de l'espece de lonas. Je la nomme Fasciolaria IIeynemanni, d'après Vr. H. He y uemann, scrubateur zolie des Limaciles.

10. Ricinula speciosa Dhr. pay. 100. Celte forme est mo variete putite mais parfaitement levelopée de la R. Reeveana Crosse. (Journ. de Conch. W, 189. pag. 47.)

11. Dotium Japonicum Utr. pag. 104. pl. IXXV XXXVi et $D$. luteostomum Käst., quoiqu'essentiellement différents daus le dessin, apparticmuent a mne seule espece, comme je me suis persuade par l'examen de l'exemplaire de la collection de Mr. I, isclike yui a servi à la lescription de li ïster. Le nom de Küster jonit de la priorite. Comparez lischke Mreves-Conchyl. fiay. 65.

12. Anomalocardia pulchella Dh\% pag. 113. J'en ai depuis recu de la Chine des expmplaires un peu plus grands. 



\section{IN DEX.}

pag.

Anomulocardia aequilatera Dkr. . . . . 109

Anomalocardia Carpenteri Dkr. . . . 86

Anonalocurdia Ehrenbergi Dhr. . . . . 116

Anomalocardia granosa L. . . . . . . . 113

- Anomalocardia latrncularia Röm. . . 37

Anomalocardia Lischkei Dkr. . . . . . $115 \mid$

Anomalocardia oblonga Phil. . . . 85. 113

Anomalocurdia paucigranosa Dk\%. . . 85

-Anomalocardia pulchella Dkr. . . . . . 113

Anomalocardia reagifera Dler. . . . . . 84

Anomalocardia subgranosa D/r. . . . . 122

Anomalocardia subrubra Dlrr. . . . . . 83

Anomalocandia mopygimelana Bory . . . 115

Apollon olivator Meuschen . . . . . . . 55

Arca Arlumsiance Dhr. . . . . . . . 88

Arca Americana d'0rb. . . . . . . . 132

Arca angusta Dls. . . . . . . 93

Arca bistrigate Dkr. . . . . . . . . 87

Arca bisulcata Lan. . . . . . . . . 134

Arca candida Helblingii Chenum. . . . 125

Arca compacta Revere . . . . . . . 109

-Arca constricta Dhr. . . . . . . . . 111

Arca contraria lieeve . . . . . . . 123

Arca Crossei Ukr. . . . . . . . . 136

Arca cruciata Pliil. . . . . . . . . . 89

Arca erythraeonensis Jonas . . . . . . 123

Arca fusco-marginata Dler. . . . . . . 136

-Area insignis Dlr. . . . . . . . . . . . 93

- Arca maculata lieeve. . . . . . . . 110

-Arca Martensï Dl\%. . . . . . . . . 112

Arce Martinii Recl. . . . . . . . . 133

Arca oblonga Goldf.. . . . . . . . 85. 107

Alca oblonga Phil. . . . . . . . . . . 85

Arca scapha Chemm. . . . . . . . . . . 84

- Arca signata Dhr. . . . . . . . . . 112

Area xmbonute Tane. . . . . . . 1.31

- Irra veluta Reene . . . . . . . . 124
Arca venusta Dhi. . . pag.

Argonauta gomilola billw. . . . . . . . 30

Argonaute Gruneri D/.r. . . . . . . . 29

Argouanta luians Dillw. . . . . . . . . 30

Argonaute Kochianus D/:r. . . . . . . 129

Aulus Oken. . . . . . . . . 20

- Aulus fosciatus (Solenj) Spengler. . . . 118

Aulus pulchellus Dlar. . . . . . . . . 20

Aulus Winteriumus Wir. . . . . . . . 120

Azor Scheepmalieri Dkr. . . . . . . . 121

- Barbatia Anolphi Ulir. . . . . . 107. 133

Burbatice barbate (Arce) L. varr. . . . 132

Barbatia erythraeensis Jonas . . . . . 123

- Barbatia eximia Dlor. . . . . . . . . 90

Barbatia Grayana Wlir. . . . . . . . 92

Barbatia llublingii Clennt. . . . . . 93

Bubatia mollis D\%r. . . . . . . . . . 92

Barbatia oblonga Dlr. . . . . . . . 107

Barbutia pectunculiformis Dlar. . . . . 88

Barbatia Petersii DFr. . . . . . . . 135

Barbatia Rodatzi Dlir. . . . . . . . 89

- Barbatie solidula Dk. . . . . . . 114

Barbatia traprezina Lam. . . . . . . 108

Barbatia velata Sow. var. . . . . . . 124

Bubatia verustu J\%r. . . . . . . . 91

Buccinmon Austrate seu Chimense Chemn. . . 105

Bucciumm dolium L. . . . . . . . . 106

Buccinum fasciatum Brug. . . . . . . 106

Bucciunn olearium L. . . . . . . . . 106

Bucciuum perdix L. . . . . . . . . 106

Buccisum pictun Dkr. . . . . . . . . 97

Bucciunm prismaticum Martyı . . . 127

Buccinum semiplicutum Dlov. . . . . . 96

Bulbus Ilumplu. . . . . . . . . . . 18

Bulbus incruvers Dla\%. . . . . . . . . 17

Bulla rapa L. . . . . . . . . . 18

Bullic valida D/s\%. . . . . . . . . 33 
Tiursa aftinis Brorl.

Dolinn Cassis Bolt

$-\mid \begin{aligned} & 1 \mathrm{ag} . \\ & 106\end{aligned}$

Bursa anceps I'fi'.

Dolium Clinesse Ijillw. . . . . . . . . . . 105

Bursa asperrima Dhr. . . . . . . . 57

Bursa bituhercularis Lam. . . . . . . . 57

Bursa concinna Dk\%. . . . . . . . . 55

Bursa cruentata Sow. . . . . . . . 58

Bursa Cumingiana D7r. . . . . . . . 59

- Bursa fusco-costata Dhr. . . . . . . . . 57

Bursa Grayana Dhr. . . . . . . . . 58

Bursa lamellosa Dkv. . . . . . . . . 56

Bursa tubercnlata Brod. . . . . . . . 54

Bursa tumida Dkr. . . . . . . . . 56

Bursa Zelelori I)kr. . . . . . . . . 56

Byssoarca Martinï Recl. . . . . . . 133

Byssoarca velata Sow. . . . . . . 124

Cadium link . . . . . . . . 106

Callista Gotthardi Dli. . . . . . . . . . 73

Cardium Reeveanum Dlr. . . . . . . . 22

Cassis glabrata Dkr. . . . . . . . . 35

- Cerithium scabricosta Dlw. . . . . . . . 31

- Circe minima Mont. . . . . . . . . . 50

- Circe undata Dler. . . . . . . . . . 50

Cochlea pennata liumph . . . . . . . . 106

Cucullaea oblonga Miill. . . . . . . 107

Cultellus attemuatus Dkr. . . . . . - 72

Cultellus Califomianus Com. . . . . . 130

Cultellus magnus Sclum. . . . . . . . 11

Cultellus maximus Frmel. . . . . . . . 11

Cultellus orientatis Dlir. . . . . . . . . 10

Cyclina intumescens Röm. . . . . . . . 49

- Cypraea gangrenosa Sol. var. Repntsii . . 31

Cytluerea apicalis Phil. . . . . . . . 50

- Cytherea arguta Röm. . . . . . . . . 39

Cythesea Chione L. . . . . . . . . . 13

Cytherea cordiformis Dkr. . . . . . . . 11

Cytherea Cyrilli Phil. . . . . . . . . 50

Cytherea IIagenonvï Dikr. . . . . . . . . 13

Cytlierea Ilindsii Ilanl. . . . . . . . . 69

Cytherea Limenia Röm. . . . . . . . . 39

Cytherea nivea Ilanl. . . . . . . . . . 42

Cytherea pacifica Dillw. . . . . . . . . 13

Cytherea planulata Błod. . . . . . . . . 69

Cytherea scabriuscula Phil.. . . . . . . 82

- Cytherca semiarata Dlsr. . . . . . . . 52

Cytherea umbonella Lam. var. . . . . . . 42

Ijiplodonta bullata $D \mathrm{kr}$. . . . . . . . . . . 76

Diplodonta subrugosa Dkr. . . . . . . . 15

Diplodonta Tenezuelensis Dikr. . . . . . . 15

loolium amphol'a Plíl. . . . . . . . . . . 105

Dolium ampullacemm I’hil. . . . . . . . . 105

Doliun costatum Desh. . . . . . . . 106

Dolium costatum magnum Mart. juv. . . . 105

Dolium crenulatum Pliil. . . . . . . . 106

Dolimm Cumingii Wanl. . . . . . . . 106

Dolium dentatun Barnes . . . . . . . 106

Doliun Deshayesij Reeve . . . . . . . 106

Dolium Dunkeri Hanl. . . . . . . . . 106

Dolium fasciatum Mart. . . . . . . . 106

Dolimn fasciatum Kien. . . . . . . . . 106

Dolium Favannei IIanl. . . . . . . . . 106

Doiiun fimbriatum Sow. . . . . . . . 106

Doliun galea (Bucc.) I. . . . . . . . 105

Dolium Japonicum Dkr. . . . . . 104. 105

Dolium líeneri Plil. . . . . . . . . . 105

Dolium lactescens Mart. . . . . . . . 106

Doliun maculatum Lam. . . . . . . 106

Dolium melanostoma Jay . . . . . . . 105

Dolinm minjac Adans. et Desh. . . . . . 106

Dolium olearium Brıg. . . . . . . . . 105

Dolium perdix (Bucc.) L. . . . . . . . 106

Dolium plumatum Green . . . . . . . 106

Dolium jomum (Bucc.) L. . . . . . . . 106

Dolium lingens (Cassis) Swains. . . . . . 106

Dolium tenur Mlie. . . . . . . . . . 105

Dolium tessplatum lam. . . . . . . . 106

Dolium varipgatum Lam. . . . . . . . 105

Dolium variegatum Phil. . . . . . . 105

Dolium zonatum Grees . . . . . . . . 106

Donax euglyptus Dhr. . . . . . . . 78

Donax scrijla L. . . . . . . . . . . 74

Donar splendens Dhr. . . . . . . . . 79

Dosinia Adansoni Phil. . . . . . . . . 80

Dosimia Ceylonica Dlir. . . . . . . . 81

Dosinia excisa Cliemn. . . . . . . . 82

- Dosinia regularis Dkr. . . . . . . . . 182

Dosinia Roemeri Dkr. . . . . . . . 143

Uosinia subdichotoma Dkr. . . . . . . 81

Dosinia tenuilirate Dhr. . . . . . . . 80

Fasciolaria Audouni Jonas, vas. . . . . 95

Fasciolaria badia Kiranss . . . . . . . 95

Fasciolaria jnemis donas . . . . . . . 44

- Fasciolaria Lischleane Dir. . . . . . 44

Fasciolaria lugubris Reeve . . . . . . . 95

Fasciolaria purpurea Jonas, var. . . . . 94

Fasciolaria tulipa L. var. . . . . . . 37

Fisus longicauda Bory . . . . . . . . 128

Fusus longissinus Gmel. . . . . . . . . 99

-Fusus Meyeri Dhr. . . . . . . . . . 127 
Fusus nodosoplicatus Dkr. . . . . . 99

-Fusus Paeteli Dkr. . . . . . . . . 100

Fusus pirulatns Reeve var. . . . . 103. 129

-Fusus Rudolphi Dkr. . . . . . . . . 128

Fusus strigatus Pliil. . . . . . . . 100

Fusus tenuiliratus Dkr. . . . . . . . . 98

Fusus ventricosus Beck . . . . . . . . 99

-Gomphina Melanaegis Röm... . . . . 40

Gyrineum natator (Trit.) Bolt. Link. . . . 55

Haliotis Dohrniana Dhr. . . . . . . . 48

llemilusus Swains. . . . . . . . . 35

llemifinsus Belcheri (Murex) Jinds var. . 35

Janira Sclum. . . . . . . . . 68

Lampas Selium. . . . . . . . 58

Latirns gemmatus Reeve. . . . . . . 127

Leguminum maxima Chemn. . . . . . . 11

l.joconcha Nürch .. . . . . . . . . . . 53

Lioconcha Limenia Röm. . . . . . . . 39

Incina carnosa DK\%: . . . . . . . . 76

Lueina columbella Lam. . . . . . . . . 77

- Lacina mirabilis Dkr. . . . . . 77

Lueina undata Penn. . . . . . . . . . 76

Macha Scheepmakeri Dkr. . . . . . 121

Machaera hould. . . . . . . . . . 20

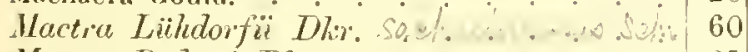

Mactre Rodatzi Dlr. . . . . . . 25

Mactra rugifera Dhr: . . . . . . 41

Walea litilabris Val. . . . 106

Mlarginella Burchardi Dkr. . . . . 36

Meretrix attenuata Dkr. . . . . . . 53

Mercenaria paucilamellata Dkr. . . . 52

Neretrix Lamarckii Desh.. . . . . . 54

Meretrix morphina Sow. . . . . . . 54

Meroë concinna Dhor. . . . . . . . 74

Mitra Adcemsii Dkr. . . . . . 48

- Mitra arenacea Dkr. . . . . . . 33

Mitra asperrima Dohrn . . . : . 45

Jitra llammea Quoy et Gaim. . . . . . 47

- IIitra foreolata Dkr. . . . . . . . . . 46

Mitra Gambiana Dohnn . . . 48

Alitra Hanleyi Dohrn . . . . . . . . . . 47

Iitra Samuelis Dohm . . . . 45

Youssoie Allans. . . . . . . . . . 132

Tulinic Rodatzi Dkr. . . . . . 25

Hlurciu scansilis Pöm. . . . . . . . . 51

Murex anceps Pir.

Murex Bareleyi Reere. . . . . . 66

- Murex Belcheri Hinds var. . . . . . . 35

-17urex crispus Brod. . . . . . . . . 125

-llurex depresso-spinsous Dlir. . . 126
Murex longicomis Dhr. . . . . . . 64

Murex multicrispatus Dkr. . . . . 125

Murex Steeriae Reeve. . . . . . . . 16

Murex trigonulus Lam. vas. . . . . . 65

Murex trunculus L. . . . . . . . . 126

Mysia Leaclı. . . . . . . . . . . 76

Nassu coturnix Dhr. . . . . . . . . 97

-Nassa semisulcata Dkw. . . . . . . . 96

Neptunea Bolten . . . . . . . . . . 7

- Neptunea castanea Mörch . . . . . . 5

- Neptunea harpe Mörch . . . . . . . 5

Noetia contruria Reeve var. . . . . . . 122

Pecten Tischkei Dkr. . . . . . . . . 19

Pecten multisquamatıs Dkr. . . . . 67

Pecten rutiraliatus Reeve . . . . . . 20

Perten sulcicostatus G. B. Sow. . . . . 67

Pecten Yessoensis Jay . . . . . . . 61

Peristernia gemmata Reeve . . . . . . 127

Peristernia prismatica Martyn . . . . . 127

Pharelle ovalis Lkr. . . . . . . . . 118

Pinna trigonium Dkr. . . . . . . . . 27

Plicatula deltoidea Dir. . . . . . . . . 27

Plicatula ramosa Lam. . . . . . . . . 27

Pteronotus Swains. . . . . . . . . . 65

Pusionella Gray . . . . . . . . . 33

Pyrula papyracea Lan. . . . . . . . . 13

Rimella rosea Reeve. . . . . . . . 55

Ranella tuberculatá Brod. . . . . . . . 55

Ranella tuberosissima Reeve . . . . . . . 59

Ricinula arachnoides Lam. . . . . . . 101

Riciunla clathrata Lam. var. $\beta . \quad$. . . . . 101

Ricinula ricinns L. . . . . . . . . . 101

Rícinula speciosa Dlr. . . . . . . . 100

Scapharica pumila Dhr. . . . . . . . 108

Siliıua Mlılf: . . . . . . . . . . . 20

Siliqua Tournef. . . . . . . . . . 20

Siliquaria Califormiana Conr. . . . . 130

Siliquaria centrulis Conr. . . . . . . 130

Siliqueria nitidissime Dhr. . . . . . .,117

Silipuraria polita Carp. . . . . . . . . . 117

Solen acutanguhus Dkor. . . . . . . . 117

Solen Caribaeus Lam. . . . . . . . . 130

Solen Dombeyi Lam. . . . . . . . . 131

Solen exignus DR\% ner. . . . . . . 116

Solen gibbus spengl. . . . . . . . 130

solen gracilis Phil. . . . . . . . . 71

Solen grandis Dkr. . . . . . . . 71

Solen Guineensis Chenn. . . . . . . . 9

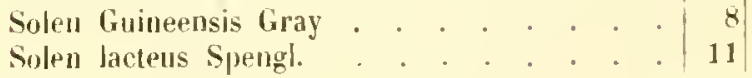


Solen Lompeanus D7.

Solen Tischkeanus D7r: - 729

Solen Maluccensis Dkr. . . . . . . . $7: 2$

Solen maximus Ginel. . . . . . . . . 11

Solen Mörchii Dhr. . . . . . . . . 131

Solen Nicobaricus Bolt. . . . . . . . . 11

Solen planus Lam. . . . . . . . . . 11

Solen radiatus L. . . . . . . . . . 21

Solen rufus Bosk . . . . . . . . 131

Solen Schulzeanus Dlir.

Solen Timorensis Dlor. . . . . . . . 9

Solen truncatus l'hil. . . . . . . . . 8

Solen Woodwardi DK.r. . . . . . . . . 70

Solen vagina $L_{\text {. . . . . . . . . . . } 72}$

Spondylus mudus seu inermis Chemr. . . . 26

Spondylus sanguineus Dkr. . . . . . . 26

Sunelta Link . . . . . . . . . . . 74

Sunetta concinna Dhr. . . . . . . . 74

Tagelus Gray . . . . . . . . . . . 9

Tapes Mïhlr. . . . . . . . . : 14

Tapes (Textrix) Carpenteri Rüm. . . . . 38

Tapes Schnellianus Dkr. . . . . . . 75

Tellina rotundata Mont. . . . . . . . 15

Textrix Carpenteri Röm. . . . . . . . 38

Tivela arguta Röı. . . . . . . . . . 39

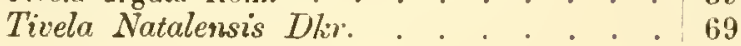

- Tivela subglobosa Dlir. . . . . . . . . 68

Torcula caelata Mörch . . . . . . 102

Trigona Natalensis Dkr. . . . . . . . . 69

Trigona subglobosa Dkr. . . . . . . . 68

Triton L. . . . . . . . 4

Triton Lam. . . . . . . . . . . . 4

Tritomium carinatum Dkr. . . . . . . 1

-Tritonium Mörchianum Dhr. . . . . . 2

-Tritonium Rombergi Dhv. . . . . . . 4

Tritonium rutilum Mörch . . . . . . 3

Turbinella gemmata Reeve . . . . . . 127

Turritella caelata Mörch . . . . . . . 102

Turritella Cumingii Reeve . . . . . . . 103

Turritella dura Mörch var. . . . . . . 103

Turritella varicosa Brocchi . . . . . . . 102

Venus ala papilionis Chemu. . . . . . . 75

Venus Chinemsis Chemu. . . . . . . . 50

Vemus Deshavesii llanl. . . . . . . . . 4

Venus papilionacea Lam. . . . . . . . 75

Venus quadriradiala Desh. . . . . . . . 14

Venus Rodatzi Dkr. . . . . . . . . 13

Veulus rotundata Gmel. . . . . . . . . 75

Veuus scripta L. . . . . . . . . . . 50

Vola Klein . . . . . . . . . . 68

Voluta Kaupiï Dhr. . . . . . . . . . 63 

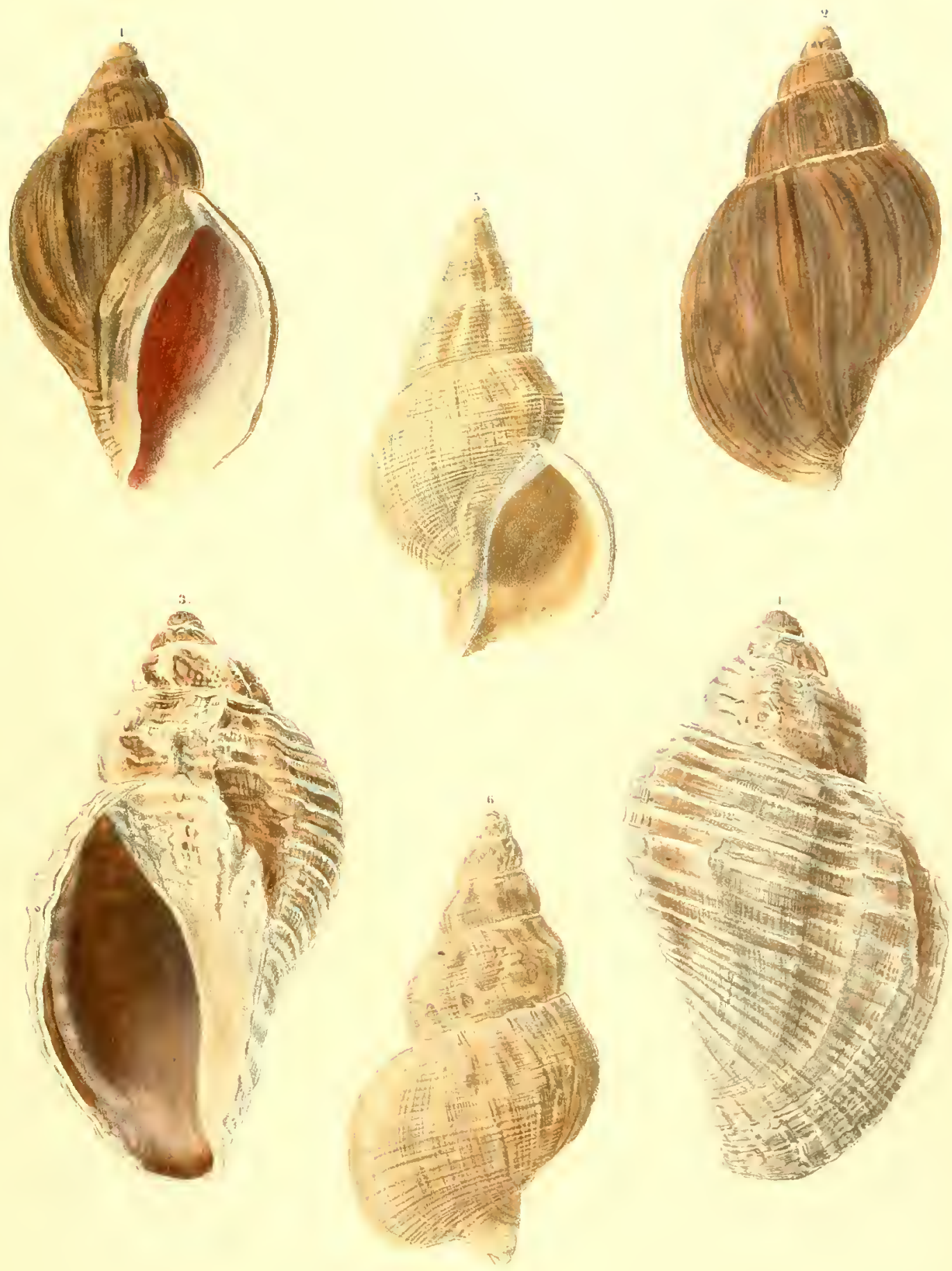

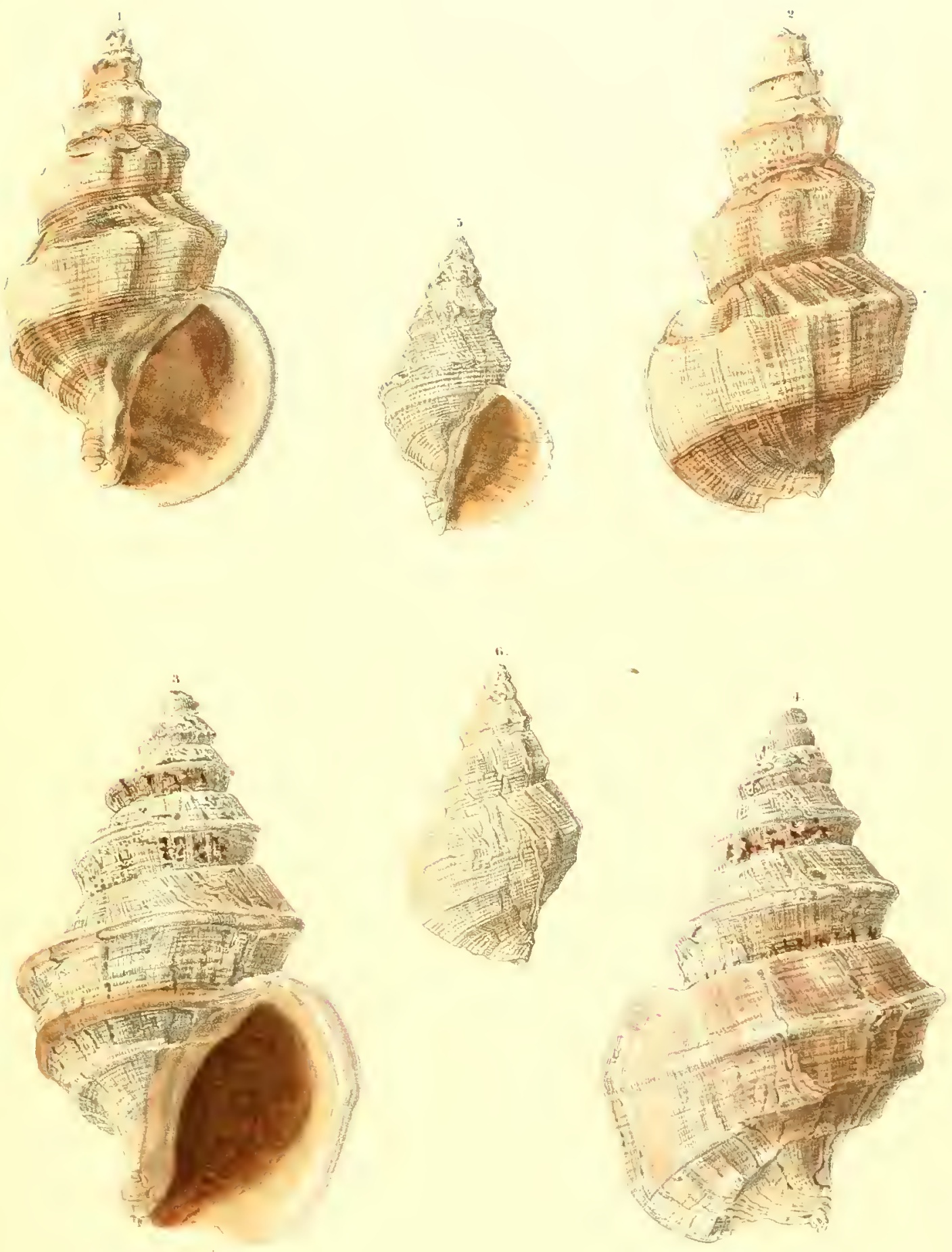

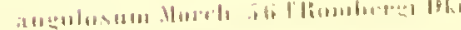

$$
\text { Fhize ate }
$$


. 

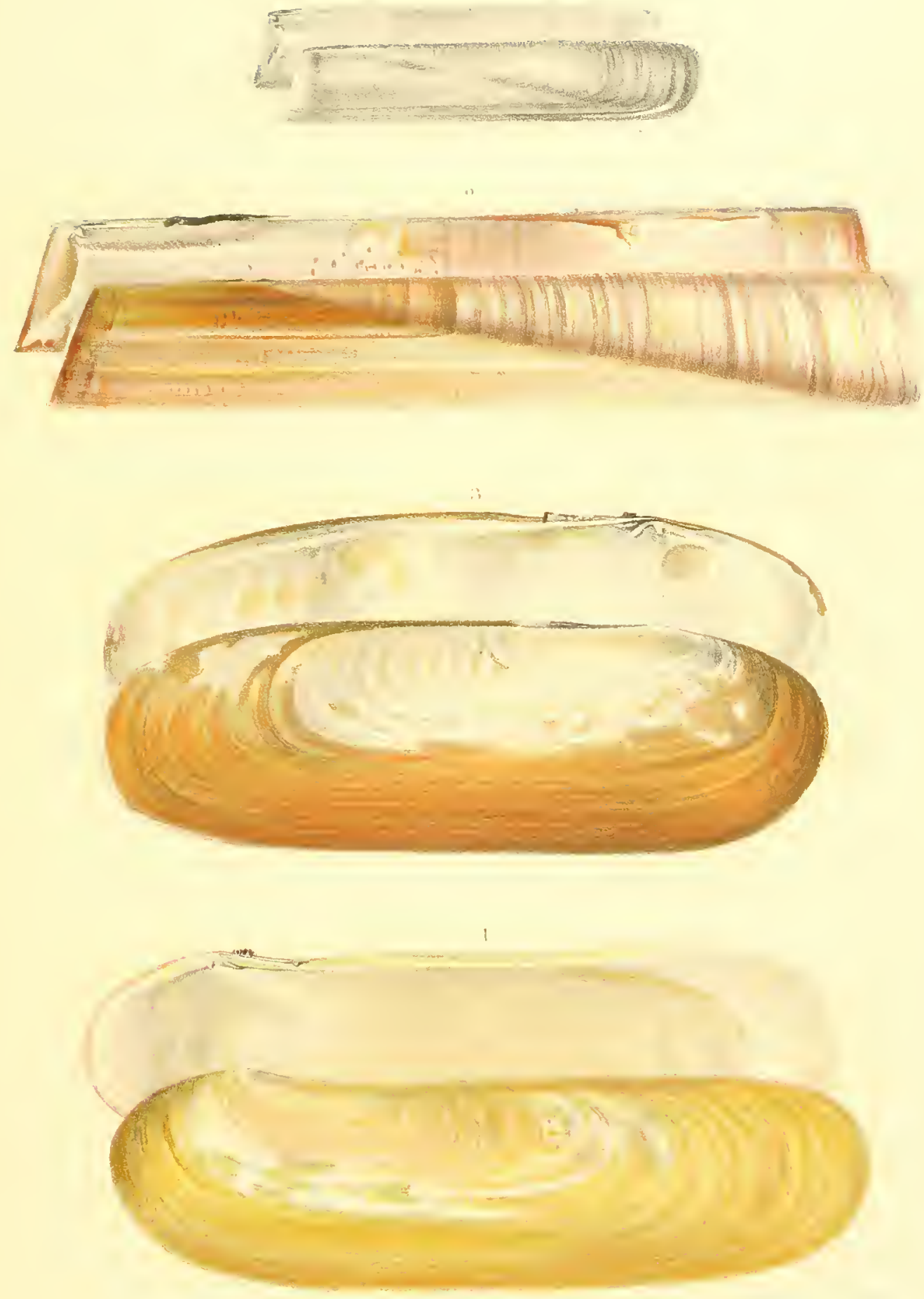

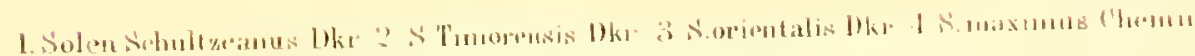




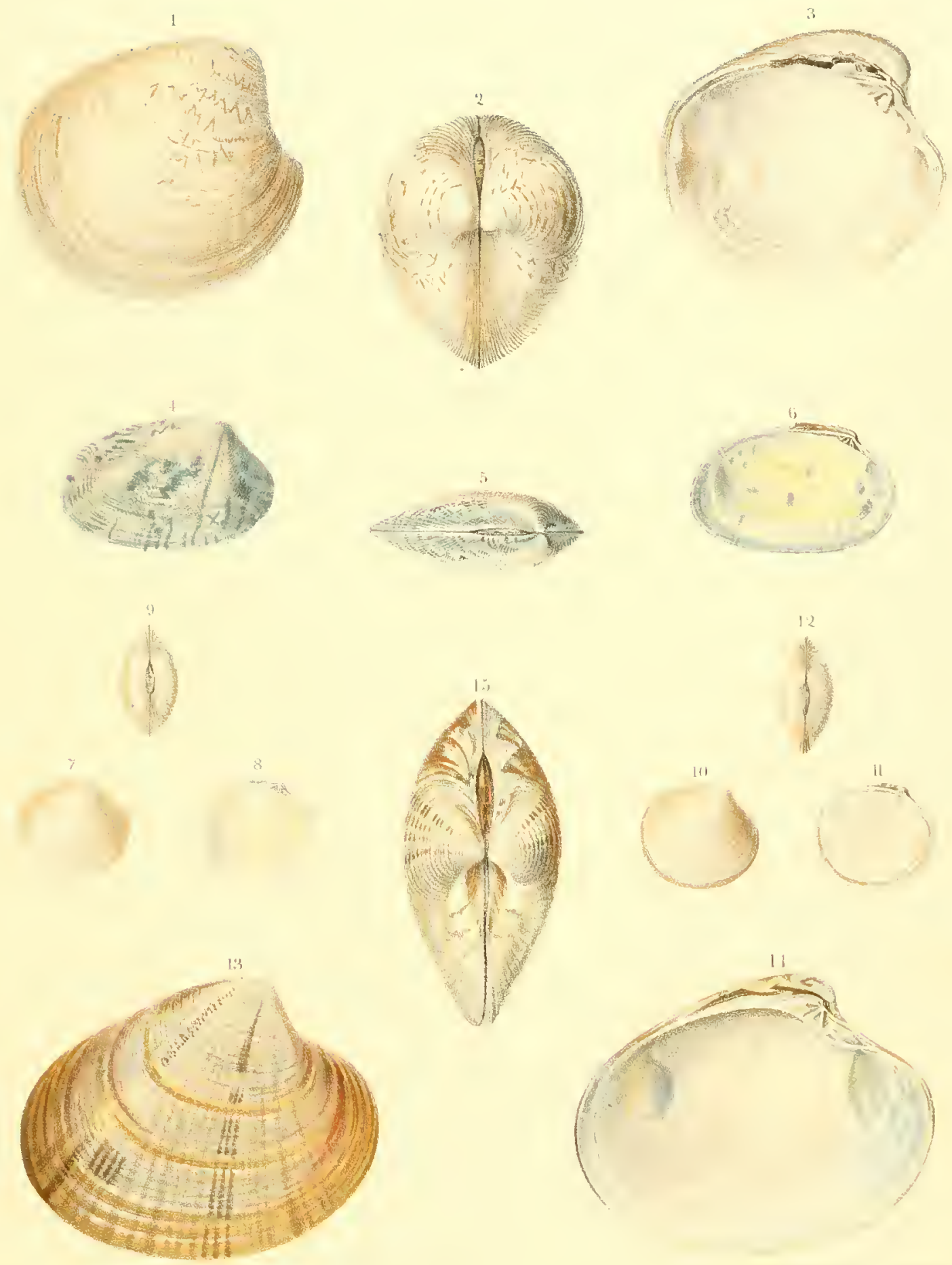

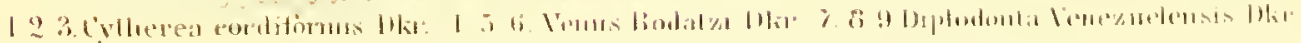

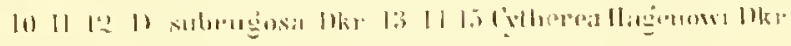





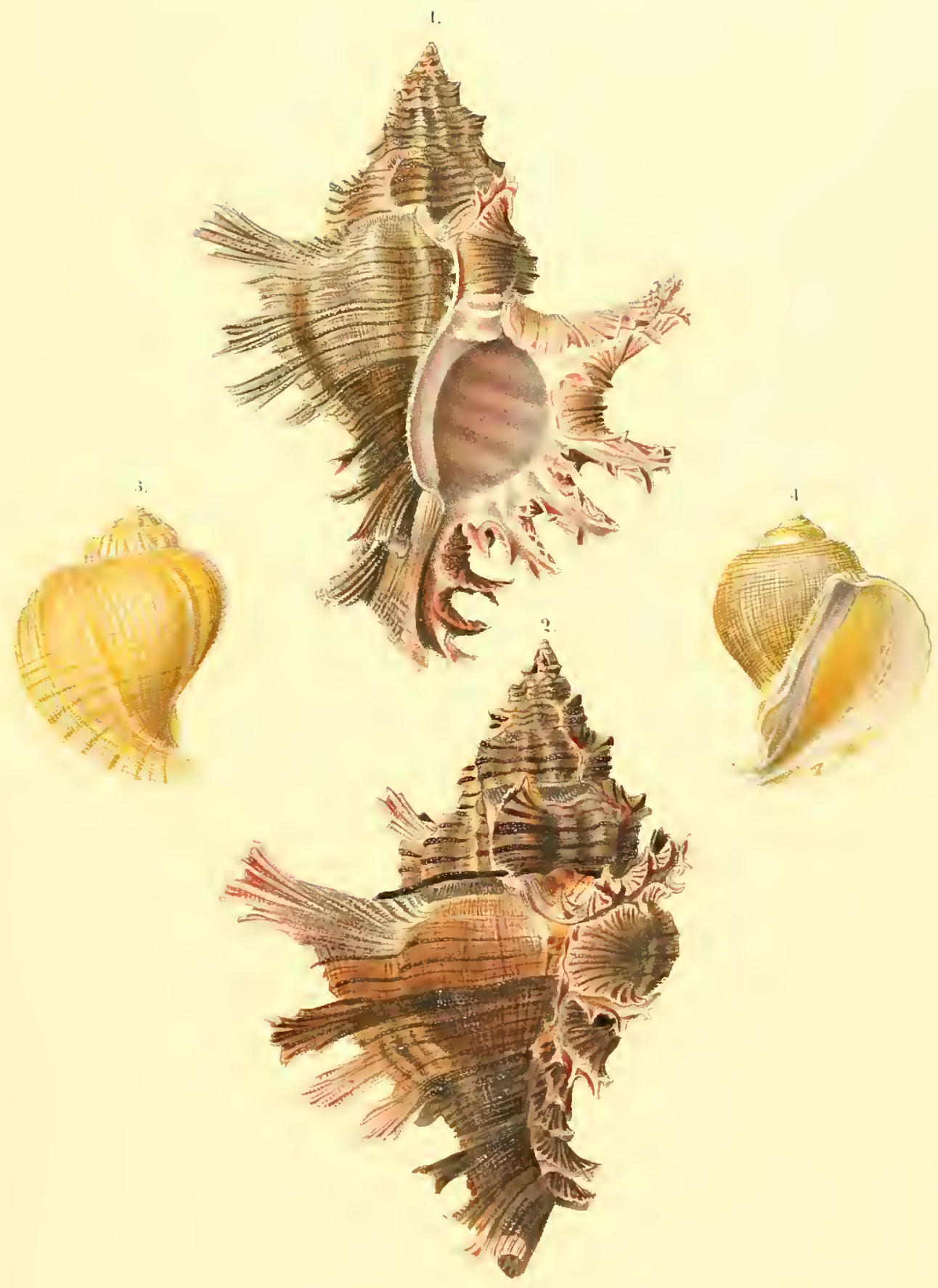

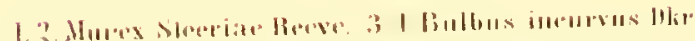




$$
\text { :" }
$$





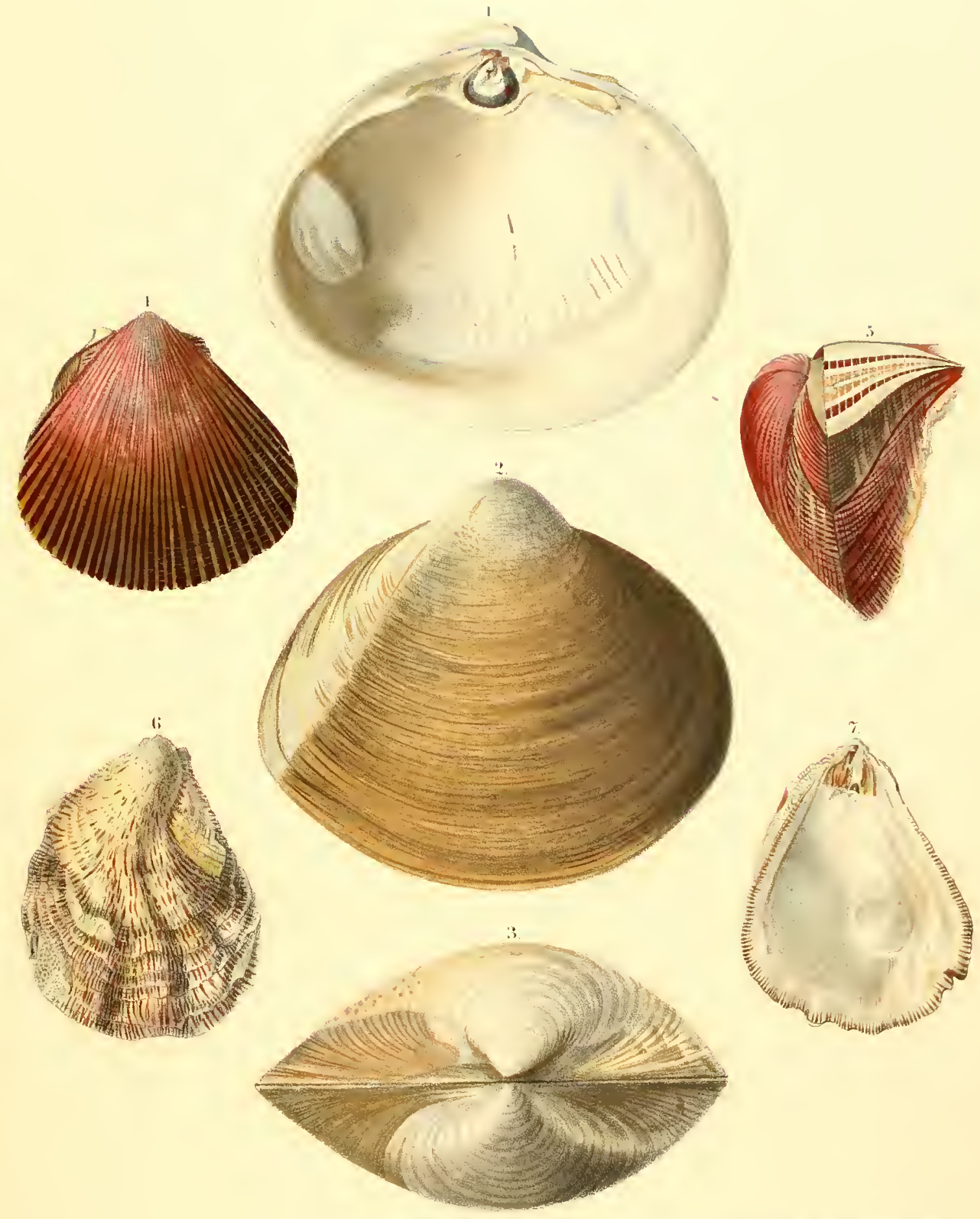

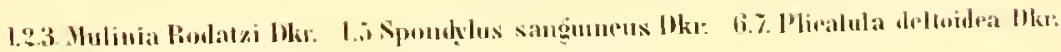





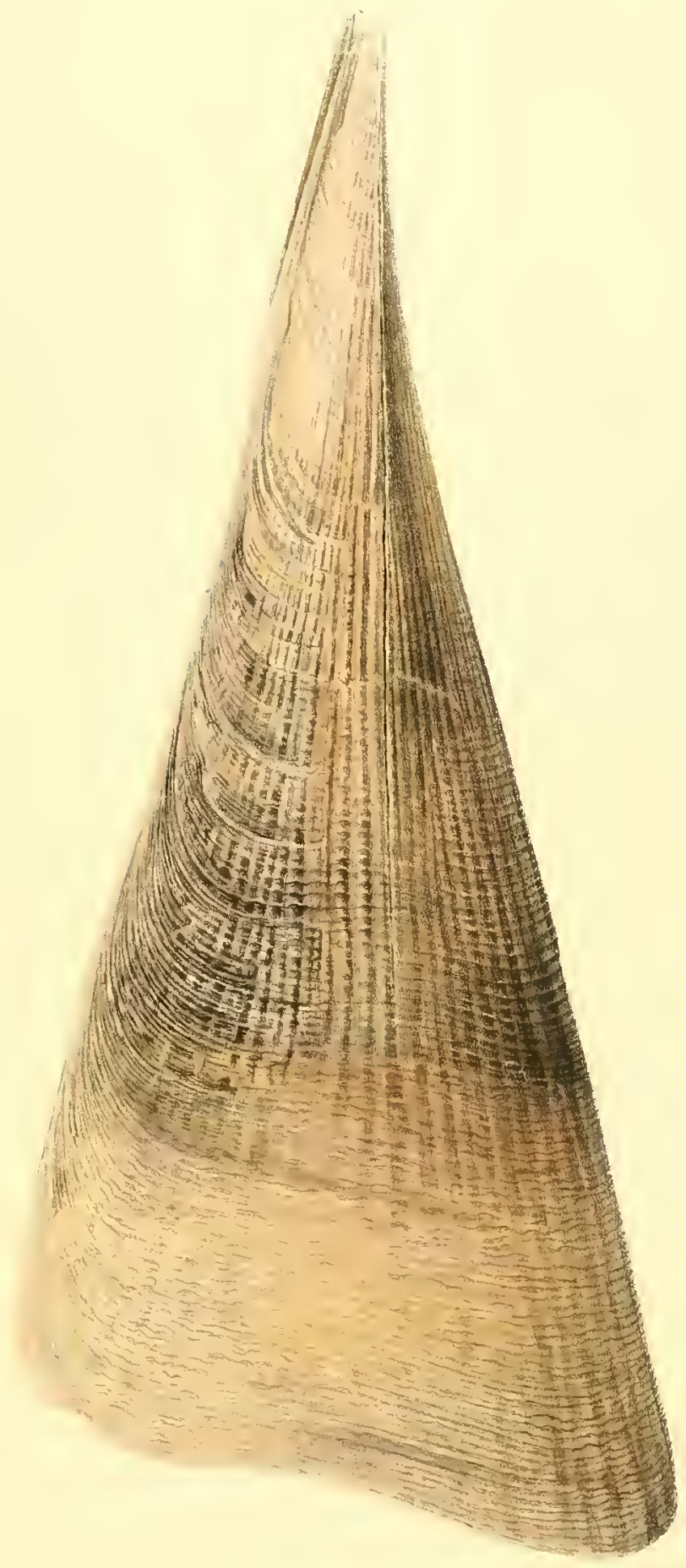

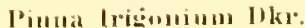


$$
\text { - }
$$ 

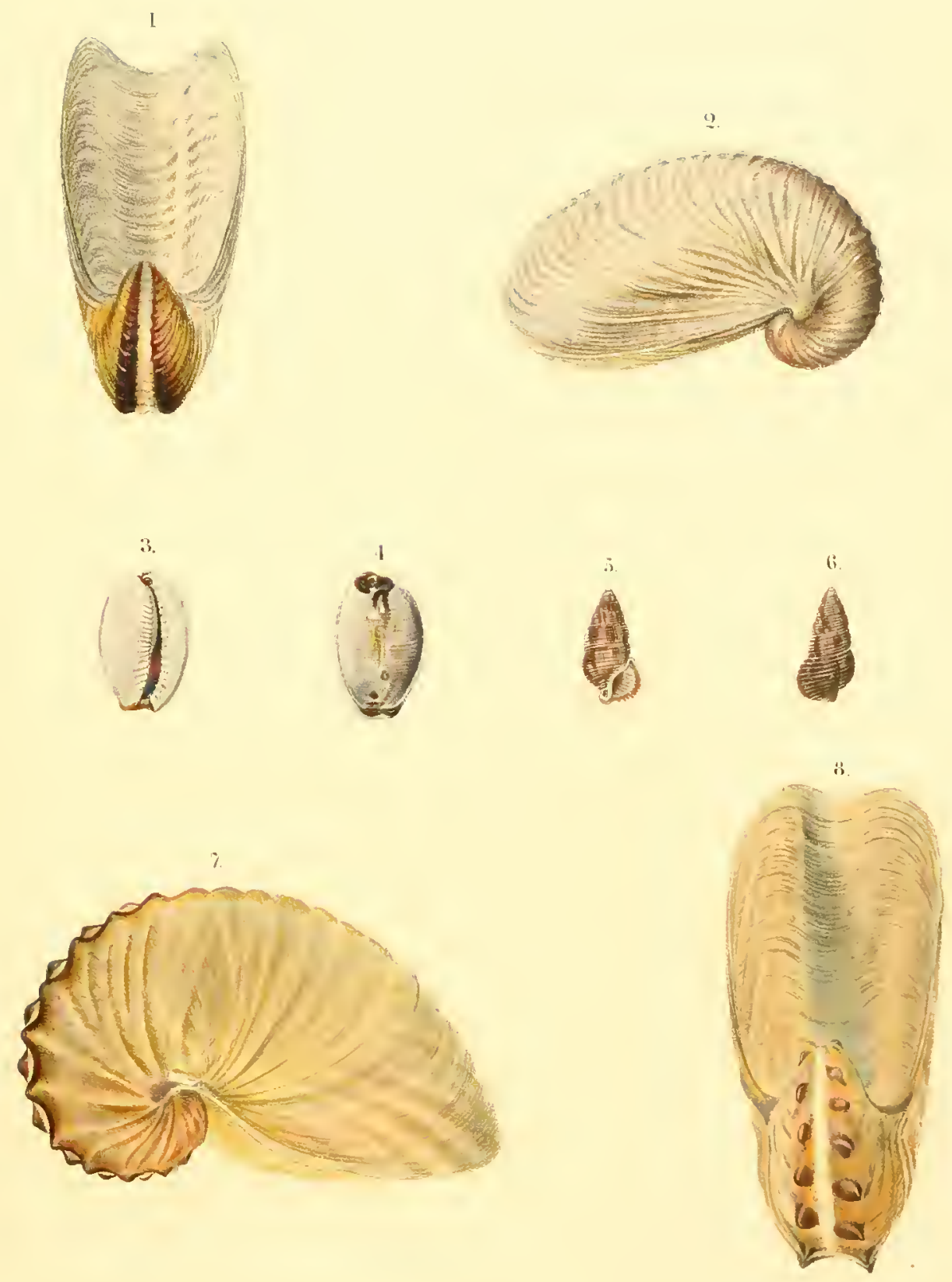

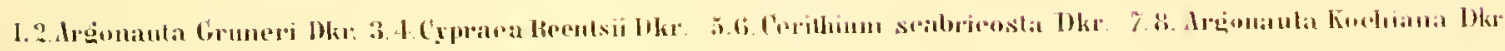



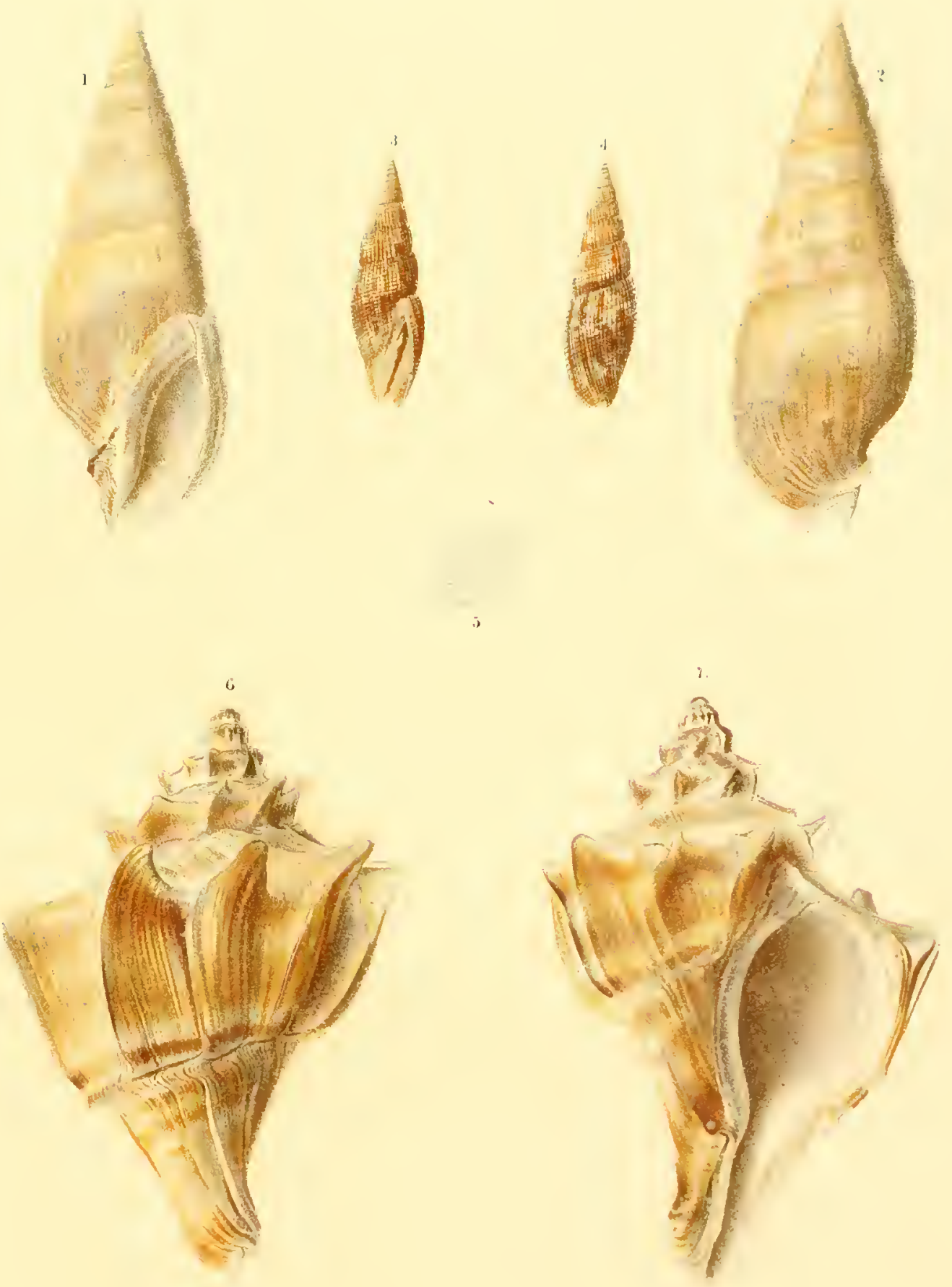

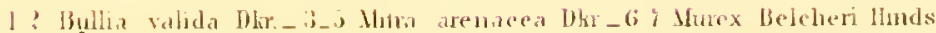




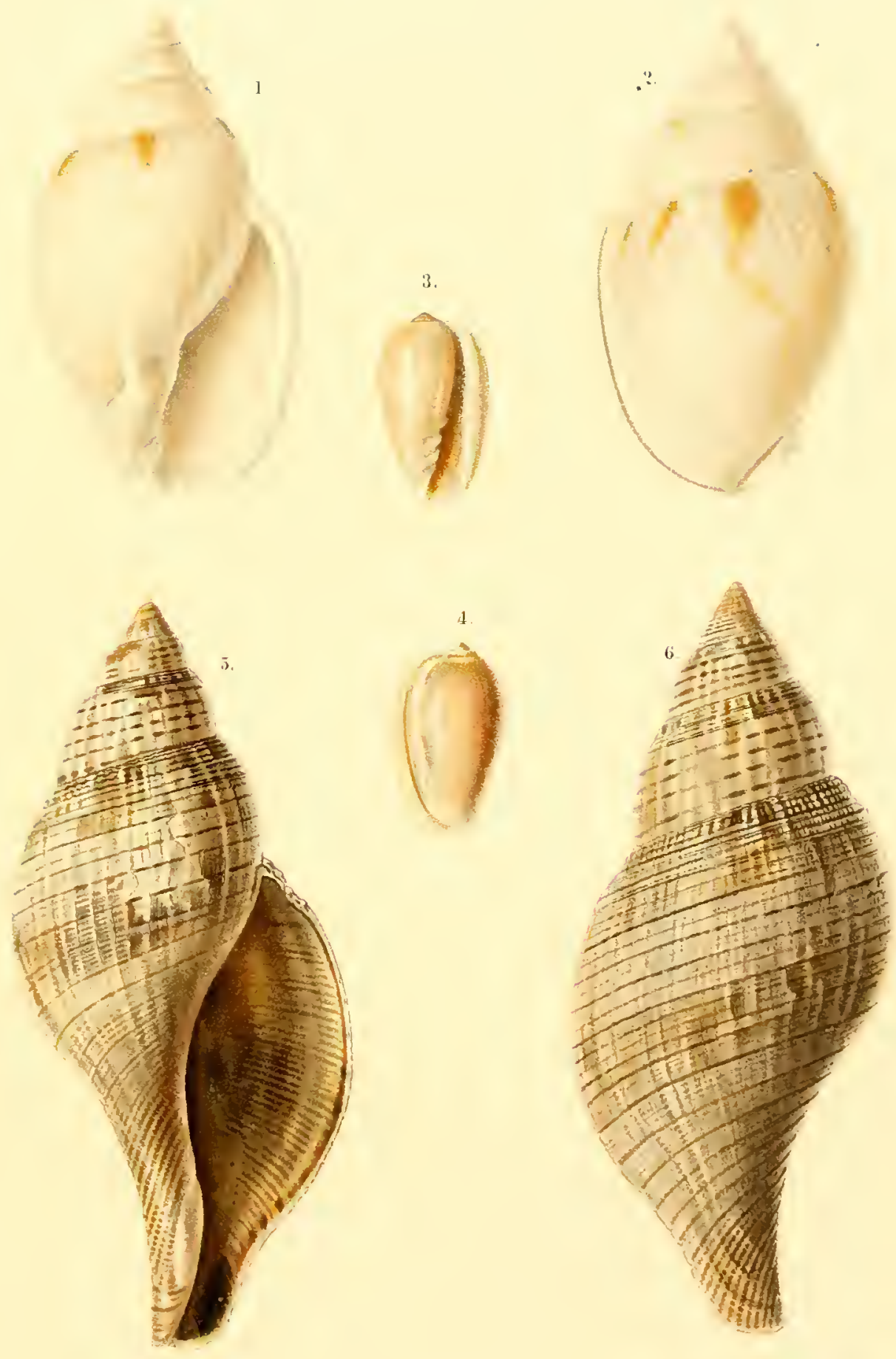

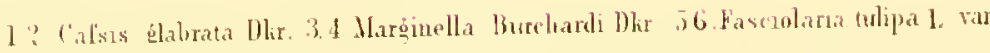




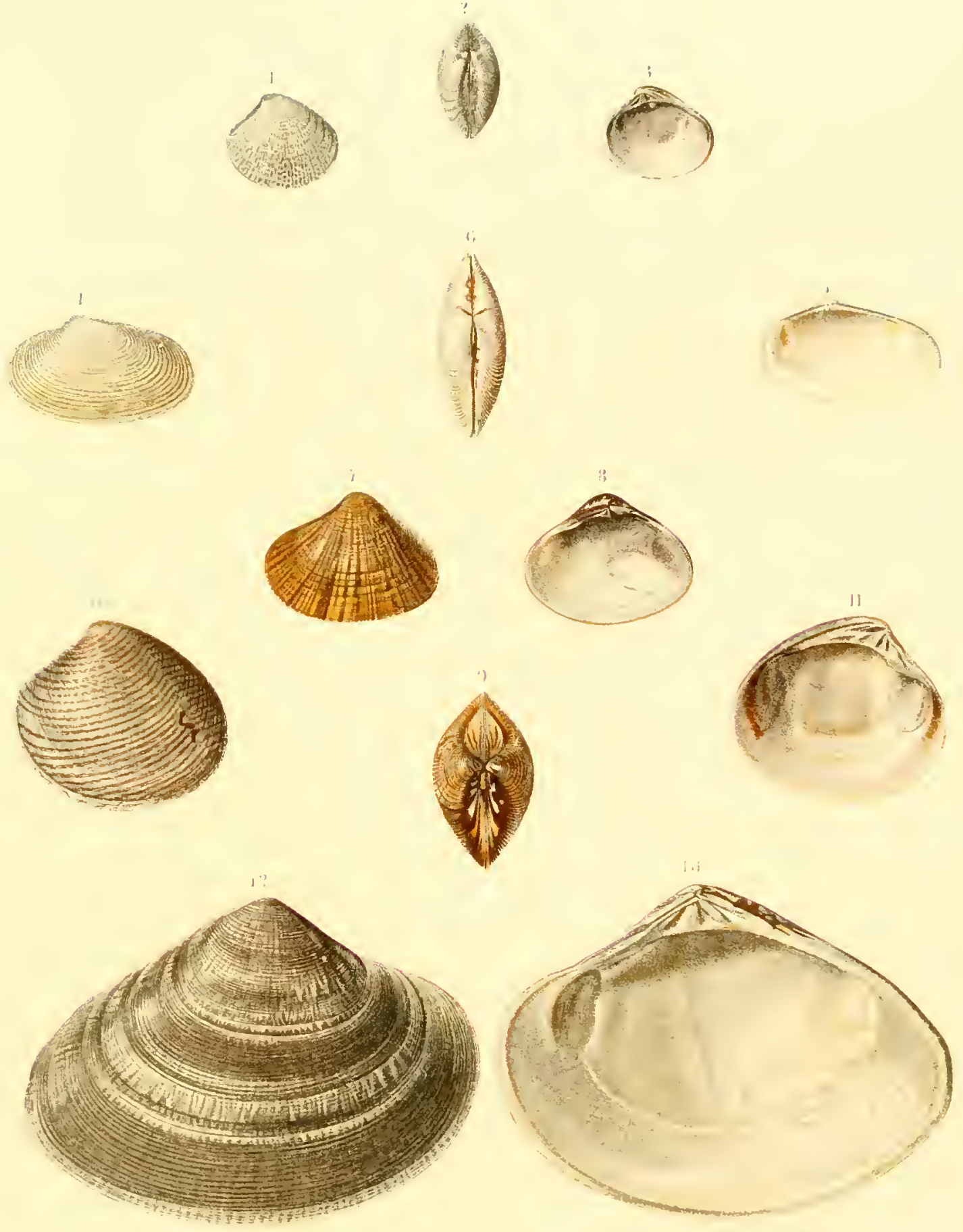


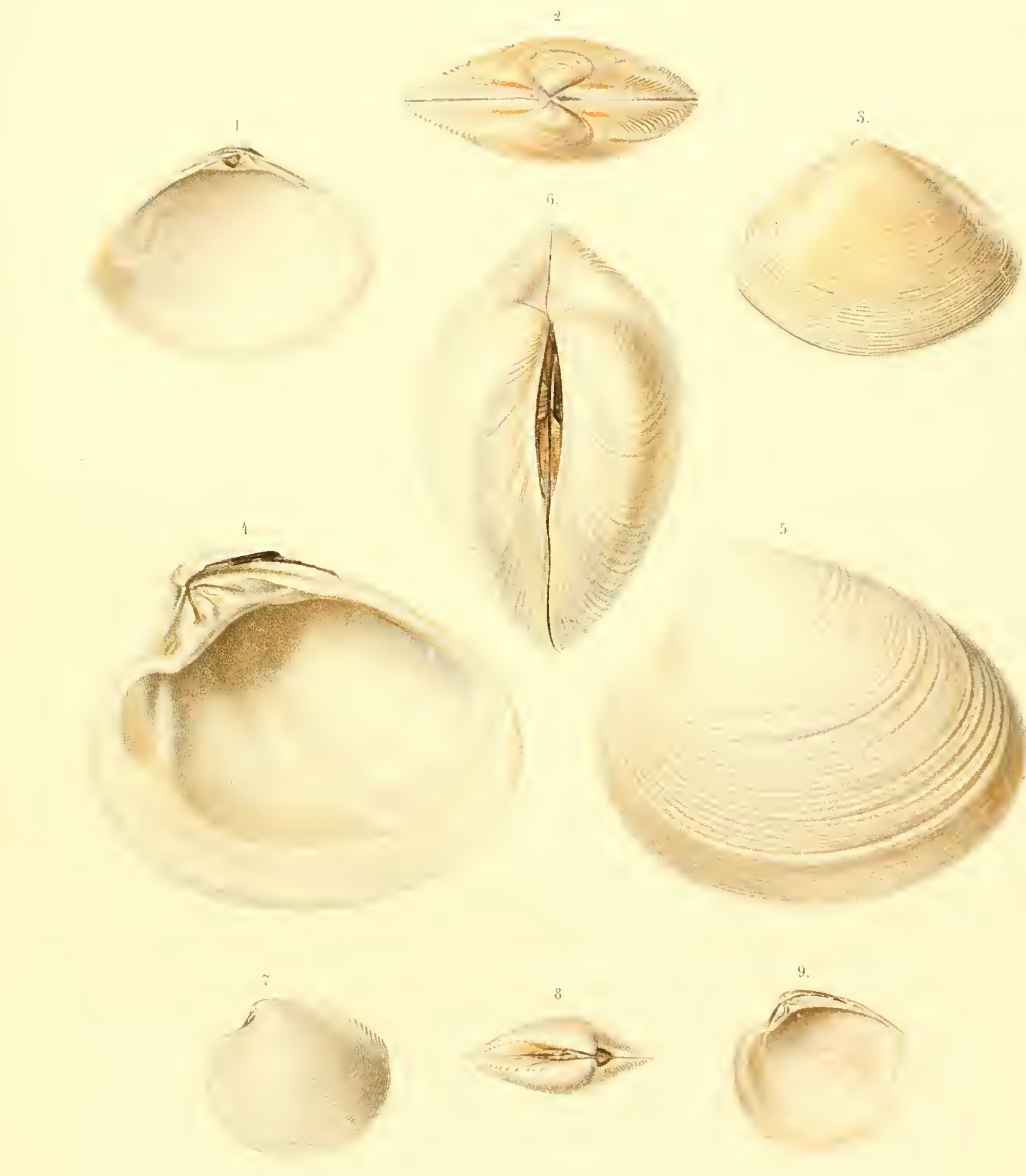


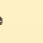



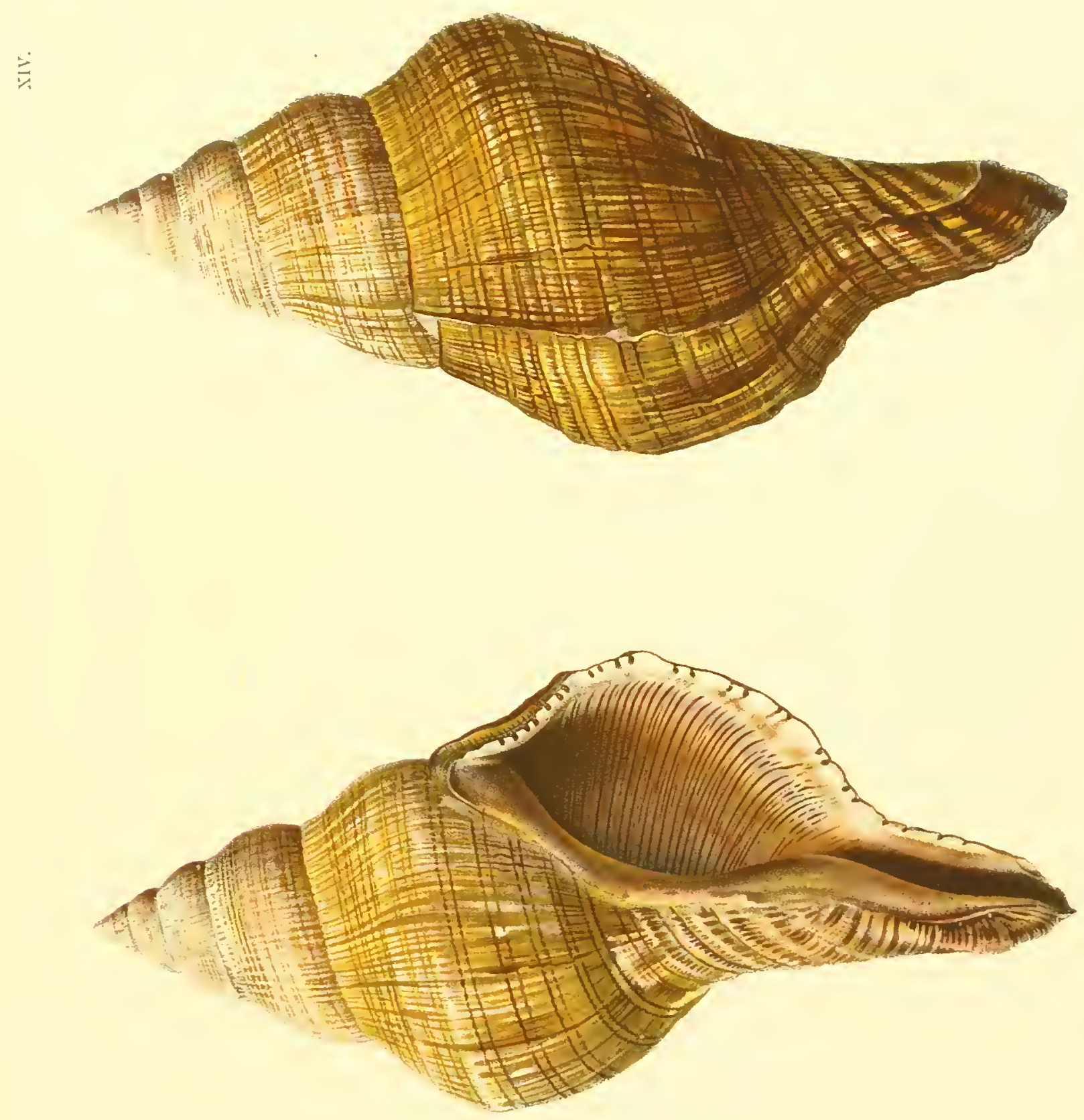

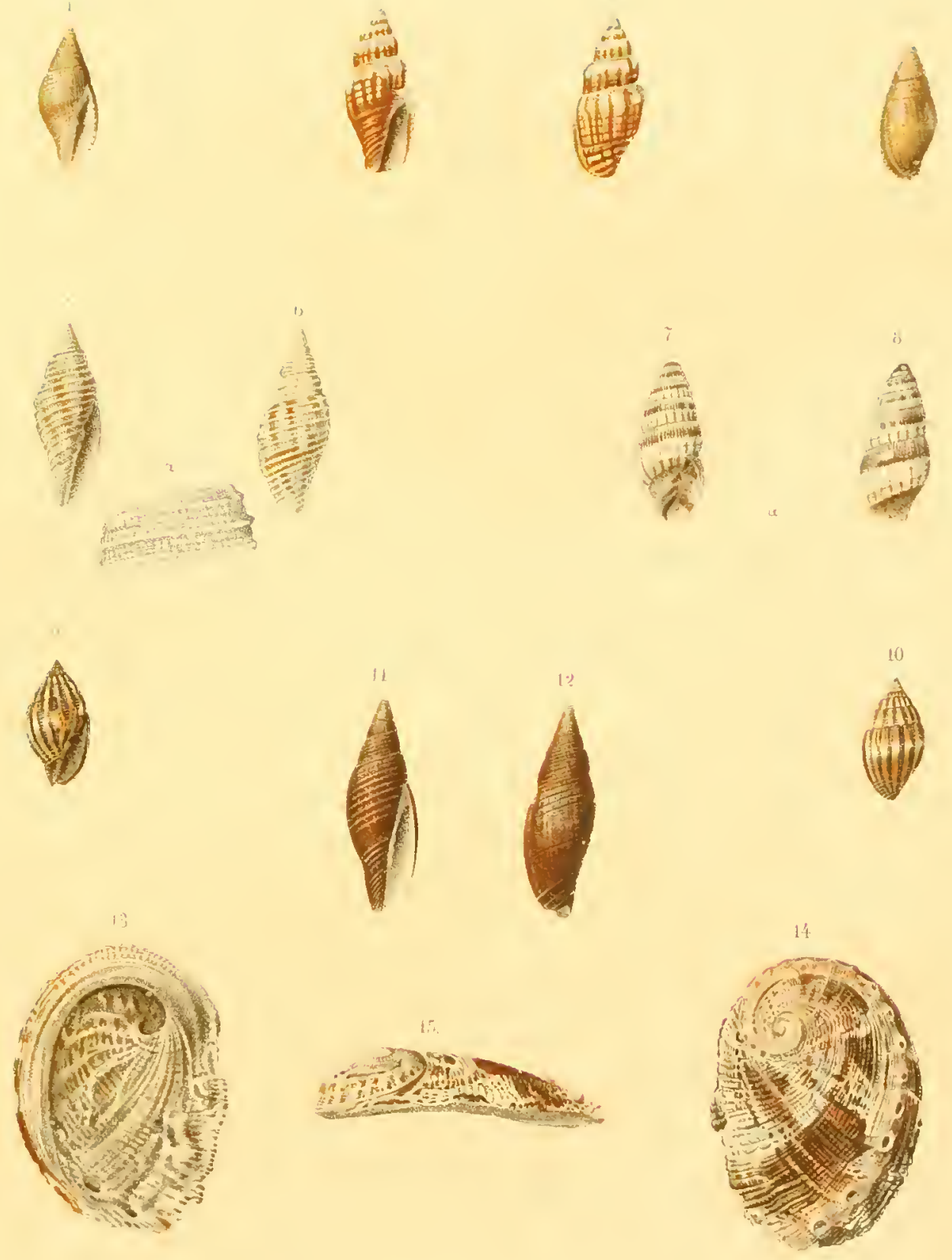

lat $\mathrm{All}$
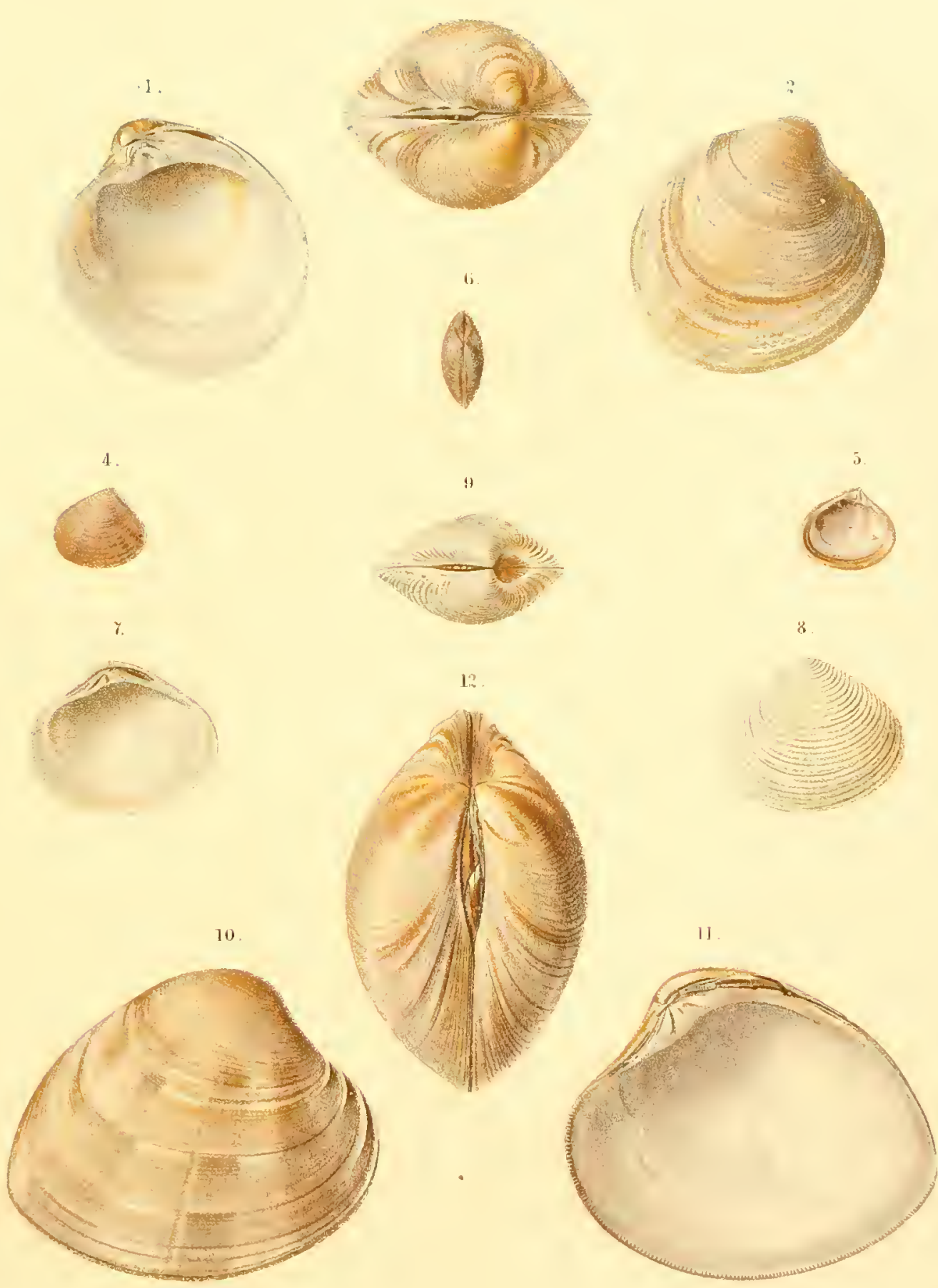

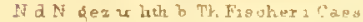



Tat IVIl.
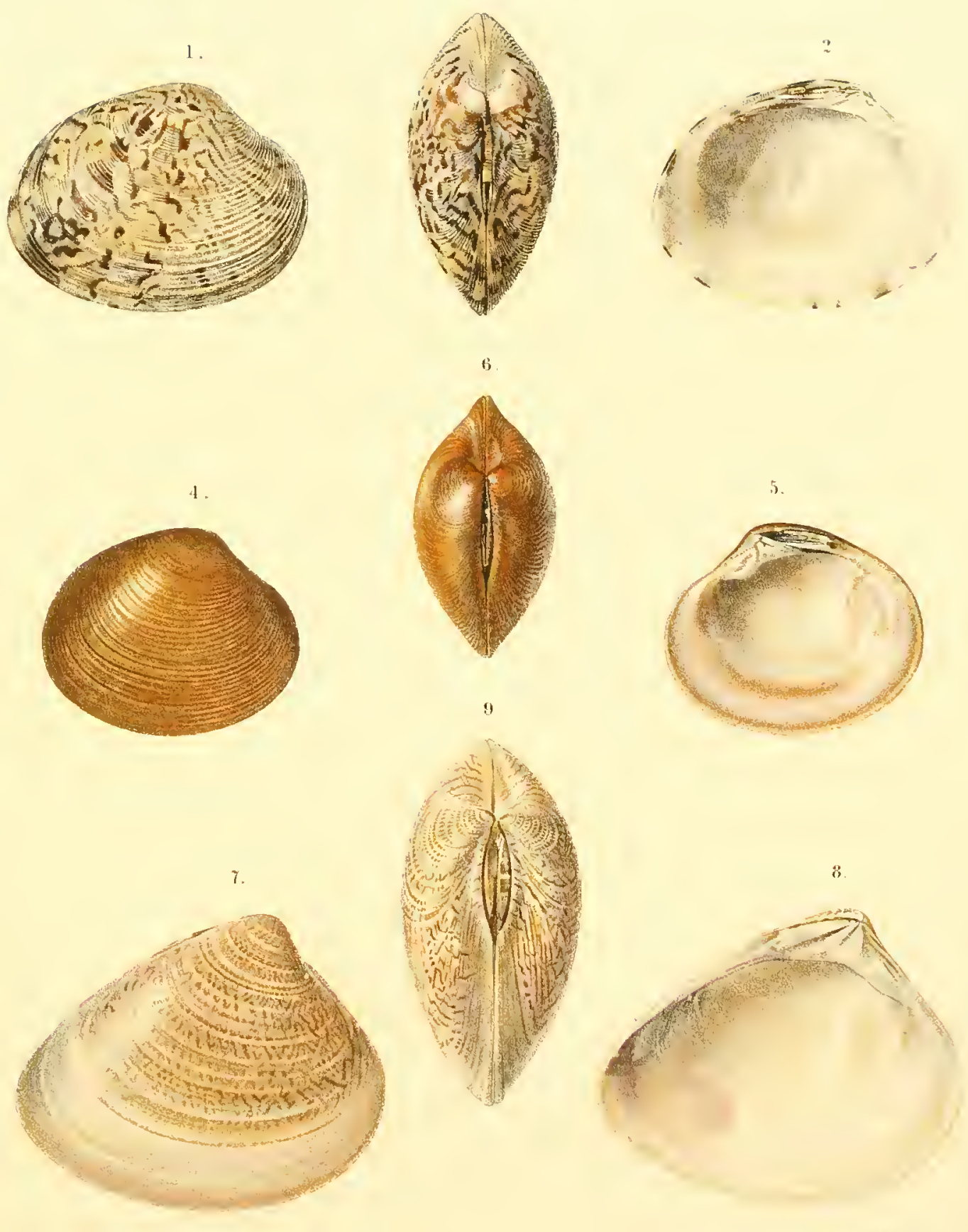

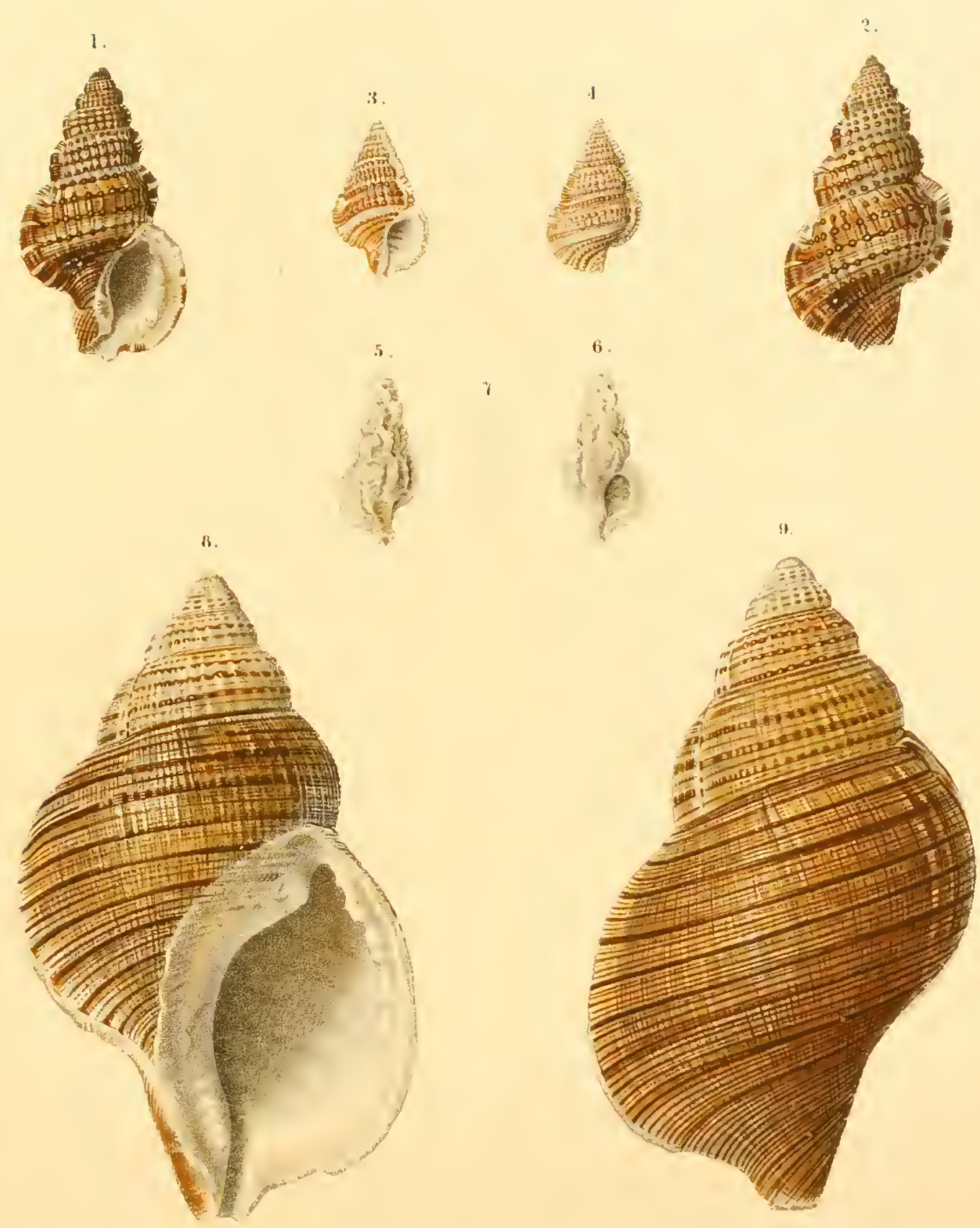

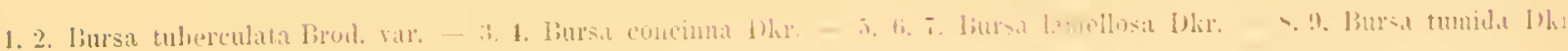




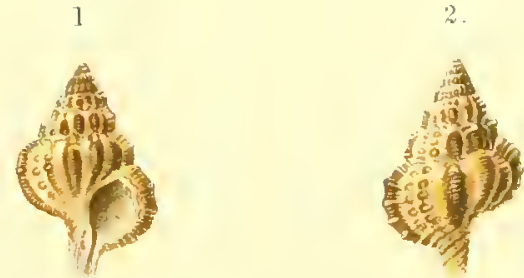
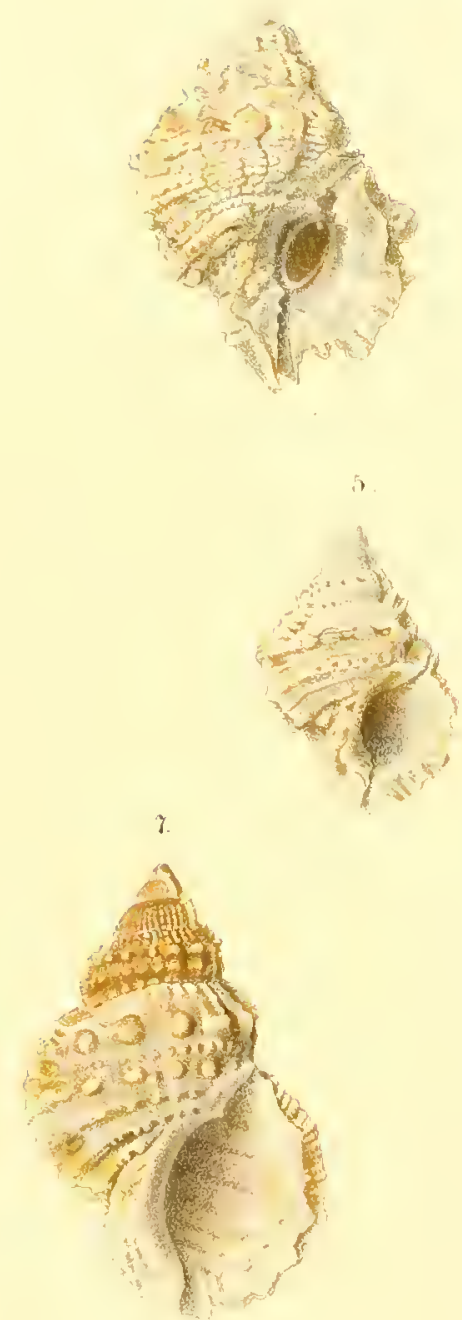

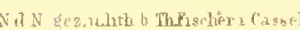

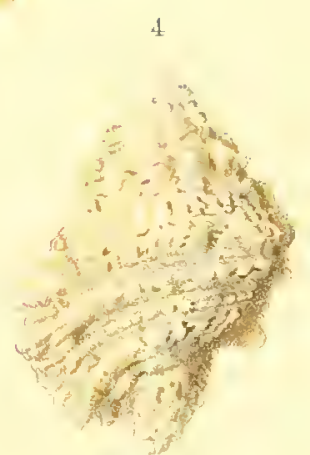

(i)
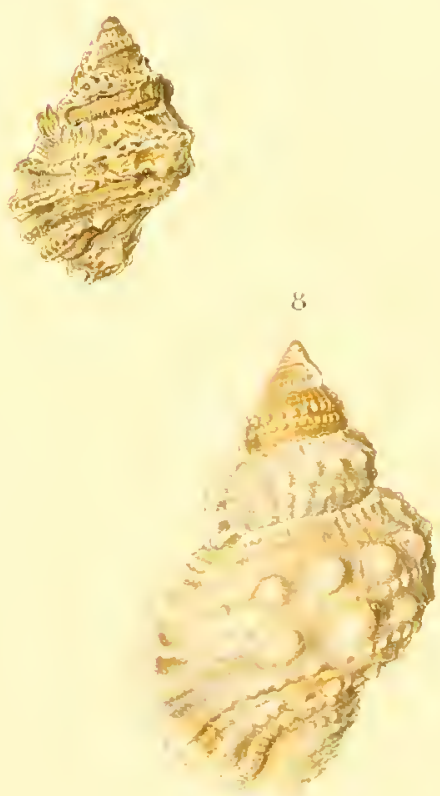

1. 2. Bursa fusco-costata Dkr. - 3. 4. Bursa asperrima Dkr. - 5, 6. Bursa Grayana Dkr. 7. 8. Bursa Cumingiana Dkr 

ह

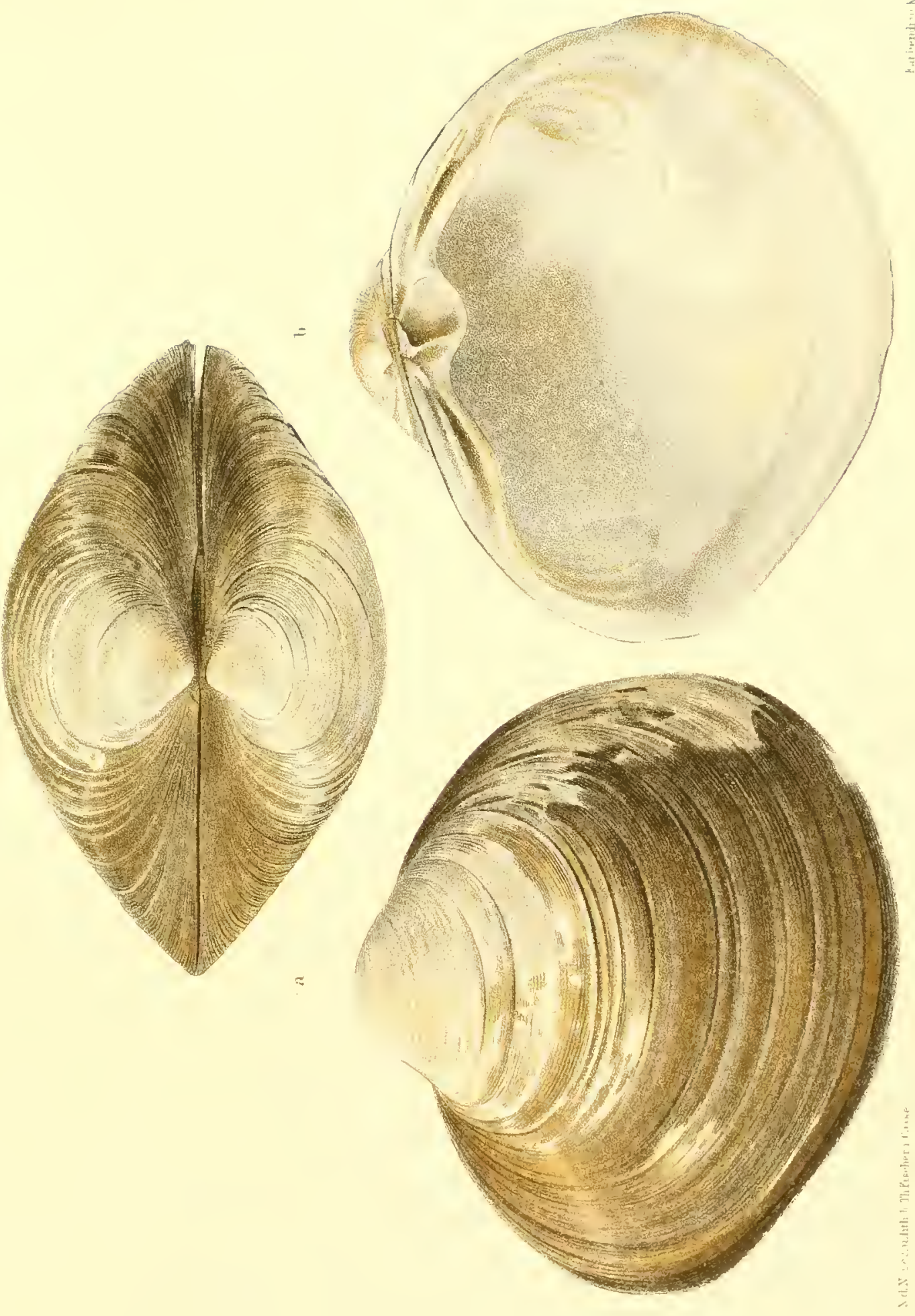

望 

Til XX

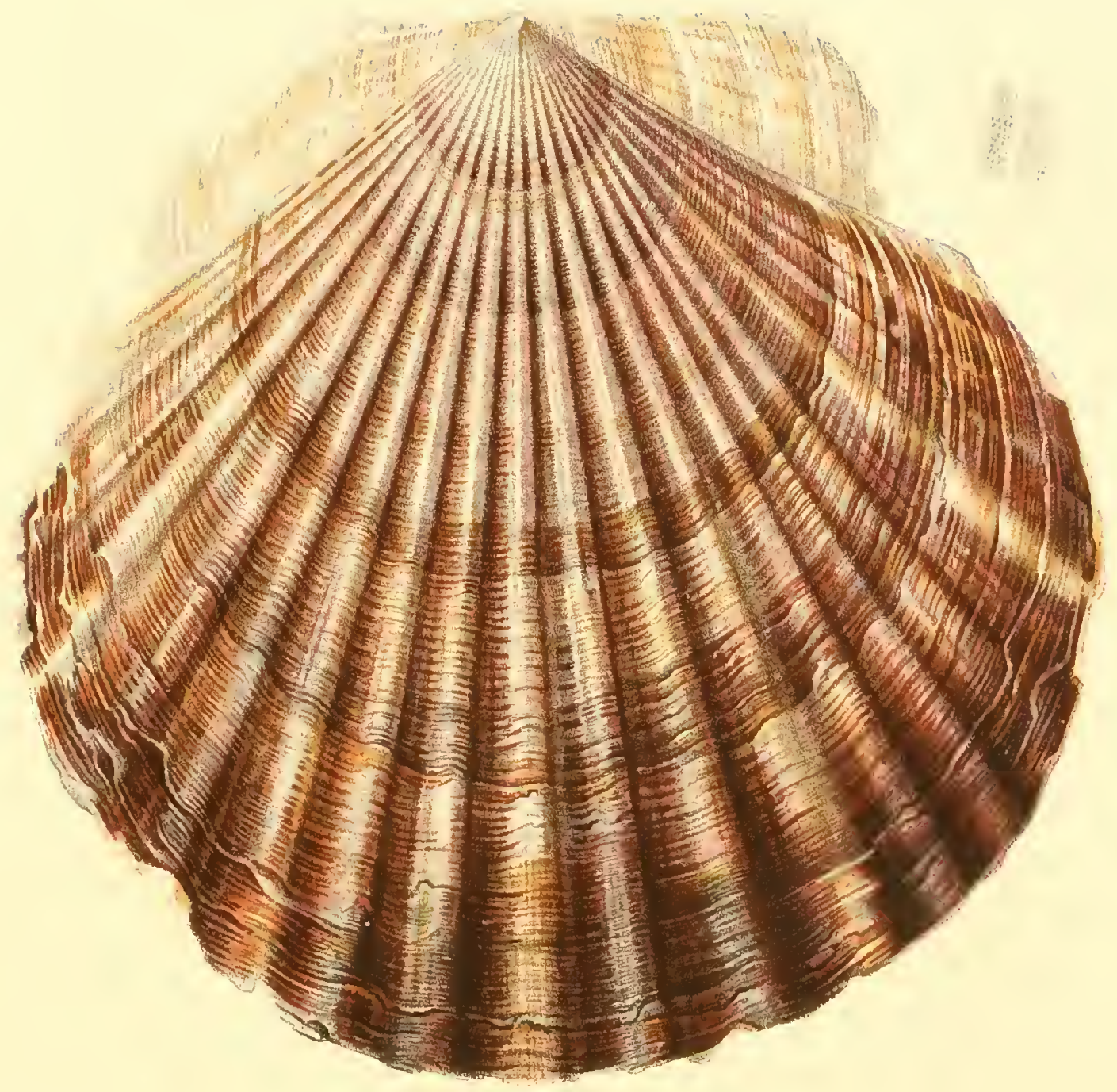



Taf $\mathrm{XXI}$
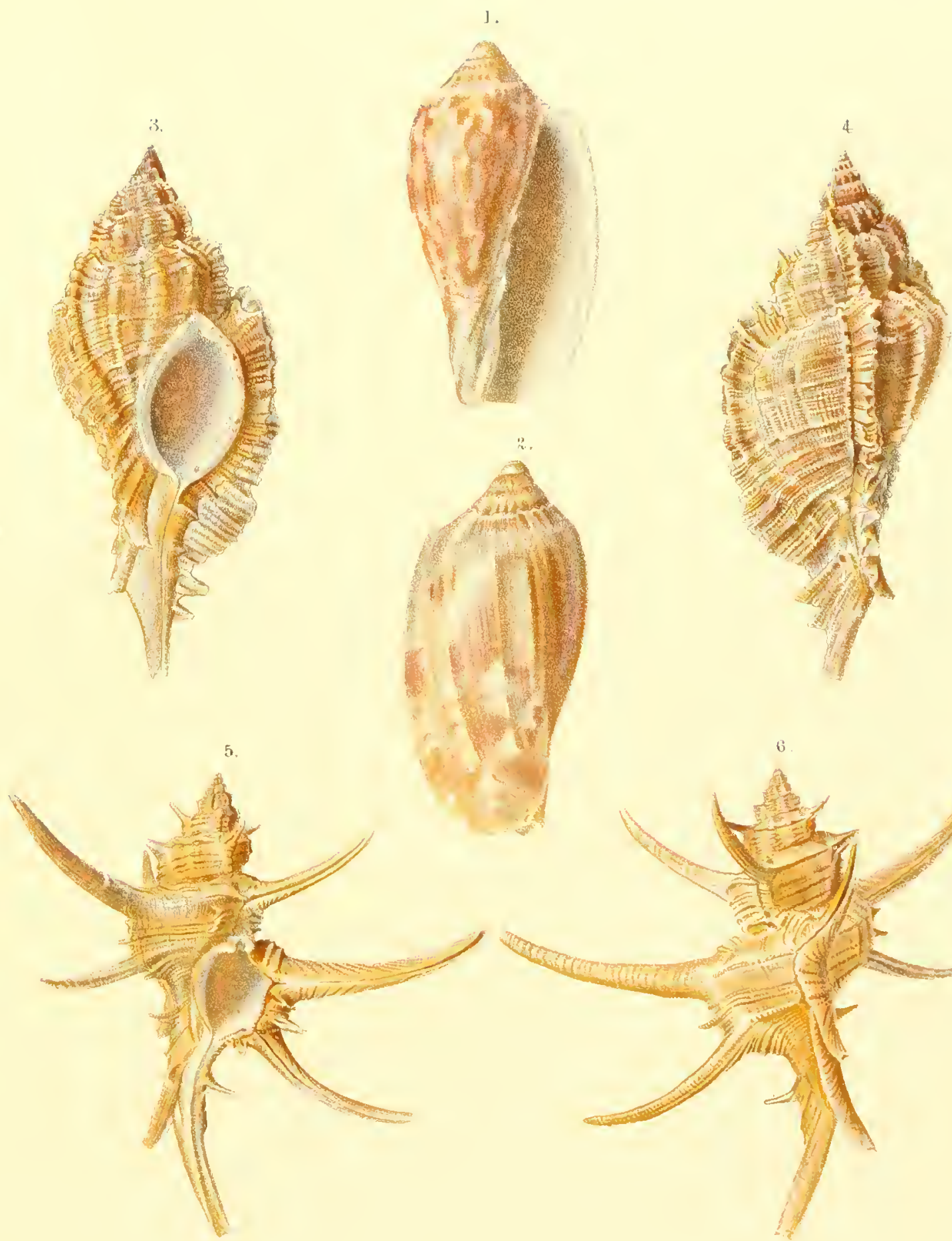

(3)

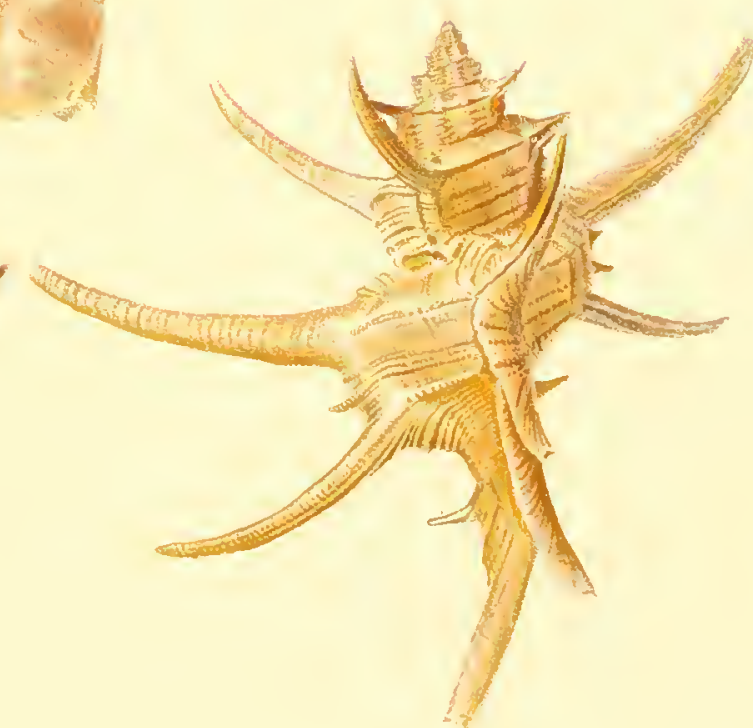



Taf. XXIII.
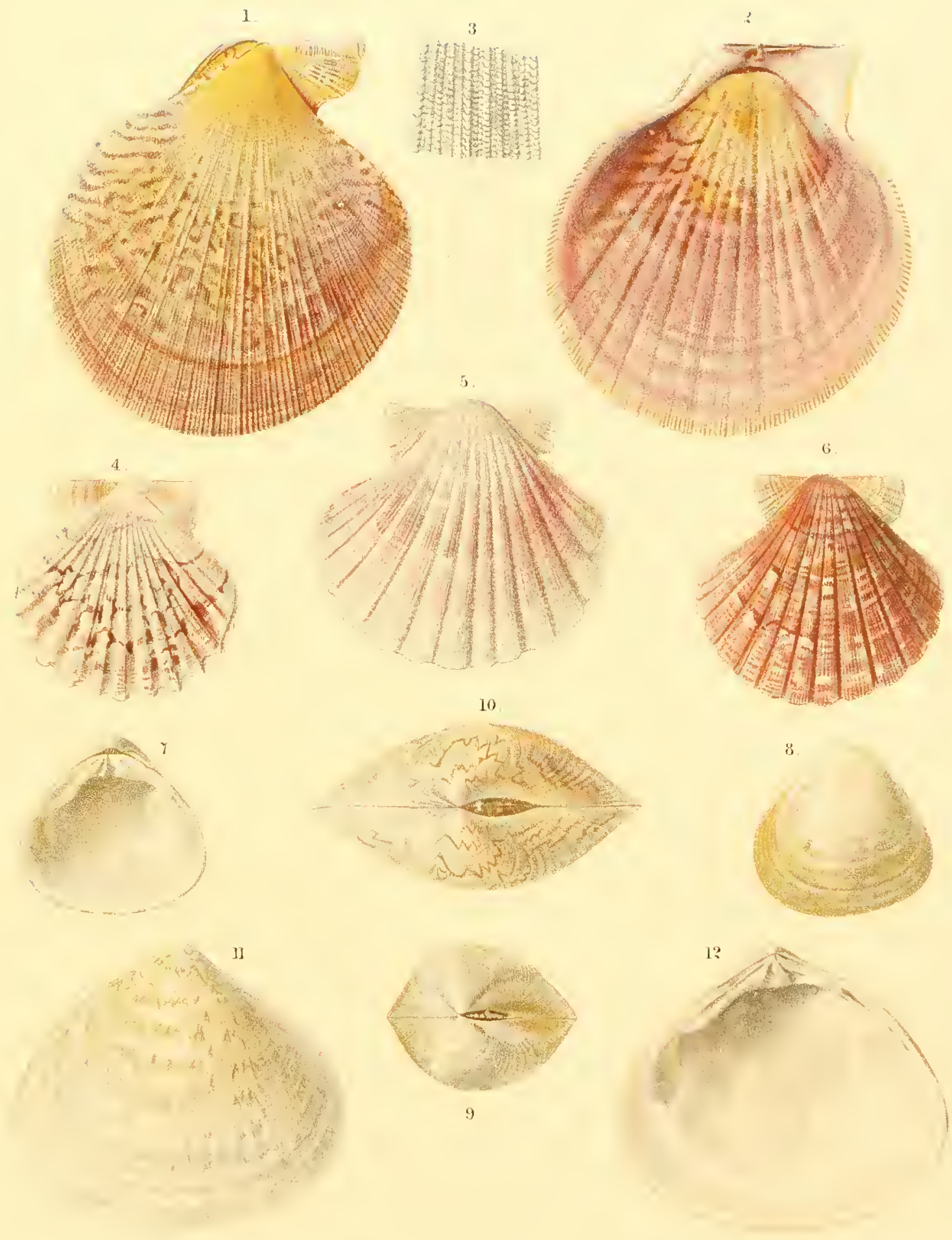

1. 2. 3. Pecten multisquamatus Dkr. - 4. 5. 6. Pecteu sulcicostatus G. B. Sow - 7. 8. 9. Tivela suluglobosa Dkr. 10. 11. 12. Tivela Natalensis Dkr. 


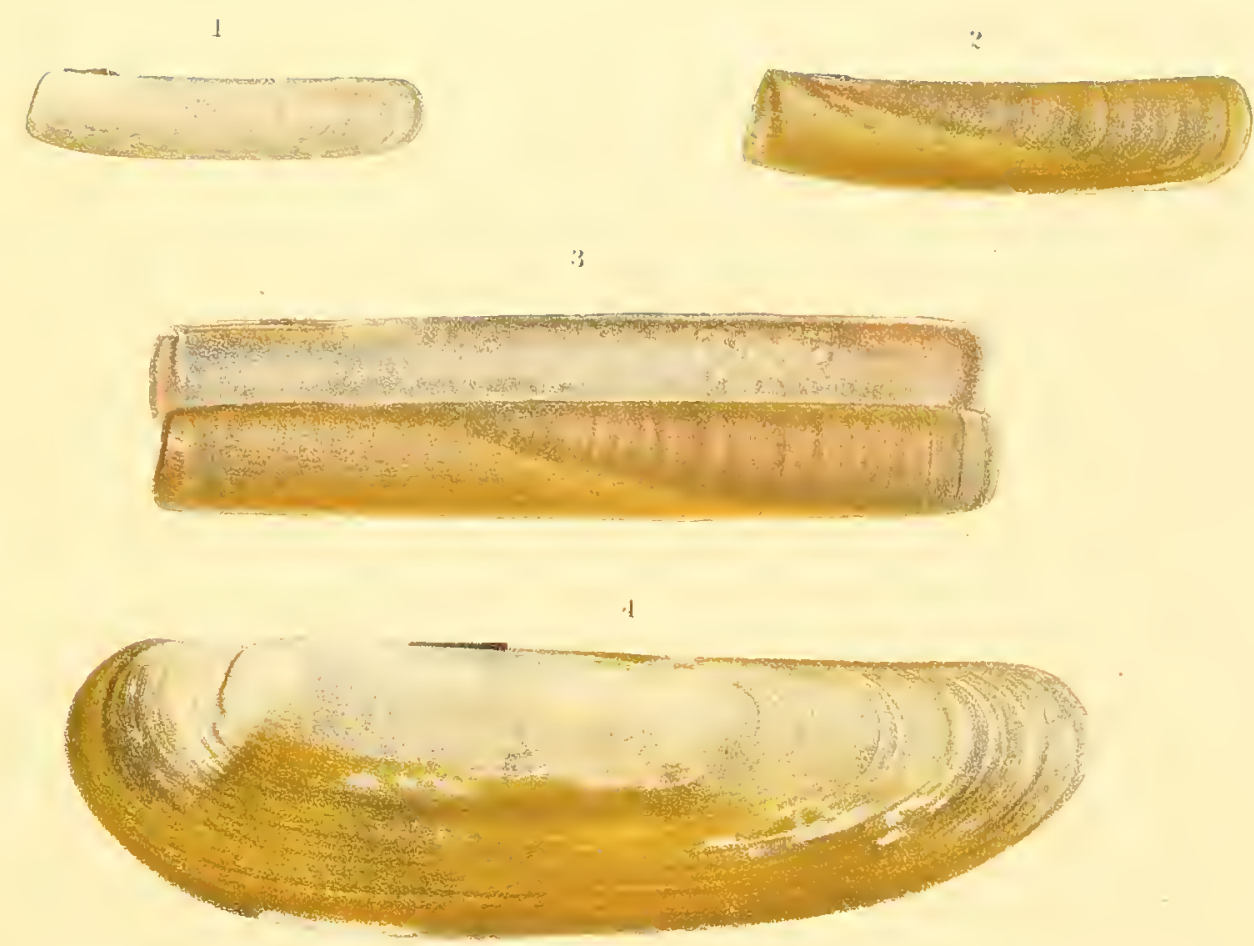

5

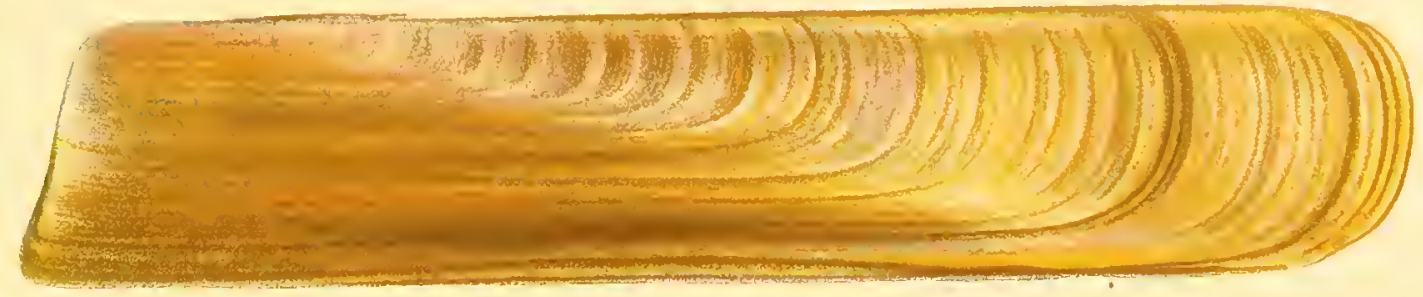

c

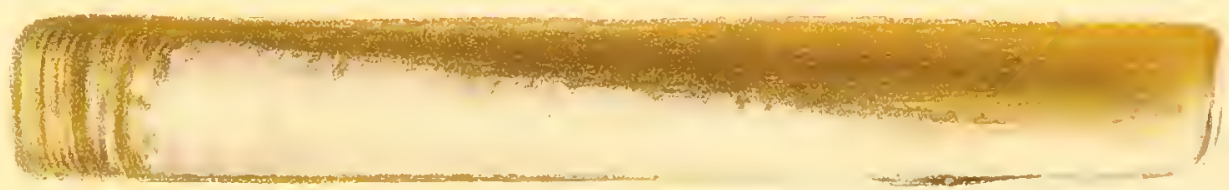

1. Sulen Lischkeants 1)kr. - 2. S. Woodwardi Dkr. - 3. S. gracilis Phil. - 1. Cultellns attennatus Jhr 5. Solen grandis Dkr. - 6. S. malaccensis Dkr. 

窟
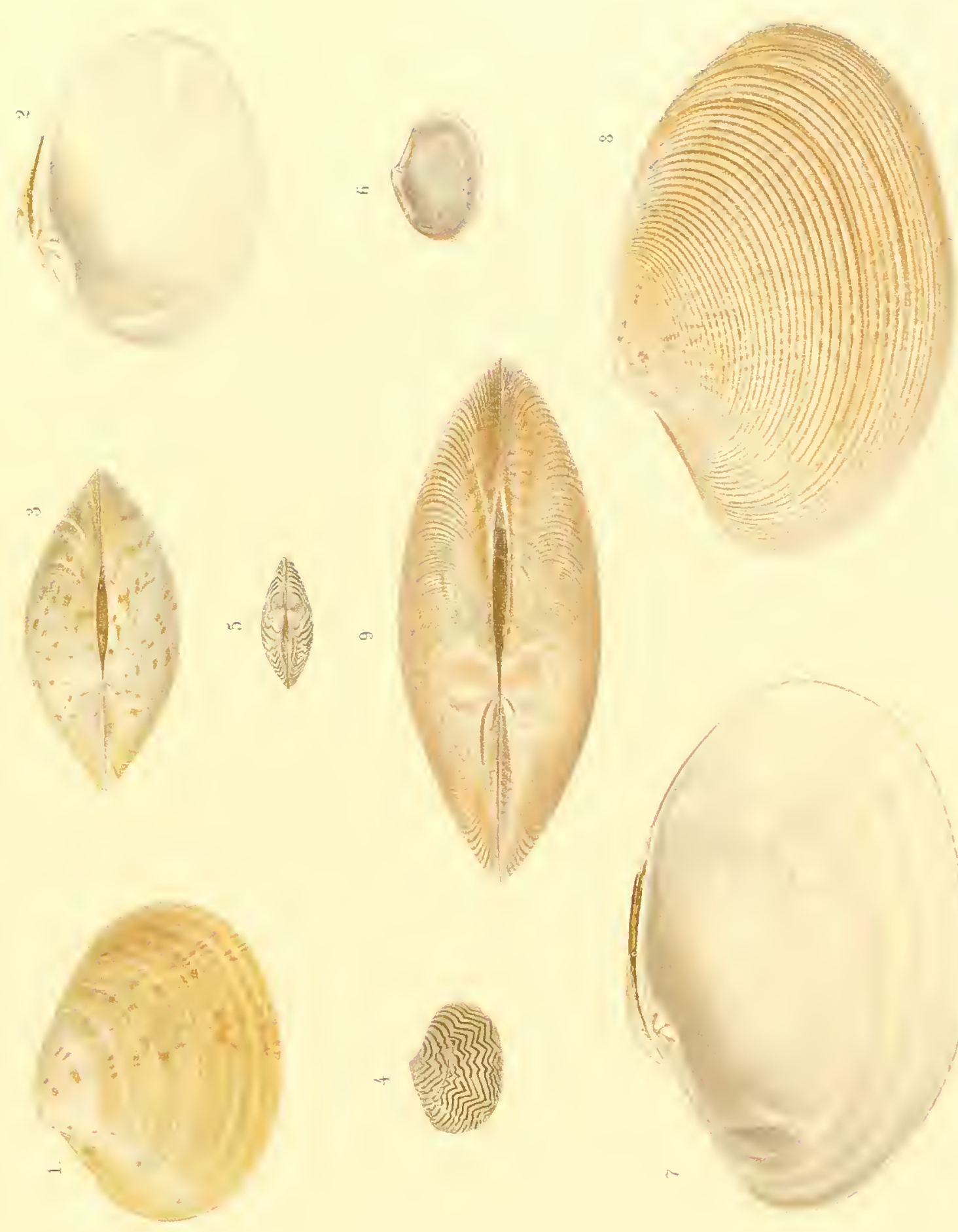



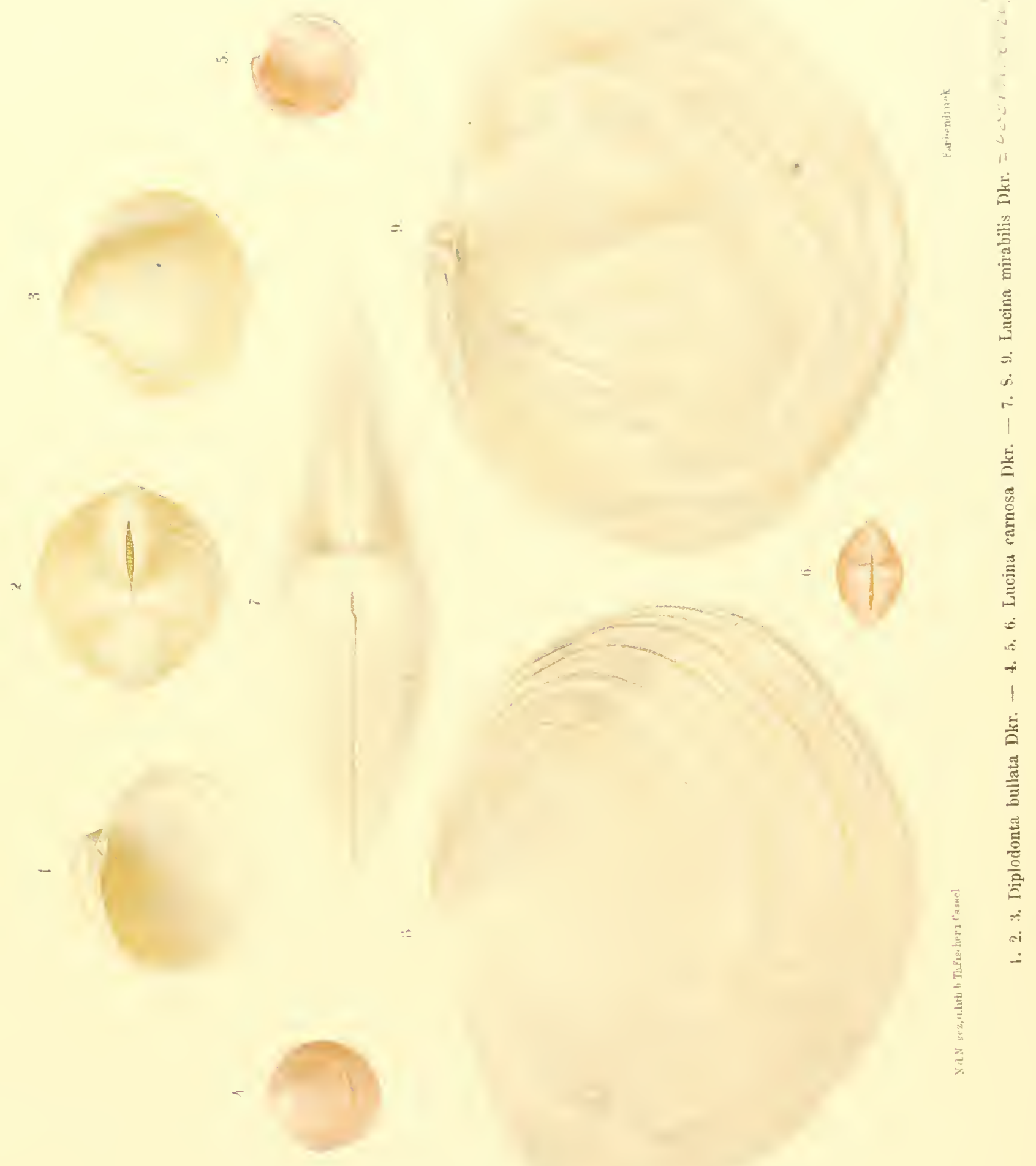


• 
Taf. XXYII.
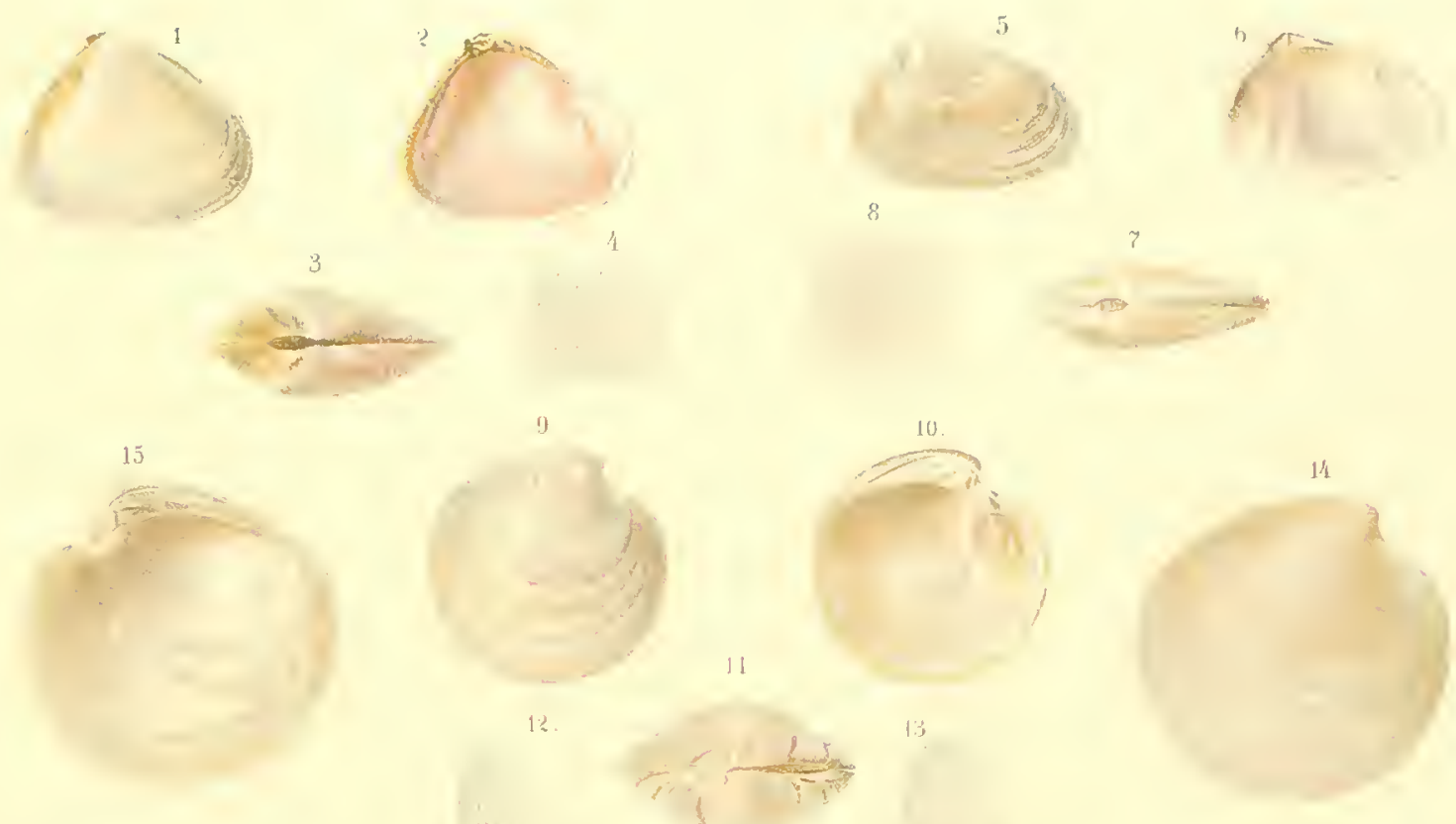

$1 / 4$

1
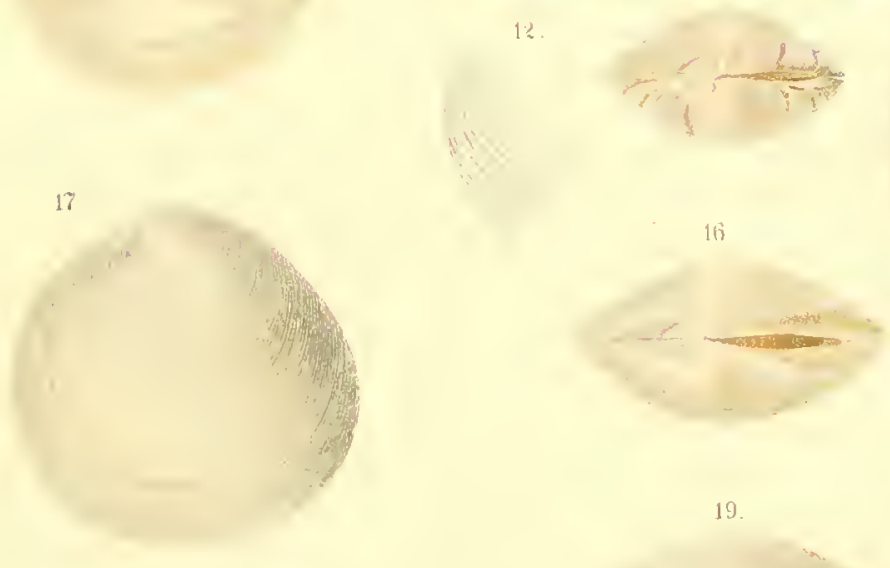

20.
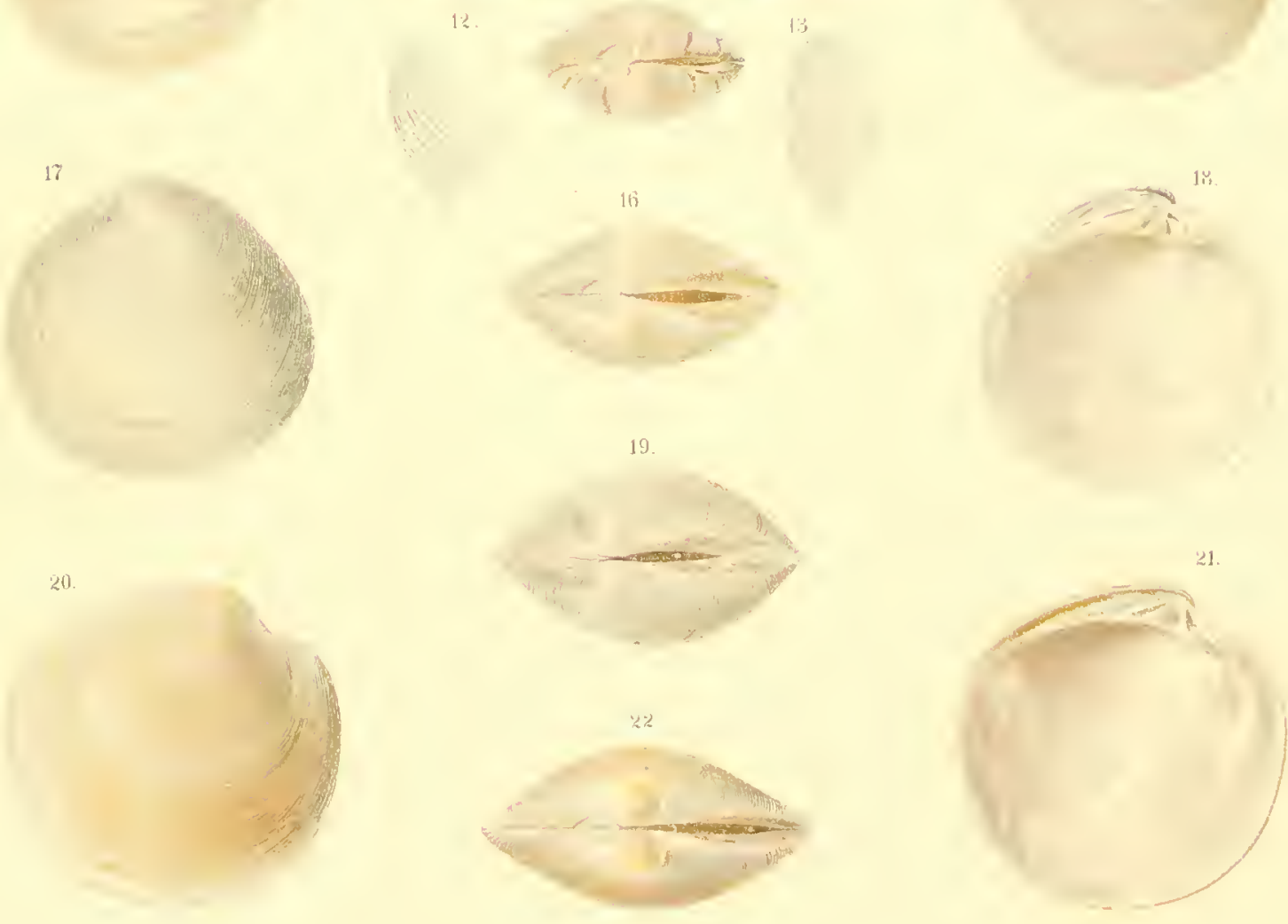

Fallindron h

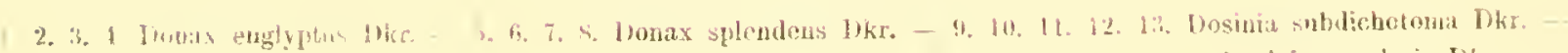

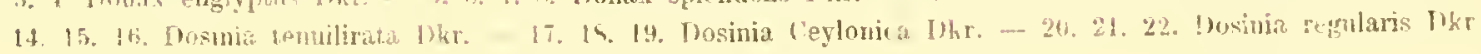




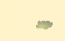

. 

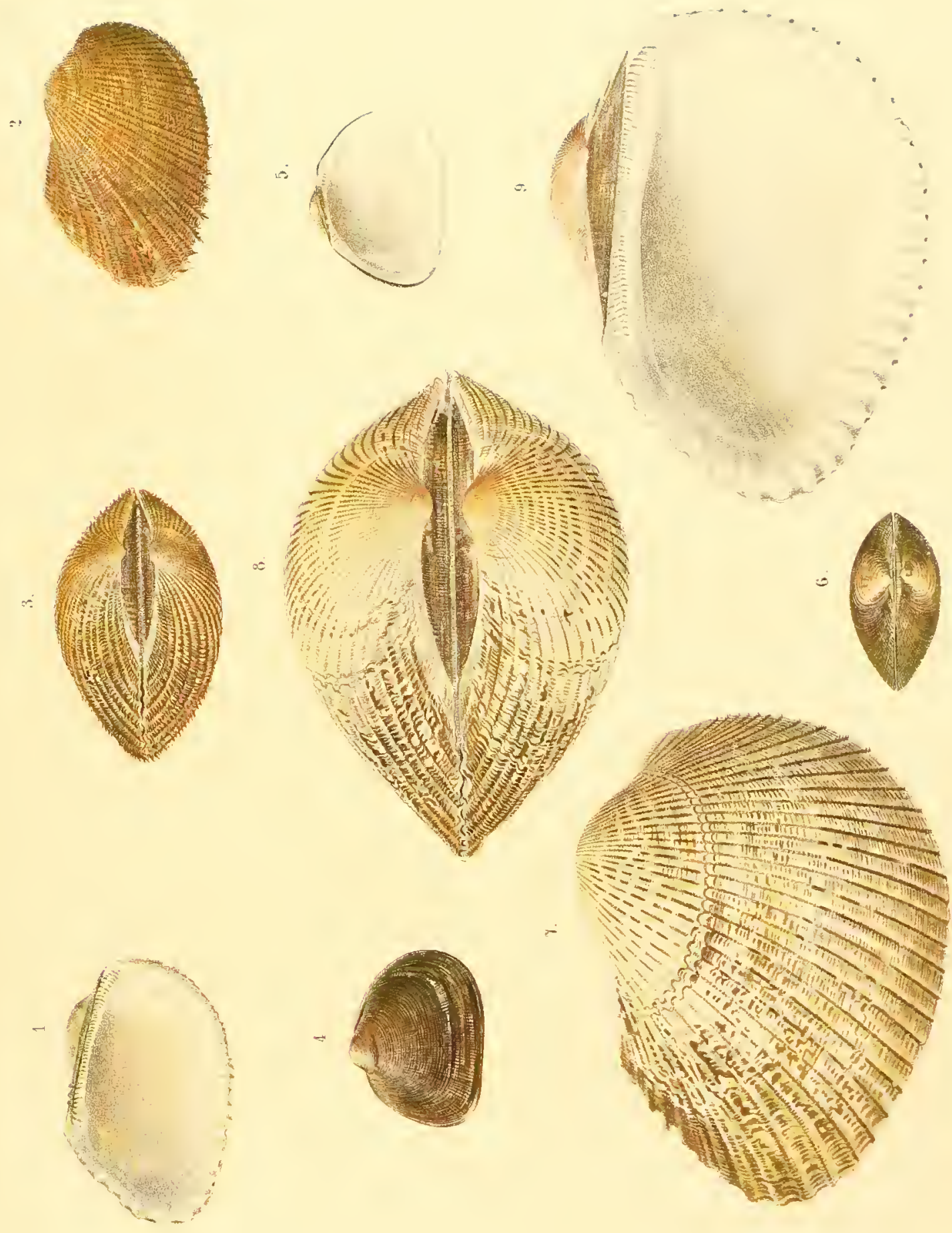



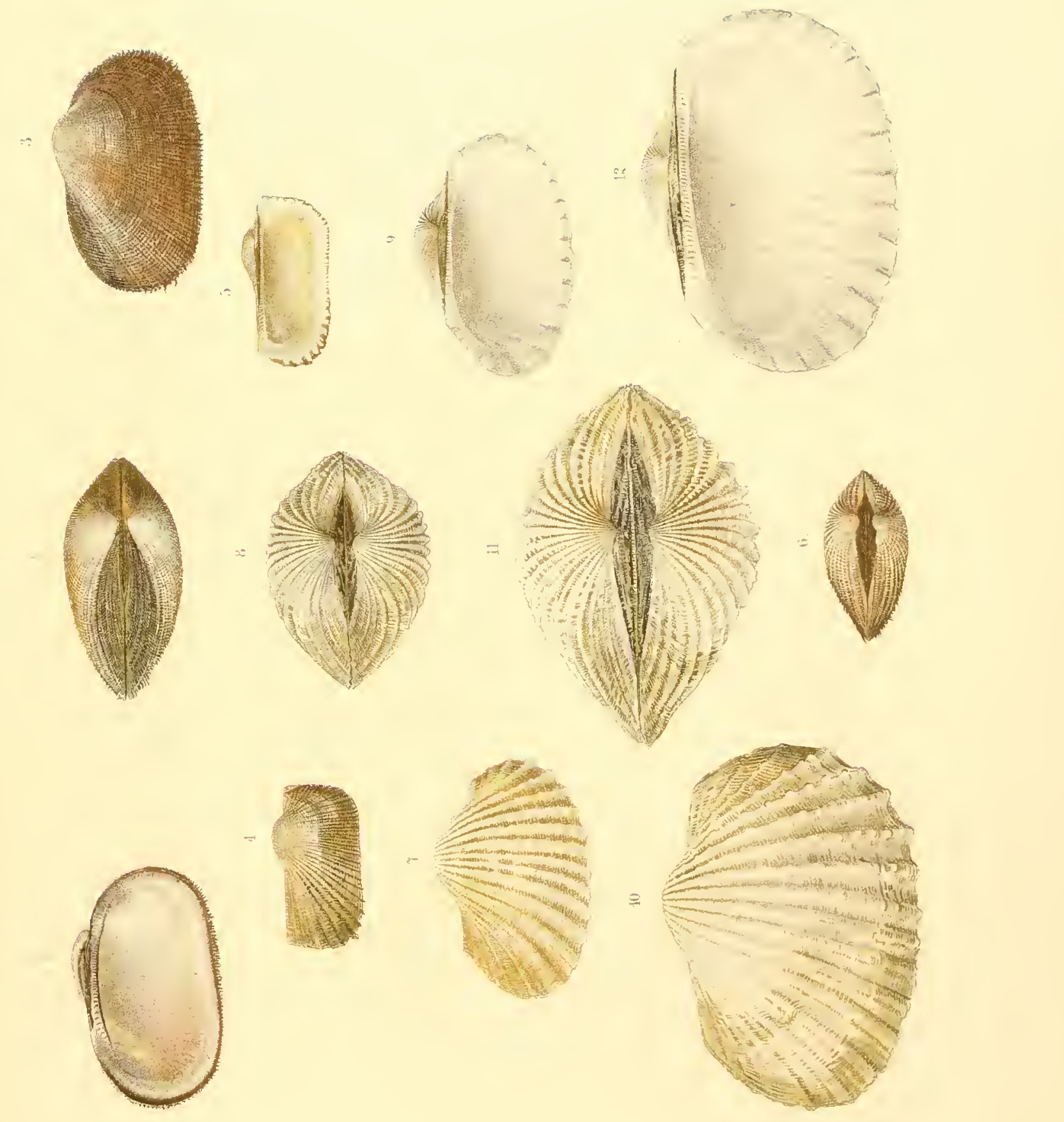


ت
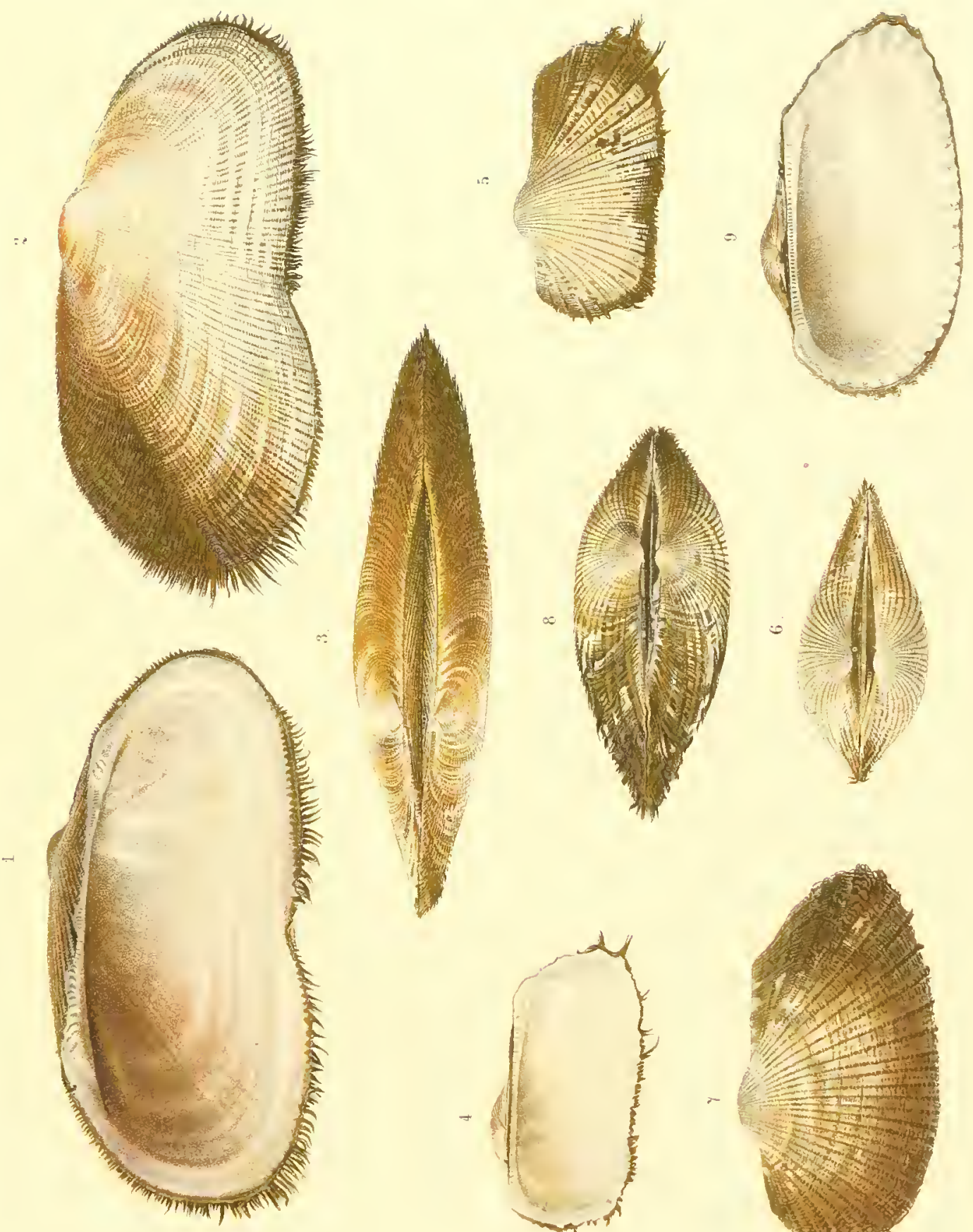

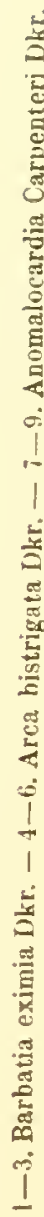

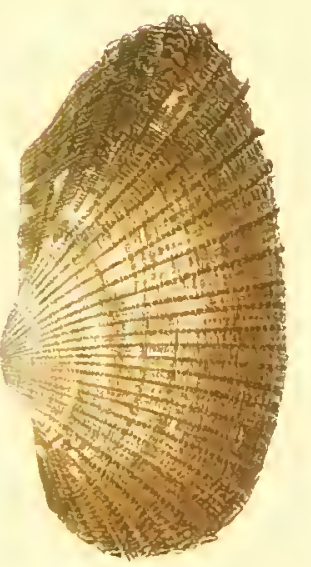



Taf. XXXI.
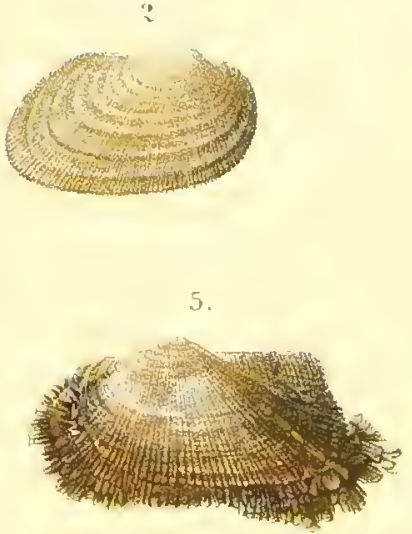

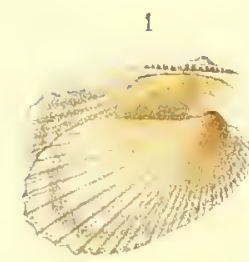

y

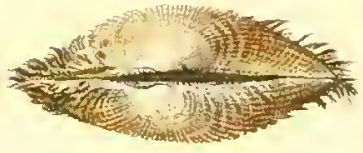

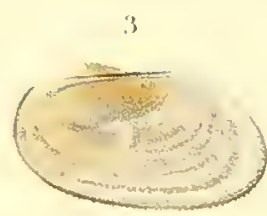

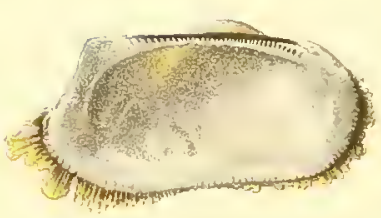

11
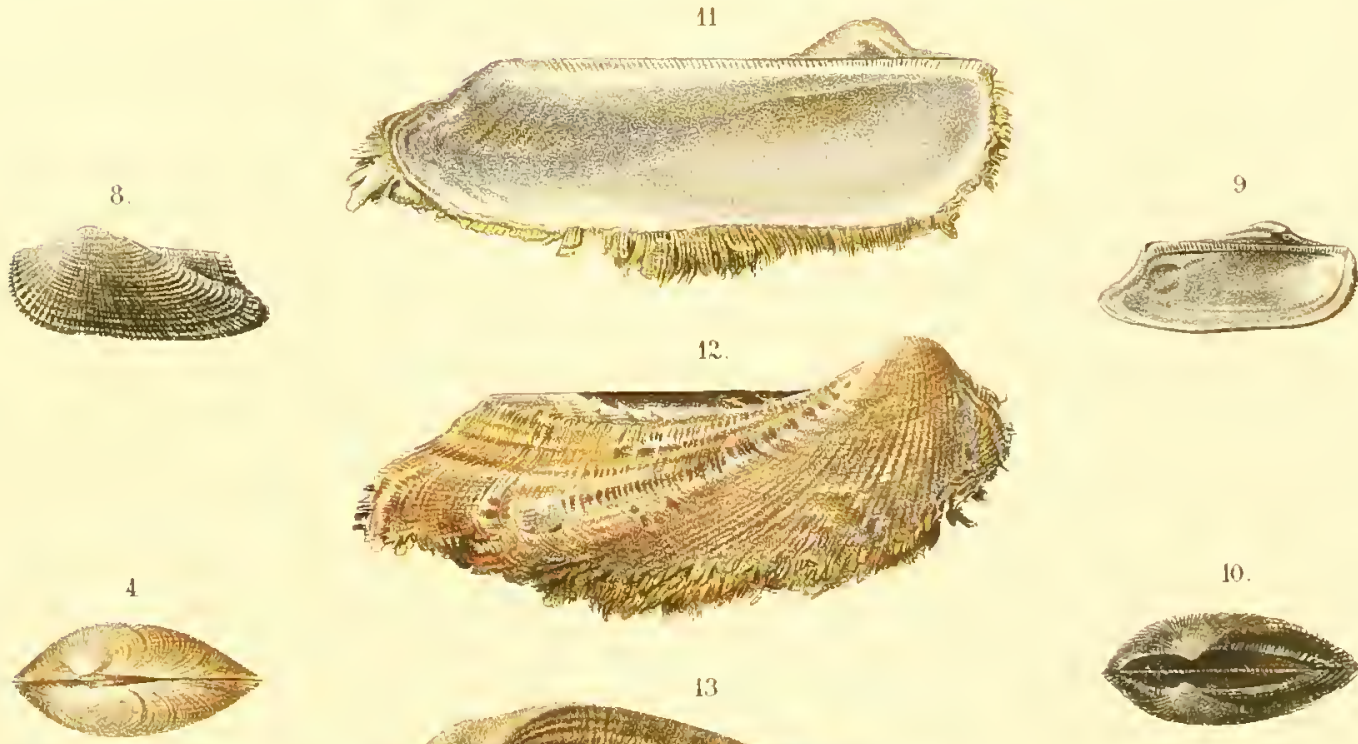

10
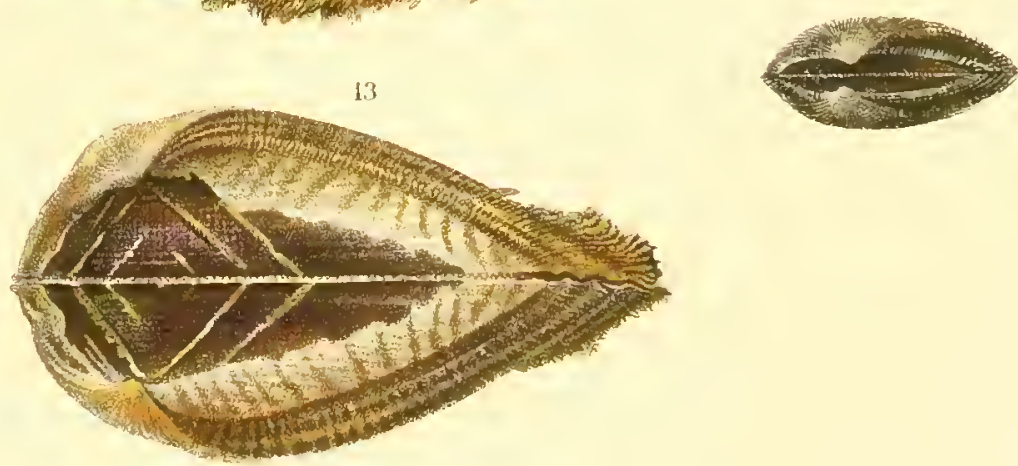

1. Arca venusta Dkr. - 2. 3. 4. Barbatia mollis Dkr. - 5.6. 7. Barbatia Grayana Dkr.

8. 9. 10. Arca angusta Dkr. - 11. 12. 13. Arca insignis Dkr. 

Taf. XXXII

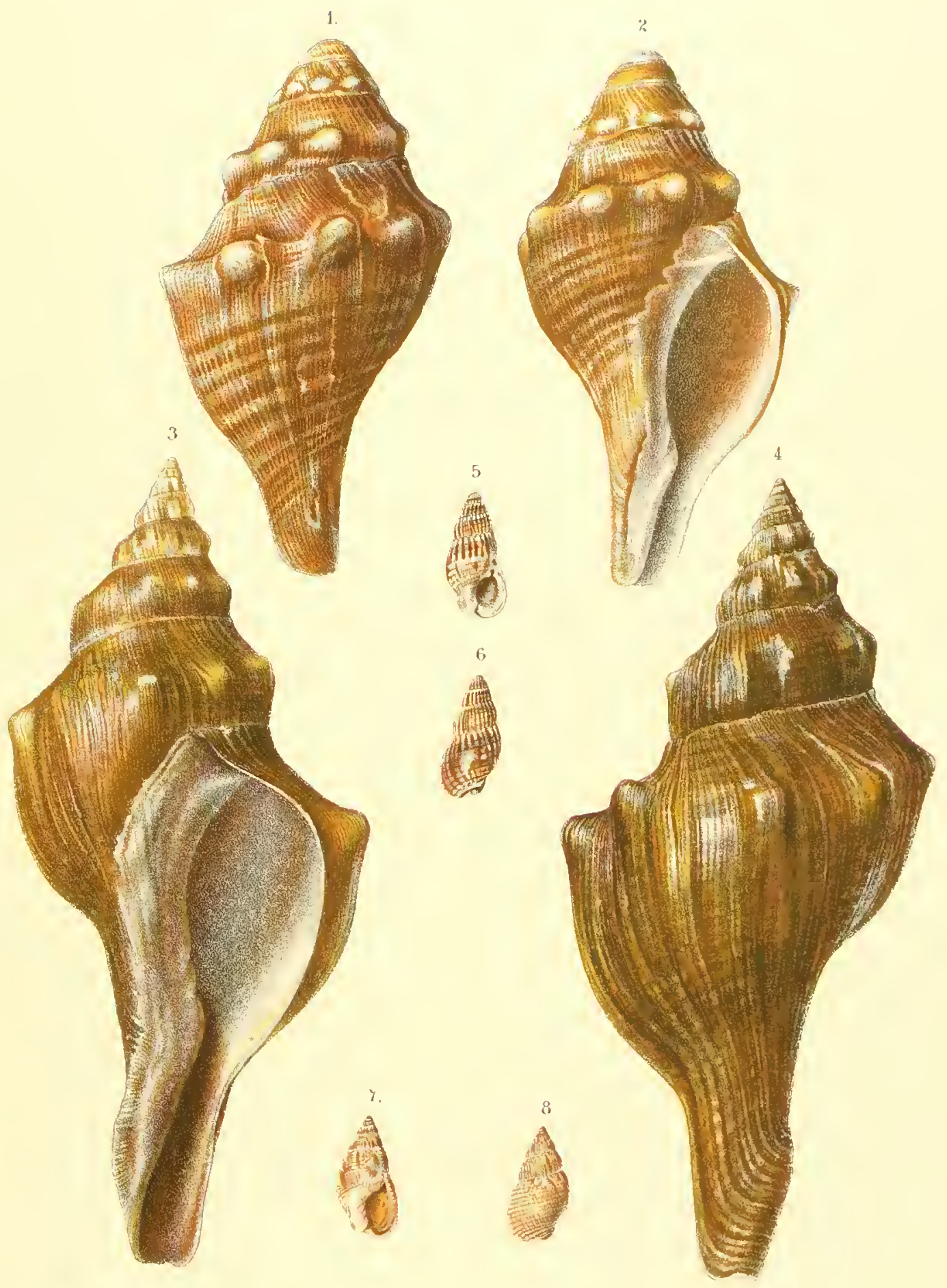

1. 2. Fasciolaria purpurea Jon, var, - 3,4. F. Audonini Jon. var. - 5. 6. Nassa semisulcata Dkr. 7. 8. N. coturnix Dler. 

Taf XXXIII.

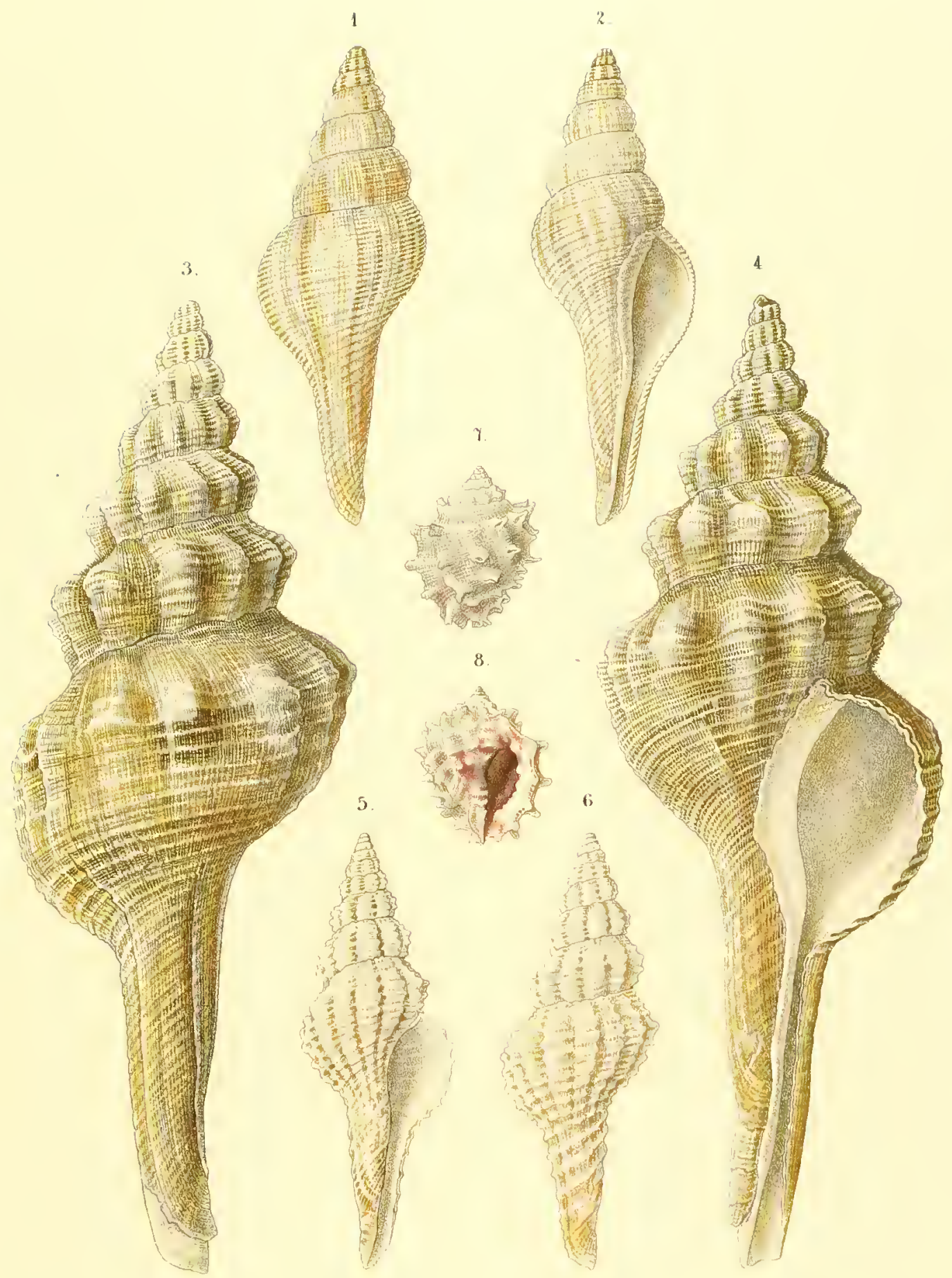

1. 2. Fusus tenuiliratus Dkr. - 3. 4. F. nodosoplicatus Dkr, - 5.6. F. Päteli Dkr. - 7. 8. Ricinula speciosa Dkr. 



$$
111
$$



Taf. XXXV.

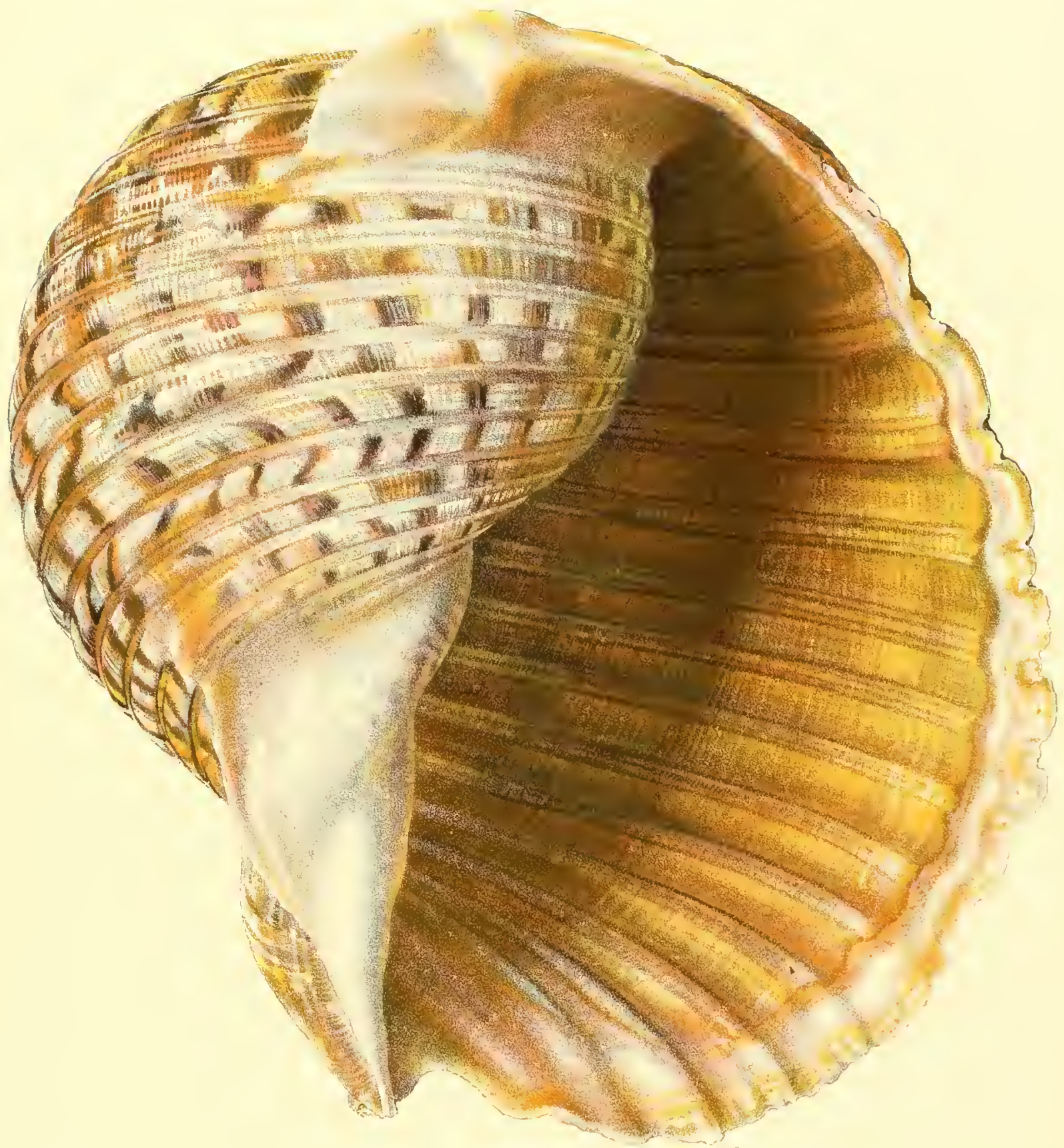




$$
\text { - }
$$


Taf. XXXVI.

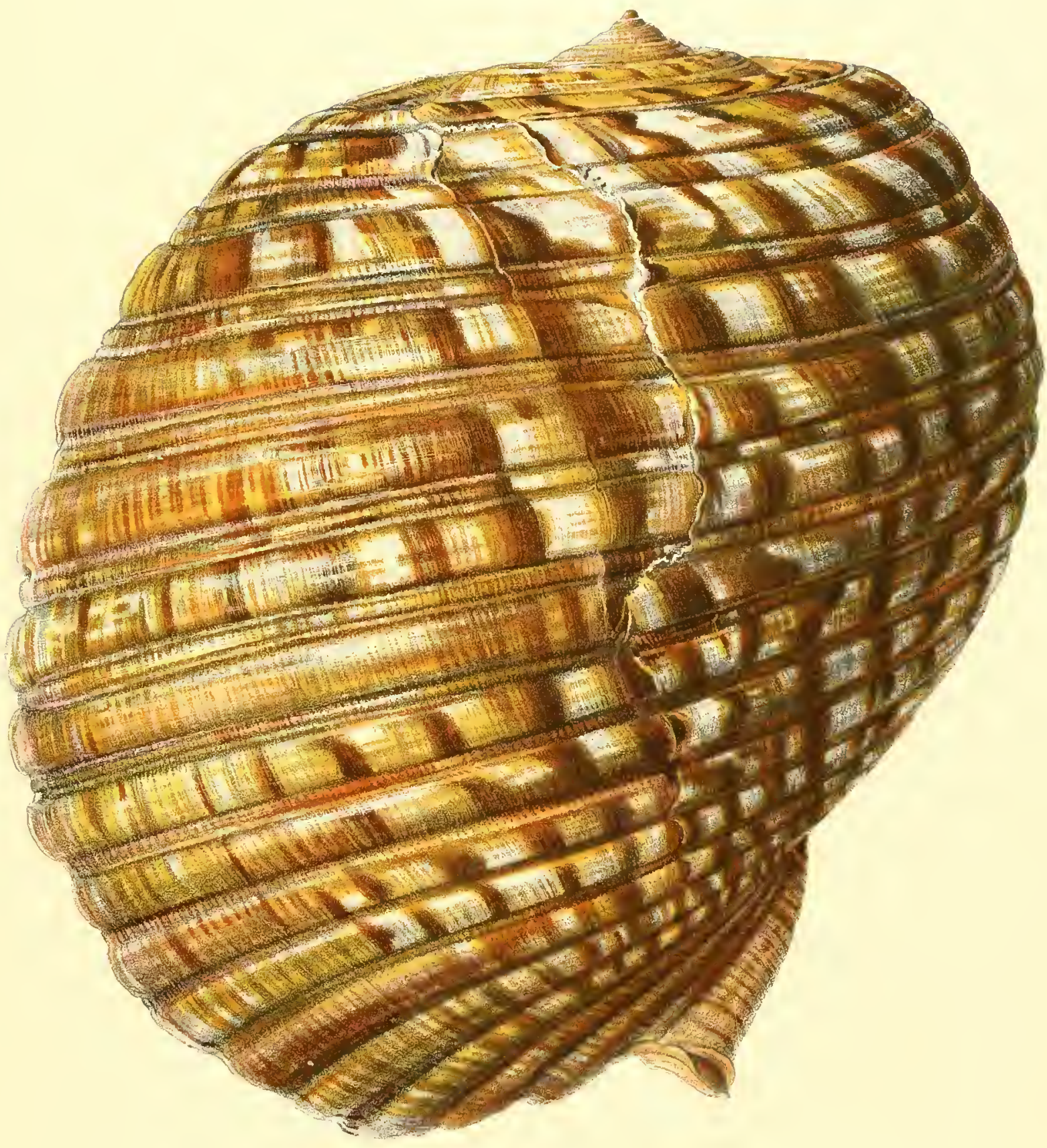

Dolium Japonicum Dkr. 


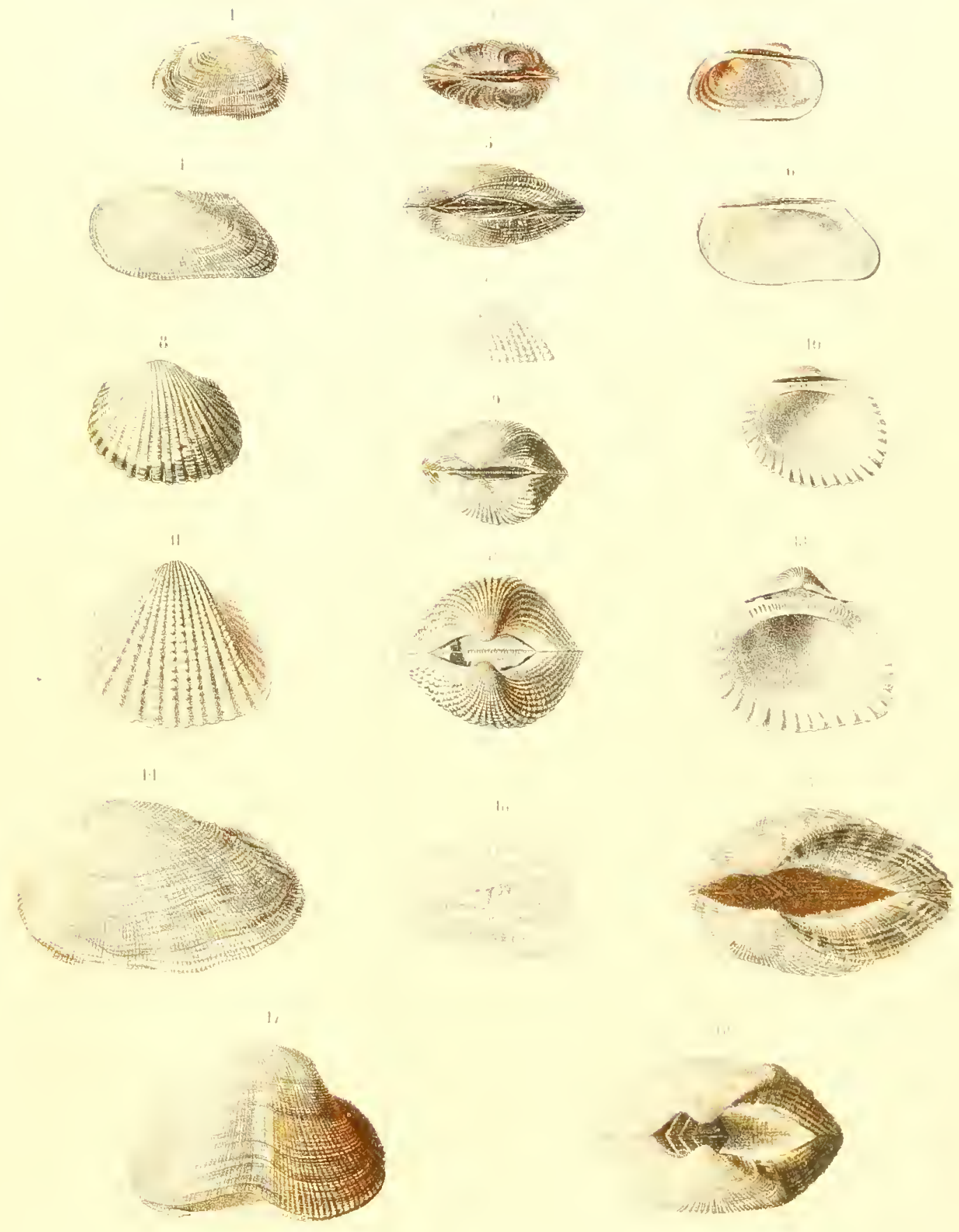

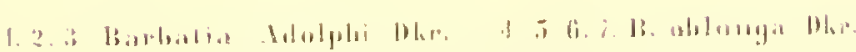

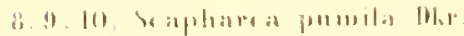

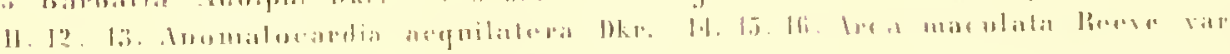

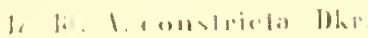


$\equiv$
$\equiv$
$\vdots$
$=$
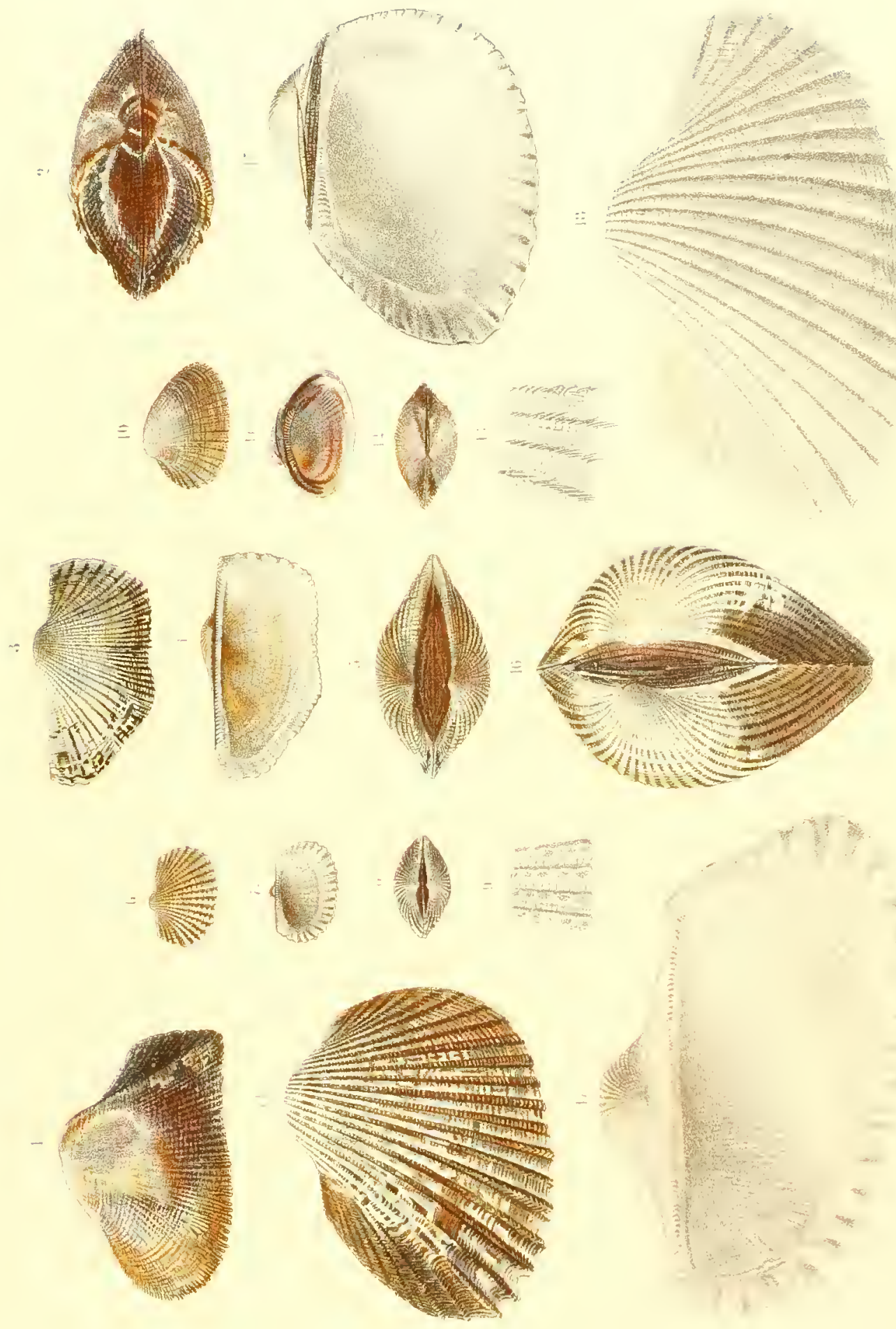



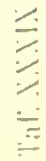
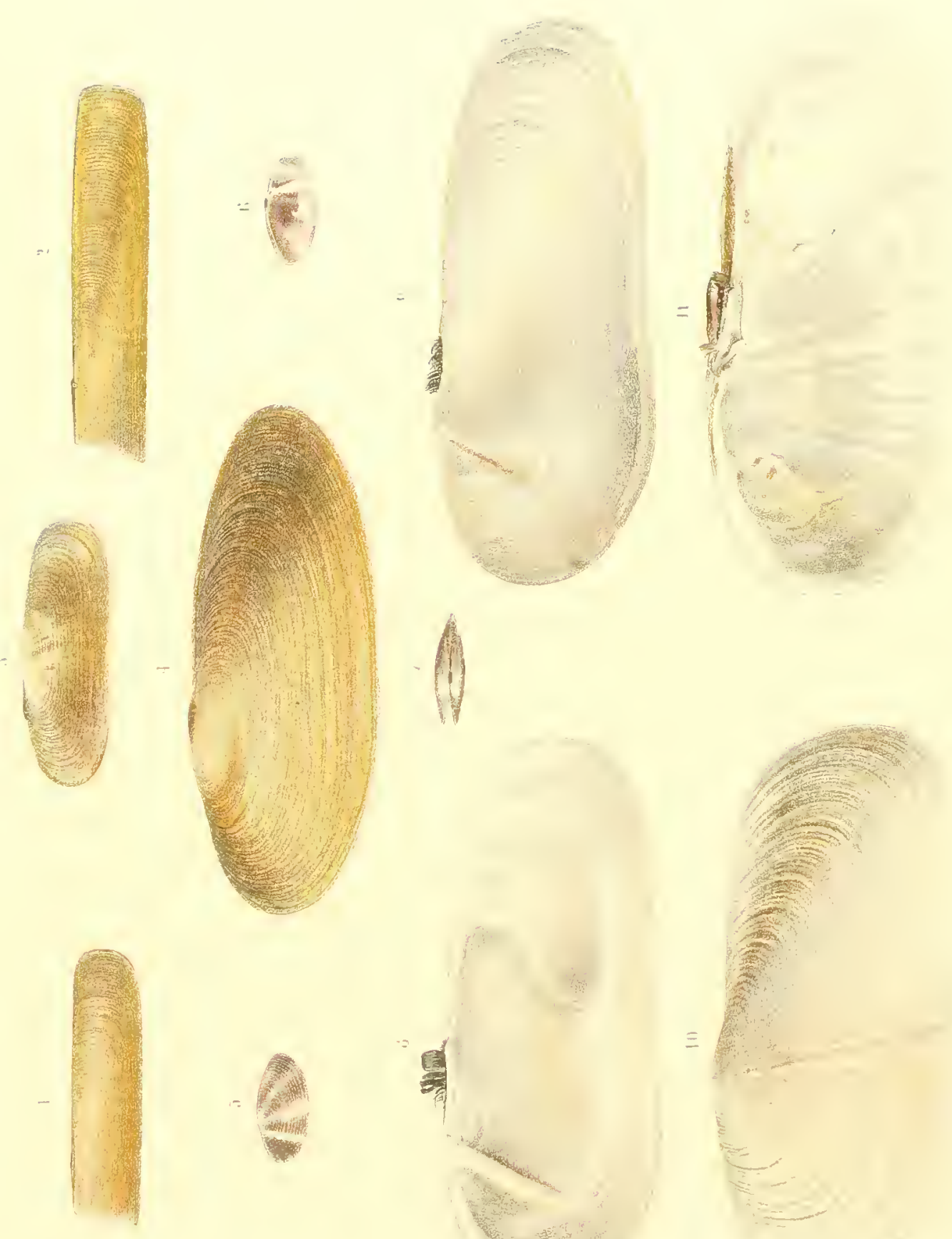

$\stackrel{i}{\equiv}$

$=$

三

$=$

吾蓄

-

严

三

三

恶
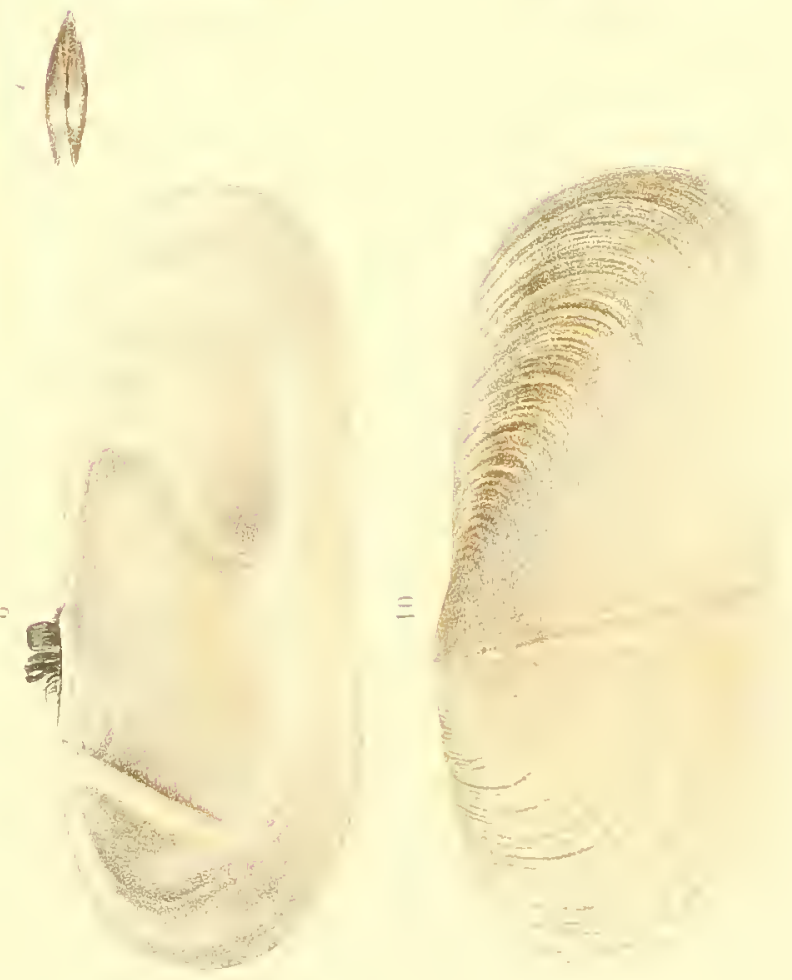

$\therefore$

毛実

三一

$=$

=

$\therefore$

$\therefore \equiv$

$\div$

产

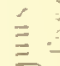

$\equiv$

寻

要 



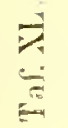

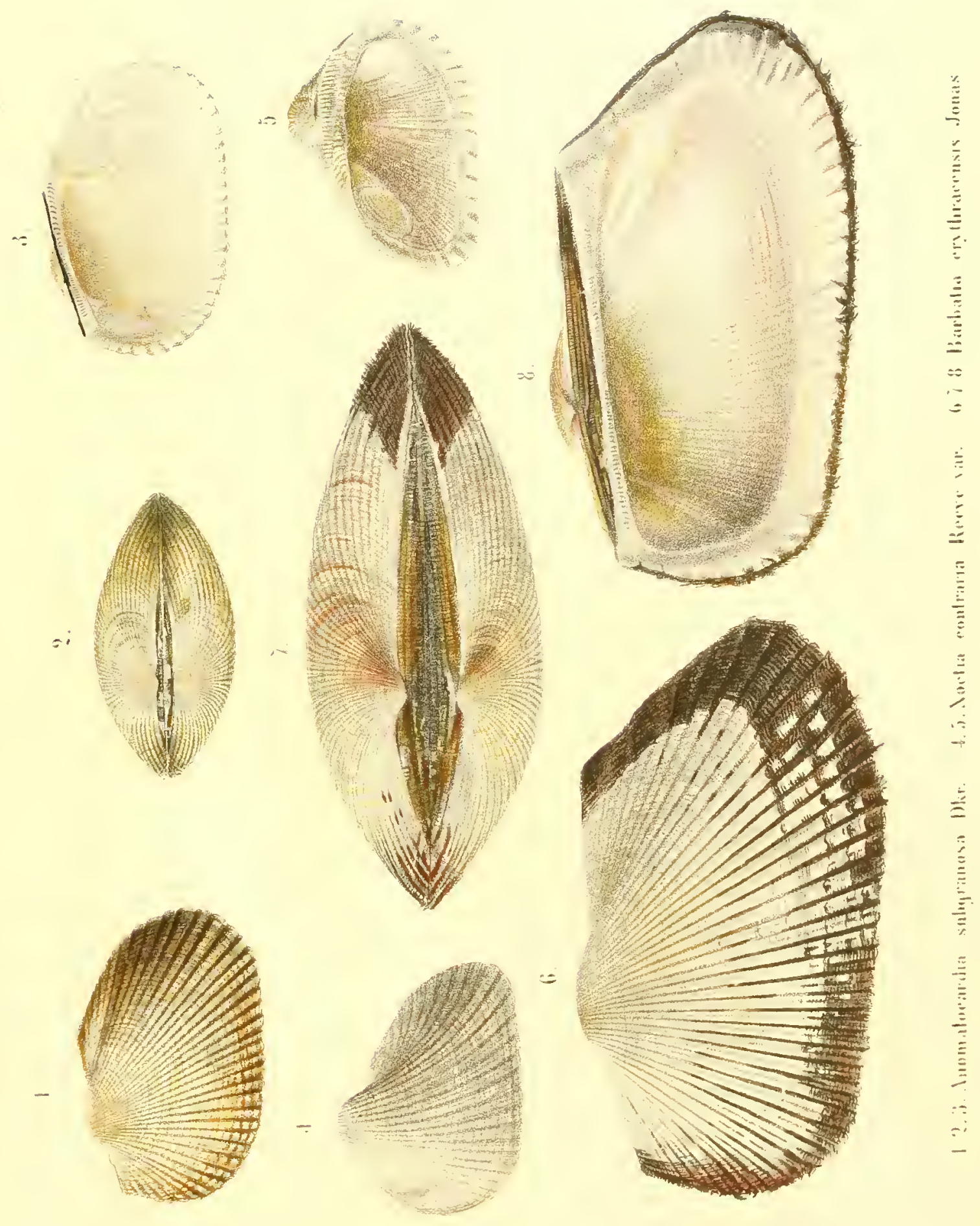




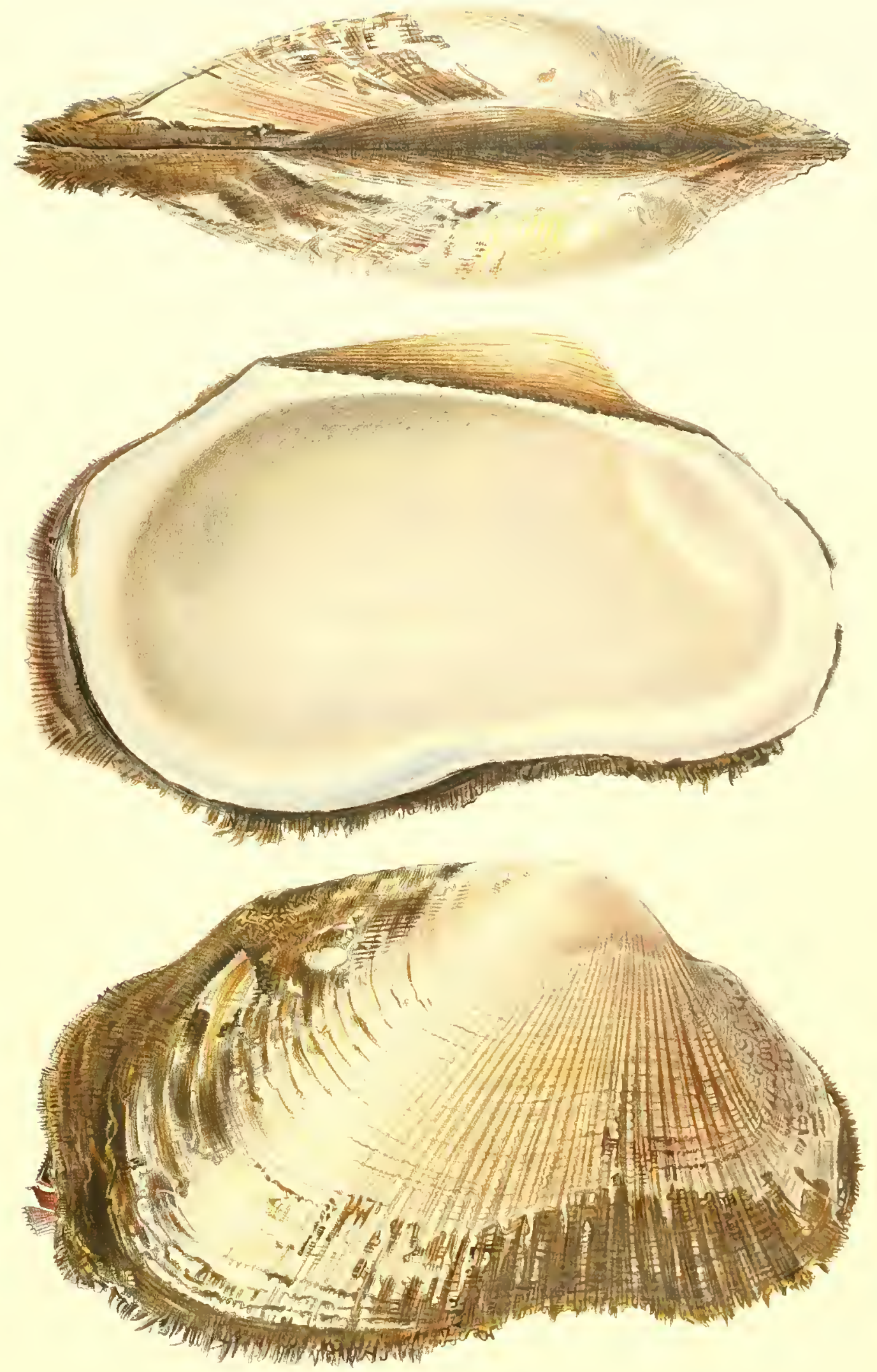



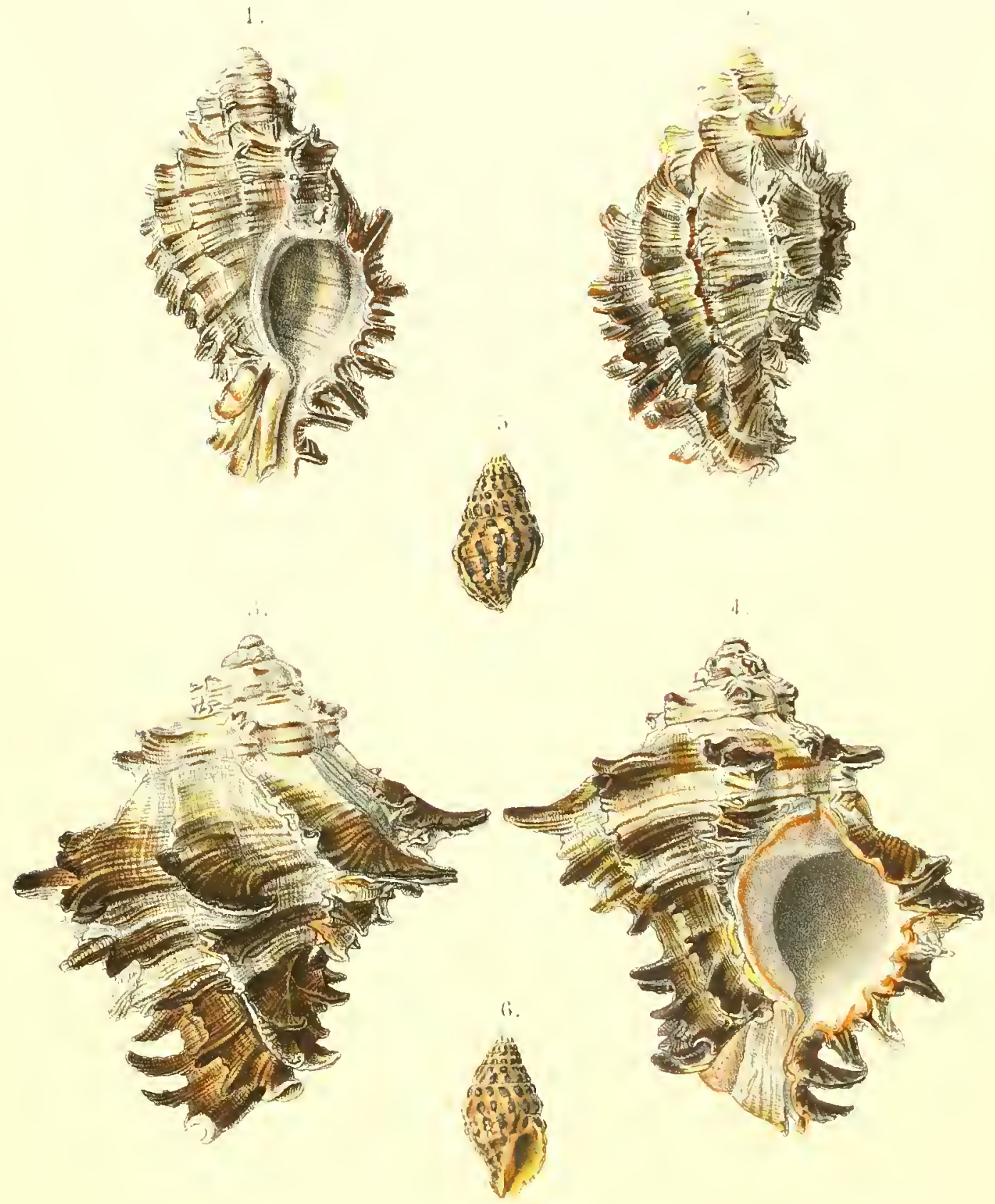



Tal 11.III
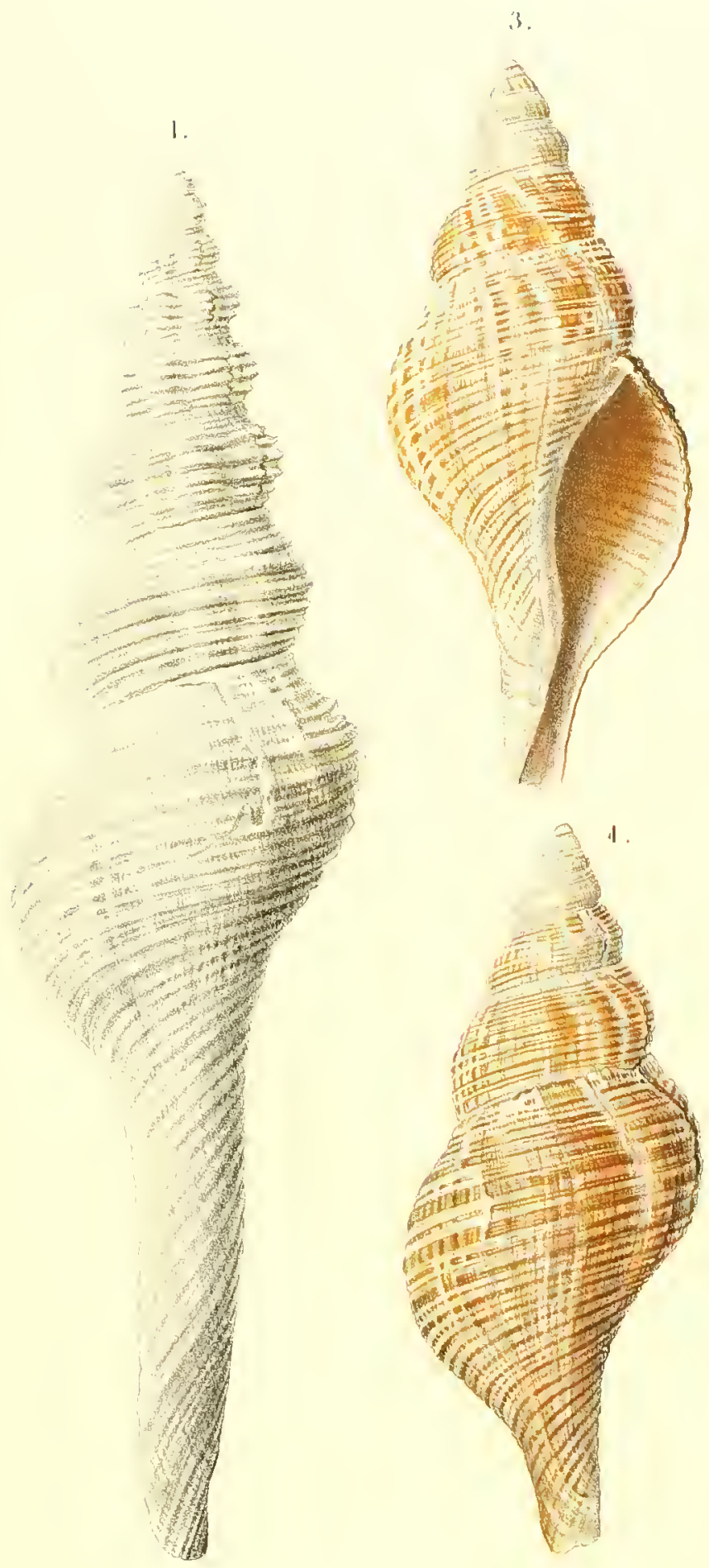

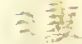

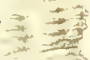

$= \pm$

$-\frac{\pi}{2}$
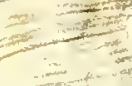

$-7$
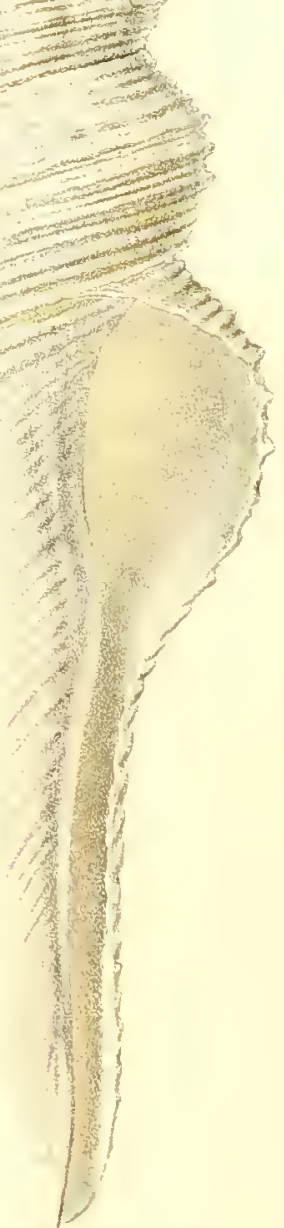
lial $\mathrm{slll}$
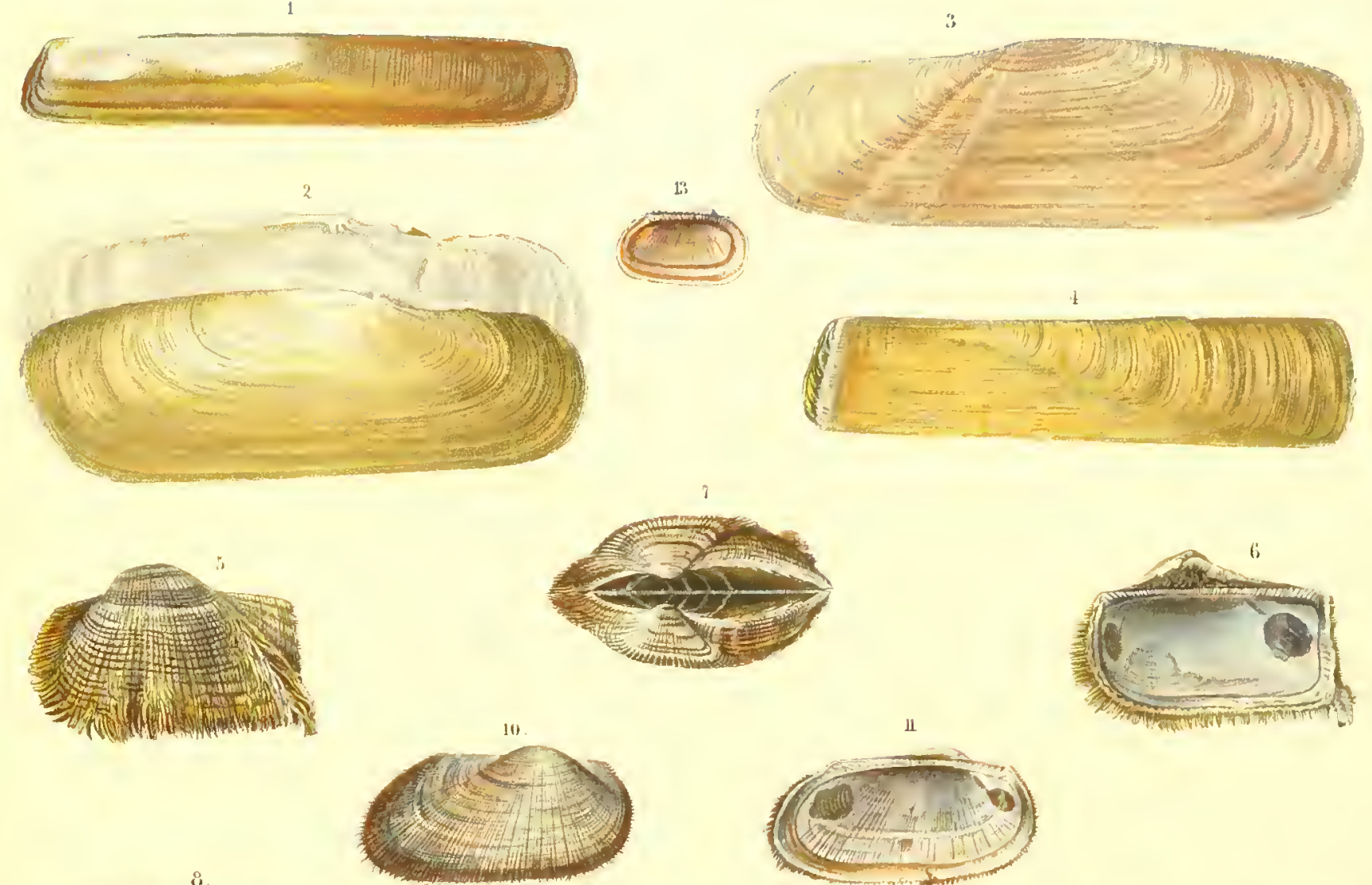

11

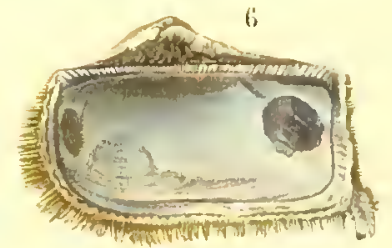

8
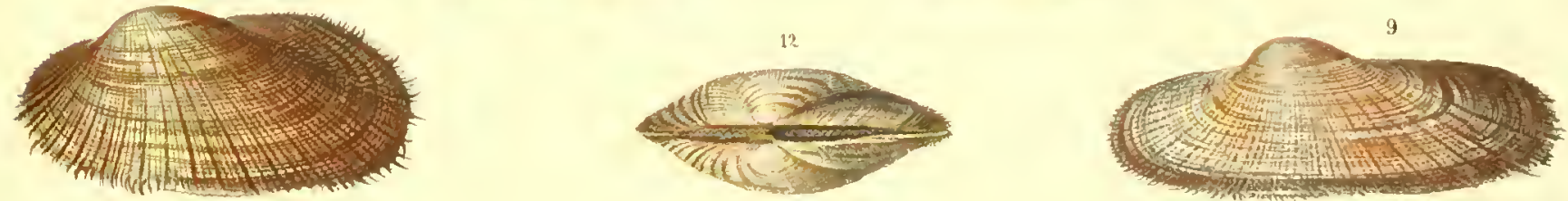

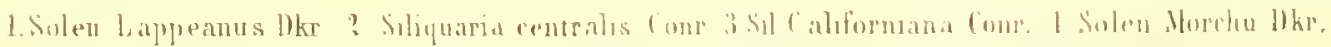

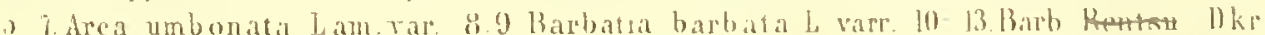

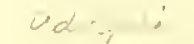



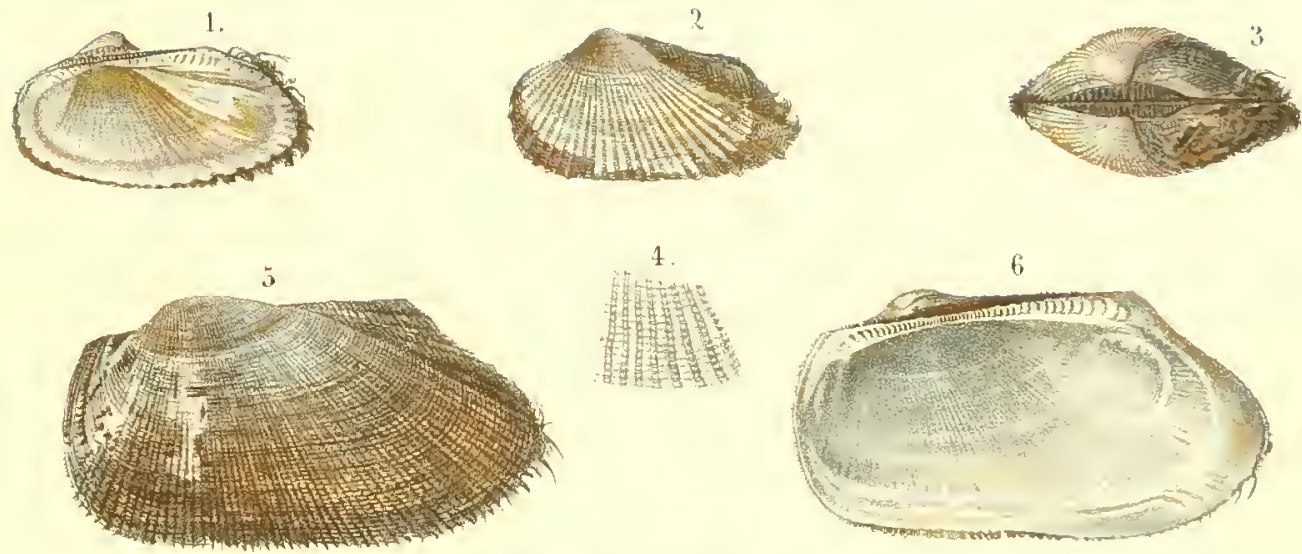

i
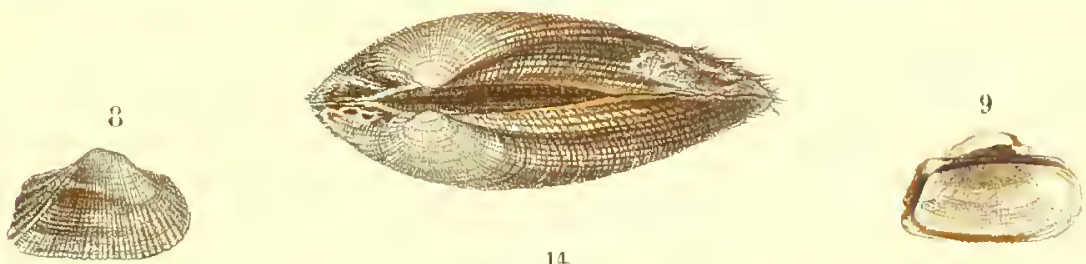

14

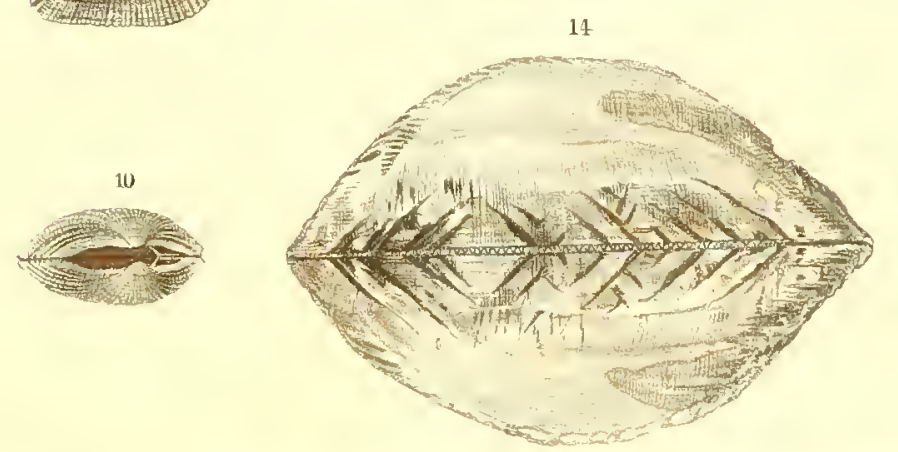

12
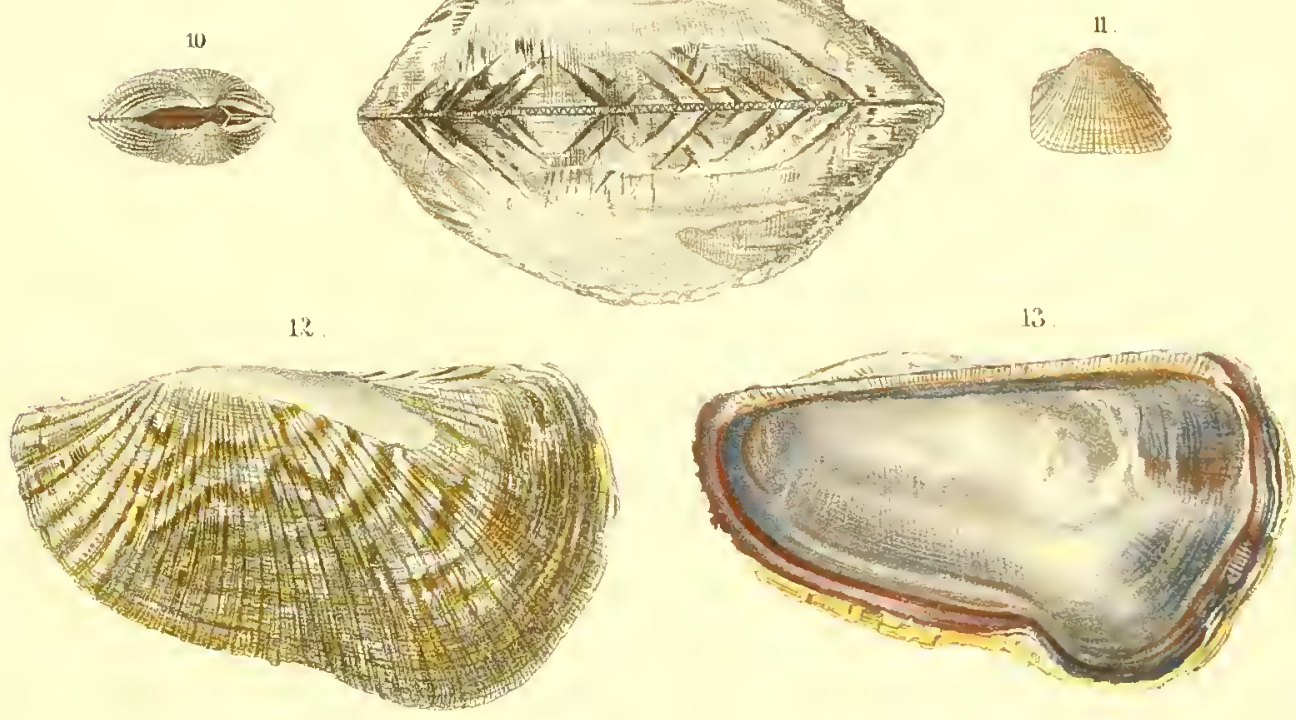

1-4. Area Martina lied j i Barbatua l'etersul lik

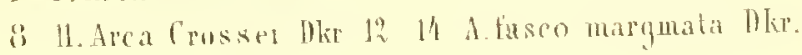


Oardor

- 



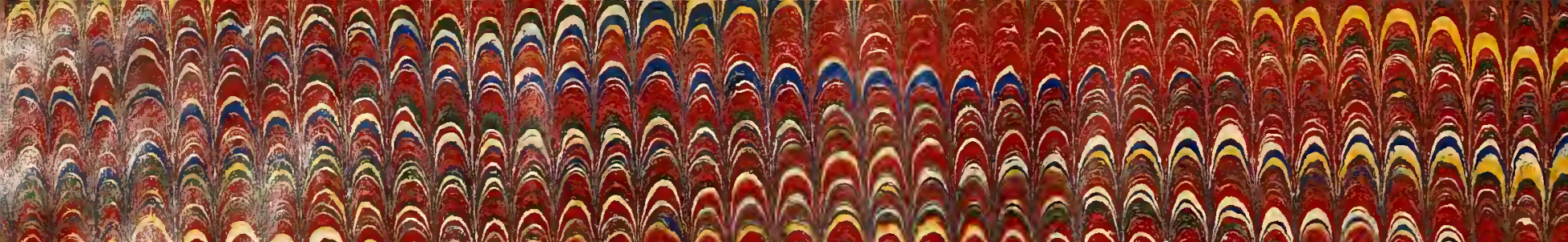

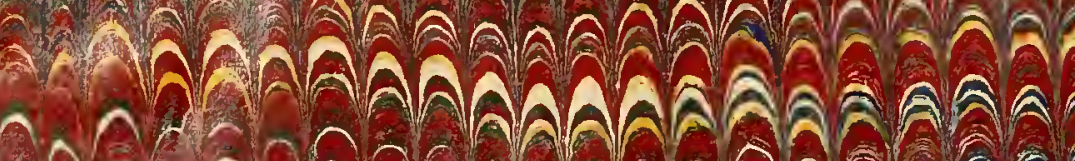

Mำ

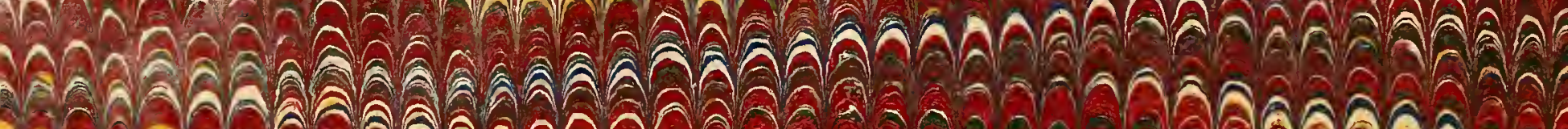

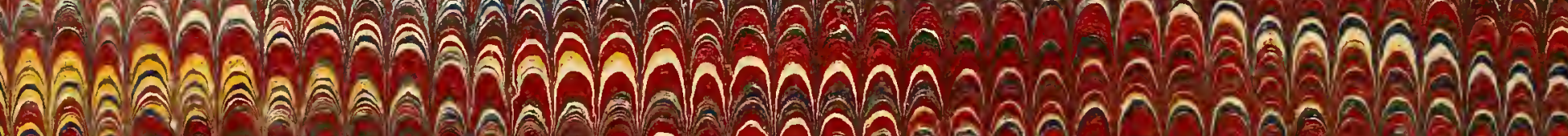

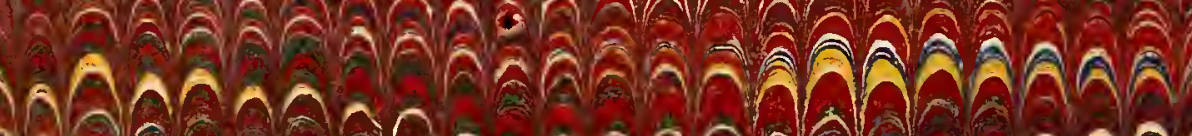

ดงล่อง 1010

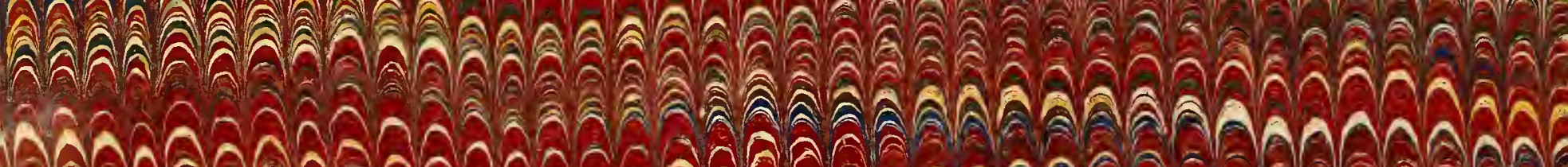
MnMA

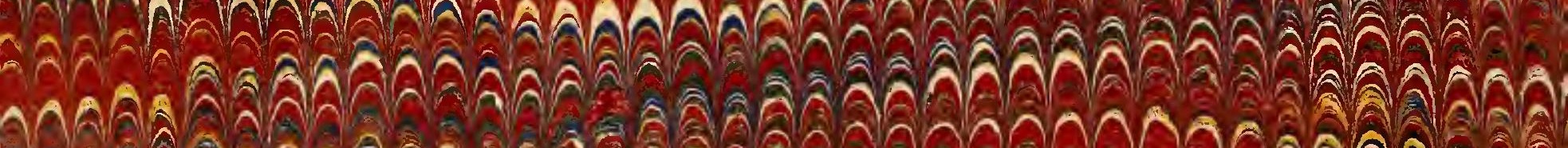

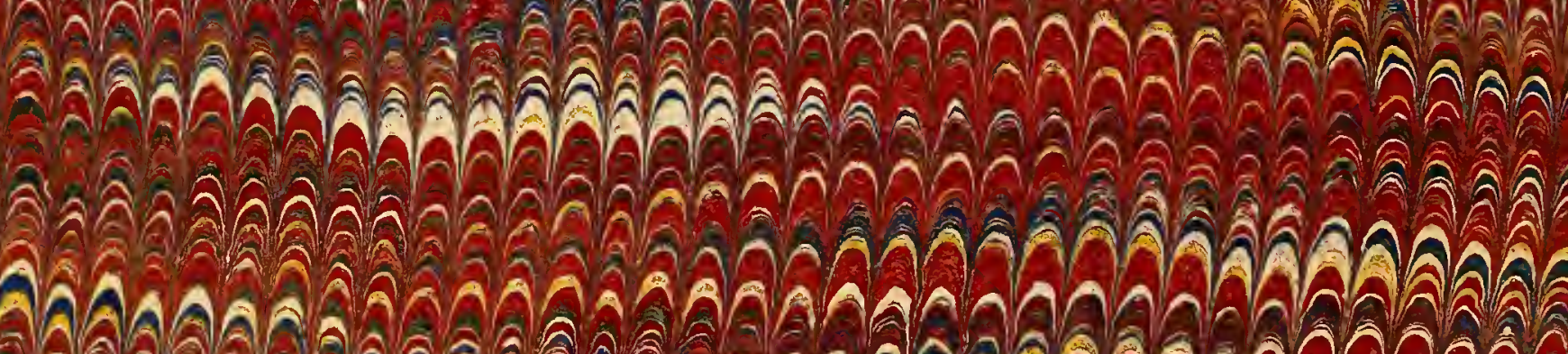
1.

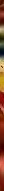

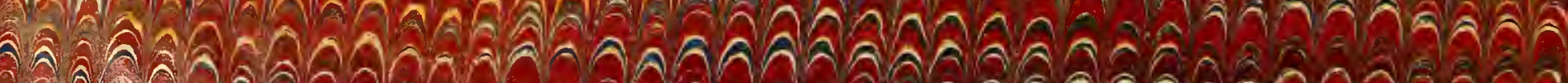

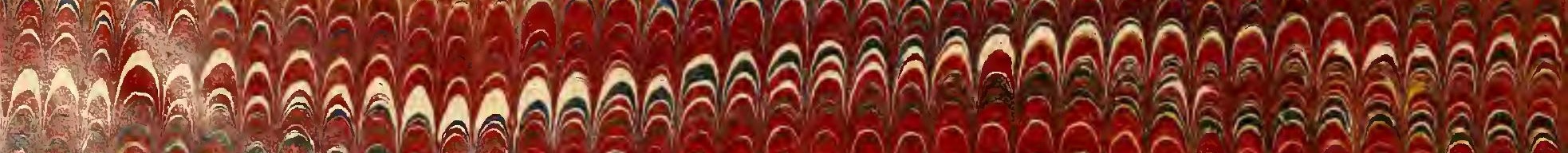

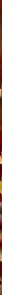


